Revista de

Estudios

Kantianos

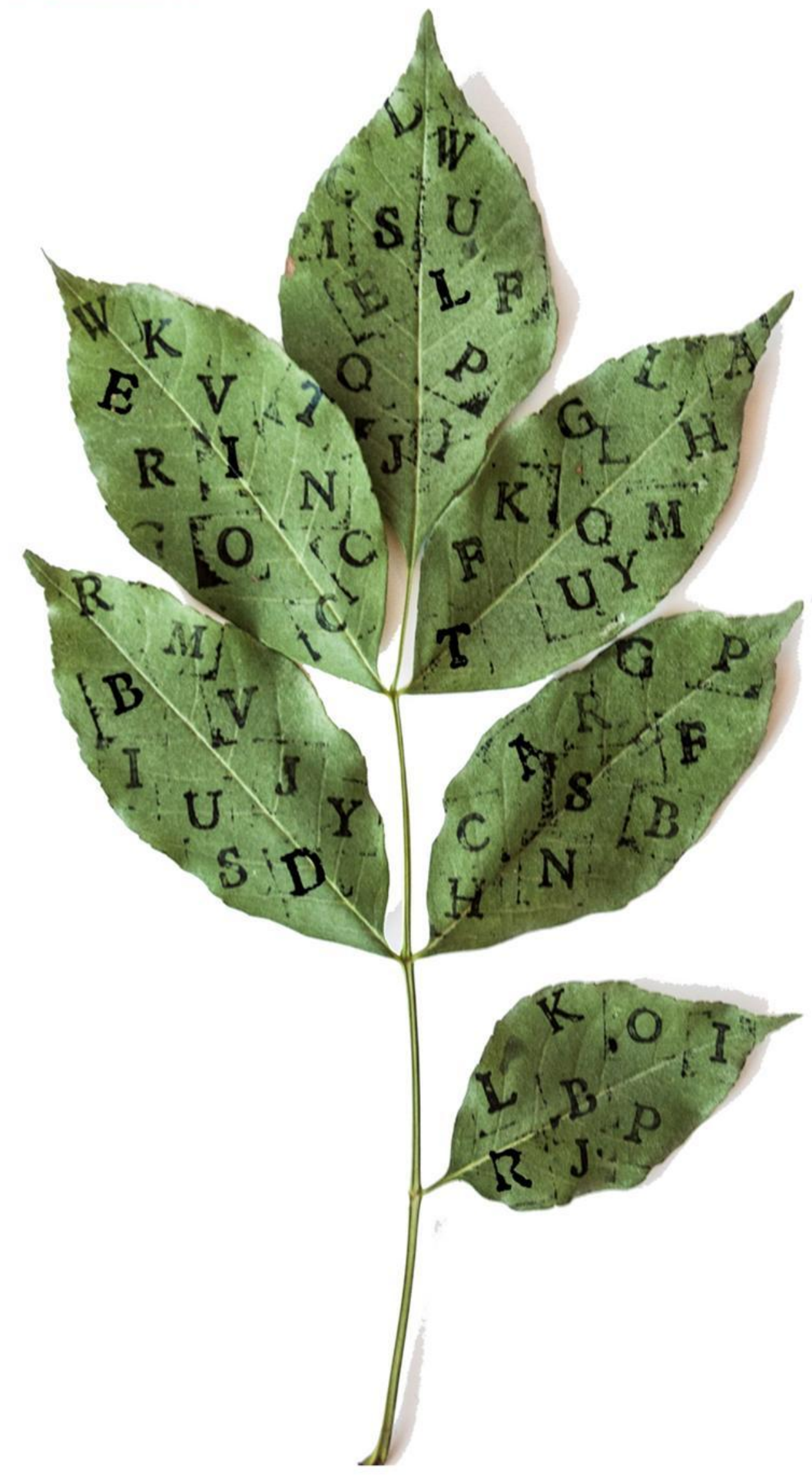


Revista de Estudios Kantianos 


\section{Revista de Estudios Kantianos}

Publicación internacional de la Sociedad de Estudios Kantianos en Lengua Española Internationale Zeitschrift der Gesellschaft für Kant-Studien in Spanischer Sprache International Journal of the Society of Kantian Studies in the Spanish Language

\section{Dirección}

Pedro Jesús Teruel, Universitat de València

pedro.teruel@uv.es

Hernán Pringe, CONICET-Universidad de Buenos Aires/

Universidad Diego Portales, Santiago de Chile

hpringe@gmail.com

\section{Secretario de edición}

Fernando Moledo, CONICET-Universidad de Buenos Aires

fernandomoledo@filo.uba.ar

\section{Secretaria de calidad}

Marcela García, Universidad de Morelia, México

garciar.marcela@gmail.com

\section{Editores científicos}

Jacinto Rivera de Rosales, UNED, Madrid

Claudia Jáuregui, Universidad de Buenos Aires

Vicente Durán, Pontificia Universidad Javeriana, Bogotá

Julio del Valle, Pontificia Universidad Católica del Perú, Lima

Jesús Conill, Universitat de València

Gustavo Leyva, Universidad Autónoma de México, México D. F.

María Xesús Vázquez Lobeiras, Universidade de Santiago de Compostela

Wilson Herrera, Universidad del Rosario, Bogotá

Pablo Oyarzun, Universidad de Chile, Santiago de Chile

Paula Órdenes Azúa, Universität Heidelberg 


\section{Comité científico}

Juan Arana, Universidad de Sevilla

Reinhardt Brandt, Philipps-Universität Marburg

Mario Caimi, Universidad de Buenos Aires

Monique Castillo, Université de Paris-Est

Adela Cortina, Universitat de València

Bernd Dörflinger, Universität Trier

Norbert Fischer, Universität Eichstätt-Ingolstadt

Miguel Giusti, Pontificia Universidad Católica del Perú

Dulce María Granja, Universidad Nacional Autónoma de México

Christian Hamm, Universidad Federal de Santa María, Brasil

Dietmar Heidemann, Université du Luxembourg

Otfried Höffe, Universität Tübingen

Claudio La Rocca, Università degli Studi di Genova

Juan Manuel Navarro Cordón, Universidad Complutense, Madrid

Carlos Pereda, Universidad Nacional Autónoma de México

Gustavo Pereira, Universidad de la República, Uruguay

Ubirajara Rancan de Azevedo, Universidade Estadual Paulista, Brasil

Margit Ruffing, Johannes Gutenberg-Universität Mainz

Gustavo Sarmiento, Universidad Simón Bolívar, Venezuela

Sergio Sevilla, Universitat de València

Roberto Torretti, Universidad Diego Portales, Santiago de Chile

Violetta Waibel, Universität Wien

Howard Williams, University of Aberystwyth

Allen W. Wood, Indiana University

Diseño, editor de estilo y maqueta

Josefa Ros Velasco, Universidad Complutense de Madrid

\section{Entidades colaboradoras}

Sociedad de Estudios Kantianos en Lengua Española (SEKLE)

Departament de Filosofia de la Universitat de València
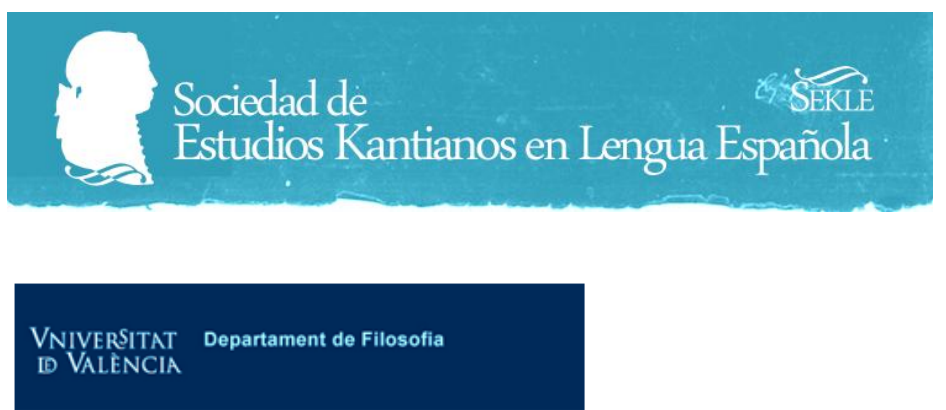


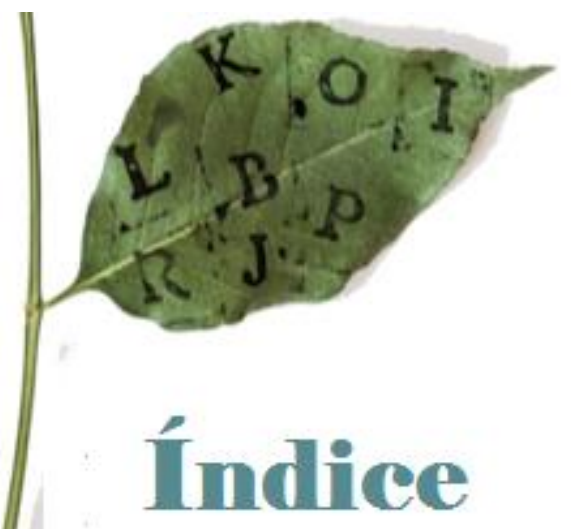

\section{Artículos}

9 Pensar como operación - Acerca de los presupuestos e implicaciones de la lógica formal moderna

Max Gottschlich

DOI 10.7203/REK.2.1.10059

20 Los conceptos kantianos de "facultad" y de "mente" frente a la lectura epigenética Antonino Falduto

DOI 10.7203/REK.2.1.10011

29 Arqueología filosófica y hermenéutica. Apuntes sobre la interpretación de la historia de la filosofía en Kant

José García Gómez del Valle

DOI 10.7203/REK.2.1.8811

48 Continuidad y novedad en la concepción histórica de Kant en El conflicto de las facultades Natalia Lerussi

DOI 10.7203/REK.2.1.9892

60 It's impossible to will to be punished? Exploring consensual way out of the Kantian dilema Matías Parmigiani

DOI 10.7203/REK.2.1.8813

\section{Recensiones}

89 Immanuel Kant (trad. Alba Jiménez): Lecciones de filosofía moral Mrongovius II.

Salamanca, Sígueme, 2017, 160 pp. ISBN: 978-8-4301-1954-7

Pablo Veraza Tonda

DOI 10.7203/REK.2.1.9990 
91 Faviola Rivera Castro: Virtud, Felicidad y Religión en la Filosofía Moral de Kant. México, Instituto de Investigaciones Filosóficas-UNAM, 2014, 328 pp. ISBN: 978-607-02-4788-0

Gustavo Leyva

DOI 10.7203/REK.2.1.9992

93 Vicente de Haro Romo: Duty, Virtue and Practical Reason in Kant's Metaphysics of Morals. Hildesheim/Zürich/New York, Georg Olms Verlag, 2015, 342 pp. ISBN: 978-3487-15348-3

Eduardo E. Charpenel

DOI 10.7203/REK.2.1.9998

96 Paolo Grillenzoni: Kant e la scienza (1755-1760). Roma, Aracne, 2016, 575 pp. ISBN: 9788-854-89523-2

Daniele Savino

DOI 10.7203/REK.2.1.10054

100 Nuria Sánchez Madrid: A Civilização como destino. Kant e as formas da reflexão.

Florianópolis, Nefiponline, 2016, 288 pp. ISBN: 978-85-99608-16-6

Josefa Ros Velasco

DOI 10.7203/REK.2.1.9801

103 Laura Anna Macor: Die Bestimmung des Menschen (1748-1800): Eine Begriffsgeschichte. Forschungen und Materialien zur deutschen Aufklärung. Abteilung II: MonographienFMDA II, 25. Stuttgart-Bad Cannstatt, Frommann-Holzboog, 2013, 432 pp. ISBN: 978-37728-2615-3

Daniel Schwab

DOI 10.7203/REK.2.1.9989

\section{Informes}

109 Rezension zur Internationalen Tagung "Teleologische Reflexion in Kants Philosophie" Anna Pickhan (geb. Brechtel)

DOI 10.7203/REK.2.1.9993

\section{Entrevistas}

112 Entrevista a Pablo Muchnik

Fernando Moledo

DOI 10.7203/REK.2.1.10064

\section{Convocatorias y normas para autores}

118 Kant en México

DOI 10.7203/REK.2.1.10085

119 II Premio Kant para Jóvenes Investigadores e Investigadoras DOI 10.7203/REK.2.1.10086 
120 IV Congreso Internacional de la SEKLE, Valencia, 2018 DOI 10.7203/REK.2.1.10088

121 Normas para autores DOI 10.7203/REK.2.1.10091 


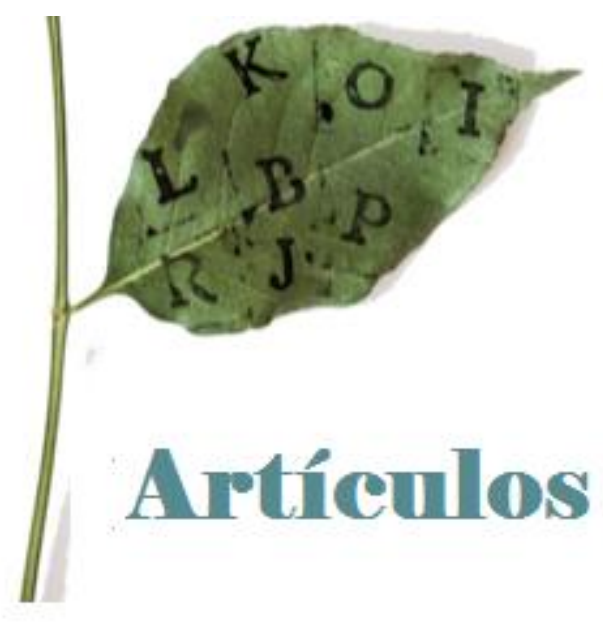




\title{
Pensar como operación - Acerca de los presupuestos e implicaciones de la lógica formal moderna
}

\author{
MAX GOTTSCHLICH ${ }^{1}$
}

\begin{abstract}
Resumen
La lógica formal no es una ciencia que se encuentre libre de presupuestos. Más bien, su representación de la forma lógica se basa en presupuestos a los cuales la lógica misma no llega. Este artículo se propone aclararlos. Para ello, en un primer momento, consideraremos las determinaciones fundamentales de la forma lógica. En un segundo paso, esta consideración será profundizada a partir del análisis del concepto lógico-formal de "concepto". Con él se plantean problemas que hacen necesario avanzar en la reflexión sobre la forma lógica. Ese avance necesario es la lógica trascendental en el sentido en el que la entiende Kant.
\end{abstract}

Palabras clave: Concepto, lógica, lógica trascendental

\section{Thinking as an Operation - About the Presupositions and Implications of Modern Formal Logic}

\begin{abstract}
Formal logic cannot claim to represent a presuppositionless science. In fact, its account of logical form rests upon a set of presuppositions, which is not justified within logic itself.This article shall elaborate on this in two steps. First,we shall highlight the primaldeterminations in formal logic's account of logical form. Second, we shall deepen this with regard to the account of the concept. In doing so, we will encounter systematic problems, the resolution of which necessarily gives rise to a genuine self-reflection of logical form, which is transcendental logic in terms of Kant.
\end{abstract}

Key Words: Concept, logic, trascendental logic

Mediante la variación de un conocido enunciado de Fichte se puede afirmar: dime lo que tú entiendes por lógica y te diré cómo entiendes al hombre. La lógica es siempre una auto-explicación del pensar. Así recaen en ella las decisiones fundamentales en la determinación de lo teórico y lo práctico. La auto-explicación de la forma lógica recorre entonces tres niveles epocales: 1) la forma lógica será, en su funcionalidad determinante de objetos, objetiva (gegenständlich): lógica formal. Que el pensar se conciba como operación se aclarará especialmente en vistas a la relación del concepto con la intuición. 2) Esta funcionalidad se vuelve reflexiva, es fundamentada y delimitada: esto lo logra la lógica transcendental de Kant. 3) Se conceptúa la unidad entre funcionalidad y reflexividad en cuanto tal, se concibe la forma lógica en cuanto sujeto-objeto que se mueve a sí mismo: esto es lo que expone la lógica dialéctica de Hegel. ${ }^{2}$

Actualmente se considera a la lógica formal incuestionablemente como la lógica. ¿Quién se atrevería a cuestionar esto sin perder el juicio? Queremos en lo que sigue, emprender con gusto esto. La tesis afirma que, en la lógica formal, el pensar se concibe de modo técnico-práctico, que también

${ }^{1}$ Katholische Privat Universität Linz.

${ }^{2}$ No se ve - no sólo en el espacio angloparlante, sino también en el germanoparlante -, salvo pocas excepciones, la necesidad de la lógica transcendental de Kant, o sea la de Fichte, que en todo caso pueden reclamar el estatus de una nota al pie en las historias de la lógica. La lógica dialéctica de Hegel parece, en cualquier caso, ser indiscutiblemente la lógica genuina. 
en ello reside -bien visto- la necesidad relativa de su punto de vista. Pero una absolutización de esta auto-interpretación de la forma lógica tiene -uno tiene que decirlo drásticamente-, en definitiva, consecuencias mortales para el entorno del mundo humano. Queremos, por eso, aproximarnos al tema de la lógica formal de un modo completamente no-técnico, a saber, de un modo filosófico, es decir, queremos cuestionarla en sus presupuestos e implicaciones. Pues también la lógica formal tiene sus presupuestos, que quedan a sus espaldas. En un primer paso, actualizaremos las determinaciones más fundamentales en la formulación de la lógica formal. En un segundo paso, queremos profundizar esto con vistas al concepto lógico-formal del "concepto". Los problemas sistemáticos que trataremos con esto son precisamente aquellos cuya solución hará necesario, en primer lugar, el paso a la lógica transcendental en el sentido de Kant.

\section{La formulación de la forma lógica}

La lógica formal es el punto de vista de la inmediatez en la formulación de la forma lógica, la primera objetivación del pensar. Ella se basa en la emancipación del entendimiento, que expresó por primera vez el eleatismo (Parménides). ${ }^{3}$ El pensar se aparta de su estar hundido en los contenidos intuitivos sobre sí, y se vuelve objetivo (gegenständlich) en la forma de las determinaciones fijas del pensar. Esto se presenta en la forma de una doble oposición ${ }^{4}$ :

a) como fijación de lo universal en cuanto concepto (del entendimiento) no-intuitivo, idéntico consigo mismo, que tiene que estar libre de contradicciones frente a lo singular intuitivo, que se contrapone al concepto en cuanto existencia exterior.

b) como oposición dentro de lo universal mismo, de las determinaciones del entendimiento, que se desintegran en universalidades particulares (esto es, las formas lógicas: del concepto, del juicio, del silogismo, así como los principios de lo lógico mismo).

Con ello ya se consigna la necesidad relativa del punto de vista que tiene la lógica formal: sin una contraposición entre lo universal y lo singular, yo no podría comunicar nada, pues en la comunicación comparto algo sobre las cosas, y no a ellas mismas. Si sólo tuviéramos intuiciones que recorreríamos sin concepto, sólo a través del cual distinguimos y relacionamos, no llegaríamos a ningún objeto, sino que seríamos un manojo de impresiones humeano. Esta sería la primera comprensión de la autonomía del concepto; ella es la fundamentación que queda de toda cientificidad, ya que ésta no se dirige a lo singular, sino que va a lo universal. ${ }^{5}$ Pero la oposición entre concepto e intuición se lleva eleáticamente hacia una separación. Así, la autonomía del concepto tiene que significar independencia de la intuición. Pues la esfera de la intuición representa la disipación de lo lógico en la diversidad, representa la apariencia, mientras que la esfera del pensar representa el ser y saber verdadero, puesto que este mismo se relaciona con la esencia que es idéntica a sí misma, que posibilita la determinidad (Bestimmtheit) unívoca y libre de contradicción. Esto tiene también, en primer lugar, su razón: sin la producción de referencias unívocas no podríamos formar ninguna proposición con una dirección de sentido unívoca. Ahora bien, dado que, no obstante, el ámbito de la intuición (tanto del lado del sujeto como del objeto), en el que parece existir algo así como la kínesis, no puede corresponderse ni con el criterio eleático de la logicidad, ni con el hecho de estar libre de

3 "El pensar en cuanto entendimiento permanece en la determinidad fija y en la diferenciabilidad de la misma frente a otras; un tal abstracto limitado vale para él en cuanto existiendo y siendo para sí." (G.W.F. Hegel, Enzyklopädie der philosophischen Wissenschaften, en: Gesammelte Werke, vol. 20, ed. U. Rameil, W. Bonsiepen y H.C. Lucas, Hamburgo 1992, § 80, 118)

${ }^{4}$ En el sentido de la lógica de la esencia hegeliana el pensar está aquí en el estatus de la reflexión externa, que al mismo tiempo ella misma es reflexión externa.

${ }^{5}$ Aristóteles, Metaphysik I, 2. 
contradicción, ni con la identidad abstracta, entonces la independencia de intuición tiene que estar asegurada concibiendo el concepto sólo como determinante y la intuición sólo como lo determinado. La lógica formal se basa exactamente en el descubrimiento eleático de la autonomía del concepto.

He dicho hace un momento que la lógica formal es la primera objetivación de la forma lógica. ¿Qué significa esto? Si pensamos a partir de Kant que la síntesis de lo múltiple (de los contenidos de la conciencia) para la unidad de la conciencia es una forma lógica, entonces la inmediatez consiste en la mera objetividad de la síntesis en cuanto, dicho con Fichte, hecho de conciencia. Las formas y principios lógicos deben, por tanto, ser considerados como elementos positivos comprensibles por sí mismos y que no son más fundamentables. Con esto se alude a la funcionalidad de la síntesis de modo determinado: a saber, la funcionalidad en cuanto posición de una identidad y relacionalidad (Relationalität) objetiva, en la cual se consigue conservar en su objeto el carácter de necesidad del pensar.

Con este trasfondo se comprenden ambos presupuestos fundamentales de la lógica formal:

(1) La separación entre forma y contenido del pensar: la lógica tiene que ser la doctrina de la validez neutral del contenido de enunciados, o bien de silogismos. Ella hace abstracción del contenido del pensar, indiferente a la distinción entre lo a priori y lo empírico, y mira sólo a la forma en cuanto conexión objetiva. Los múltiples contenidos de conciencia son presupuestos formal-lógicamente como dados y ya en sí mismos constituidos. ${ }^{6}$ Aristóteles enseña así, que la lógica tiene que limitarse al encadenamiento de lo ya conocido, ${ }^{7}$ porque la lógica formal no es capaz ni de inferir lo más universal en el sentido de los principios de lo lógico ni lo singular. ${ }^{8}$ Tanto lo más universal como lo singular son formal-lógicamente sólo tomados de modo inmediato. ${ }^{9}$ Pero lo que se toma en lo particular, las formas de encadenamiento en el que ellas están, son esencialmente (en el sentido de la lógica hegeliana) estructuras y campos de significado.

(2) La separación entre forma y contenido se basa -y esto es el punto decisivo para nuestro tema- en la separación entre medio y fin, en el sentido de la teleología externa. ${ }^{10}$ Dicho de otro modo: [se basa] en la independencia de la forma lógica en cuanto medio de determinación neutral de contenidos. ${ }^{11}$ Así, la forma lógica no se piensa como algo que se mueve por sí mismo, como un contenido que se produce de modo determinado, ni como relacionado con el yo. Ella no es ningún sí-mismo, sino que se concibe como una determinación fija, con la que puede operarse -justamente como una herramienta que también debe tener una firmeza, pues de lo contrario yo no puedo operar con ella. "Operar" significa un aplicar formas presupuestas como dadas, más preciso: el producir de la igualdad consigo por medio de un material presupuesto, asimismo, como dado (el argumento fregeano) en el sentido de la subsunción. ${ }^{12}$ La lógica formal es esencialmente lógica de la subsunción. Esto se ha de distinguir, como podemos añadir de inmediato, de la formulación lógico-transcendental de la subsunción en el sentido de la reflexión determinante de Kant, pues ésta se concibe como un actuar lógico a priori, que constituye en primer lugar la objetividad del objeto. La forma lógica no se aplica formal-lógicamente a sí misma, sino que ella presupone, en cuanto usuario, a un sujeto concebido psicológicamente y, con ello, [a un sujeto que está] puesto de modo extra-lógico. ${ }^{13} \mathrm{Al}$

${ }^{6}$ Cf. Fichte, Vom Unterschiede zwischen der Logik und der Philosophie selbst, als Grundriss der Logik und Einleitung in die Philosophie, GA II/14 [= TL II]: 198.

7 Aristóteles, Analytica posteriora I 1, 71a6.

${ }^{8}$ Aristóteles, Analytica priora I 27, 43a $25 \mathrm{ff}$

${ }^{9}$ Cf. K.-W. Zeidler, Der logische Ort der Freiheit, en: H.-D. Klein (ed.), Ethik als prima philosophia?, Würzburg 2011, $115-117$.

${ }^{10}$ En el sentido de la lógica hegeliana, este pensamiento está, en definitiva, en el estatus de la "objetividad"

${ }^{11}$ Cf. M. Wladika, Nivellierung, Prinzipialisierung und Revolutionierung von Erfahrung. Formen neuzeitlichen Denkens, aus dem Zusammenhang zwischen Descartes und Hegel herausentwickelt, Würzburg 2007, 44.

${ }^{12}$ Esto es necesario, si la forma lógica no se piensa como ella misma en movimiento. La subsunción presupone la oposición de un universal dado y de un particular dado.

${ }^{13}$ Por esta razón Hegel ha tratado juntas, en la "Fenomenología del espíritu”, las leyes lógicas y psicológicas. 
mismo tiempo, las formas y los principios de la lógica aparecen como entidades ónticas (seiende) ${ }^{14}$ que deben ser accesibles para el sujeto psicológico, de un modo lógico-formal inexplicable. Por lo tanto, tenemos una coexistencia entre una mala formulación subjetiva y una mala formulación objetiva de la forma lógica. ${ }^{15}$ Por eso la lógica formal oscila entre formas de fundamentación contrapuestas: entre el nominalismo, que concibe a la forma lógica como un sistema de signos establecido $^{16}$, y un platonismo, que considera a lo lógico como el reino de las entidades que son en sí. En esto es importante observar que aquello a lo que se aplica la forma lógica recién entonces puede ser exactamente determinable y, con ello, dominable, si se toma en sus estructuras y campos de significado esenciales.

Lo dicho vale tanto para la lógica formal tradicional como para la lógica formal moderna. Pero hay entre ambas formulaciones de la lógica formal diferencias considerables. En nuestro contexto puedo señalar lo siguiente: el paso hacia la lógica formal moderna consiste en la ejecución consecuente de la separación entre forma y contenido, así como entre medio y fin. Pues la silogística aristotélica y la posterior tradición de la lógica formal no se ha concebido completamente como [una lógica] de contenido neutral. La estructura lógica de un enunciado (proposición) tiene que ser -esto afirma primeramente la pretensión- "puramente" representable, aislándose de:

a) la "gramática superficial" del "lenguaje cotidiano", que, aparentemente, no es isomorfo con la forma lógica, así como aislándose de la ambigüedad que en el uso y en el significado de los signos lingüísticos (especialmente de la cópula "es”) se contrapone al referente semántico unívoco;

b) el presupuesto ontológico de una relación de substancia-accidente, a la que se refiere en último término la formulación de la estructura lógica del enunciado, en el sentido de la estructura sujetopredicado. ${ }^{17}$ En su lugar entra la estructura función-argumento. ${ }^{18}$

Esto fue posible mediante el desarrollo de un lenguaje de signos que se apoya en la matemática. ${ }^{19}$ Tal como el cálculo parece ser una operación que es independiente del individuo que calcula, así también debe ser representable, en la clasificación "bien formada" de los signos, lo lógico "puro", la funcionalidad de la forma lógica independiente de lo psicológico (en lo que se suprime la dialéctica según la cual los signos sólo tienen su significado en la conciencia de un ser hablante y escuchante en sí). Con esto enlaza el platonismo lógico-formal. Pero también esto trata sólo mediatamente de un conocimiento de la forma lógica. El objetivo consiste en el desarrollo de instrumentos sintácticos para la elaboración y revisión de estructuras de orden. El motivo fundamental de la lógica formal moderna se anticipa por tanto, en cierto modo, en la distinción leibniziana entre characteristica universalis y calculus ratiocinator. La characteristica universalis tendría que hacer posible el acceso a la esencia de las cosas en su determinidad unívoca y libre de contradicción, y ciertamente con ayuda de un procedimiento conclusivo de cálculo, de un modo sencillo y automatizable. La lógica formal moderna debe sus enormes éxitos al hecho de que aspira al carácter

${ }^{14}$ En el sentido de la lógica de Hegel.

15 Lo que en Frege también se expresa: "no entiendo bajo pensamientos el hacer subjetivo del pensar, sino su contenido objetivo, que es capaz de ser la propiedad común de muchos." (G. Frege, Über Sinn und Bedeutung, en: Funktion - Begriff - Bedeutung, ed. M. Textor, Göttingen 2007, 29, nota 5)

${ }^{16}$ La lógica formal moderna tiende hacia el nominalismo en cuanto ultima ratio. Cfr. E. Tugendhat u. U. Wolf, Logischsemantische Propädeutik, Stuttgart 1986, 139.

${ }^{17}$ Este es el punto central de la crítica a la lógica formal moderna desde la perspectiva del aristotelismo: P. Kreeft, Socratic Logic: A Logic Text using Socratic Method, Platonic Questions, and Aristotelian Principles, St. Augustines Press 2010.

${ }^{18}$ G. Gabriel, Traditionelle und moderne Logik; en: Zwischen traditioneller und moderner Logik. Nichtklassische Ansätze, ed. W. Stelzner y M. Stöckler, Paderborn 2001, 21-34, aquí: 23. Con esto se evita el problema lógico-formal no resuelto (semánticamente, el problema de la methexis), "cómo se debe entender el significado de una proposición compuesta a partir de un término singular y a partir de un término general". (Tugendhat u. Wolf, Logisch-semantische Propädeutik, 135)

${ }_{19}$ Esto se muestra fundamentalmente en Frege: "the peculiar character of concept-script is that the mathematical formula language inspires the very essence of the logical symbolism" (E. Kanterian, Frege. A Guide for the Perplexed, Londres-Nueva York 2012 14) 
funcional, automatizable de la forma lógica. Este es un progreso consecuente con respecto a la lógica formal, pues con ello se ha formado, de hecho, la autarquía instrumental de la forma de contenido neutral.

Siempre se fundamentó la separación entre forma y contenido, entre medio y fin, sobre la base de la consecución de este objetivo. La lógica formal moderna se diferencia, entonces, de la lógica tradicional aristotélica, particularmente en que, en ella, la formulación técnico-práctica de la forma lógica está puesta explícitamente. La lógica formal fue siempre en sí (como muy tarde con los estoicos se puede ver esto). En Aristóteles no tenemos aún, por cierto, ninguna lógica formal que se interprete como mero (es decir, libre) instrumento puesto para cualquier fin, sino que las formas lógicas consideradas en el Organon tienen siempre que servir, en último término, para concebir la presencia intuitiva de lo universal. La lógica formal como tal se forma recién en la escuela peripatética y estoica, por lo cual la lógica se comprende de modo explícito en el estoicismo meramente de manera técnica, a saber, como medio para la auto-conservación argumentativa de la ḋ $\alpha \rho \alpha \xi i \alpha^{20}{ }^{20}$ En la lógica formal moderna no se trata más de esto, sino del perfeccionamiento de la aplicabilidad de la forma lógica. Frege concebirá la conceptografía explícitamente como herramienta para fines completamente determinados (aunque Frege establezca este fin, en primer lugar, en algo teórico, a saber, la fundamentación de la aritmética a partir de la lógica formal, para indagar la verdadera esencia del número). El logro de esta herramienta de la conceptografía consiste según Frege, primeramente, en su capacidad de representación con respecto a la forma lógica, a diferencia del llamado lenguaje natural. Este logro lo caracteriza en base a la distinción entre el ver mediante el mero ojo y el ver mediante un microscopio. ${ }^{21}$ En ello se expresa ya, indirectamente, que la "precisión", que posibilita el instrumento, es relativa a intereses que, en último término, son técnicoprácticos. Precisión no significa otra cosa que la producción de una determinidad unívoca y libre de contradicción, sin la que no sería posible ningún saber de orientación y disposición. Si Frege concibe el carácter de medio de la lógica formal para la ciencia, más que como un canon, o que como un organon para el descubrimiento de nuevas verdades - una pregunta que curiosamente, a partir de los textos de fregueanos, no se puede responder unívocamente ${ }^{22}$ - es de menor importancia. En nuestro contexto, es importante que la metafóra de Frege apunta fundamentalmente a la esfera de lo técnicopráctico.

El devenir explícito del carácter técnico-práctico de la lógica formal en la modernidad tiene también una consecuencia masiva para la auto-comprensión de la lógica formal. Me refiero aquí a la oposición ya considerada entre un platonismo lógico-formal, como el que representa entre otros Frege, por un lado, y un planteamiento (Ansatz) nominalista-pragmático, por otro lado. El platonismo lógico-formal comprende lo lógico aún, en cierto modo, como "lenguaje", y ciertamente en el sentido de que los signos lógicos se refieren, si se quiere, a un reino de significados que son en sí, es decir, unas estructuras de ordenación. ${ }^{23}$ La lógica consiste, por consiguiente, en proposiciones que expresan algo, las estructuras más universales del pensar en general - desde luego, en el sentido de aquello que Kant tiene en mente cuando habla de la lógica formal en cuanto una "lógica universal". Pero un platonismo lógico-formal correcto apenas se sostiene hoy en día; evidentemente él no pudo sostenerse. Hoy en día -y esta es la alternativa- un sistema lógico-formal no se comprende más, por regla general, como "lenguaje", sino que "logical formulas are only forms or schemas of well-formed

${ }^{20}$ Kuno Fischer observa espléndidamente al respecto: "La verdad es por tanto aquí un modo de representación, ella es solamente subjetiva, su criterio es solamente formal. Las formas del pensar no valen por consiguiente según su valor objetivo de conocimiento, sino según su fuerza probatoria subjetiva, según el grado de fijeza con el que ellas pueden presentar una representación y conferirle validez. No lo que se comprueba, es aquí el punto central, sino lo que se puede comprobar, lo que uno quiere. Este dominio sobre los medios de comprobación necesitan los estoicos; la conciencia de tener este dominio pertenece a la auto-satisfacción y autarquía que ellos buscan [...] No es la ciencia su fin, ni su principio regulador, sino el razonamiento.” (91).

${ }^{21}$ Cf. Kanterian, Frege, 10-13.

${ }^{22}$ Kanterian, Frege, 13.

${ }^{23}$ En el sentido de la lógica hegeliana se formula allí el punto de vista de la "esencia que está siendo" (seienden Wesen) 
propositions and inferences, to be supplied with appropriate interpretations (models) to evaluate them logically." 24 Las estructuras de ordenación buscadas aparecen, desde la perspectiva de la lógica formal, sin duda sólo de modo relativo en los domains of discours dados como necesarios; los principios (sobre todo el de no-contradicción) tienen, de todas formas, sólo el estatus de axiomas. Así se conciben las formas y principios lógicos, en último término, pragmáticamente, es decir, de manera nominalista, en cuanto posiciones relativas al juego lingüístico. Lo que se lleva a cabo aquí, en el terreno lógico-formal, es la transformación de todo ser-en-sí en un ser-para-nosotros -esto es, como muestra el capítulo de la ilustración de Hegel en la Fenomenología del espíritu, el motivo fundamental del pensar de la utilidad, del primado de lo técnico-práctico, que se llama Ilustración. El platonismo cae entonces necesariamente en un perspectivismo. ${ }^{25}$ Pero no podemos pasar por alto que esto sólo es consecuente, porque es jla consecuencia necesaria de la aspiración a la formación de una autarquía instrumental de la forma lógica!

¿Qué se sigue de aquí para la auto-comprensión de la lógica formal? Algo absolutamente importante. Pues con esto se hablará desde el comienzo, de manera inconcebible, de una forma lógica en singular -de la forma lógica. No hay entonces, así parece, una formulación universal o adecuada de la forma lógica, que de alguna manera inferimos de sus formas particulares, sino que la forma lógica se separa inmediatamente (sin concepto, dicho con Hegel), de acuerdo con el interés y el fin de aplicación en las formas clásicas y no clásicas de la lógica de enunciados y predicados, de sus axiomatizaciones y cálculos. La hay entonces sencillamente, tal como hay especies naturales en la naturaleza. Así, es evidente en el siglo XX lo que ha valido ya en sí para la lógica formal: ella tiene la unidad fundante de las formas y principios lógicos fuera de sí: ella se separa técnico-prácticamente, es decir, en vistas de exigencias de aplicación y necesidades, es decir, empero: según criterios extralógicos. Es muy decisivo ver esto. Pues a partir de aquí se responde también la pregunta tan molesta de la moderna philosophy of logic acerca de cómo se integra la continuamente creciente diversidad en la interpretación de la forma lógica, en un concepto universal de la forma lógica. Así, no se plantea la pregunta, de si una lógica "clásica" o "no clásica" de los enunciados o predicados representa adecuadamente a la forma lógica, ya que su sentido radica en último término en el hacer posible aplicaciones técnicas determinadas, por ejemplo cuando se trata de conexiones electro-técnicas cuya regulación hace necesaria más de dos valores ( 0 y 1 , es decir, por ejemplo, no hay o hay corriente). En la lógica formal moderna, para subrayarlo una vez más, no se trata explícitamente de la theoria, del conocimiento de la naturaleza verdadera de la forma lógica, sino del perfeccionamiento técnico del operar con estructuras de ordenación. Esto se realiza en definitiva con la programación y el manejo de máquinas; operar con "informaciones" empleadas en conjuntos de datos. Hoy en día necesitamos este instrumental diariamente (máquinas de búsqueda, etc.). El carácter de necesidad de la forma lógica - por consiguiente, el fundamento de la autonomía del concepto al que se echa mano - se convierte, él mismo, en medio para cualesquiera fines. Si formulo esto y uno piensa con ello en la fórmula kantiana del fin en sí del imperativo categórico con respecto al hombre, entonces este es el indicador de las consecuencias que una absolutización de este punto de vista tiene para el entorno humano del mundo.

\footnotetext{
${ }^{24}$ Kanterian, Frege, 12

${ }^{25}$ Dicho de otro modo: El eleatismo de los platónicos y el perspectivismo y nihilismo de los sofistas (Gorgias) son sólo las dos caras de una medalla, a saber, del problema no resuelto de la methexis. Por eso el Platón tardío retoma, con vistas al proble ma de la apariencia, del medio del sofista, su propio eleatismo y, con ello, [retoma] la pregunta no resuelta sobre la pensabilidad de la methexis en la reflexión.
} 


\section{La comprensión técnica del concepto}

Detallemos ahora nuestro análisis del concepto de "concepto". Consideremos en primer lugar la lógica formal tradicional, tal como se presenta en la Lógica Jäsche. "Concepto" designa "una representación general o reflexionada. ${ }^{, 26}$ Esto no es la esencia inmanente de un particular, ni acaso lo universal por antonomasia (forma formarum), sino "una representación de aquello que es común a varios objetos. ${ }^{27}$ El ser reflexionado de la representación significa, a saber, la fijación de un rasgo, es decir, de una propiedad que unifica bajo sí a muchas representaciones de cosas. Conceptualizar (begreifen) algo significa determinar, identificar algo singular mediante algo universal en la forma de la predicación (algo en cuanto algo); significa diferenciar algo de otra cosa y referirse a ello. Recién en el predicar tenemos relación sensu stricto con el pensar de modo lógico formal. Al respecto, Fichte escribe: "el concepto pone sólo el carácter de un algo: es esto y esto, es decir, todo lo que no se excluye mediante esta determinación." ${ }^{28}$ Esto significa también que el discurso sobre el concepto ya sólo tiene sentido, de modo lógico-formal, si éste no es, simplemente, una representación subjetiva, un signo o nombre vacío, sino [si] comprende (begreift) algo, por lo tanto, [si] se vuelve objetivamente sobre sí, [si] es pertinente (sachhaltig). Este algo es lo universal en cuanto rasgo idéntico a sí mismo en muchos [particulares].

¿Pero cómo llegamos a este algo? La pregunta apunta a los presupuestos del operar lógicoformal, que caen fuera de su campo visual, es decir, que son remitidos a lo psicológico. La lógica formal tradicional anticipa una teoría de la formación del concepto (de la que la lógica moderna, a partir de Frege, quiere abstraerse). Con esto se trata de responder a la pregunta "¿cómo se vuelven conceptos las representaciones dadas en el pensar?"29 Allí se presupone que las representaciones son dadas y que sólo mediante su determinación posterior surge el concepto. ${ }^{30}$

La referencia a la reflexión da un indicio del origen lógico de lo universal, que sobrepasa la explicación psicológica, la olvidada génesis lógico-formal a priori del concepto, ${ }^{31}$ pues en esto está llamada la atención sobre la yoidad (Ichheit) en cuanto fuente de la universalidad. La reflexión se presenta en una clasificación de tres actos (comparación, reflexión y abstracción), en esto se produce el concepto, poniendo de relieve lo común de las representaciones dadas de la intuición. ${ }^{32}$ Hay que decir, frente a esto, que estos tres actos son sólo un acto: al fijar la igualdad frente a la desigualdad ya está realizada la abstracción. El poner la identidad es ya el acto completo de la abstracción. Ella es la objetivación de la unidad de la conciencia. En esto consiste la génesis lógica del concepto, olvidada por la lógica formal. El concepto (empírico) es lo común en el sentido de lo igual en la intuición, lo idéntico respecto de lo múltiple. Si, por el contrario, la teoría de la abstracción es interpretada de modo empírico-psicológico, entonces ella se vuelve una petitio principii. ${ }^{33}$ Pero la circularidad tiene, como auto-condicionalidad previa, un segundo aspecto. Ella conduce a la comprensión de que el concepto no sólo puede ser interpretado como mera posición, sino, dicho con Fichte, se ha de pensar desde el auto-ponerse del saber. Sólo entonces se puede fundar suficientemente la necesidad del concepto como forma lógica, mientras que la génesis del concepto debe aparecer lógico-formalmente, como dice Fichte, en cuanto "algo casual de la determinación posterior de la primera

\footnotetext{
${ }^{26}$ I. Kant, Logik, en: AA IX, $\$ 1,91$.

${ }^{27}$ Kant, Logik, 91.

${ }^{28}$ Fichte, TL II: 198

${ }^{29}$ Kant, Logik, $\$ 5,93$. Con lo que se puede hablar en el sentido de Kant, en este contexto, sólo de conceptos empíricos, ya que los conceptos puros son ya presuposición de toda teoría de la abstracción.

${ }^{30}$ Cf. Fichte, TL II: 205.

${ }^{31}$ Cf. Fichte, TL II: 196.

32 "El lógico, entonces, puede analizar ante todo, mediante su yo frente a todo pensar, y frente a cualquiera conceptos, la imagen del individuo en su rasgo distintivo (Fichte, TL II: 202)

${ }^{33}$ Cf. Fichte, TL II: $201-202$
} 
representación." ${ }^{34}$ Lo universal qua rasgo no es pensado a partir de la autoconciencia como lo universal de todo lo universal, no [es pensado] como negatividad (en el sentido de Hegel) ${ }^{35}$ sino como positividad, ${ }^{36}$ como un producto en reposo, con el que opera un entendimiento externo.

Pero el concepto no se relaciona sólo con lo intuitivamente singular, sino igualmente con las especies, es decir, con los géneros, esto es, con lo general mismo: la lógica formal forma así pirámides conceptuales, en las que el concepto se diferencia con respecto a su intención (contenido qua propiedad) y extensión (multitud de todas las entidades que caen, como instancias de un rasgo X, bajo el concepto $\left.{ }^{37}\right) \cdot{ }^{38}$ La positividad del concepto se muestra aquí en que las pirámides del concepto espacializan lo lógico y las especies, es decir, los géneros están concebidos como determinidades con las que se opera. ${ }^{39}$

Hasta aquí con respecto a la lógica formal tradicional. El mayor problema consiste en que el concepto está, lógico-formalmente, infundado:

(a) Lógico-formalmente no se pregunta cómo y bajo qué principio puede ser posible la producción de una unidad en la multiplicidad de representaciones, en el sentido de un rasgo. La pregunta por la posibilidad del uso lógico del entendimiento (de la unidad de los conceptos en los juicios, de la unidad de los juicios en la conclusión $)^{40}$ no se presenta.

(b) ¿Qué pretensión de pertinencia (Sachhaltigkeit) puede erigir el concepto qua rasgo? El concepto lógico-formal no es presentación de una unidad en sí en la multiplicidad, presentación de una esencia inmanente en lo múltiple (en el sentido de lo universal ontológicamente relevante), sino una unidad que, con respecto a una diversidad de representaciones presupuestas como dadas, es puesta. Está presupuesto de modo lógico-formal que lo que es (Seinde) no se divide a sí mismo y que nosotros tendríamos la tarea de pensar su determinidad en-sí y para-sí (en el sentido de la dihaíresis platónica), sino que nosotros dividimos, según rasgos, puntos de vista subjetivos, que son en último término de naturaleza técnico-práctica. La unidad en la multiplicidad (presupuesta), que es lo universal de modo lógico-formal, es esencialmente posición. La lógica formal puede comprender lo universal y su identidad (abstracta) sólo como posición, porque de lo contrario se daría como resultado la contradicción que ella trata de evitar. Así fue destacado en la polémica de los universales: si las species y genera fueran algo más que posiciones, [si fueran] ontológicamente relevantes, entonces valdrían, al mismo tiempo, determinaciones contradictorias de ellas mismas. La humanitas en la persona $\mathrm{X}$ sería aquí, y al mismo tiempo en la persona $\mathrm{Y}$, allí. ${ }^{41}$ En este sentido, es consecuente que la lógica formal moderna no hable más de especies y géneros -lo que sin duda está conectado con la pretensión de una relevancia ontológica-, sino de clases. Las clasificaciones de lo que es, son construibles a voluntad. No hay en ellas ninguna infima species ontológicamente relevante. Pero esto ha tenido la consecuencia de que el discurso sobre los derechos humanos no tenga, de modo lógico-

\footnotetext{
${ }^{34}$ Fichte, TL II: 205.

${ }^{35}$ Que lo universal es negatividad, lo muestra ya la sabiduría que se expresa sensiblemente, en el sentido de la Fenomenología del espíritu (lo universal como el no-aquí, no-ahora, no-esto).

${ }^{36}$ El carácter de la positividad, tal como lo resalta el Hegel temprano, consiste en que algo es puesto como sólo idéntico consigo mismo y como indiferente frente a su relación con otros.

${ }^{37}$ Kant, Logik, \$7, 95. Con esto, la extensión encierra en sí, tanto la relación de género-especie, como también la de género o sea especie e individuo. Pero en esta medida, el concepto tiene que ser el significado, tanto lo determinante (intensión) como lo determinado (extensión) - un aspecto especulativo del concepto en la lógica formal, que, en la lógica formal moderna (desde Frege), es considerado como un defecto.

${ }^{38}$ Fichte indica en este contexto que la lógica formal, en el discurso sobre el contenido y la extensión del concepto, concibe a la síntesis que el concepto es cuantitativamente. (Fichte, TL II: 209). Así, es consecuente que la lógica formal moderna conciba la forma lógica a partir de la matemática.

${ }^{39}$ Así se conciben las reglas de la silogística, que son la pieza fundamental de la lógica tradicional, en cuanto operaciones en las que se produce una relación de conceptos con otros conceptos que coordina o subsume.

${ }^{40}$ Esto será la apercepción transcendental ( $\mathrm{KrV}$ B 131).

${ }^{41}$ Cf. K. Flasch, Art. Allgemeines/Besonderes, en: HWPh vol. 1, Darmstadt 1971, Sp. 172-177.
} 
formal, fondo. El clasificar se funda sólo en el acuerdo en el uso de estos conceptos, en definitiva, en la utilidad. La formulación lógico-formal de lo universal es, por consiguiente, también la fundamentación del primado de lo técnico-práctico. Si lo universal sólo es puesto, entonces para el actuar no tiene ninguna normatividad, que sería reconocida como requerimiento para la autodelimitación de la libertad al disponer de un objeto determinado. ${ }^{42}$

Pues bien, i[vamos] a la forma del concepto en la lógica formal moderna! Uno pregunta en primer lugar: ¿qué clase de entidad es el concepto $?^{43}$ En primer lugar, él no es:

(a) "Entidad psicológica". Frege destaca: la expresión "concepto" tiene que ser usada estrictamente en sentido lógico, diferenciada de su sentido psicológico. ${ }^{44}$ Así la lógica formal moderna excluye la teoría de la abstracción, por lo cual su problemática se oculta en los presupuestos previos. ${ }^{45}$

(b) "Objeto concreto" en el sentido de la cosa individual.

El punto de partida de la determinación del concepto no es, a diferencia de la LógicaJäsche, la relación con la conciencia, sino la relación con el lenguaje, que es concebido ciertamente como una estructura (Gebilde) objetiva, como un sistema de signos funcional. En analogía con la distinción tradicional de sujeto y predicado en el juicio, uno distingue en el análisis del enunciado singular el término singular, es decir, denominador, que se refiere al objeto "concreto", es decir, a algo $^{46}$ intuible que es espacio-temporalmente identificable, del término general que representa a un "objeto abstracto". ${ }^{47}$ Los objetos abstractos ${ }^{48}$ son determinaciones del pensar que no se identifican inmediatamente de modo intuitivo, es decir, espacio-temporalmente, sino sólo en relación con el lenguaje (en cuanto sistema de signos) (en lo que también se incluye la comprensión según la cual es imposible un acceso a-lingüístico a lo universal). Así se resalta en primer lugar una doble significación: el concepto es, en el uso lógico: a) predicador, es decir, un término general en cuanto "expresión atómica" (signo), b) el sentido [es] el significado del predicador y, en cuanto tal, ejemplo paradigmático de un objeto abstracto. ${ }^{49}$ Con esto, el significado del predicador puede ser interpretado de dos maneras: como intensión o como extensión, en el sentido de "clase" ${ }^{50}$ que reúne "entidades".

La forma lógica del concepto (del predicador, pero también de las relaciones) se piensa, con respecto a Frege -a quien recurrimos aquí como un caso paradigmático-, desde la función matemática $\left(\mathrm{y}=\mathrm{x}^{2}\right)$. Aquí también se muestra una doble significación: así, el concepto está, por un lado, determinado como aquello que la función expresa, es decir, como el "valor" determinado de la función que se pone mediante un argumento - este valor es el concepto en cuanto el "significado de un predicado" ${ }^{\text {, }}$ es decir, el contenido puesto consigo mismo, en la forma de la identidad. Por otro lado, el concepto es la función, el contexto funcional mismo, es decir, el producir de la identidad, consigo misma, de un contenido. Así, el predicador se determina como un operador n-ario (de una o más

\footnotetext{
${ }^{42}$ La supresión de lo concretamente universal en favor de lo abstractamente universal se corresponde en el concepto de libertad con la fijación del arbitrio frente a la libertad positiva (cf. Wladika, Nivellierung, Prinzipialisierung und Revolutionierung von Erfahrung, 36). El nivel de la lógica transcendental se corresponde con la libertad interpretada moralmente (separación de la ley moral y la acción individual). En Kant ya se expresa que el concepto de lo universal concreto es un presupuesto previo de la praxis moral. La fórmula de la humanidad del imperativo categórico muestra que el actuar moral está en el terreno del concepto concreto de lo universal.

${ }^{43}$ Tugendhat u. Wolf, Logisch-semantische Propädeutik, 128.

${ }^{44}$ G. Frege, Über Begriff und Gegenstand, en: Funktion - Begriff - Bedeutung, 47

${ }^{45}$ Cf. Ch. Thiel, Gottlob Frege: Die Abstraktion, en: J. Speck (ed.), Grundprobleme der großen Philosophen, vol. Philosophie der Gegenwart I, Göttingen ${ }^{3} 1985,9-44$

46 "Objeto es todo lo que es algo (uno habla de 'entidades')." (Tugendhat u. Wolf, Logisch-semantische Propädeutik, 128)

${ }^{47}$ Cf. G. Siegwart, Art. Begriff, en: Enzyklopädie Philosophie, Berlin 2010, 232-236.

${ }^{48}$ Cf. W. Künne, Abstrakte Gegenstände. Semantik und Ontologie, Frankfurt am Main 2007.

${ }^{49}$ Cf. Siegwart, Art. Begriff, 235 b.

${ }^{50} \mathrm{La}$ expresión "clase" es igualmente ambigua: puede designar una propiedad general como también un conjunto de objetos.

${ }^{51}$ G. Frege, Über Begriff und Gegenstand, 53.
} 
cifras) que determina términos y produce fórmulas (por ejemplo, en el sentido de la conexión "y"). ${ }^{52}$ El operador permite que resulte un "valor de verdad" en relación con uno o más operantes (¡lo que se ha de elaborar!), es decir, que ha de resultar en relación con uno o más "argumentos". El concepto en cuanto operador determina un objeto como elemento o no de una clase. En esto está presupuesto que hay objetos y que éstos están constituidos en sí. Luego ponemos clases que, mediante una propiedad lógica que satisfacen todos los objetos de la clase, se definen a voluntad. La clase se representa mediante el predicador como signo intuitivo, es decir, como una conexión funcional que, en relación con determinadas aplicaciones subjuntivas, proporciona un "valor de verdad". Así, la pregunta acerca de la verdad en logicis parece fácil de responder: el enunciado es, entonces, verdadero/falso, si el objeto cae o no "bajo" el concepto designado mediante el predicador. Esto depende de lo dado previamente: si el objeto designado es justamente un elemento o no de la clase. ${ }^{53}$

En esto radica, en primer lugar, un progreso en la formulación de la forma lógica. El concepto en cuanto operador ya se concibe como forma, que con respecto a un material dado pone un contenido determinado, produce una determinidad unívoca, y como herramienta a través de la cual se pone una determinidad unívoca. Esta es una anticipación de la negatividad de la forma lógica. La terminología (denominador, predicador, etc.) muestra al mismo tiempo el punto de vista de la inmediatez, en el que el actuar lógico se objetiva instrumentalmente en entidades cuasi-míticas. La lógica formal lleva a cabo con esto el paso desde la sustancia a la función, tal como sucede, sobre todo, en la ciencia natural moderna. Dicho con Hegel: si la lógica formal tradicional era una lógica de la "conciencia perceptiva", entonces la lógica formal moderna es una lógica tal de la conciencia comprensiva. Si bien el concepto todavía es concebido como algo fijo, no obstante el carácter de ser una función de determinación propia del concepto se pone de relieve con mayor claridad que en la lógica formal tradicional. El operante (la terminología expresa el espíritu de la técnica) es puesto como aquello que, en sí mismo, es indeterminado (variable no saturada), que tiene su determinidad exclusivamente mediante el operador en cuanto elemento funcional. Esto se corresponde con la relación entre el fenómeno y la ley natural formulada matemáticamente. Lo singular no significa nada en sí mismo, sino que allí sólo es relevante en la medida en que pueda considerarse como un elemento funcional en un contexto formulable según la regularidad. Con esto es claro que el concepto así considerado no es ninguna esencialidad óntica (en el sentido del platonismo), sino que su ser es ser-puesto (en el sentido de la lógica de Hegel).

Con este progreso, no obstante, no es eliminado el problema de la falta de una fundamentación lógica del concepto. Así, el problema de la methexis se presenta en la forma de la pregunta por la existencia de los "objetos abstractos". Ellos no son cosas particulares, pero tienen que ser "algo", una entidad independiente del sujeto. Al mismo tiempo, el ser-puesto del concepto lógicoformal se manifiesta como un haz de atributos. ¿Cómo va esto junto? ¿Cómo nos son accesibles los “objetos abstractos"? ¿Cómo puede un predicador, en cuanto signo lingüístico que siempre es una entidad intuitiva, designar o representar algo inteligible, que no es intuitivo, como su significado? ¿Cómo se puede pensar que un objeto intuitivo $a$ puede caer bajo un concepto $F$ ?

La lógica formal puede dejar pasar estas preguntas, en primer lugar, con el derecho que le otorga el punto de vista de la inmediatez. Mientras la reflexividad de la forma lógica misma no esté concebida, la pregunta acerca del modo de existencia del concepto no puede ser respondida. Así, la lógica formal procede pragmáticamente, intentando reducir estas preguntas al uso de los conceptos: la objetividad de los conceptos no es una propiedad de los mismos, sino [que su propiedad es] la

${ }^{52}$ Siegwart, Art. Begriff, 233a

53 "Fa" es verdadero (en el sentido de Frege), si el objeto a cae bajo el concepto F. Pertenece a la naturaleza de un concepto, el hecho de que algunos objetos caen bajo él y otros no. Cf. M. Dummett, The Interpretation of Frege's Philosophy, Duckworth $1981,166$. 
vinculabilidad dada de reglas del uso del concepto para los "usuarios del lenguaje". 54 Ellas son accesibles para nosotros en tanto "disponemos" de ellas, es decir, [en tanto] las usamos correctamente. El criterio para ello es el éxito de la aplicación. Así, en último término, la teoría funcionalista del concepto se junta pragmáticamente con el nominalismo: para el concepto no "hay" ningún significado independiente fuera de su uso, sino sólo en su uso dentro de un juego lingüístico determinado. El término general, en cuanto signo lingüístico, sólo tiene, por tanto, que funcionar como algo universal, [tiene que] ser por tanto universal según su modo de empleo, sin que represente con ello algo universal. Lo universal del significado del término general consiste sólo en su respectiva funcionalidad en juegos lingüísticos dados, en el sentido del mismo modo de empleo de una expresión. Si, entonces, los significados deben ser "abstracta de expresiones bajo sinonimia" 55 , vuelve a aparecer la teoría de la formación de conceptos de Frege, que había sido dejado de lado, por la puerta de atrás. En esto, no obstante, no podemos detenernos. Independiente de la consideración de la pregunta acerca de la relación entre lo lógico y lo real, que debe permanecer como aporética, esto ya es insostenible debido a la explicación circular. Subyace el mismo círculo en el que se basa la teoría de la formación de conceptos: ¿cómo se verifica el modo de empleo similar o igual de una expresión, sin el presupuesto de ese concepto, que no tiene que ser nada independiente del uso ${ }^{56} \mathrm{Se}$ necesita un criterio a partir del cual uno pueda juzgar y comparar modos de empleo diversos. Pero este criterio no es otra cosa más que el concepto. Además, sólo se puede establecer la identidad, la igualdad o la diversidad de los modos de empleo, si estos conceptos ya se "tienen" o "aplican". Esto, no obstante, sólo es posible, si el concepto -por ejemplo de la identidad o igualdad misma- no coincide inmediatamente con su uso, sino que más bien es distinto de éste y pertenece originariamente al pensar. Negando y presuponiendo a un mismo tiempo la diferencia entre concepto y nombre, el nominalismo pragmático se contradice. Esta contradicción permanece como aporía, en cuanto la lógica formal quiere mantenerse en una ingenuidad artificial contra su auto-reflexión y superación parcial: la lógica transcendental.

Traducción: Nicolás Trujillo; revisión: Max Maureira

\footnotetext{
${ }^{54}$ Siegwart, Art. Begriff, 235b.

${ }^{55}$ Siegwart, Art. Begriff, 235b.

${ }^{56}$ Esta problemática reaparece en Kant como dialéctica del significado y del uso de las categorías. Por un lado, los conceptos del entendimiento tienen significado sólo en el uso empírico en cuanto ordenación de la intuición: "sólo nuestra intuición sensible y empírica les puede otorgar a ellos sentido y significado." (KrV B 149). A su vez, tiene empero que valer: "los conceptos puros del entendimiento están libres de esta limitación, y se refieren a objetos de la intuición en general, ella puede ser semejante a la nuestra o no, siempre que sea sensible y no intelectual“ ( $\mathrm{KrV}$ B 148). En esto se expresa que la espontaneidad del concepto presupone que el concepto, en cuanto principio del orden, debe ser ya significante en sí mismo, si él debe poder producir espontáneamente lo común de las representaciones de la intuición. Cf. B. Liebrucks, Sprache und Bewußtsein, vol. 4: Die erste Revolution der Denkungsart. Kant: Kritik der reinen Vernunft [SuB 4], Frankfurt am Main 1968, 516; H. Röttges, Dialektik als Grund der Kritik. Grundlegung einer Neuinterpretation der „Kritik der reinen Vernunft" durch den Nachweis der Dialektik von Bedeutung und Gebrauch als Voraussetzung der „Analytik“, Meisenheim 1981.
} 



\title{
Los conceptos kantianos de "facultad" y de "mente" frente a la lectura epigenética
}

\author{
ANTONINO FALDUTO ${ }^{1}$
}

\begin{abstract}
Resumen
En este artículo voy a estudiar la innovación radical que, en la historia de la filosofía, constituyen de los conceptos kantianos de "facultad" y "mente". Con este propósito me concentraré en el debate en torno a las facultades que tiene lugar en el siglo XVIII en Europa en general y, en particular, en Alemania. Terminaré mi análisis señalando de qué manera el término "facultad" sólo puede ser interpretado en conexión con la concepción filosófica pura de Kant sobre el concepto de "mente", la cual será distinguida de un análisis epigenético de tipo empírico acerca de la mente humana.
\end{abstract}

Key words: Facultad, Mente, Epigénesis

\section{Kant's concepts of "faculty" and "mind" versus epigenetic reading}

\begin{abstract}
In this paper, I will study the radical innovation of Kant's concepts of "faculty" and "mind" in the history of philosophy. With this aim, I will focus on the discussion concerning the debate on the faculties during the Eighteenth Century in Europe in general and particularly in Germany. I will end my analysis by noting how the term "faculty" can be rightly interpreted only in connection with Kant's pure philosophical treatment of the concept of Gemüt, which will be distinguished from an epigenetical, empirically characterized analysis of the human mind.

Palabras clave: Faculty/Vermögen, Mind/Gemüt, Epigenesis
\end{abstract}

\section{Introducción}

Immanuel Kant es el primer filósofo que defiende una estructura tripartita de las facultades de la mente humana desde un punto de vista filosófico puro, basado en una clara distinción entre el entendimiento y la sensibilidad. ${ }^{2}$ De ese modo, Kant desarrolla un nuevo tipo de investigación en contraste a lo que otros pensadores pretendían haber hecho anterior o contemporáneamente en el campo psicológico. Entre esos otros pensadores se encuentran: Christian Wolff, Alexander Gottlieb Baumgarten, Johann Georg Sulzer, Johann Nikolaus Tetens, Georg Friedrich Meier y Johann August Eberhard. Todos ellos dieron cuenta de un rol decisivo de la facultad del sentimiento o de la sensibilidad dentro de la estructura de la mente humana. A partir de sus estudios, la parte sensitiva del alma adquiere un lugar específico en el contexto de las investigaciones sobre las facultades del alma, en conjunción con las indagaciones dirigidas a las facultades del conocimiento y del deseo. Sin

\footnotetext{
${ }^{1}$ Martin-Luther-Universität Halle-Wittenberg.

${ }^{2}$ Cfr. Gabriel Rivero, Zur Bedeutung des Begriffs Ontologie bei Kant. Eine entwicklungsgeschichtliche Untersuchung,

Berlin/Boston, de Gruyter 2014.
} 
embargo, estos autores estaban interesados, en su mayoría, únicamente en una investigación de carácter empírico, basada simplemente en la observación de los procesos mentales. En ese sentido, resulta especialmente importante el hecho de que el estudio de las facultades, que había sido caracterizado por los autores arriba mencionados como un proyecto meramente empírico-psicológico, gana por primera vez relevancia desde una perspectiva estrictamente filosófica a partir de las investigaciones de Kant. Esto se debe al hecho de que, a diferencia de lo que ocurría antes, Kant entiende el estudio de las facultades como un estudio acerca de las condiciones de posibilidad del conocimiento, del deseo, y de la apetencia. Teniendo ello en cuenta, en este trabajo voy a sostener que una lectura epigenética de la teoría de las facultades que Kant desarrolla en su proyecto crítico resultaría insuficiente, si no se tiene en cuenta el desarrollo de sus investigaciones sobre las facultades que tienen lugar en el ámbito de la filosofía pura, con plena independencia de lo empírico. Para desarrollar mi propuesta, voy a recurrir al estudio de la radical innovación de los conceptos kantianos de "facultad" (Vermögen) y "mente" (Gemüt) en la historia de la filosofía.

El punto de partida de mi análisis, será, en ese sentido, una breve consideración lexicográfica sobre el término Vermögen en la época de Kant. En segundo lugar, me concentraré en el estudio de un evento particular: la Preisaufgabe de la Academia de Ciencias de Berlín propuesta entre los años 1773 y 1775. Esta convocatoria de la Academia es de central importancia, pues en ella se plantea por primera vez de forma explícita la pregunta por la naturaleza y las características de las facultades fundamentales del conocimiento y del sentir. En tercer lugar, completaré mi análisis del concepto de facultad haciendo notar de qué manera este término sólo puede ser comprendido correctamente si se lo interpreta en conexión con el tratamiento filosófico puro del concepto de Gemüt en un sentido kantiano, que debe distinguirse de un análisis epigenético y empírico del alma humana.

\section{Consideraciones lexicográficas}

Una primera explicación sobre el modo en el cual el término Vermögen era usado en la época de Kant puede obtenerse a partir de tres diccionarios filosóficos: los diccionarios de J.G. Walch (1726), J.H. Zedler (1732-1754) y J.C. Adelung (1774-1786).

En el Philosophisches Lexicon de Walch el término es tratado en relación con el ámbito metafísico. De ello da cuenta allí el paralelismo entre el término Vermögen y la palabra latina potentia. Walch se refiere a dos facultades activas y finitas: entendimiento (Verstand), identificada con la "potencia del pensamiento", y voluntad (Wille), definida como la "potencia del querer".

En el diccionario de Zedler es posible encontrar un tratamiento similar del término Vermögen. Concretamente, se puede leer en éste al respecto lo siguiente: "La facultas rationalis se compone de intellectu et voluntate, de entendimiento y voluntad". ${ }^{3}$

En el diccionario de la lengua alemana editado por J.C. Adelung (1774-1786), el término Vermögen es analizado como la posibilidad para producir una modificación. ${ }^{4}$ Aunque éste sea definido de manera muy general, el significado destaca su uso filósofico. ${ }^{5}$ En efecto, el término es definido fundamentalmente como una condición para la realización de actos de percepción, de deseo,

\footnotetext{
${ }_{3}^{3}$ Johann Heinrich Zedler, Grosses Vollständige Universal-Lexicon Aller Wissenschaften und Künste, Halle/Leipzig 1732-1754. Volumen 9, Columna 69

${ }^{4}$ Grammatisch-kritisches Wörterbuch der Hochdeutschen Mundart mit beständiger Vergleichung der übrigen Mundart, besonders aber der Oberdeutschen, von Johann Christoph Adelung, Leipzig, Johann Gottlob Immanuel Breitkopf und Compagnie 1793.

5 J. C. Adelung, Grammatisch-kritisches Wörterbuch, volumen 4 (Seb-Z), columna 1096: «Vermögen ist ein sehr allgemeiner Ausdruck, welcher als ein solcher auch in der philosophischen Schreibart am üblichsten ist».
} 
y de volición. Este es el uso del término que hacían la mayoría de los filósofos, los cuales a su vez lo asociaban con una pluralidad de facultades posibles. ${ }^{6}$

Luego de esta breve introducción lexicográfica, voy a concentrarme en un ejemplo que da cuenta con claridad de la tenaz discusión en torno al estudio de las facultades que tuvo lugar en la época de Kant. Se trata de la discusión motivada por el concurso de la Academia de las Ciencias de Berlín, el cual estaba dirigido a examinar detalladamente las dos facultades del alma: la facultad de conocimiento y la facultad de sentir.

\section{Las Preisaufgaben de 1773 y de 1775}

El concurso sobre las dos facultades fundamentales del alma, la facultad de conocimiento y la de sentir, fue anunciado por la Real Academia Prusiana de las Ciencias por primera vez en el año 1773 y luego reeditado en $1775 .^{7}$ Los concursos de esta naturaleza tenían el propósito de promover el progreso de la ciencia sobre una temática específica. ${ }^{8}$

La Academia de Berlín proponía estos concursos anualmente, bajo el patrocinio de Federico II de Prusia y siguiendo el ejemplo de la Academia de las Ciencias de Francia y de la Sociedad Real de Londres. ${ }^{9}$ Durante esa época, la filosofía experimentó un progreso considerable, que también puede ser visto como el resultado de la fundación de una sección específica para la filosofía dentro de la Academia. ${ }^{10}$

En general, los concursos suscitaban como respuesta el envío de una docena de ensayos. Pero, en algunos casos, hubo que repetir los concursos una, y hasta varias veces, porque los ensayos presentados no alcanzaban el nivel suficiente. Una vez premiado un ensayo, la Academia lo publicaba. A la vez había textos que recibían un accésit (por lo general, dos o tres textos además del premiado). ${ }^{11}$ Con esta dinámica, la Academia jugó un rol preponderante en la vida cultural europea, al menos hasta 1786/1787, esto es, hasta la muerte de Federico II.

No tanto las respuestas, sino más bien las preguntas como tales eran esperadas con ansiedad y los pensadores más influyentes de la época (Euler, Lagrange, d’Alembert, Condorcet, Kant, Rousseau y Herder entre otros) participaron activamente de las competencias desde que en 1744 se anunciara por primera vez públicamente un concurso.

En virtud de la importancia capital que tenían los concursos de la Academia, resulta especialmente relevante para el tema concerniente a este trabajo, el llamado a concurso sobre las facultades del alma. Como ya se ha dicho anteriormente, en 1773 se plantea por primera vez la pregunta sobre la relación entre las dos facultades básicas del alma y en 1775 se plantea esta pregunta por segunda vez. En esta última ocasión, hubo que proveer una descripción más detallada de la investigación pretendida, ya que hasta 1744 no había llegado ninguna respuesta satisfactoria como resultado del primer llamado. Sin embargo, en 1776 la Academia sí encontró algunos ensayos dignos de ser premiados. La pregunta reformulada fue la siguiente:

El alma posee dos facultades originales [...]: la facultad de conocer y la de sentir. [...] Solicitamos:

${ }^{6}$ J. C. Adelung, Grammatisch-kritisches Wörterbuch, volumen 4 (Seb-Z), columna 1097: «Das Vermögen zu begehren, das Begehrungsvermögen, das Vermögen zu wollen, zu erkennen, sich zu erinnern, zu urtheilen u.s.f.».

${ }^{7}$ Ver Nouveaux Mémoires de l'Academie Royale des Sciences et Belles-Lettres. Anné MDCCLXXIII. Berlin 1775, p. 11 ss.

${ }^{8}$ Cfr. Hans-Heinrich Müller, Akademie und Wirtschaft im 18. Jahrhundert. Agrarökonomische Preisaufgaben und Preisschriften der Preußischen Akademie der Wissenschaften. Versuch, Tendenzen und Überblick, Berlin, Akademie-Verlag 1975, p. 46 ss.

${ }^{9}$ Cfr. Cordula Neis, Anthropologie im Sprachdenken des 18. Jahrhunderts: Die Berliner Preisfrage nach dem Ursprung der Sprache (1771), Berlin/New York, de Gruyter 2003, p. 74

${ }^{10}$ Cfr. C. Neis, Anthropologie im Sprachdenken des 18. Jahrhunderts, pp. 76-77.

${ }^{11}$ Cfr. C. Neis, Anthropologie im Sprachdenken des 18. Jahrhunderts, p. 83. Ver también Hans-Heinrich Müller, Akademie und

Wirtschaft im 18. Jahrhundert. Agrarökonomische Preisaufgaben und Preisschriften der Preußischen Akademie der

Wissenschaften. Versuch, Tendenzen und Überblick, Berlin, Akademie-Verlag 1975, pp. 47-48. 
1. Un desarrollo exacto de las propiedades originales de ambas facultades y de las leyes generales que ellas siguen.

2. Una investigación exacta de la dependencia recíproca de ambas facultades y de la manera en la que una ejerce influencia sobre la otra.

3. Principios básicos, que digan claramente cómo el genio y el carácter del ser humano depende del grado, de la fuerza, de la vivacidad y de los progresos que una u otra de las facultades hayan alcanzado y de la proporción que existe entre ambas. $^{12}$

Sin duda alguna la autoría de la pregunta del concurso ha de ser atribuida a Johann Georg Sulzer, quien claramente distingue entre la facultad cognoscitiva y la facultad sensitiva, considerándolas como las dos únicas facultades básicas del alma. ${ }^{13}$ Según Sulzer, la facultad sensitiva no juega ningún rol en el conocimiento teórico, el cual es competencia absoluta de la facultad cognoscitiva. Por su parte, la facultad cognoscitiva es completamente excluida del dominio práctico, el cual es competencia exlusiva de la facultad sensitiva. ${ }^{14}$

Tres escritos obtuvieron el accésit en 1776: Johann August Eberhard ganó el primer premio $^{15}$ y los otros dos escritos premiados fueron los de Johann Gottfried Herder ${ }^{16}$ y Joachim Heinrich Campe. ${ }^{17}$ En todos estos trabajos, la distinción entre las dos facultades esenciales del alma se logra recurriendo a una fundamentación psicológica. Los textos de Campe y de Herder (en este último caso, de modo todavía más evidente) proponen el uso de meros esquemas fisiológicopsicológicos para responder a la cuestión. Por su parte, Eberhard intenta evaluar el problema desde una perspectiva más cercana a la tradición de Leibniz y de Wolff, aunque con algunos puntos innovadores relevantes. ${ }^{18}$ De ese modo, gracias a su cercanía a las ideas de Sulzer y a las expectativas del jurado, Eberhard se consagra ganador. ${ }^{19}$ Pero el concurso de la Academia no sólo resulta relevante en vista del propósito de este trabajo por dar testimonio de la discusión sobre las facultades en los años 70 , sino también, y muy especialmente, porque además se ha de considerar que Kant estaba informado acerca del concurso y que seguía la competencia con gran interés. De hecho, Kant menciona el concurso de la Academia no sólo en su correspondencia, sino que también anota en su ejemplar de la Metaphysica de Baumgarten la solicitud completa del concurso (que podemos encontrar en la Reflexión 184a).

\section{La concepción kantiana de "facultad" en el contexto de su noción de "mente"}

Sobre la base del precedente análisis lexicográfico y del debate sobre las facultades en el siglo XVIII, quisiera plantear ahora la cuestión concentrándome especialmente en la filosofía de Kant.

En la concepción kantiana de las facultades de la mente, además del término alemán Vermögen (facultad), aparecen también para referirse a las facultades, los términos

\footnotetext{
12 Johann Gottfried Herder, Vom Erkennen und Empfinden, den zwo Hauptkräften der Menschlichen Seele, en Johann Gottfried Herder, Sämtliche Werke, Volumen 1-33, Berlin 1877-1913 (Volumen 8, Berlin 1892, pp. 263-333).

${ }^{13}$ Cfr. Anmerkungen über den verschiedenen Zustand, worinn sich die Seele bey Ausübung ihrer Hauptvermögen, nämlich des Vermögens, sich etwas vorzustellen und des Vermögens zu empfiden, befinde, en Vermischte Philosophische Schriften: Aus den Jahrbüchern der Akademie der Wissenschaft in Berlin gesammelt, volumen 1: Leipzig, 1773, volumen 2: Leipzig, 1781.

${ }^{14}$ Cfr. Peter Grove, «Johann August Eberhards Theorie des Gefühls», en Hans-Joachim Kertscher - Ernst Stöckmann, Ein Antipode Kants? Johann August Eberhard im Spannungsfeld von spätaufklärerischer Philosophie und Theologie, Berlin/Boston, de Gruyter 2012, pp. 119-131, y Jürgen Brummack - Martin Bollacher, «Kommentar», en Johann Gottfried Herder, Werke in zehn Bände, volumen 4: Schriften zu Philosophie, Literatur, Kunst und Altertum 1774-1787, Frankfurt am Main, Deutscher Klassiker Verlag 1994, pp. 795-1407.

${ }^{15}$ Johann August Eberhard, Allgemeine Theorie des Denkens und Empfindens, Berlin, Voß 1776.

${ }^{16}$ Johann Gottfried Herder, Vom Erkennen und Empfinden, den zwo Hauptkräften der Menschlichen Seele.

17 Joachim Heinrich Campe, Die Empfindungs- und Erkenntnißkraft der menschlichen Seele: die erstere nach ihren Gesetzen beyde nach ihren ursprünglichen Bestimmungen, nach ihrem gegenseitigen Einflusse aufeinander und nach ihren Beziehungen auf Character und Genie betrachtet, Leipzig, Weygandsche Handlung 1776.

${ }^{18}$ Cfr. P. Grove, «Johann August Eberhards Theorie des Gefühls», pp. 124-125.

${ }^{19}$ Cfr. Denis Thouard, Schleiermacher : Communauté, Individualité, Communication, Paris, Vrin 2007, pp. $32-33$ (passim).
} 
Gemüthsvermögen $^{20}$, Gemüthsfähigkeiten ${ }^{21}$, Gemüthsarten ${ }^{22}$, Gemüthskräfte y Gemüthsanlage. ${ }^{23}$ Todos ellos denotan la clase general a la cual pertenecen las facultades específicas; sensibilidad y razón, pero también: imaginación, juicio, sentido, voluntad y deseo. Como puede constatarse, todas las palabras alemanas arriba mencionadas están formadas por un término pertenenciente al campo semántico de "facultad", "fuerza", "capacidad", "disposición" y precedidas por la palabra Gemüt (mente). Y es a este concepto (Gemüt) al que quisiera ahora dirigir mi atención para poder entender correctamente el significado que Kant le atribuye al concepto de facultades de la mente.

En algunas ocasiones Kant utiliza los términos Seele (alma) y Gemüt (mente) como sinónimos. Sin embargo, en otras ocasiones las distingue tajantemente. ${ }^{24}$ Una exposición exhaustiva de la distinción entre estos términos puede lograrse en base a la lectura del texto de Kant $\mathrm{Zu}$ Soemmerring über das Organ der Seele..$^{25}$ En él, Kant asimila Gemüt a animus y diferencia este concepto al de Seele/anima. Gemüt es concebido específicamente como el concepto bajo el cual las representaciones son unificadas. ${ }^{26}$

Si bien este concepto, Gemüt, que también se discute en la tercera Crítica, puede ser analizado, en primer lugar, en relación con el ámbito biológico. Pero de aquí no se sigue, sin embargo, que en ello esté implicada necesariamente una lectura biológica. Como puede verse en la tercera Crítica, Gemüt es definido como un "principio vital" del ser humano, conectado con el cuerpo humano, pero no identificado con él. En este punto dos autores parecen jugar un papel fundamental en las consideraciones de Kant: Soemmerring y Blumenbach.

Soemmerring busca en sus investigaciones sobre el alma un enlace similar entre el cuerpo humano y su estructura mental funcional. Él fue uno de los autores más influyentes respecto de las teorías "anatómicas-funcionalistas" de la mente en el siglo XIX en Alemania y uno de los fundadores de la neurofisiología moderna. Además, era conocido de Johann Friedrich Blumenbach, un importante exponente del vitalismo. Durante sus estudios en Göttingen, Soemmerring asistió a cursos dictados por Blumenbach y permanenció en contacto con él, luego de abandonar la ciudad para ofrecer cursos en otros lugares de Alemania (Kassel y Mainz). ${ }^{27}$

Resulta valioso considerar la relación entre Soemmerring y Blumenbach, como un medio a través del cual las tesis de Blumenbach influenciaron los escritos de Kant. En ese sentido, lo más destacable es la referencia de Kant a la teoría de la epigénesis. Esta teoría, defendida por Blumenbach, postula un desarrollo gradual del embrión a partir de un material previamente no organizado. En algunos pasajes de la tercera Crítica, Kant cita la teoría biológica de Blumenbach y

\footnotetext{
${ }^{20}$ Cfr.EE, AA 20: 207.09 .

${ }^{21}$ Cfr. GSE, AA 02: 253.12; Versuch über die Krankheiten des Kopfes, AA 02: 264.06.

${ }^{22}$ Cfr. GSE, AA 02: 218.34; 219.03 , y Bem. zu GSE, AA 20: 79.11.

${ }^{23}$ Cfr.KU, AA 05: 235.34, 307.14; MS, AA 06: 399.11.

${ }_{24}$ Cfr. Anthropologie Parow, Anthropologie Philippi, Anthropologie Friedländer.

${ }_{25}$ «Zu Soemmerring über das Organ der Seele», apéndice a Samuel Thomas von Soemmerring, Über das Organ der Seele, Königsberg 1796. Ver Mauro Di Giandomenico, "Kant, Soemmerring e il dibattito sulla "sede dell'anima"», en Costantino Esposito - Pasquale Ponzio - Paolo Porro - Veneranda Castellano (eds.), Verum et Certum. Studi di storiografica filosofica in onore di Ada Lamacchia, Bari, Levante 1998, pp. 167-191; Werner Euler, «Die Suche nach dem 'Seelenorgan'. Kants philosophische Analyse einer anatomischen Entdeckung Soemmerrings», en Kant-Studien, 93 (2002), pp. 453-480; Peter McLaughlin, «Soemmerring und Kant: Über das Organ der Seele und den Streit der Fakultäten», en Soemmerring-Forschungen, 1 (1985), pp. 191-201; Pedro Jesús Teruel, «Das Organ der Seele. Immanuel Kant y Samuel Thomas Sömmerring sobre el problema mente-cerebro», en Studi kantiani, XXI (2008), pp. 59-76.

${ }^{26}$ Cfr.AA 12: 32. Ver Hansmichael Hoenegger, «Geist, mens, nous. Teleologia della filosofia e sistema teleologico delle facoltà in Kant», en Eugenio Canone (ed.), Per una storia del concetto di mente, vol. II, Firenze, Olschki 2007, pp. 327-368; Pedro Jesús Teruel, «Significato, senso e ubicazione strutturale del termine Gemüt nella filosofia kantiana», in Stefano Bacin - Alfredo Ferrarin - Claudio La Rocca - Margit Ruffing (eds.), Kant and Philosophy in a Cosmopolitan Sense /Kant und die Philosophie in weltbürgerlicher Hinsicht. Akten des XI. Internationalen Kant-Kongresses, Boston-New York, De Gruyter 2013, volume 4, pp. 507-518.

27 Cfr. Stefano Fabbri Bertoletti, Impulso, formazione e organismo. Per una storia del concetto di Bildungstrieb nella cultura tedesca, Firenze, Olschki 1990.
} 
parece intentar acercar su investigación transcendental del conocimiento humano a la teoría de Blumenbach.

Estos pasajes asumen un rol importante en el contexto del análisis dedicado al concepto de Gemüt, ya que parecen indicar la posibilidad de una interpretación de la teoría de Kant sobre las facultades desde un punto de vista epigenético. Una primera referencia en este sentido puede tomarse de la Crítica de la razón pura, y más precisamente del parágrafo dedicado al "Resultado de la deducción de los conceptos del entendimiento" (§ 27 de la Deducción transcendental).

Aquí Kant trata la cuestión de las únicas "dos maneras en las cuales puede ser pensada una correspondencia necesaria de la experiencia con los conceptos de los objetos de ella". Al respecto establece que "o bien la experiencia hace posibles esos conceptos o bien los conceptos hacen posible la experiencia". ${ }^{28}$ La solución de Kant es bien conocida: la experiencia depende de las categorías y no al contrario. ${ }^{29}$ Hacer que los conceptos a priori dependan de la experiencia -afirma Kantcorrespondería a una suerte de "generatio aequivoca", a partir de la cual una cierta cosa se deriva de otra cosa completamente diferente, lo cual resulta de un origen totalmente impropio. Por ello, Kant explica la correspondencia entre los conceptos del entendimiento y la experiencia sosteniendo que el fundamento de esta última se encuentra en la razón pura, y más precisamente en las categorías. Y en ese contexto, Kant compara el tratamiento de la relación entre la experiencia y los conceptos a priori con la epigénesis: Kant identifica el hecho de "que las categorías contienen, por el lado del entendimiento, los fundamentos de la posibilidad de toda experiencia en general" con "un sistema de la epigénesis de la razón pura". ${ }^{30}$ Esta comparación se debe a que la experiencia es pensada como el producto de la actividad de la mente. Sin embargo, una interpretación epigenética del proceso mental en Kant es, evidentemente, controversial.

Kant mismo escribe al respecto que el hecho de que las categorías contengan por el lado del entendimiento el fundamento de la posibilidad de toda la experiencia en general puede entenderse "por decirlo así" (B 167) como un sistema de la epigenesis de la razón pura. Por otro lado, la referencia a presupuestos empíricos en la exposición de la empresa crítica, a lo que parecería dar lugar la alusión a una epigenesis de la razón pura, podría llevar a una falsa concepción de la filosofía pura. De hecho, Kant se refiere a Blumenbach a propósito del concepto de organismo, pero no recurre a él para dar una explicación general de la mente.

En el $§ 81$ de la tercera Crítica, por ejemplo, Kant tematiza la forma de causalidad que nos permite pensar la posibilidad de un ser organizado y sugiere que podemos explicar la finalidad interna de los organismos por medio de la teoría "ocasionalista" o bien por medio de la teoría del "preestabilismo". ${ }^{31}$ Pero explicar los organismos en términos del ocasionalismo -advierte Kantsignifica perder todo concepto de la naturaleza. ${ }^{32}$ Por tanto, resta únicamente la teoría del preestabilismo. Ahora bien, Kant describe dos diferentes versiones de esta teoría. De acuerdo con la primera, cada organismo se genera a partir de su propia especie como educto. Por su parte, la segunda afirma que el organismo ha de describirse como un producto. En la primera versión se trata de la teoría de la "preformación individual" o "evolución", mientras que, en la segunda, se trata de la teoría de la "epigenesis" o "preformación genérica". Según esta última estrategia explicativa, la capacidad productiva del progenitor "está preformada de acuerdo con las predisposiciones internas finales que fueron impartidas en su origen (Stamm), y por tanto la forma específica ya estaba preformada virtualmente". ${ }^{33}$ Kant parece inclinarse por esta estrategia explicativa. Además, afirma que la razón

\footnotetext{
${ }^{28} \mathrm{KrV}$, B 166/AA 03: 128.09-12.

${ }^{29} \mathrm{KrV}, \mathrm{B}$ 167/AA 03: 128.12-19.

${ }^{30} \mathrm{Ibid}$.

${ }^{31} \mathrm{KU} \S 81$, AA 05: 422-423.

32 KU \& 81, AA 05: 422.32 .

${ }^{33} \mathrm{KU} \S 81$, AA 05: 422.36-37, 423.01-08.
} 
considera esta explicación de forma positiva ya antes de que le sea dada cualquier tipo de prueba al respecto. A ello se suma que esta explicación ha de ser preferida, en tanto que en ella se considera a la naturaleza como autoproductiva, con el mínimo recurso a lo sobrenatural. ${ }^{34}$ En esta sección de la tercera Crítica, Kant destaca el rol de Blumenbach en el establecimiento de los principios de aplicación de esta teoría y ofrece apreciaciones positivas sobre este científico. ${ }^{35}$ Pero, a pesar de esto, Kant hace notar finalmente que Blumenbach se pone demasiado a merced del mecanicismo de la naturaleza por la admisión de un "principio para nosotros desconocido, de una organización primitiva, un elemento indeterminable pero inconfundible": el Bildungstrieb ("impulso de formación"). ${ }^{36}$

De acuerdo con la teoría de Blumenbach, cada ser viviente posee un "impulso de formación" (también llamado nisus formativus) que lo diferencia de todo ser inanimado y motiva su formación y crecimiento. Este impulso tiene una influencia sobre la materia no formada, deviene activo y acompaña a los cuerpos de los seres animados durante su vida completa. El impulso de formación constituye, de ese modo, la fuerza vital más importante, sin la cual no sería posible la vida: es diferente y precede a toda otra fuerza. ${ }^{37}$

Sin sobreestimar la importancia de la teoría del Bildungstrieb de Blumenbach en el pensamiento de Kant, podemos limitarnos a destacar el interés kantiano por la teoría de la epigénesis y su apreciación de los estudios de Blumenbach, y con ello su interés por una explicación epigenética de los procesos de la mente humana. Pero esta explicación no puede ser considerada como el elemento fundamental del análisis crítico de la mente, si es que no queremos dar una imagen equivocada de un análisis filosófico puro. El pensamiento de Kant no puede ser asociado de manera reductiva a una peculiar interpretación del innatismo por el hecho de destacar su interés en cuestiones de biología. Y tampoco conviene argumentar a favor de un origen epigenético de la teoría kantiana de la mente. Una interpretación estrictamente biológica de la empresa crítica de Kant, basada en una interpretación epigenética de la mente, falla, porque no es capaz de explicar el intento kantiano de realizar un estudio de las facultades con independiente de todo elemento empírico. Por supuesto, es posible concentrarse en el nivel empírico y pensar desde ahí la investigación de las facultades que Kant lleva a cabo, considerándola como una investigación de carácter biológico. Pero realizar esto no es lo pretendido por Kant en sus escritos críticos. Pues, si leemos las tres Críticas, encontramos fundamentalmente una investigación sobre las condiciones de posibilidad del conocimiento que se derivan de un análisis a priori. ${ }^{38}$

\section{Consideraciones finales}

En base al estudio de los conceptos de "facultad" (Vermögen) y de "mente" (Gemüth), que antes de Kant se mueven estrictamente en el ámbito de la psicología empírica, podemos constatar que una lectura epigenética de la teoría de las facultades que Kant desarrolla en su proyecto crítico es insuficiente, porque no tiene en cuenta las investigaciones de Kant que, en el ámbito de la filosofía pura, se dirigen al estudio de las facultades con entera independencia de lo empírico. En ese sentido, una lectura psicológica fuerte de la empresa crítica kantiana, basada en una interpretación epigenética de la mente, falla, pues no logra explicar el hecho de que Kant estudie también las facultades de manera enteramente independiente de lo empírico, en general, y de lo psicológico, en particular. Ciertamente es posible concentrarse en el nivel empírico de la investigación kantiana y adoptar

$34 \mathrm{KU} \& 81$, AA 05: 424.07-18.

35 KU \& 81, AA 05: 424.19-28.

36 KU § 81, AA 05: 424.19-34.

37 Cfr. Johann Friedrich Blumenbach, Ueber den Bildungstrieb und das Zeugungsgeschäft, Göttingen 1791

${ }^{38}$ Cfr. Antonino Falduto, The Faculties of the Human Mind and the Case of Moral Feeling in Kant's philosophy, Berlin/Boston, de Gruyter 2014. 
entonces un punto de vista psicológico. De hecho, una investigación como esa efectivamente es llevada a cabo en los estudios antropológicos de Kant, que justamente sustituyen la disciplina tradicional de la psicología empírica. Sin embargo, eso no es lo que se propone Kant en las obras críticas, sino todo lo contrario, pues en éstas se trata de fundamentar por medio de un análisis a priori las condiciones de posibilidad del conocimiento.

Traducción de Gabriel Rivero.

Bibliografía

AA.VV. Anmerkungen über den verschiedenen Zustand, worin sich die Seele bey Ausübung ihrer Hauptvermögen, nämlich des Vermögens, sich etwas vorzustellen und des Vermögens zu empfinden, befinde, en Vermischte Philosophische Schriften: Aus den Jahrbüchern der Akademie der Wissenschaft in Berlin gesammelt, Leipzig, Volumen I, 1773, Volumen II, 1781.

AA. VV., Nouveaux Mémoires de l'Academie Royale des Sciences et Belles-Lettres. Anné MDCCLXXIII. Berlin 1775.

Stefano Fabbri Bertoletti, Impulso, formazione e organismo. Per una storia del concetto di Bildungstrieb nella cultura tedesca, Firenze, Olschki 1990.

Johann Friedrich Blumenbach, Ueber den Bildungstrieb und das Zeugungsgeschäft, Göttingen, 1791.

Johann Christoph Adelung, Grammatisch-kritisches Wörterbuch der Hochdeutschen Mundart mit beständiger Vergleichung der übrigen Mundart, besonders aber der Oberdeutschen, Leipzig, Johann Gottlob Immanuel Breitkopf und Compagnie, 1793.

Jürgen Brummack - Martin Bollacher, «Kommentar», en Johann Gottfried Herder, Werke in zehn Bände, volumen 4: Schriften zu Philosophie, Literatur, Kunst und Altertum 1774-1787, Frankfurt am Main, Deutscher Klassiker Verlag 1994, pp. 795-1407.

Joachim Heinrich Campe, Die Empfindungs- und Erkenntnißkraft der menschlichen Seele: die erstere nach ihren Gesetzen, beyde nach ihren ursprünglichen Bestimmungen, nach ihrem gegenseitigen Einflusse aufeinander und nach ihren Beziehungen auf Character und Genie betrachtet, Leipzig, Weygandsche Handlung, 1776.

Johann August Eberhard, Allgemeine Theorie des Denkens und Empfindens, Berlin, Voß, 1776.

Werner Euler, «Die Suche nach dem 'Seelenorgan'. Kants philosophische Analyse einer anatomischen Entdeckung Soemmerrings», Kant-Studien 93 (2002), pp. 453-480.

Antonino Falduto, The Faculties of the Human Mind and the Case of Moral Feeling in Kant's philosophy, Berlin/Boston, Walter de Gruyter, 2014.

Mauro Di Giandomenico, «Kant, Soemmerring e il dibattito sulla "sede dell'anima"», en Costantino Esposito - Pasquale Ponzio - Paolo Porro - Veneranda Castellano (eds.), Verum et Certum. Studi di storiografica filosofica in onore di Ada Lamacchia, Bari, Levante 1998, pp. 167191.

Peter Grove, «Johann August Eberhards Theorie des Gefühls», en Hans-Joachim Kertscher - Ernst Stöckmann, Ein Antipode Kants? Johann August Eberhard im Spannungsfeld von spätaufklärerischer Philosophie und Theologie, Berlin/Boston, de Gruyter 2012, pp. 119 131.

Johann Gottfried Herder, Vom Erkennen und Empfinden, den zwo Hauptkräften der Menschlichen Seele. En: Johann Gottfried Herder, Sämtliche Werke, Volumen VIII, Berlin, 1892. 
Hansmichael Hoenegger, «Geist, mens, nous. Teleologia della filosofia e sistema teleologico delle facoltà in Kant», en Eugenio Canone (ed.), Per una storia del concetto di mente, vol. II, Firenze, Olschki 2007, pp. 327-368.

Immanuel Kant, Beobachtungen über das Gefühl des Schönen und Erhabenen, en: Kant, Immanuel, Gesammelte Schriften Hrsg.: Volúmenes 1 - 22 Preussische Akademie der Wissenschaften, Volumen 23 Deutsche Akademie der Wissenschaften zu Berlin, a partir del volumen 24 Akademie der Wissenschaften zu Göttingen. Berlin 1900 y ss. [=AA] Vol. 02.

, Erste Einleitung in die Kritik der Urteilskraft, en AA, 20.

Kritik der reinen Vernunft, Riga 1781 (A), 1787 (B).

Kritik der Urteilskraft, en AA, 05.

Metaphysik der Sitten, en AA, 06.

, Versuch über die Krankheiten des Kopfes, en AA, 02.

, Vorlesung über Anthropologie Parow, en AA, 25.

, Vorlesung über Anthropologie Philippi, en AA, 25.

, Vorlesung über Anthropologie Friedländer, en AA, 25.

«Zu Soemmerring über das Organ der Seele», apéndice a Samuel Thomas von Soemmerring, Über das Organ der Seele, Königsberg 1796.

Peter McLaughlin, «Soemmerring und Kant: Über das Organ der Seele und den Streit der Fakultäten», Soemmerring-Forschungen 1 (1985), pp. 191-201.

Hans-Heinrich Müller, Akademie und Wirtschaft im 18. Jahrhundert. Agrarökonomische Preisaufgaben und Preisschriften der Preußischen Akademie der Wissenschaften. Versuch, Tendenzen und Überblick, Berlin, Akademie-Verlag, 1975.

Cordula Neis, Anthropologie im Sprachdenken des 18. Jahrhunderts: Die Berliner Preisfrage nach dem Ursprung der Sprache (1771), Berlin/New York, de Gruyter, 2003.

Gabriel Rivero, Zur Bedeutung des Begriffs Ontologie bei Kant. Eine entwicklungsgeschichtliche Untersuchung, Berlin/Boston, Walter de Gruyter, 2014.

Pedro Jesús Teruel, «Das Organ der Seele. Immanuel Kant y Samuel Thomas Sömmerring sobre el problema mente-cerebro», Studi kantiani, XXI (2008), pp. 59-76.

Pedro Jesús Teruel, «Significato, senso e ubicazione strutturale del termine Gemüt nella filosofia kantiana». En Stefano Bacin - Alfredo Ferrarin - Claudio La Rocca - Margit Ruffing (eds.), Kant and Philosophy in a Cosmopolitan Sense /Kant und die Philosophie in weltbürgerlicher Hinsicht. Akten des XI. Internationalen Kant-Kongresses, Boston-New York, De Gruyter 2013, volume 4, pp. 507-518.

Denis Thouard, Schleiermacher: Communauté, Individualité, Communication, Paris, Vrin, 2007.

Johann Heinrich Zedler, Grosses Vollständige Universal-Lexicon Aller Wissenschaften und Künste, Halle/Leipzig, Johann Heinrich Zedler, 1732-1754. 



\title{
Arqueología filosófica y hermenéutica. Apuntes sobre la interpretación de la historia de la filosofía en Kant
}

\author{
JoSE MARÍA GARCÍA GÓMEZ DEL VALLE
}

\begin{abstract}
Resumen
Este escrito quiere presentar una aproximación a una posible "hermenéutica de la historia de la filosofía" en Kant, para ello contextualiza la recepción del pensamiento kantiano en la hermenéutica filosófica del siglo XX y expone un conjunto de pautas kantianas para la interpretación del pasado filosófico.

Key words: Hermenéutica, Historia de la filosofía
\end{abstract}

\section{Philosophical Archaeology and Hermeneutics. Remarks on Kant's Interpretation of the History of Philosophy}

\author{
Abstract \\ The aim of this paper is to provide an aproximation to a possible "hermeneutics of the history of philosophy" in Kant, \\ situating the discussion in the context of the reception of Kant's thought by the Philosophical Hermeneutics of the 20th \\ Century and presenting a set of Kantian principles for the interpretation of past philosophies. \\ Palabras clave: Hermeneutics. History of Philosophy.
}

I.

If there be nothing new, but which is Hath been before (...)

(Shakespeare 2002: 499)

El pensamiento de Kant marcó un punto de inflexión en la historia de la filosofía que incidió además decisivamente en la consideración filosófica de esa misma historia ${ }^{2}$. El presente escrito se centra en sus reflexiones acerca de la posibilidad de una interpretación filosófica de la historia de la filosofía, las cuales, condicionadas ellas mismas históricamente y desarrolladas en el marco de su proyecto filosófico transcendental, presentan -tal es la convicción que motiva este estudio- rasgos que hoy podrían ser denominados específicamente "hermenéuticos". Se ensaya rescatar, por tanto, ese momento "hermenéutico" en Kant a partir de algunos apuntes sobre el carácter metódico de su confrontación con la historia de la filosofía y prestando atención asimismo a la propuesta kantiana de ciertas pautas interpretativas acerca de cómo leer los textos de la tradición.

No obstante, para dar con algo parecido a una "hermenéutica de la historia de la filosofía" en Kant es preciso, en primer lugar, vencer dos resistencias: la de la "hermenéutica filosófica" frente a

${ }^{1}$ Investigador independiente. Email de contacto: jmggv@web.de

${ }^{2}$ Vid. v.g. Heydenreich (1791, § 11) y Braun (1990, Cap. V, §§ 28-31). 
la filosofía de Kant (que determina la posibilidad de una recepción distintivamente hermenéutica de la obra del filósofo) y, por otro lado, la del propio Kant ante la historia (o historiografía) de la filosofía (que servirá, además, para acentuar las dificultades de aquella apropiación hermenéutica). Pues, a pesar de que el propio Kant pudo hacer alguna -aunque por compendiosa, no menos significativaaportación a la hermenéutica bíblica ${ }^{3}$ y a que su reflexión estética sirvió de inspiración a la hermenéutica romántica de comienzos del siglo XIX, la filosofía hermenéutica del pasado siglo, la que podría marcar el carácter específico de la ocupación con el pasado filosófico como manera preeminente de hacer filosofía contemporánea, ha manifestado una oposición de principio a integrar en su comprensión de la filosofía los rasgos fundamentales de una propuesta como la kantiana. Sin necesidad de comprometerse en este punto con una particular concepción de la "hermenéutica" como proyecto filosófico, cabe recordar que el impulso inaugural de la hermenéutica del siglo XX atendía programáticamente a la tarea de una fundamentación de las ciencias del espíritu ligada a los debates en torno al carácter metódico de las disciplinas históricas, que se contraponía a la noción de conocimiento y de experiencia impuesta por una determinada interpretación de la obra de Kant, la lectura neokantiana que tomaba pie en una comprensión de Kritik der reinen Vernunft como "teoría de la experiencia", i.e. como fundamentación metodológica de las ciencias matemático-naturales, y que sólo de manera derivada encontraba aplicación en el ámbito histórico o explicitaba las diferencias entre las ciencias de la naturaleza y de la cultura. A partir de la crítica fundamental a la noción de "experiencia”, liberándola además de un estricto marco epistemológico y disciplinar, este programa hermenéutico reivindicaba como formas privilegiadas de experiencia en sentido propio v.g. la confrontación con las expresiones de la cultura y el arte y señalaba la falta de un posicionamiento fundamental de la filosofía kantiana respecto a la naturaleza histórica del conocimiento y su articulación esencialmente lingüística - una carencia que muy temprano cifraron las "metacríticas" de Hamann y Herder. Así, el proyecto de una "crítica de la razón histórica", que según la expresión de Ortega (1933/34: 186) debía servir de contrapposto a la tarea crítica kantiana, terminó por desbordar su propia concepción originaria y converger con otras formas más radicalmente enfrentadas a la comprensión neokantiana de la filosofía (como la fenomenología o la filosofía de la existencia), de tal manera que la figura filosófica que podía ofrecer el proyecto transcendental, en tanto que inscrito en un determinado enclave histórico y condicionado por una comprensión imperante ciertamente unilateral (en clave teórico-cognoscitiva y vinculada paradigmáticamente a la fundamentación de las ciencias naturales), la hacía inasumible, tanto para esta incipiente comprensión de la filosofía como "hermenéutica", los motivos de esta resistencia hermenéutica a la asimilación del proyecto filosófico-transcendental (i.e. aquello de Kant que no se deja integrar en una comprensión de la filosofía como práctica hermenéutica, como actividad de apropiación históricamente condicionada de saberes y pensamientos de la tradición, como interpretación de textos transmitidos, etc.), que las objeciones del propio Kant ante una comprensión histórica de la filosofía - las cuales, por cierto, podrían ser asumidas hasta cierto punto como un temprano diagnóstico del denominado morbus hermeneuticus. Todos los reproches que Kant hubiera de hacer al historiador de la filosofía investido falsamente como filósofo se encuentran concentrados en unas pocas líneas del prefacio a sus Prolegomena, en las que se dirige

\footnotetext{
${ }^{3}$ Vid. el "capítulo hermenéutico" del escrito sobre la religión ( $R G V$, AA 6: 109ss.) y Dilthey (GS XIV: 651ss.).

${ }^{4}$ Cf. v.g., en ese sentido, la remisión a una "experiencia general de la vida" que no queda cubierta sin resto por cualesquiera consideraciones metodológicas y que señala, además, el carácter "derivado" de las categorías científico-naturales ya en Dilthey (1978: 359).

${ }^{5}$ Vid. sobre esto Figal (2009). - Aunque es sabido que la aportación a la discusión estética de la "filosofía hermenéutica" parte de una crítica de principio al carácter subjetivista de una estética del gusto como la kantiana (cf. Gadamer 1991: 75ss., así como Gadamer 1939 y 1958), en términos generales, una apropiación explícitamente hermenéutica de la filosofía de Kant sólo ha parecido viable desde la Kritik der ästhetischen Urteilskraft (vid. v.g. Gadamer 1983: 8. Cf. en este sentido también Makkreel 1990 y Figal 2009: 131ss.). Por otro lado, Kant und das Problem der Metaphysik, así como la noción de "hermenéutica" desde la que Heidegger acomete ese trabajo de interpretación en su doble función metódica como "introducción histórica" a Sein und Zeit y como aportación elemental a una programada "destrucción de la historia de la ontología", merecería quizás un desarrollo aparte que aquí, sin embargo, por razones obvias de espacio y de contexto, no podrá llevarse a cabo. (Véase, no obstante, sobre la motivación hermenéutica de esta interpretación heideggeriana de Kant v.g. Bollnow 1933 y Gadamer 1975.)
} 
contra aquellos eruditos para los cuales la "historia de la filosofía" es su "filosofía" (Es giebt Gelehrte, denen die Geschichte der Philosophie (der alten sowohl, als neuen) selbst ihre Philosophie ist...", AA 4: 255). Que se refiera a ellos como "eruditos" es ya una nota sintomática, que da un criterio de diferenciación frente a la tarea que Kant estima como propiamente filosófica (pues, en última instancia, "un filósofo no es un erudito" ["Ein Philosoph ist kein Gelehrter..."], V-Lo/Busolt, AA 24: 619). Distingue con ello, en ese mismo pasaje, la labor del erudito de la del filósofo: mientras que el trabajo del historiador consiste en dar cuenta de lo ya acontecido ("... von dem Geschehenen der Welt Nachricht zu geben", Prol, Vorwort, AA 4: 255), los filósofos son "quienes se esfuerzan por crear desde la fuente misma de la razón" ("diejenigen, die aus den Quellen der Vernunft selbst zu schöpfen bemüht sind...”, ibid.). Aquí aparece, por tanto, una comprensión de la filosofía como actividad estrictamente racional opuesta por principio al relato de "lo acontecido" y, con ello, se señala con toda severidad el carácter -por definición- secundario de la tarea del historiador con respecto al trabajo del filósofo - aquél ha de narrar o dar noticia de lo ya realizado por éste. La historia (ya acontecida y narrada) de la filosofía anterior no parece poder -de suyo-integrarse en el proceder mismo de la razón que genera desde sí, por vez primera, originalmente, un pensar que -sólo él- puede ser considerado filosófico.

Según lo anterior, para Kant cualquier intervención que haya de presentarse legítimamente como una aportación al pensamiento filosófico ha de venir testada en directa confrontación con su fuente originaria (que no es otra que la razón misma), sin que quepa posibilidad de sancionar el carácter vinculante de lo transmitido históricamente y sin que haya motivo alguno para admitir la autoridad de cualquier instancia tradicional o la legitimidad de cualquier saber heredado. El pensamiento de Kant procede así consecuentemente según el imperativo ilustrado de la crítica (a la que han de someterse por igual la religión y la autoridad política, cf. $\mathrm{KrV}$ A XI, en nota), y que la concibe, además, en términos filosóficos, como la crítica de aquella facultad misma de la razón (y no, por cierto, "de libros y sistemas" ["eine Kritik der Bücher und Systeme"], ibid., A XII). De igual manera, la crítica filosófica en tanto que actividad enfáticamente racional, no puede recurrir a opiniones transmitidas como argumentos de autoridad. Si para Kant, frente a ciertos usos académicos, para refutar una propuesta filosófica o un determinado contenido doctrinal no puede bastar el recurso a una opinión pretérita o a un libro eminente, se debe esto a que cualesquiera libros de filosofía ya escritos han de haberse producido a partir de exactamente los mismos principios racionales que son, por definición, accesibles por igual tanto al lector como al autor de dichas obras. ${ }^{6}$ El trabajo "sistemático", el quehacer propiamente filosófico, es ajeno al argumento de autoridad e inmune a toda objeción crítica que haya de fundarse exclusivamente en la remisión a cualesquiera registros doxográficos existentes. Es a la sola razón a la que hay que acudir como fuente común desde la que emana -y en relación con la cual es posible confrontar y validar- cualquier ensayo legítimamente filosófico. No se reconoce por tanto tampoco autoridad alguna (pues "la razón es un principio activo que no ha de tomar nada de la mera autoridad de otros" ["Vernunft ist zwar ein thätiges Princip, das nichts von bloßer Autorität Anderer [...] entlehnen soll'], Log, AA 9: 76); cualquier remisión a un autor ilustre (así como, obviamente, cualquier versión posible del argumentum ad verecundiam) está por principio excluida de la práctica filosófica. La validez de la razón como fuente primera de la verdad filosófica es anónima ("las verdades racionales valen de manera anónima: aquí no se trata de quién ha dicho algo, sino de qué ha dicho" ["Vernunftwahrheiten gelten anonymisch: hier ist nicht die Frage: Wer hat es gesagt, sondern Was hat er gesagt?"], Ibid.: 78); de tal manera que lo que haya de ser admitido en general en términos de reflexión filosófica no podrá decidirlo un canon de textos eminentes establecido tradicionalmente, puesto que la "piedra de toque" del pensamiento filosófico lo

${ }^{6}$ Así, escribe Kant, “...la refutación de proposiciones racionales puras recurriendo a libros [...] es algo enojoso”, pues, en última instancia, estos libros "...no han podido ser creados de otras fuentes que de aquellas de las cuales estamos tan cerca nosotros como sus autores..." "“Allein es ist mit dem Widerlegen reiner Vernunftsätze durch Bücher (die doch selbst aus keinen anderen Quellen geschöpft sein konnten, als denen, welchen wir eben so nahe sind, als ihre Verfasser) eine mißliche Sache.” ÜE, AA 8: 187). 
constituye ese recurso a la razón humana común (i.e. el despliegue consecuente de lo que pueda dar de sí a partir de un principio). Si en el ámbito de la filosofía como actividad racional no cabe la remisión a la autoridad de otros, no cabe aducir por tanto las palabras de un autor ni refutar ninguna proposición refiriendo únicamente lo contenido en libros que conforman una determinada tradición; si en filosofía todo depende de cuán radicalmente pueda uno acercarse a la fuente originaria de la verdad, que no es otra que la mera razón humana, la cual es, por definición, anónima; es más, si cualquier autor está sometido por igual al criterio de verdad instituido - de nuevo- por la mera razón, de la cual se encuentra tan cerca (o tan lejos) como cualquier otro, entonces, la filosofía, como tal, no ha de poder reconocer elemento normativo alguno que pueda asociarse, sólo por razones históricas, i.e. desde la validez que pueda conferirle su transmisión o conservación, a un conjunto determinado de escritos. En última instancia, dice Kant, no hay -ni puede haber- autores "clásicos" en filosofía".

Se percibe ya aquí de manera especialmente pregnante la distancia que separa al proyecto kantiano de la tarea de la filosofía concebida hermenéuticamente, más aún cuando el modelo que se tiene a la vista es el de la hermenéutica filosófica del siglo XX, que no se comprende a sí misma como el instrumental disciplinado para la interpretación de textos religiosos o jurídicos, ni como una teoría universal de la interpretación de los clásicos de la tradición cultural y literaria, tampoco como propuesta metodológica de fundamentación de las ciencias sociales y humanas, sino que vincula la posibilidad misma del quehacer filosófico contemporáneo a la lectura y la interpretación del pasado filosófico (y que se reconoce así, explícitamente, en aquello que antes se señaló como un carácter "secundario": el de la "narración" y, por tanto, la remisión a algo ya acontecido).

Parece entonces que sólo una comprensión de la historia humana como caída y una suerte de mecanismo de "compensación" (por utilizar un término de la psicología), como reacción quizás al carácter manifiestamente secundario (lógicamente secundario) de la actividad historiográfica, podría motivar la reprobación de todo nuevo ensayo de contribuir de manera original al saber filosófico en los eruditos del pasaje anteriormente citado (del prólogo a Prolegomena), i.e. en quienes identifican la "historia de la filosofía" como su "filosofía". Persiste en ellos la convicción de que no queda nada relevante por decir, i.e. de que, al cabo, “...no puede decirse nada que según su opinión no haya sido ya dicho..." ("Widrigenfalls kann nichts gesagt werden, was ihrer Meinung nach nicht schon sonst gesagt worden ist...", Prol, AA 4: 255), y no es casual que Kant abriera sus consideraciones en los Prolegomena con estos comentarios; pues, más bien, fue precisamente una tal recepción de su opus magnum lo que motivó la redacción misma de este libro (i.e. en parte contra la tendencia a entender las aportaciones de la primera Crítica desde clasificaciones históricas heredadas y posiciones conocidas del pasado filosófico, las cuales habían de obstaculizar toda comprensión siquiera tentativa del carácter particular de la contribución kantiana ${ }^{8}$ ) y, posteriormente, también del escrito polémico contra Eberhard (Über eine Entdeckung..., de 1790) ${ }^{9}$. Tras el mencionado reproche ("no hay nada

\footnotetext{
${ }^{7}$ Dice Kant: “... lo que sea correcto filosóficamente no lo puede ni lo debe aprender nadie de Leibniz, sino que la piedra de toque, que yace tan cerca de uno como de cualquier otro, es la razón humana común, y no hay ningún autor clásico de la filosofía." (“...was philosophisch-richtig sei, kann und muß keiner aus Leibnizen lernen, sondern der Probirstein, der dem einen so nahe liegt wie dem anderen, ist die gemeinschaftliche Menschenvernunft, und es giebt keinen klassischen Autor der Philosophie." ÜE, AA 8: 219 , en nota.)

219 , en nota.)
${ }^{8}$ Kant se refiere a esta particularidad de la recepción histórica del pensamiento científico y filosófico, la cual se encuentra igualmente sometida al mecanismo por el que no sólo los nuevos avances encuentran una resistencia de principio sino que, más aún, cuando son aceptadas las nuevas teorías sucede esto, en primer lugar, desde el prisma que motivaba aquella primera resistencia. Pues, como comenta Terrasson al tratar del paso de la física cartesiana a la newtoniana: "Una infinidad de hombres no asumirá la filosofía que no ha sido aún generalmente aceptada, hasta que ésta no tenga a su favor a la mayoría. Pero entonces no entrará en su entendimiento más que en la forma de un prejuicio." "“Eine unzähliche Menge Menschen werden die Philosophie, die noch nicht überall eingeführet ist, nicht eher annehmen; als bis sie die mehresten Stimmen auf ihrer Seite haben wird. Alsdann wird sie in ihrem Verstande nichts anders Eingang finden, als in der Gestalt eines Vorurtheils." Terrasson 1756, Einl., I. Abs., \$ 24 , p. 67.) - Una referencia a este pasaje de Terrasson se encuentra en la sección dedicada a los prejuicios de sus lecciones sobre enciclopedia filosófica (cf. PhilEnz, AA 29: 26 y la nota 63 a nuestra traducción, EF: 100s.).

${ }^{9}$ Véase sobre esto el comentario de Heydenreich (1791, § 3: 220): "Si bien ciertos filósofos creen encontrar en Leibniz una 'crítica de la razón'; yo confieso, sin embargo, que casi me atrevería a dudar de si los que afirman esa 'crítica de la razón' leibniziana realmente saben qué significa 'crítica de la razón'." ["Zwar glauben gewisse Weltweise im Leibnitz eine Vernunftkritik zu finden
} 
nuevo bajo el Sol”, etc.) había detectado Kant un prejuicio, por el cual “...uno cree ver por todas partes aquello que ya conoce..." (“....man allenthalben das zu sehen glaubt, was einem schon sonst bekannt war...” Prol, AA 4: 262 ${ }^{10}$ y que se traduce en relación con la recepción histórica de la filosofía en la censura de lo nuevo, en el gesto inquisidor del historiador que señala en el pasado filosófico el referente pretérito de toda aportación que pretenda ser novedosa, que la desvela entonces como mero sucedáneo de algo ya sido, reflejo de una aportación ya hecha, etc. Y, sin embargo -y aquí se señala una pauta de la interpretación de la historia de la filosofía que podría tener el carácter de una "contrapartida hermenéutica" kantiana al referido "prejuicio histórico"-, que tal cosa sea en general posible, que el historiador de la filosofía pueda advertir en el pasado de la disciplina algo como anticipación, depende, en última instancia, de que el trabajo filosófico mismo, aquel que Kant distinguía de la labor estrictamente historiográfica, pueda proporcionar una indicación de hacia dónde ha de dirigir la mirada. Kant destaca esto al comienzo de Über eine Entdeckung..., cuando escribe: “i... cuántos descubrimientos considerados novedosos no son vistos ahora por hábiles intérpretes de manera totalmente clara en los antiguos, después de que se les haya indicado hacia dónde han de mirar!” (“...allein wie viele für neu gehaltene Entdeckungen sehen jetzt nicht geschickte Ausleger ganz klar in den Alten, nachdem ihnen gezeigt worden, wornach sie sehen sollen!" ÜE, AA 8: 187. Algo que, a su vez, encuentra expresión aún antes en una carta de Lambert a Kant de 1765: "Pues ésta es gente que lo encuentra todo en los antiguos, tan pronto se les dice qué deben buscar." ["Denn dieses sind Leute, die in den Alten Alles finden, sobald man ihnen sagt, was sie suchen sollen."] AA 10$, p. 53$)^{11}$

La convicción del erudito experimenta, así, una inversión hermenéutica que impone como pauta de la interpretación un criterio primero "sistemático" (aquí laxo, en su oposición usual a "histórico"). La "historia de la filosofía" se comporta de una manera necesariamente secundaria en relación con la "filosofía" propiamente dicha, pero no sólo en el sentido antes aludido de que la narración de lo acontecido haya de ser lógicamente secundaria con respecto al acontecimiento (i.e. que dependa de que acontezca eso que ha de ser narrado, etc.), sino en un sentido aún más relevante en este punto para la discusión de la relación de la filosofía con su historia, i.e. en el sentido de que la mirada misma del historiador ha de venir guiada ya por un criterio sistemático que sólo puede ser aportado por el filósofo. Si la tarea propiamente "histórica" de una "historia de la filosofía" está doblemente condicionada de esta manera por lo específicamente "filosófico", la posibilidad de una "historia filosófica de la filosofía" podría ganarse en una apropiación explícita de este carácter ya sistemáticamente determinado del acercamiento al pasado filosófico.

ich gestehe aber, [...] daß ich fast wagen dürfte, zu zweifeln, ob die Behaupter einer Leibnizschen Vernunftkritik Überhaupt wissen was Vernunftkritik sey."]

${ }^{10}$ En las lecciones de lógica se recoge una clasificación de los prejuicios y se identifica como uno de los más significativos, entre los de la "consideración de la época", el "prejuicio de la antigüedad". La referencia a la tematización kantiana de los prejuicios tiene interés en este punto por su aplicación a las reflexiones acerca de la recepción de la historia de la filosofía, pues uno de los motivos que explican el surgimiento de este tipo de prejuicios lo señala Kant atendiendo v.g. a cómo los textos antiguos superan las expectativas que motivan su misma lectura y se descubre en ellos, de manera totalmente inesperada, "algo que uno no creería en principio posible atendiendo a las circunstancias de la época en la que vivieron sus autores" (cf. Log, AA 9: 80). Ese asombro (Verwunderung), que en seguida se convierte en admiración (Bewunderung), se vincula aquí específicamente a una experiencia de lectura como la que arriba se señalaba: "Aquí se ven los prejuicios surgidos de la consideración que se tiene por la antigüedad. Es por ello que hay tantos defensores de la antigüedad que, tan pronto se ha inventado algo en tiempos recientes, se apresuran a mostrar que los antiguos ya lo sabían, que no se trata por tanto de algo realmente nuevo, sino que ha sido, más bien, extraído y sacado de nuevo a la luz de los escritos de los antiguos." "Hier sieht man, welche Vorurtheile aus dem Ansehen entspringen, welches man gegen das Alterthum hat. Dahero giebt es so viele Verfechter des Alterthums welche, so bald in neueren Zeiten etwas erfunden wird, sogleich zeigen, daß die Alten das alles auch schon gewust haben, daß es also eigentlich nichts neues, sonderen nur von den Schriften der alten heraus gesuchtes und etwas ans Licht gebrachtes sey." V-Lo/Blomberg, AA 24: 182)

11 Vid. este mismo pensamiento de nuevo en las lecciones de lógica: "El prejuicio favorable a la antigüedad predomina especialmente entre los literatos, en tanto que se dedican propiamente a la lectura de los escritores antiguos. - Estos creen ahora encontrar nuevos descubrimientos en los escritos de los antiguos. Pero por lo común no los encuentran hasta que no han sido ya descubiertos." "'Das Günstige Vorurtheil des Alterthums herscht insonderheit unter den Literatoren, als welche sich eigentlich mit Lecture der alten Schriftsteller beschäftigen. - Diese glauben nun neue Entdeckungen bereits zu finden in den Schriften der Alten. Aber gemeinhin finden sie dieselbe nicht eher, als bis sie schon entdeckt sind." V-Lo/Busolt, AA 24: 642s.) 
¿Puede sin embargo comprenderse esta clave sistemática de lectura de la historia de la filosofía como una propuesta propiamente hermenéutica? ¿Cabe aún hablar, en general, de algo como una "hermenéutica de la historia de la filosofía" en Kant? ¿No legitima, más bien, por lo visto hasta el momento, la resistencia de Kant ante (contra) una filosofía comprendida históricamente, aquella primera resistencia hermenéutica ante Kant (más precisamente de la "hermenéutica filosófica" contra Kant)? Cuando, además, no sólo se critica por parte de Kant la identificación de la filosofía con su historia (su historiografía), sino que se reconoce un mecanismo del prejuicio en la base de una tal comprensión, que es sometido a una crítica señaladamente "ilustrada"12, se niega el carácter vinculante de la tradición, se elimina el papel ejemplar de lo clásico y su carácter normativo, no se admite autoridad constituida alguna para el pensamiento filosófico, sino sólo el recurso a una razón humana común (situada, en principio, allende la historia), etc., ¿no muestra lo visto hasta ahora de la consideración kantiana de la historia de la filosofía, más bien, su total desavenencia con un planteamiento hermenéutico vinculado en alguna de sus manifestaciones más conocidas v.g. a una "rehabilitación hermenéutica" de la noción de "autoridad" y de "tradición", a una vindicación de los "prejuicios" como "preestructura ontológica de la comprensión”, etc.? ${ }^{13}$ ¿No indica la comprensión apenas esbozada de la "historia de la filosofía" y su papel en la tarea propiamente filosófica (por lo anterior, para Kant, más bien: contra dicha tarea), tal como ésta aparece en primera línea y de la manera más literal en los pocos textos de Kant aludidos, esta falta de adecuación del planteamiento kantiano con el proyecto hermenéutico como propuesta fuerte de filosofía? ${ }^{14}$

¿O cabe leer aún las reflexiones de Kant acerca de la interpretación de la historia de la filosofía, en tanto que "arqueología filosófica" (cf. FM/Lose Blätter, AA 20: 341), en una clave específicamente hermenéutica?

II.

Either criticism is no good at all (a
very defensible position) or else
criticism means saying about an
author the very things that would
have made him jump out of his
boots.
Chesterton (1911: 52)

La reflexión de Kant en torno a la posibilidad de llevar a cabo una interpretación propiamente filosófica de la historia de la filosofía toma pie en una contraposición de conocimiento histórico y racional ya conocida y tematizada en su época, y que en términos de una distinción entre el conocimiento histórico (cognitio historica) y el filosófico (cognitio philosophica) abre las reflexiones de Chr. Wolff en su Discursus praeliminaris (cf. Wolff 1728, $\S \S 1 \mathrm{ss}$.) ${ }^{15}$. El conocimiento histórico en la definición de Wolff es el conocimiento "de lo que es" (ibid. § 3); a su vez, el filosófico es conocimiento "del fundamento (o de la razón)" de "lo que es" (ibid. § 6). Mientras que el histórico consiste en la mera noticia de una cuestión fáctica, el conocimiento filosófico atiende al fundamento de ese estado de cosas para dar cuenta de cómo tal es posible (ibid. § 7). Por su parte, G. F. Meier, que asume de Wolff esta clasificación, distingue igualmente en este sentido entre "conocimiento

${ }^{12}$ Vid. el comentario de Kant sobre la admiración exagerada de los autores antiguos: "Estimar a los antiguos de un modo tan desmesurado significa retrotraer el entendimiento a sus años infantiles y desatender el uso del propio talento particular." ("Die Alten so übermäßig schätzen, heißt: den Verstand in seine Kinderjahre zurückführen und den Gebrauch des selbsteigenen Talentes vernachlässigen." Log, AA 9: 79). Cf., sobre la estagnación en el ámbito teórico causada por esta admiración de los antiguos, también PhilEnz, AA 29: 26s. o V-Lo/Busolt, AA 24: 643.

${ }_{13}^{13}$ Vid., sobre todo, los correspondientes capítulos en Gadamer (1991: 331ss.).

${ }^{14}$ Pues aquí habría que recordar que con Wahrheit und Methode Gadamer se propuso exponer los rasgos fundamentales de una

"filosofía hermenéutica" que sólo la modestia invirtió en "hermenéutica filosófica" (cf. Gadamer 1995: 147).

${ }^{15}$ Los editores Gawlick y Kreimendahl señalan en la introducción posibles anticipaciones de esta división (vid. ibid.: XXI). 
racional" (vernünftige Erkentniß, cognitio rationalis), el cual ha de ser "distinto a partir de las razones" ("auf eine deutliche Art aus Gründen", Meier 1752, § 17: 6), y "conocimiento histórico" (gemeine oder historische Erkentniß, cognitio vulgaris, historica; ibid., § 18). En la medida en que Meier comprende también la verdad ("verdades" en plural, i.e. en sentido "material") como un "conocimiento verdadero", diferencia asimismo entre "verdades históricas" y "verdades dogmáticas": "Por verdades (veritates) se entiende también el conocimiento verdadero mismo, y entonces son todas las verdades, o bien dogmáticas (veritates dogmaticae), o bien históricas (veritates historicae). Las primeras pueden y deben ser conocidas a partir de las características internas de la verdad, las últimas, sin embargo, sólo a partir de las externas." ("Durch Wahrheiten (veritates) versteht man auch die wahre Erkenntniß selbst, und alsdenn sind alle Wahrheiten entweder dogmatische (veritates dogmaticae), oder historische (veritates historicae). Jene können und müssen aus den innerlichen Kennzeichnen der Wahrheit erkant werden, diese aber nur aus den äußerlichen." Ibid., § 104: 26; cf. Hinske 1998: 29)

Para la comprensión kantiana del pensamiento filosófico como conocimiento racional son decisivos ambos aspectos formales de la distinción: la remisión al saber acerca del "fundamento" (Grund, ratio) de "lo que es", de "la cosa", que el propio Kant vindica ocasionalmente frente a otros ensayos de definición ${ }^{17}$, y la postulación de una nota externa o interna de la verdad según se trate del conocimiento histórico o del racional, que ha de redundar en un acceso distintivo a uno u otro tipo de conocimiento. Además, hay un elemento que aparece en el contexto de las referidas consideraciones de Wolff que tendrá en Kant una presencia destacada e insistentemente reiterada en sus reflexiones acerca de la posibilidad de una apropiación filosóficamente relevante de la historia de la filosofía. Se trata de la constatación hecha por Wolff al tratar de la diferencia entre el conocimiento filosófico y el histórico de que, al aducir la razón dada por otro a un determinado estado de cosas, se está así, de hecho, recurriendo a un "estado de cosas", a algo estrictamente "fáctico" (Cognitio philosophica alterius est res facti, Wolff $1728, \S 8$ ). En tal caso no hay conocimiento propiamente filosófico, sino más bien sólo "histórico" (cf. ibid. § 9).

Kant se apropia entonces de estas consideraciones de la filosofía escolar de su tiempo y las pone en juego en el contexto de sus reflexiones metódicas acerca de la vinculación del pensamiento filosófico con su pasado y de la posibilidad de una historia filosófica (o filosofante) de la filosofía (cf. FM/Lose Blätter, AA 20: 340s.). Los caracteres formales de la distinción señalados anteriormente se traducen en Kant en otras tantas divisiones; así distingue en relación con el origen objetivo de los conocimientos entre los racionales y los empíricos y, en relación con el origen subjetivo, los racionales de los históricos ${ }^{18}$. Un conocimiento filosófico puede ser racional y, sin embargo, haber sido asumido o aprendido como algo dado ${ }^{19}$. En este caso, si bien el conocimiento es, él mismo,

\footnotetext{
${ }^{16}$ Antes había anotado Meier que "un conocimiento falso o incorrecto (cognitio falsa) no es propiamente conocimiento" (cf. ibid., $\S \S 27$ y 92$)$.

${ }_{17}$ V.g., frente a la caracterización de Meier de la filosofía (Weltweisheit, philosophia) como "una ciencia de las propiedades más generales de las cosas en la medida en que son conocidas sin la fe" ("eine Wissenschaft der allgemeinern Beschaffenheiten der Dinge, in so ferne sie ohne Glauben erkant werden", Meier 1752, § 5: 2), comenta Kant: "Preferimos mantener la definición que reza: la filosofía es la ciencia que trata acerca de las razones (fundamentos) de las cosas." "Wir wollen also lieber die definition beybehalten, in welcher es heißt: Philosophia est scientia, qvae circa rationes rerum versatur." Refl. 1632, AA 16: 52)

${ }^{18}$ Así, v.g. en la lección de lógica editada por Jäsche: "Los conocimientos racionales se contraponen a los históricos. Aquéllos son conocimientos a partir de principios (ex principiis); éstos a partir de datos (ex datis). - Un conocimiento puede haber surgido a partir de la razón y aún así ser histórico; como cuando v.g. un mero literator estudia los productos de una razón ajena, entonces su conocimiento de tales productos racionales es meramente histórico." ("Vernunfterkenntnisse werden den historischen Erkenntnissen entgegengesetzt. Jene sind Erkenntnisse aus Principien (ex principiis); diese Erkenntnisse aus Daten (ex datis). Eine Erkenntniß kann aber aus der Vernunft entstanden und demohngeachtet historisch sein; wie wenn z.B. ein bloßer Literator die Producte fremder Vernunft lernt, so ist sein Erkenntniß von dergleichen Vernunftproducten bloß historisch." Log, AA 9, p. 22)

${ }^{19}$ Vid. al comienzo de las lecciones sobre enciclopedia filosófica: "Un conocimiento puede ser histórico según su forma, aun cuando según su materia es filosófico. Esto sucede cuando el conocimiento racional no surge del propio pensamiento, sino por imitación. Objetivamente un conocimiento semejante puede ser filosófico, pero en uno u otro sujeto fue producido históricamente." ("Eine Erkenntnis kann der Form nach historisch seyn; obgleich ihrer Materie nach sie Philosophisch ist, wenn nemlich die Vernunft-Erkenntniß nicht aus eigenem Dencken, sondern durch nachahmung entspringt. Objectiv kann eine solche Erkenntniß. Philosophisch seyn, aber in einem und dem andern subiect ist sie historisch erzeugt." PhilEnz, AA 29: 6) En la primera Crítica se
} 
objetivamente racional, subjetivamente no podría ser sino histórico. Quien de este modo quisiera crear un acceso a tales complejos racionales, en realidad "sólo sabría y juzgaría tanto como le fuera dado" ("er weiß und urteilt nur so viel, als ihm gegeben war", $\mathrm{KrV}$ A 836/ B 865), careciendo por tanto de recursos para evaluar a partir de su propia razón el contenido doctrinal y sus fundamentos propiamente filosóficos. Frente a esta manera de acceder a la filosofía en clave histórica, afirma Kant que la tarea de una interpretación filosófica en sentido estricto implicaría, más bien, hacer valer los contenidos doctrinales como tales conocimientos racionales (i.e. juzgarlos desde los principios de los que únicamente adquieren legitimidad $)^{20}$.

Definiendo así ambos tipos de conocimiento ("según la forma", "nach dem modo cognoscendi", V-Lo/Philippi, AA 24: 398) y señalando igualmente la posibilidad de crear un acceso "subjetivamente histórico" (i.e. externo) a un conocimiento que es, de por sí, "objetivamente racional" (i.e. de suyo interno), las reflexiones de Kant permiten atender a dos posibilidades inscritas, como dos caras de una misma moneda, en la recepción de toda filosofía históricamente transmitida; pues aquí se contempla, por un lado, la posibilidad de que el despliegue de la conceptualidad filosófica en viva confrontación con la cosa misma de cuyo fundamento o razón ha de dar cuenta, devenga mera terminología, que el libre desenvolvimiento del pensar filosófico quede fijado en tesis, en contenido doctrinal, en enunciado, de tal manera que el carácter procesual del quehacer teórico, como efectuación que ha de consumarse desde sí y siempre de manera renovada, se agote en resultado y conclusión, dejando así cerrado todo acceso al camino mismo que lo legitima como despliegue de la propia razón ${ }^{21}$. Pero, a su vez, y por el mismo motivo, se abre una perspectiva de apropiación productivamente filosófica de contenidos doctrinales históricamente dados, pues en ellos, como conocimientos objetivamente racionales ha de yacer, por definición, la posibilidad misma de una interpretación que libere y despliegue las virtualidades teóricas inscritas en su textualidad más inmediata, que permita ganar una comprensión de lo expresado en ellas y que consiga así, en cierta manera, vivificar el sentido de lo ya dicho, explicitarlo como tal conocimiento racional. Tanto la amenaza de la atrofia doctrinal y el enquistamiento de la conceptualidad filosófica devenida mera terminología, como la posibilidad de una apertura y revitalización del saber filosófico tradicional, son perspectivas que Kant, asumiéndo a su vez consideraciones que le vinieron dadas, supo hacer

lee en este sentido: "Cuando abstraigo de su contenido objetivo, entonces todo conocimiento es, considerado subjetivamente, o bien histórico, o bien racional. El conocimiento histórico es cognitio ex datis, el racional, por el contrario, cognitio ex principiis. Independientemente del origen del conocimiento, éste puede ser histórico si quien lo posee sólo lo conoce en el grado y en la medida en que a él le ha venido dado de otra parte..." ("Wenn ich von allem Inhalte der Erkenntnis, objektiv betrachtet, abstrahiere, so ist alles Erkenntnis subjektiv entweder historisch oder rational. Die historische Erkenntnis ist cognitio ex datis, die rationale aber cognitio ex principiis. Eine Erkenntnis mag ursprünglich gegeben sein, woher sie wolle, so ist sie doch bei dem, der sie besitzt, historisch, wenn er nur in dem Grade und so viel erkennt, als ihm anderwärts gegeben worden..." KrV A 835s./ B 864s.). A renglón seguido destaca Kant la aplicación al propio quehacer filosófico de estas distinciones: "Quien haya estudiado verdaderamente un sistema de filosofía, v.g. el wolffiano, si bien tendrá en la cabeza todos los principios, definiciones y demostraciones, junto con la articulación de la totalidad del edificio doctrinal, y le fuera tan evidente que podría incluso contar con sus dedos todo esto, no tendría sin embargo más que un conocimiento histórico completo de la filosofía de Wolff." ("Daher hat der, welcher ein System der Philosophie, z. B. das Wolffische, eigentlich gelernt hat, ob er gleich alle Grundsätze, Erklärungen und Beweise zusamt der Einteilung des ganzen Lehrgebäudes, im Kopf hätte, und alles an den Fingern abzählen könnte, doch keine andere als vollständige historische Erkenntnis der Wolffischen Philosophie; er weiß und urteilt nur so viel, als ihm gegeben war." KrV A 836/ B 864) - Si bien el antecedente más decisivo para esta distinción parece poder localizarse precisamente en Wolff y la filosofía escolar, en este punto cabe traer a colación igualmente aquel pasaje de las Regulae en las que Descartes se remite a un parecido principio de interpretación de la historia de la filosofía y que ejemplifica de un modo similar cuando escribe: “...nunca llegaremos [...] a ser filósofos, aunque hayamos leído todos los razonamientos de Platón y Aristóteles, si no podemos emitir un juicio firme sobre las cuestiones propuestas: pues de este modo parecería que hemos aprendido no ciencias, sino historias (non scientias,... sed historias)." (AT X: 367, trad. cast.: 73s.)

20 "Los conocimientos racionales que lo son objetivamente (i.e. que pueden surgir en principio sólo de la propia razón del hombre), deben llevar ese nombre también subjetivamente sólo cuando han sido creados a partir de las fuentes universales de la razón, de la cual puede surgir la crítica, e incluso la reprobación de lo aprendido, i.e. a partir de principios." ("Vernunfterkenntnisse, die es objektiv sind (d.i. anfangs nur aus der eigenen Vernunft des Menschen entspringen können), dürfen nur denn allein auch subjektiv diesen Namen führen, wenn sie aus allgemeinen Quellen der Vernunft, woraus auch die Kritik, ja selbst die Verwerfung des Gelernten entspringen kann, d.i. aus Principien, geschöpft worden.” KrV A 836s./B 864s.)

${ }^{21}$ Según comenta Hinske (1998: 23), "no hay quizás otro pensamiento de Wolff que Kant haya asimilado y repensado con más entusiasmo y aprobación que su advertencia ante una mera cognitio philosophiae historica, un conocimiento meramente histórico y sólo doxográfico de la filosofía mediante el cual el carácter original del conocimiento filosófico se torna en su más evidente contrario." 
productivas para la reflexión acerca de la posibilidad de una interpretación ciertamente filosófica de la historia de la filosofía.

Éstas son, además, las reflexiones que dan pie a la distinción entre "aprender (o enseñar) filosofía" y "aprender (o enseñar) a filosofar" 22 , pues si la transmisión de la filosofía ha de permitir el libre despliegue de la razón de uno a partir de principios, lo que ha de ser enseñado (o aprendido) no será tanto una filosofía, un contenido doctrinal dado, como, más bien, una instrucción acerca de cómo se ha de filosofar. Y así, escribe Kant, v.g. en las lecciones sobre enciclopedia: "lo que debe ser enseñado no es el conocimiento mismo, sino el método para filosofar" ("Nicht sowohl die Erkenntniß selbst, sondern die Methode zu philosophiren, muß unterrichtet werden", PhilEnz, AA 29: 6.). Estas reflexiones de Kant inciden, por tanto, en la interrogación acerca de posibilidad de una interpretación filosóficamente relevante de la historia de la filosofía, que, a su vez, y como ya se anotó, toma pie en la mencionada distinción entre conocimiento "histórico" y "filosófico" y de la determinación de su carácter, o bien subjetivo, o bien objetivo, y redundan así igualmente en la posibilidad -mencionada más arriba- de crear un acceso meramente histórico al conocimiento objetivamente filosófico, así como de una apropiación racional (i.e. legítimamente filosófica) del material doctrinal atesorado por la tradición ${ }^{23}$. En ese sentido, como comenta Kant -de nuevo en el contexto de sus lecciones sobre

${ }^{22}$ Cf. v.g. Log, AA 9: 22: "A partir de la diferencia mencionada entre conocimientos racionales objetivos y subjetivos se hace evidente igualmente que desde cierta perspectiva se puede aprender filosofía, sin que uno pueda filosofar" ("Aus dem angegebenen Unterschiede zwischen objectiv und subjectiv rationalen Erkenntnissen erhell nun auch, daß man Philosophie in gewissem Betracht lernen könne, ohne philosophiren zu können.") Esta máxima por la cual el docente no ha de enseña "pensamientos", sino "a pensar", no "filosofía" sino "a filosofar" (cf. NEV, AA 2: 306s.), condensa, como es sabido, el programa didáctico-filosófico kantiano y lo identifica como una apuesta propiamente "ilustrada"; cf. v.g. Lledó (1995). Uno de los argumentos que sostienen esta distinción en Kant se relaciona directamente con consideraciones de tipo epistemológico acerca del estatus científico de la filosofia (i.e. el hecho de que la filosofía no haya alcanzado "el seguro camino de la ciencia"), y más concretamente con la imposibilidad de encontrar un sistema filosófico que cumpla como modelo para la imitación y la mera asunción dogmática o doctrinal. Precisamente a este aspecto de la distinción podría aplicarse lo dicho por Husserl (1910: 8) en Philosophie als strenge Wissenschaft: "Kant gustaba de decir que no se puede aprender filosofia, sólo aprender a filosofar. ¿Qué otra cosa puede ser esto, más que un reconocimiento de la acientificidad de la filosofía?" ("Kant liebte es zu sagen, man könne nicht Philosophie, nur Philosophieren lernen. Was ist das anderes als ein Eingeständnis der Unwissenschaftlichkeit der Philosophie.") Sobre esto vid. KrV A 838/ B 866, así como el siguiente pasaje de las lecciones sobre enciclopedia: "La filosofía no debe ser imitada, puesto que para la imitación se precisa de un modelo sin fallos. Con todo, es bien posible imitar la filosofía; y esto sucede cuando se escoge un modelo, el cual, sin embargo, no puede ser perfecto, y se busca comprenderlo con la ayuda del docente. Así, uno comprende finalmente al autor, quizás hasta tan bien como para poder instruir a otros. No obstante, de este modo uno mismo no entiende las cosas, puesto que ni siquiera se ha preocupado de eso; y a lo mejor incluso el autor mismo tampoco llegó a comprenderlas. En sentido propio, no se puede aprender de memoria ninguna filosofía, porque en primer lugar debe haber un filósofo que suministre un arquetipo que no contenga errores y que, consecuentemente, sea apropiado para la imitación. Cuando imito una filosofía y el modelo de que dispongo no es correcto, entonces toda mi filosofía tampoco sirve para nada." ("Die Philosophie muß nicht nachgeahmt werden, denn zur Nachahmung gehört ein Bild ohne Fehler. Man kann zwar auch die Philosophie nachahmen, dies geschieht, wenn man sich ein Muster wählt, welches freylich nicht vollkommen seyn kann, man such es durch Hülfe des Lehrers zu verstehen, man versteht zuletzt den Autor vielleicht so gut, daß man auch andere unterrichten kann, aber man sieht die Sachen selbst nicht ein, denn darum hat man sich nicht bekümmert und vielleicht verstand sie der Autor selbst nicht. [...] Eigentlich kann keine Philosophie auswendig gelernt werden, weil erstlich ein Philosoph da seyn muß der ein Urbild geliefert hat, das ohne Fehler und folglich zur Nachahmung geschickt ist. [...] Wenn ich eine Philosophie nachahme und das Muster nicht richtig ist, so ist meine gantze Philosophie auch nichts nutze." PhilEnz, AA 29: 6s.)

${ }^{23}$ Así, e.g. en una reflexión de datación dudosa, pero que Adickes sitúa en 1769 o bien en la primera mitad de los 70, se lee: '“Aprender una filosofía' significa: la filosofía subjetiva, i.e. lo que efectivamente es pensado; pero entonces uno no la puede juzgar. 'Aprender a filosofar' es objetivo: cómo se ha de pensar, i.e. las reglas del correcto uso de la razón; por lo tanto se ha de diferenciar entre el espíritu filosófico y el espíritu de una filosofia, y aquél consiste en el método de la razón." ("'Eine philosophie lernen' bedeutet: die subiective Philosophie, $d$. $i$. was wirklich gedacht ist; aber alsdenn kan man sie nicht beurtheilen. 'philosophiren lernen' ist obiectiv: wie man denken soll, d. i. die Regeln des richtigen Gebrauchs der Vernunft; also ist der philosophische Geist vom Geiste einer Philosophie unterschieden und besteht in der Methode der Vernunft." Refl. 1651, AA 16: 65 s.) En la década de los 50, y comentando la referida definición de filosofía del Auszug de Meier (1752, § 5) escribe Kant: "Se debe distinguir el conocimiento filosófico del conocimiento de la filosofía. Lo primero es un habitus rationes rerum cognoscendi y es adquirido meditando, examinando y perscrutando; consiste más en el método de utilizar su propia razón que en colmar la memoria con numerosas proposiciones que han sido afirmadas alguna vez. La cognitio philosophiae, sin embargo, es el conocimiento de aquello que ha sido expuesto en los escritos de los filósofos acerca de los fundamentos de las cosas. Este tipo de filosofía tiene su asiento en la memoria. Se leen definiciones, que se aprenden mediante ejemplos y escolios, se imprimen en la memoria, se toma noticia de igual manera del entramado de proposiciones en la demostración de un teorema, para luego repetirlo fielmente. Cuando esta gente olvida las palabras de una definición, entonces no tiene la capacidad de volver a formularla." ("Man muß jedoch das Philosophische Erkentniß von der Kenntniß der Philosophie unterscheiden. Das erstere ist ein habitus rationes rerum cognoscendi und wird meditando, examinando und perscrutando acqvirirt; es besteht mehr in der methode seine Vernunft zu gebrauchen, als in der Anfüllung des Gedachtnißes mit vielen schon ausgeführten Sätzen. Die cognitio philosophiae aber ist die Kenntniß desjenigen, was in den Schrifften der Weltweisen von den Gründen der Dinge vorgetragen worden. Diese Art der 
enciclopedia-, cuando lo que se pretende es dar cuenta de la obra de un autor en términos que puedan ser filosóficamente relevantes: "Ningún docente de filosofía debe meramente explicar al autor, sino que, al mismo tiempo, debe dar una instrucción acerca del método de cómo se ha de filosofar." ("Kein Lehrer der Philosophie muß den Autor bloß expliciren, sondern zu gleicher Zeit eine Instruction geben von der Methode wie man philosophiren soll." PhilEnz, AA 29: 7) Así, parece que no es ni la patente "acientificidad" (Unwissenschaftlichkeit) de la disciplina (que según la citada expresión de Husserl delata la distinción misma entre "enseñar filosofía" y "enseñar a filosofar"), ni la inexistencia de una "filosofía" como tal sistema ${ }^{24}$, lo que exige, en primer lugar, en relación con la enseñanza de la filosofía -y frente a la transmisión de contenidos doctrinales- más bien aquella orientación acerca de "cómo filosofar". Puesto que -según señala Kant- "presuponiendo incluso que efectivamente existiera una filosofía: nadie que la estudiara podría decir de sí mismo que es un filósofo, ya que su conocimiento de ella seguiría siendo sólo subjetivamente histórico." ("Gesetzt aber auch, es wäre eine [sc. Philosophie] wirklich vorhanden: so würde doch keiner, der sie auch lernte, von sich sagen können, daß er ein Philosoph sei, denn seine Kenntniß davon wäre doch immer nur subjectivhistorisch.” Log, AA 9: 25). Es por tanto la determinación esencial de la filosofía como saber racional la que excluye la mera asunción dogmática de tesis y enunciados ya fijados y postula la instrucción acerca de un "método" para el uso de la razón ${ }^{25}$. - De lo anterior se sigue que, según su propia naturaleza racional, en tanto que un "filosofar", el saber filosófico ha de consistir en un "cómo" (y no, por tanto, en un "qué").

Esta comprensión de la filosofía legitima, en primer lugar, la insistencia en aquella exigencia de "aprender a filosofar" ("Uno debe esforzarse en filosofar, no meramente en aprender filosofía. Pues si hiciésemos esto último nuestro conocimiento sería meramente histórico y no generado desde nosotros mismos." ["Man muß sich bemühen philosophiren, nicht bloß Philosophie zu lernen. Denn täten wir letzteres so wäre unser Erkenntnis bloß historisch und nicht aus uns selbst geschöpft."] V-Lo/Dohna, AA 24: 704) ${ }^{26}$. La filosofía exige una particular apropiación racional del contenido doctrinal, que consistirá, más bien, en que no haya al cabo apropiación de contenido doctrinal alguno. De lo que se trata entonces en la confrontación con el pasado filosófico es del ejercicio de la propia razón con ocasión de un contenido previo dado (histórico). Y es esta posibilidad abierta por la ejercitación en el método de cómo pensar, desplegado en la confrontación con un contenido doctrinal históricamente dado, lo que ha de otorgar un nuevo sentido y definir una nueva

Weltweisheit hat in dem Gedächtniße ihren Sitz. Man ließt definitionen, lernt sie durch die beygefügte Exempel und scholien verstehen, drükt sie dem Gedächtniße ein, macht sich eben so den Zusammenhang der Sätze in der demonstration eines Lehrsatzes bekannt, um e wieder treulich von sich zu geben. Wenn solche leute die Worte der definition vergeßen haben, so haben sie auch die Fähigkeit nicht, selbige aufs neue zu machen." Refl. 1632, AA 16: 52s.) Es por esto que, en las lecciones sobre enciclopedia filosófica, Kant afirma que en sentido propio, ninguna filosofía se puede aprender de memoria, puesto que el acceso meramente histórico al conocimiento filosófico parece contradecir el carácter propio de este conocimiento, que sería la capacidad de generar y articular el saber acerca de los fundamentos mismos de las cosas desde la propia razón (cf. PhilEnz, AA 29: 7).

${ }^{24}$ Cf. Log, AA 9: 25: "La razón por la que, de entrada, no se puede aprender filosofía, es porque aún no está dada (i.e. aún no existe)." ("Man kann daher schon aus dem Grunde Philosophie nicht lernen, weil sie noch nicht gegeben ist.") Y en NEV, AA 2: 307: "Para aprender (o estudiar) además filosofía, debería en primer lugar existir realmente una filosofia." ("Um also auch Philosophie zu lernen, müßte allererst eine wirklich vorhanden sein.")

${ }^{25}$ En ese sentido dice Kant: "Con la finalidad de ejercitarse en el pensamiento propio o en el filosofar, atenderemos más al método del uso de nuestra razón que a las proposiciones mismas a las cuales hemos llegado mediante ese método." ("Wir werden also zum Behuf der Übung im Selbstdenken oder Philosophiren mehr auf die Methode unsers Vernunftgebrauchs zu sehen haben als auf die Sätze selbst, zu denen wir durch dieselbe gekommen sind." Log, AA 9: 26)

26 "Se puede distinguir entre las dos expresiones: 'aprender filosofía' y 'aprender a filosofar'. Aprender significa imitar los juicios de otros, es por tanto muy distinto del propio reflexionar. [No aprender filosofía - sino aprender a filosofar, de lo contrario todo queda en imitación - de lo que se trata, sin embargo, es de alcanzarlo por uno mismo mediante el ejercicio del entendimiento. Únicamente quien es capaz del uso propio de su razón es denominado filósofo...]...” (“Man kann einen Unterschied machen zwischen den zwei Ausdrücken Philosophie lernen und philosophieren lernen. Lernen heißt die Urteile andrer nachahmen, ist also vom eignen Nachdenken sehr unterschieden. [Nicht Philosophie lernen - sondern philosophieren lernen, sonst bleibts nur Nachahmung - aber selbst dazu gelangen durch Übung des Verstandes, darauf kommt es an. Nur der, der des Selbstgebrauch seiner Vernunft fähig ist, heißt Philosoph... J..." V-Lo/Dohna, AA 24: 698) La renuencia de la filosofía a ser aprendida por imitación implicó para Kant -al menos hasta V-Lo/Pölitz (cf. Hinske 1998)- que el específico talento filosófico debía requerir "genio" (sobre la equiparación en este contexto de "erudición" e "imitación", por un lado, y "filosofía" y "genio", por otro, vid. la nota 33 a nuestra traducción de las lecciones de enciclopedia, EF: 91s.). 
función para la historia de la filosofía. Si de lo que se trata, por tanto, es de instruir en el quehacer filosófico, i.e. en el "filosofar", el uso de las filosofías y teorías heredadas ha de redundar de manera precisa en la conformación del propio pensamiento ${ }^{27}$. De ahí que Kant se plantee legítimamente la posibilidad de asignar una tarea filosófica en sentido estricto a la confrontación con el pasado filosófico - y se pregunte, además, en estos términos: "si la historia de la filosofía misma puede ser una parte de la filosofía o si lo debe ser de la historia de la erudición en general." "“Ob die Geschichte der philosophie selbst ein Theil der Philosophie seyn könne oder der Geschichte der Gelehrsamkeit überhaupt seyn müsse.” FM/Lose Blätter, AA 20: 343) ¿Cabe entonces una lectura de los textos de la tradición que redunde efectivamente en la actividad filosófica misma? ¿Cómo ha de cumplir la ocupación con la historia de la filosofía esta función relevante para el ejercicio del quehacer filosófico en sentido propio? ¿Cómo se concreta la interpretación de la historia de la filosofía en Kant a partir de las nociones señaladas anteriormente?

Desde páginas anteriores viene perfilándose la posibilidad de un trabajo de apropiación del legado histórico-filosófico que habría de poder incidir en la ejercitación del pensamiento filosófico mismo como actividad racional. Esta última había quedado, en tanto que racional, distinguida de la histórica. Tal distinción daba pie, además, a la asignación de tareas no intercambiables para el filósofo y para el erudito. En este punto, sin embargo, hay que dejar anotado lo siguiente: si bien la erudición queda caracterizada como una forma de saber que no se confunde con el saber filosófico y que no ha de sustituir por tanto a lo que habría de configurarse como un acercamiento legítimamente filosófico al material histórico transmitido, las aportaciones de la erudición histórica, de la historiografía de la filosofía en este contexto, sí que vienen para Kant asumidas necesariamente en cualquier trabajo de apropiación filosófica del pasado de la disciplina. La erudición y sus "herramientas" (la filología, etc.) constituyen presupuestos metodológicos de la interpretación de los textos filosóficos históricamente transmitidos - también allí donde esa interpretación está guiada por un interés "sistemático". Algo similar sucede en relación con la interpretación de las Escrituras, i.e. al igual que en el ámbito de la hermenéutica bíblica la figura del erudito ("Schriftgelehrte") está subordinada a la del intérprete ("Schriftausleger", cf. RGV, AA 6: 112), en la hermenéutica de la historia de la filosofía lo está la "erudición histórica" a la "interpretación filosófica (o sistemática)". En ambos casos, sin embargo, viene exigida -o presupuesta- la erudición (“...die Auslegung... bedarf... Gelehrsamkeit”, ibid.: 113) y el intérprete "...debe poseer, además, amplio conocimiento y crítica históricos..." (“...doch noch ausgebreitete historische Kenntni $\beta$ und Kritik besitzen muß”, ibid.); aunque como ya quedó apuntado, la interpretación (Auslegung) no puede, por definición, agotarse en certificación histórica (Beurkundung), y tampoco la filosofía (o una interpretación que pretenda ser filosóficamente relevante) en erudición. Que la interpretación haya de tener un sustento firme en la erudición implica sólo que antes de decidir "qué ha podido querer decir" el autor, es preciso saber -en un primer sentido literal, etc.- "qué ha dicho efectivamente".

La división de tareas y la subordinación de una a otra, sin embargo, persiste. Ciertamente, aun cuando la interpretación de la historia de la filosofía haya de asumir y presuponer las aportaciones de la erudición filológica e historiográfica, la lectura de los textos que conforman el legado filosófico no ha de redundar en el conocimiento de los sistemas, sino confrontarlos críticamente. La prioridad del interés sistemático que guía la interpretación obliga en ocasiones a primar el "espíritu" del texto

27 "Quien quiera aprender a filosofar debe considerar todos lo sistemas de la filosofía solamente como la historia del uso de la razón y como objetos de la ejercitación de su propio talento filosófico." ("Der philosophiren lernen will, darf dagegen alle Systeme der Philosophie nur als Geschichte des Gebrauchs der Vernunft ansehen und als Objecte der Übung seines philosophischen Talents." Log, AA 9: 26). Vid. también en este sentido Refl. 4860, AA 18: 12: "El valioso propósito de la historia filosófica consiste en la prefiguración de buenos modelos y en la exposición de instructivas desviaciones, así como en el conocimiento de progreso natural de la razón desde la ignorancia (que no del simple error) hacia el conocimiento." ("Die Nützliche Absicht der philosophischen historie besteht in der Vorbildung guter Muster und der Darstellung lehrreicher Vergehungen, imgleichen in der Erkenntnis des natürlichen Fortschritts der Vernunft von der Unwissenheit (nicht dem groben Irrthum) zur Erkenntnis.") 
sobre la "letra", a forzar en alguna medida la inmediata literalidad y, por tanto, a ejercer, de tal manera, una suerte de "violencia hermenéutica" contra lo efectivamente escrito. Lo afirma el propio Kant en el "capítulo hermenéutico" del escrito sobre la religión antes citado, en el que se admite la posibilidad de una interpretación de las Escrituras que de alguna manera pueda contravenir la lectura literal del texto y que, sin embargo, a partir del interés que la guía, sea preferible a ésta: "Esta interpretación nos puede parecer a menudo forzada en vista del texto [...], incluso puede serlo efectivamente con frecuencia; y, no obstante, debe ser preferida a una interpretación literal en la medida en que sea sólo posible que el texto la admita... " "Diese Auslegung mag uns selbst in Ansehung des Texts [...] oft gezwungen scheinen, oft es auch wirklich sein, und doch muß sie, wenn es nur möglich ist, daß dieser sie annimmt, einer solchen buchstäblichen vorgezogen werden..." $R G V$, AA 6: 110). En ese sentido, al igual que en la Religionsschrift es la creencia pura, articulada desde la idea de moralidad, la que da la pauta hermenéutica de una lectura de la Biblia ${ }^{28}$ que, a pesar de parecer $-\mathrm{o}$ efectivamente ser- contraria a lo explicitado en ella, es con todo preferible a una lectura literal del texto, en el ámbito de la interpretación de la filosofía pretérita ha de ser también una pauta al menos de manera mediada- moral, la idea de la razón (i.e. la idea de sistema de una filosofía plegada al interés supremo de la razón humana), la que condiciona que en la lectura de los textos filosóficos el intérprete se vea obligado en alguna medida a acometer un acto semejante de "violencia hermenéutica". Y ésta quedará, a su vez, justificada en tanto que solamente se admita "la posibilidad de comprender de tal manera a sus autores..." ("nur die Möglichkeit, die Verfasser derselben so zu verstehen..." $R G V$, AA 6: 111) El desarrollo de las virtualidades inscritas en el texto filosófico se dirige a ganar de nuevo lo transmitido tradicionalmente (i.e. en tanto que contenido doctrinal) a partir de principios, como efectuación y vivificación de su sentido, y asume la disposición a contravenir la lectura más inmediatamente textual en vista de una perspectiva filosóficamente productiva - sólo con tal de que el texto permita esa posibilidad.

Por lo pronto, parece que con la interpretación de textos filosóficos queda abierta la posibilidad que G. K. Chesterton (1911: 52) identificaba con la función misma de "crítica literaria" ("criticism"), una función que no residiría en reiterar lo que el propio autor ya había dejado escrito, sino, más bien, en decir de él aquello que le haría "saltar de sus propias botas". Según lo anterior, en eso podría consistir por el momento la conocida máxima de "comprender al autor mejor de lo que éste pudo haberse comprendido a sí mismo". Y, sin embargo, esta primacía de la lectura orientada sistemáticamente, que consiente incluso la posibilidad de una interpretación que pueda desavenirse con lo presente en el texto de manera expresa, no ha de resolverse en la mera proyección sobre el texto de la comprensión que el intérprete trae ya consigo. Pues esto significaría redundar en aquel prejuicio del que se quejaba el propio Kant al comienzo de los Prolegomena y por el que uno basa su interpretación no "en los pensamientos del autor, sino sólo en su propia manera de pensar que se ha vuelto natural por una larga costumbre..." “"...man nicht die Gedanken des Verfassers, sondern immer nur seine eigene, durch lange Gewohnheit zur Natur gewordene Denkungsart dabei zum Grunde legt." AA 4: 262) Como se dijo, tal prejuicio no sólo no contribuye a "comprender mejor al autor", sino que, más bien, hace del todo imposible comprenderlo. No se trata por tanto de comportarse con respecto a los textos y autores de la historia de la filosofía como Schopenhauer recriminaba a Aristóteles, quien practica en sus escritos de metafísica -siempre según Schopenhauer (1986: 64)“...un hablar sin orden ni concierto sobre los filosofemas de sus predecesores, que critica y refuta desde su propio punto de vista, la mayoría de las veces a partir de enunciados sueltos y sin entrar a considerar verdaderamente su sentido, más bien como alguien que rompe las ventanas desde fuera." (“...ein Hin-und-Her-Reden über die Philosopheme seiner Vorgänger, die er von seinem Standpunkt aus meistens nach vereinzelten Aussprüchen derselben kritisiert und widerlegt, ohne eigentlich in ihren Sinn einzugehen, vielmehr wie einer, der von außen die Fenster einschlägt.”) La interpretación,

${ }^{28}$ Cf. v.g. Dilthey (GS XIV: 651ss.), Tommasi (2011: 456ss.) y Makkreel (2016: 348ss.). 
aun admitiendo la posibilidad de leer contra el texto mismo (o, al menos, en el espacio abierto por los resquicios de éste, en la medida que se contemple "sólo la posibilidad de tal interpretación"), no ha de devenir pura arbitrariedad y no ha de confundirse con la mera proyección hipertrófica del horizonte hermenéutico del intérprete o con la crítica externa de elementos doctrinales desligados de su conexión sistemática.

Y, sin embargo, se dijo, según una máxima específicamente hermenéutica que encuentra en Kant su formulación paradigmática ${ }^{29}$, ha de ser posible "entender al autor mejor de lo que éste se comprendió a sí mismo". ¿Qué es entonces eso que se comprende cuando se "comprende mejor al autor..."? Ya que, aquí, en el caso de la "historia de la filosofía", y a diferencia de lo que quizás pudiera proponer una "crítica literaria" (y, en cierto grado, también algunas formas históricamente relevantes de hermenéutica), la interpretación no busca dar cuenta de contenidos determinados de la psique del autor (su intención, etc.) ${ }^{30}$. Al contrario, lo que se ha de comprender, tal y como ya se adelantó, es la "idea" que articula y motiva el texto filosófico: "En cada libro debe uno intentar descubrir la idea del autor. Esto es algo importante y difícil. A menudo el autor mismo no es consciente de su idea, y encontrarla es entonces más difícil." ("Man muß bey jedem Buch die Idee des Autors zu entdecken suchen. Das ist etwas wichtiges und schweres. Oft hat der Autor seine eigene Idee selbst nicht gewust, und sie alsdenn zu finden, ist um desto schwerer." PhilEnz, AA 29: 28) ${ }^{31} \mathrm{Y}$ es precisamente la propuesta de dar, no con la "intención" del autor, sino con la "idea" del texto (que yace como una "simiente" en la facultad de la razón, cf. $\mathrm{KrV}$ A 834s./ B 862s.), lo que permite una confrontación con el mismo de la cual, yendo más allá de lo expresado en él, resulta una "mejor comprensión" de lo enunciado por el autor, y esto porque el texto mismo es testado y valorado a partir de la idea que lo conforma y le da sentido. Esta comprensión de la labor de una lectura filosófica incluye disposiciones extremas que avalan incluso atentar en ocasiones contra su más inmediata literalidad, pues hay casos -según reconoce el propio Kant- en los que un elemento doctrinal dado “...es comprendido de manera errónea precisamente cuando es tomado al pie de la letra" (“...wird eben so unrecht verstanden, wenn man es nach dem Buchstaben nimmt" $\ddot{U} E$, AA 8: 249). Para Kant, sin embargo, la idea misma no está dada, sino sólo prefigurada de manera "embrionaria" (cf. FM/Lose Blätter, AA 20: 342), y no representa, así, un principio a partir del cual se lleva a cabo la lectura (entendido aquí en un sentido literal como un punto de partida para la reconstrucción hermenéutica que haya de decidir de antemano el sentido del texto), sino que constituye, más bien, la

${ }^{29}$ Vid. Dilthey (GS V: 331): "El fin último del procedimiento hermenéutico consiste en comprender al autor mejor de lo que él mismo se comprendió." ("Das letzte Ziel des hermeneutischen Verfahrens ist, den Autor besser zu verstehen, als er sich selber verstanden hat".) Cf. sobre este principio interpretativo Bollnow (1949) y, para su historia anterior a Kant y su sentido en éste, Hinske (2011).

${ }^{30}$ En el mismo pasaje citado anteriormente adscribía Chesterton (1911: 51s.) a la "crítica literaria" la tarea de "tratar con la parte subconsciente de la mente del autor" ("dealing with the subconscious part of the author's mind") y, así, la función de "decir sobre los autores las cosas que ellos mismos no sabían." ("to say the things about them [sc. the authors] which they did not know themselves.") - Por otro lado, la teoría de la interpretación de Chr. Wolff se vinculaba a la investigatio mentis auctoris, i.e. a la reconstrucción de los contenidos conceptuales ligados por el autor de un texto a las palabras fácticamente presentes en éste; cf. v.g. la exposición de A. Bühler/ L. C. Madonna en la "Introducción" a Meier (1757: XXXss.), así como Beiser (2015), y F. D. E. Schleiermacher había distinguido entre la interpretación gramatical y la psicológica y remitido ésta última a la posibilidad de una comprensión del contenido espiritual de la que la obra es manifestación en la captación congenial de la subjetividad e individualidad creadora de su autor; cf. v.g. Dilthey (GS V: 328ss.) y Szondi (1975: 165ss.).

${ }^{31} \mathrm{Y}$ esto, de nuevo, en relación con aquella pauta sistemática que guía la ocupación histórica (historiográfica) y que según Kant (y Lambert) delataba el anteriormente mencionado prejuicio "historicista", v.g. en los Prolegomena: "Tales principios generales y, sin embargo, determinados, no los aprende uno fácilmente de otros, los cuales, a su vez, los han atisbado sólo de manera oscura. Uno debe haber llegado por sí mismo a ellos primero mediante su propia reflexión. Más tarde los descubre uno en sitios donde antes seguro que no los hubiera encontrado, porque sus mismos autores ni siquiera eran conscientes de que sus consideraciones se fundamentaban en una tal idea. Aquellos que nunca piensan por sí mismos poseen, no obstante, la perspicacia de descubrirlo o reconocerlo todo, después de que les haya sido indicado, en aquello que ya había sido dicho y donde antes nadie pudo verlo." ("Denn dergleichen allgemeine und dennoch bestimmte Principien lernt man nicht leicht von andern, denen sie nur dunkel obgeschwebt haben. Man muß durch eigenes Nachdenken zuvor selbst darauf gekommen sein, hernach findet man sie auch anderwärts, wo man sie gewiß nicht zuerst würde angetroffen haben, weil die Verfasser selbst nicht einmal wußten, daß ihren eigenen Bemerkungen eine solche Idee zum Grunde liege. Die, so niemals selbst denken, besitzen dennoch die Scharfsichtigkeit, alles, nachdem es ihnen gezeigt worden, in demjenigen, was sonst schon gesagt worden, aufzuspähen, wo es doch vorher niemand sehen konnte." Prol §3, AA 4: 270.) 
meta a la que ha de aspirar la interpretación; por utilizar otro recurso metafórico recurrente en Kant, la idea no es el cimiento, no es por tanto lo que sirve de soporte, lo que basa, sino la clave de bóveda, que más bien culmina la construcción, y le da así estancia y sujeción.

Aquí, como en la particular recepción kantiana de la diferenciación entre el conocimiento histórico (fáctico) y el propiamente filosófico (racional), recoge de nuevo Kant lo que hasta entonces era patrimonio común de la filosofía escolar de su época, transmitido en manuales y tratados de lógica como directrices metódicas para la lectura y la conversación y, en general, como reglas para la comprensión de la opinión de otros (cf. Hinske 2011), y lo transfigura productivamente en principio hermenéutico que habrá de posibilitar una interpretación radicalmente filosófica de la historia de la filosofía. La máxima interpretativa de "comprender mejor al autor...", es así, por lo mismo, testimonio de la asunción por parte de Kant de una convicción profundamente "ilustrada": la de la posibilidad de remitir las opiniones y convicciones de otros a un marco general de comprensión articulado por una razón humana común, encargada de arbitrar y dirimir la legitimitad -y en última instancia la verdad o falsedad- de cada aseveración u opinión dada. En tanto que criterio de lectura de las obras que conforman el pasado de la disciplina, esta interpretación, que se propone dar con la "idea", abre igualmente -como antes se había anotado- una perspectiva para el intérprete de enjuiciar y criticar el entramado conceptual presentado en el texto, es al cabo lo que permite la apropiación racional productiva de los contenidos doctrinales transmitidos y posibilita la interpretación específicamente filosófica de una filosofía dada históricamente.

A su vez, la determinación sistemática de la tarea de la interpretación del texto filosófico a partir de la idea, permite reconocer en Kant una aplicación de aquella "equidad hermenéutica" ("hermeneutische Billigkeit") tematizada por Meier en su Ensayo de una hermenéutica universal (Versuch einer allgemeinen Auslegungskunst) de 1757, un principio para la interpretación que es definido por Meier (1757, § 39: 17) de este modo: "La equidad hermenéutica (aequitas hermeneutica) es la inclinación de un intérprete a considerar como hermenéuticamente verdaderas aquellas significaciones que mejor concuerdan con las perfecciones de un autor... hasta que se demuestre lo contrario." ("Die hermeneutische Billigkeit (aequitas hermeneutica) ist die Neigung eines Auslegers, diejenigen Bedeutungen für hermeneutisch wahr zu halten, welche mit den Vollkommenheiten des Urhebers der Zeichen am besten übereinstimmen, bis das Gegenteil erwiesen wird.") $)^{32}$ - Que Kant se propuso poner en práctica una concepción semejante de la interpretación en su lectura de las filosofías del pasado, lo demuestran los giros lingüísticos que denotan una tal comprensión de la tarea hermenéutica; e.g. cuando escribe: “...si Leibniz ocasionalmente se ha expresado de manera que podía interpretarse..." que v.g. afirmaba algo evidentemente insostenible o incompatible con el entramado sistemático de su pensamiento, “... en tal caso, y en la medida en que siga siendo compatible con sus expresiones, es más ecuánime o justo, comprenderlo como si... “ (“...so ist es billiger, ihn, so lange es mit seinen Ausdrücken vereinbar ist, so zu verstehen, als ob er...” ÜE, AA 8: 203; cf. v.g. La Rocca 2002: 70). Es decir, en una situación semejante, Kant, siguiendo precisamente una máxima de lectura como la explicitada por Meier, entiende que lo justo sería precisamente interpretar al autor (en este caso a Leibniz), de una manera diferente a la que parece proponer literalmente el texto, concediendo sólo que el texto admita también esta posibilidad (i.e. "en la medida en que siga siendo compatible con sus expresiones"). Así, a partir de esta concepción de la interpretación filosófica del pasado de la filosofía, Kant se permite presentar su Kritik der reinen Vernunft como una verdadera apología del pensamiento leibniziano (“...die eigentliche Apologie für Leibniz..." ÜE, AA 8: 251) y, esto, además, frente a la actitud del historiador de la filosofía que en su vindicación elogiosa de los pensadores del pasado "les permite afirmar completos absurdos” (“...ihnen... doch lauter Unsinn reden lässt...” ibid.).

${ }^{32}$ Cf. sobre esto v.g. la ya citada introducción a la edición de Bühler y Madonna al texto de Meier, también Szondi (1975: 109ss.), Scholtz (1994) o Lau (1999: 88ss.) 
Por lo demás, esta aplicación de la "hermeneutische Billigkeit" tiene un sentido bien definido que se vincula de manera precisa a la distinción anteriormente tratada entre conocimiento histórico y racional, puesto que, cuando se trata de "afirmaciones históricas (empíricas), cualquiera puede equivocarse completamente. Por el contrario, en relación con los juicios racionales, uno ha de tener siempre algo de razón, desde algún punto de vista, y es justo conceder esto en primer lugar y, sólo posteriormente, admitir la incorrección o el error como mera limitación." ("historischen (empirischen) Behauptungen kan jemand ganz Unrecht haben [...]. Dagegen in rationalen Urtheilen muß er jederzeit von einer Seite betrachtet recht haben, und es ist billig, ihm zuerst dieses recht einzuwilligen und nur nachher die Unrichtigkeit als bloße Einschränkung hinzuzufügen." Refl. 2212, AA 16: 272) La "regla de la equidad" ("Regel der Billigkeit") a la que Kant se refiere ocasionalmente en sus lecciones de lógica ${ }^{33}$, tiene un sentido específico en la interpretación de los escritos filosóficos, pues viene exigida hermenéuticamente y resulta del todo vinculante allí donde de lo que se trata es de discernir el significado de un determinado juicio objetivamente racional, en cuyo caso es imprescindible proceder con "equidad" y disponer la interpretación de tal manera que sea conveniente y justa para con el autor, lo que en última instancia quiere decir: ajustada al sentido del texto a partir de la idea. A su vez, que las proposiciones racionales deban ser siempre -al menos en alguna perspectiva, desde determinado punto de vista- "ciertas", "verdaderas", i. e. la afirmación de que de ser erróneas lo serán sólo "parcialmente" y que, por tanto, cuando se trata de "juicios motivados racionalmente", ha de haber siempre algún enfoque desde el cual se deba dar la razón al autor interpretado y se haya de poder vincular sus afirmaciones a algún posible momento de verdad, etc., todo esto remite la motivación del principio hermenéutico de equidad en Kant, de nuevo, a una convicción que cabría definir como radicalmente "ilustrada": la de la "imposibilidad de un error total". 34

A partir de la idea -a la cual ha de atender el sentido mismo del texto en tanto que construcción racional- cabe por tanto "comprender mejor" al autor, siendo además hermenéuticamente ecuánime o justo con él, pues de lo que se trata es de dar con las posibilidades inscritas en la propia obra, virtualidades que le son objetivas al texto, pero que no se agotan en su más estricta literalidad. Esto sitúa al intérprete ante la posibilidad de someter lo propuesto en el texto a

33 “... así se considerará a alguien honesto y sincero mientras no se haya demostrado lo contrario, que se desvía de la verdad, etc. De acuerdo con la conocida regla de la equidad: a cualquiera se le presupondrá bondad, hasta que se pruebe lo contrario." ("...so wird jederman vor Ehrlich, und aufrichtig so Lang gehalten, biß das Gegentheil, daß er nemlich von der Wahrheit etc. abgehe erwiesen worden ist. Nach der Bekannten Regel der Billigkeit: Quilibet prosumitur bonus, Donec probetur contrarium." VLo/Blomberg, AA 24: 246)

${ }^{34}$ Vid., sobre este punto, PhilEnz, AA 29: 23 y Log, AA 9: 54; cf. también Hinske (1980: 31ss.). - La tesis kantiana acerca de la imposibilidad del error total se vincula explícitamente en las lecciones de lógica con la indicada disposición hermenéutica de "equidad" para con el autor del juicio que se discute: "Un conocimiento nunca puede ser absolutamente falso. Todo juicio surge del entendimiento, por lo que debe concordar en algún grado con las leyes del entendimiento y de la razón. Es por tanto imposible que un hombre emita un juicio absolutamente falso y que lo asuma como completamente verdadero. Puesto que, de lo contrario, el juicio debería contradecir las leyes del entendimiento. Así, un conocimiento que sea presentado como completamente falso, lo será, sin embargo, sólo en parte y contendrá siempre un cierto grado de verdad. Si estuviésemos obligados a admitir que algunos juicios pueden ser completamente falsos, de este modo tendría que ser posible que el entendimiento se alejara de todas las leyes y, de esta manera, bajo esta suposición, caería y desaparecería toda la consideración de nuestra lógica, pues podríamos confiar muy poco en ella. Por tanto, cuando creemos encontrar falsedad en el juicio de otro, debemos de esta manera estar convencidos de que en él debe habitar también una verdad parcial, si bien encubierta. En este principio predomina efectivamente mucha equidad (o ecuanimidad). Este modo de pensar es moral y participativo, de tal manera que, de entrada, no le niega toda la verdad a los otros en sus conocimientos." ("Niemahls aber kann eine Erkenntniß gantz und gar fälschlich seyn [...]. / Ein jedes Urtheil entspringt au. dem Verstande, daher muß es auch einigermaßen mit den Gesetzen des Verstandes, und der Vernunft übereinstimmen. I Es is dahero unmöglich, daß ein Mensch ein gantz falsches Urtheil fälle, und selbes sogar vor gantz wahr annehme. / Denn sonst müßte das Urtheil den gesetzen des Verstandes wiedersprechen. / Eine Erkenntniß also, die auch durchgehends vor falsch ausgegeben wird, wird dennoch immer nur zum Theil falsch seyn, und immer einen gewißen Grad der Wahrheit enthalten. [...] / Wenn wir annehmen sollten, daß einige Urtheile gantz, und gar falsch seyn könnten, so müßte es doch möglich seyn, daß der Verstand von allen gesetzen abweiche, und auf diese Art unter dieser Supposition würde das gantze Ansehen unserer Vernunft-Lehre fallen, und verschwinden, wir würden dagegen derselben sehr wenig trauen können. / [...] Wenn wir also in dem Urtheile eines anderen Falschheit anzutreffen glauben, so müßen wir auch eben dadurch überzeugt seyn, daß darinnen irgend eine partiale Wahrheit herschen müße, so versteckt sie auch darinn ist. / In diesem Grund Satze aber herschet auch wircklich viele Billigkeit. eine solche Art zu dencken, ist moralisch, und theilnehmend, so daß man nicht anderen sogleich alle Wahrheit in ihren Erkenntnißen abspricht." V-Lo/Blomberg, AA 24: 93 s.) 
crítica, de enjuiciarlo, pero también de reconstruir el sentido legítimo de lo contenido en él, en tanto que propuesta racional (filosófica, sistemática), desde aquella idea. No se trata entonces de que el intérprete, desde una posición externa al texto, lleve a cabo una criba de determinados contenidos doctrinales tomados como elementos aislados que quepa comparar de alguna manera con aquella idea (o principio racional de la interpretación), para, a partir de ahí, contrastar, adoptar o desechar dichos contenidos según puedan encajar, o no, en un esquema prefijado. No se trata, por tanto, de actuar como quien "rompe los cristales desde fuera" -según la expresión de Schopenhauer-, pues esto implicaría concebir los contenidos doctrinales no ya como posibilidades para la ejercitación del propio talento filosófico, ni como materiales que permitan una reconstrucción racional, sino que, más bien, una tal comprensión del trabajo de interpretación terminaría por identificarse con el mero manejo de tesis y enunciados, de resultados y nociones fijadas ya en complejos terminológicos, y no puede recrear el carácter vivo de la conceptualidad filosófica en confrontación con la cosa misma. En ese sentido, para Kant la historia de la filosofía no es una reserva de tesis y argumentos entre los cuales quepa quizás hacer una selección, poner en valor algunos, dejar de lado otros, etc., sino que ha de motivar una apropiación productiva. Esa productividad asume que las virtualidades inscritas en el propio texto, como susceptibles de despliegue racional, son irreductibles a las proposiciones allí contenidas entendidas como meras tesis o aserciones positivas acerca de uno $\mathrm{u}$ otro asunto pretendidamente filosófico. La remisión a la idea como criterio de lectura implica que la interpretación de lo dicho en el texto depende de un cuestionamiento de la plausibilidad de lo allí expuesto, de su pretensión de verdad, i.e. la interpretación del texto (de la "letra") depende y se somete a un criterio sistemático que es -él mismo- racional, i.e. filosófico (relativo al "espíritu") -y que va más allá de la mera constatación empírica de lo dicho, i.e. de lo histórico, pero también -y esto es ahora lo importante- de la naturaleza puramente dogmática del texto a la que aspira por aquella pretensión de verdad; va más allá entonces de su mismo contenido doctrinal. De lo que se trata es de ganar por vez primera ese "contenido" (que al cabo no será tal, puesto que lo "racional" no es propiamente "contenido", sino "forma", y la filosofía un "cómo", no un "qué"). - De esta manera, la tarea de una hermenéutica de la historia de la filosofía radicaría, por así decir, en convertir esa historia de nuevo en filosofía.

Según lo anterior, los dos principios para una "interpretación filosófica de la historia de la filosofía" que conectan en Kant de manera quizás más explícita e inmediata con una comprensión "hermenéutica" de la confrontación con el pasado filosófico: tanto la posibilidad de "comprender mejor al autor..." -lo que, en palabras de Dilthey (GS V: 335), constituye "el más alto triunfo de la hermenéutica" ("der höchste Triumph der Hermeneutik")-, como la de su aplicación del principio de "equidad hermenéutica" de Meier, remiten, en el caso de Kant, a una motivación que podría ser considerada típicamente "ilustrada". De esta forma, la secuencia de propuestas kantianas hermenéuticamente relevantes a la hora de presentar una interpretación distintivamente filosófica de la relación de la filosofía con su historia remiten indefectiblemente a la situación del propio Kant en la historia misma del pensamiento filosófico.

Se dijo, además, que su comprensión de la tarea de una historia filosófica de la filosofía debía ganarse en una apropiación explícita del carácter ya sistemáticamente determinado del acercamiento al pasado filosófico, que podría traducirse, en primer lugar, en la asunción del carácter racional y sistemático de la reconstrucción de la historia acontecida de la filosofía, pero que, a su vez, incita ahora a plantearse también otros interrogantes: aparte del carácter racional de la reconstrucción de lo acontecido, ¿se desvela igualmente aquí el carácter racional de lo acontecido mismo?, ¿y el carácter histórico o acontecido de lo racional? Una respuesta afirmativa a la primera pregunta señala una posición característica ante el problema de la relación de la filosofía (de la razón) con su historia que podría identificarse con aquella que más arriba se denominó típica o estereotípicamente "ilustrada", una posición que devendría de inmediato "idealista", además, si contestase afirmativamente también a la segunda. Sin embargo, la posición específicamente 


\begin{abstract}
"hermenéutica", remitida de modo necesario a la "historia de la filosofía" y consciente de su carácter "secundario", vendría a afirmar la condición históricamente devenida y narrada de la razón, de tal manera que la filosofía en sentido propio (precisamente como "filosofar", en tanto que un "cómo") podría ejecutarse ya sólo como interpretación (i.e. tendría, incluso, que saberse ya del lado de la narración, haber dejado atrás el acontecimiento).

La perspectiva de una apropiación hermenéutica de estas reflexiones de Kant pasa entonces por atender a otra dimensión de la consideración de esta posible "hermenéutica de la historia de la filosofía", que ahora, no obstante, sólo puede quedar apuntada. Se trata de prestar atención a la imagen especulativa $-\mathrm{o}$ al retrato en clave sistemática- que desde aquellas pautas interpretativas cabría presentar de esa historia, i.e. de entrar a cuestionar la tarea de una "historia de la razón pura" y su posible carácter "hermenéutico". Este planteamiento, más propio de la "filosofía de la historia" - o de la "Philosophiegeschichtsphilosophie", por emplear la retrocada expresión de Lübbe (1962)llevaría, a su vez, a plantear la pregunta por la determinación histórica de la confrontación con el pasado filosófico: ¿motiva también en Kant la propia historia acontecida de la filosofía (como res gestae) la inclusión de la narración de esa historia (como historia rerum gestarum) en la actividad propiamente filosófica?
\end{abstract}

\title{
Bibliografía
}

BEISER, Frederick: "Wolff, Chladenius, Meier: Enlightenment and hermeneutics", en J. MALPAS/ H.-H. GANDER (eds.), The Routledge Companion to Hermeneutics, New York, Routledge, 2015.

BOLLNOW, Otto F.: "Was heißt, einen Schriftsteller besser verstehen, als er sich selber verstanden hat?", en id.: Das Verstehen. Drei Aufsätze zur Theorie der Geisteswissenschaften, Mainz/R., Verlag Kirchheim \& Co., 1949.

BOLLNOW, Otto F.: “Über Heideggers Verhältnis zu Kant”, Neue Jahrbücher für Wissenschaft und Jugendbildung 9 (1933) 222-231.

BRAUN, Lucien: Geschichte der Philosophiegeschichte, in der Übersetzung von F. Wimmer bearbeitet und mit einem Nachwort versehen von U. J. Schneider, Darmstadt, Wissenschaftliche Buchgesellschaft, 1990.

CHESTERTON, Gilbert Keith: Appreciations and Criticisms of the Works of Charles Dickens, London, J. M. Dent \& Sons, 1911.

DESCARTES, René: Regulae ad Directionem Ingenii. Texte de l'edition Adam et Tannery (= AT X). Notice par H. Gouhier. Paris, Librarie philosophique J. Vrin, 1965 (4 édition). (Trad. cast. de J. M. Navarro Cordón: Reglas para la dirección del espíritu, Madrid, Alianza Editorial, 1984.)

DILTHEY, Wilhelm: Die geistige Welt. Einleitung in die Philosophie des Lebens. Erste Hälfte: Abhandlungen zur Grundlegung der Geisteswissenschaften (= GS V). Herausgegeben von G. Misch (= Gesammelte Schriften, Bd. V), Stuttgart/Götingen, B. G. Teubner Verlagsgesellschaft/ Vandenhoeck \& Ruprecht, 1957, 2. unveränderte Aufl.

DILTHEY, Wilhelm: Leben Schleiermachers. Zweiter Band: Schleiermachers System als Philosophie und Theologie (= GS XIV). Aus dem Nachlaß hrsg. von M. Redeker (= Gesammelte Schriften, Bd. XIV), Göttingen, Vandenhoeck \& Ruprecht, 1985.

DILTHEY, Wilhelm: Teoría de la concepción del mundo (= Obras de Wilhelm Dilthey, vol. 8), traducción, prólogo y notas de E. Imaz, México, Fondo de Cultura Económica, 1978.

FIGAL, Günter: "Kant und die philosophische Hermeneutik", en id.: Verstehensfragen. Studien zur phänomenologisch-hermeneutischen Philosophie. Tübingen, Mohr, 2009. 
GADAMER, Hans-Georg: El giro hermenéutico, trad. cast. A. Parada, Madrid, Cátedra, 1995.

GADAMER, Hans-Georg: Verdad y método. Fundamentos de una hermenéutica filosófica, trad. cast. A. Aparicio y R. de Agapito, Salamanca: Sígueme, 1991.

GADAMER, Hans-Georg: "Zwischen Phänomenologie und Dialektik. Versuch einer Selbstkritik" (1983), en id.: Hermeneutik II: Wahrheit und Methode. Ergänzungen, Register (= Gesammelte Werke, Bd. 2), Tübingen, J. C. B. Mohr (Paul Siebeck), 1993.

GADAMER, Hans-Georg: "Kant und die hermeneutische Wendung" (1975), en id.: Neuere Philosophie I: Hegel, Husserl, Heidegger (= Gesammelte Werke, Bd. 3), Tübingen, J. C. B. Mohr (Paul Siebeck), 1987.

GADAMER, Hans-Georg: "Zur Fragwürdigkeit des ästhetischen Bewußtseins" (1958), en D. HENRICH/ W. ISER (Hg.), Theorien der Kunst, Suhrkamp, Frankfurt/M., 1992, 4. Aufl.

GADAMER, Hans-Georg: "Zu Kants Begründung der Ästhetik und dem Sinn der Kunst", Sonderdruck aus der Festschrift für R. Hamann, Burg, August Hopfer, 1939.

HEYDENREICH, Karl H.: "Einige Ideen über die Revolution in der Philosophie, bewirkt durch Immanuel Kant, und besonders über den Einfluß derselben auf die Behandlung der Geschichte der Philosophie", en A. CROMAZIANO, Kritische Geschichte der Revolutionen der Philosophie in den drey letzten Jahrhunderten. Aus dem Italienischen mit prüfenden Anmerkungen und einem Anhange über die Kantische Revolution versehen von K. H. Heydenreich, Leipzig, Weygandsche Buchhandlung, 1791, II. Theil. (= Aetas Kantiana, vol. 95. Impression Anastaltique. Culture et Civilization, Bruxelles, 1968.)

HINSKE, Norbert: "De l'accueil correct des idées d'autrui. Culture de la conversation et de la lecture de Wolff à Kant", trad. fr. D. Dinev, en Kant et Wolff: Héritages et ruptures, sous la direction de S. Grapotte et T. Prunea-Bretonnet, J. Vrin, Paris, 2011.

HINSKE, Norbert: Zwischen Aufklärung und Vernunftkritik. Studien zum Kantischen Logikcorpus (= FMDA II, Bd. 13), Stuttgart-Bad Cannstatt, 1998.

HINSKE, Norbert: Kant als Herausforderung an die Gegenwart, Freiburg/München, Alber Verlag, 1980.

HUSSERL, Edmund: Philosophie als strenge Wissenschaft (1911), hg. v. W. Szilasi, Frankfurt/M., Vittorio Klostermann, 1965.

KANT, Immanuel: Kant's Gesammelte Schriften. Akademie-Ausgabe (= AA), herausgegeben von der Preußischen Akademie der Wissenschaften u. a., 29 Bände, Berlin 1900 ff.

KANT, Immanuel: Enciclopedia filosófica (= EF), traducción, introducción y notas de J. M. García Gómez del Valle, s.l. [Girona], Palamedes Editorial, 2012.

KANT, Immanuel: Kritik der reinen Vernunft $(=\mathrm{KrV})$, hg. v. J. Timmermann (Philosophische Bibliothek, Bd. 505), Hamburg, Felix Meiner, 1998.

LA ROCCA, Claudio: "Introducción”, en I. KANT: La polémica sobre la crítica de la razón pura (Respuesta a Eberhard). Introducción de C. La Rocca, traducción y notas de M. Caimi, Madrid, A. Machado Libros, 2002.

LAU, Victor: Erzahlen und Verstehen: historische Perspektiven der Hermeneutik (Epistemata: Reihe philosophie, 27), Wurzburg, Koningshausen \& Neumann, 1999.

LLEDÓ, Emilio: "Notas históricas sobre un modelo universitario", en: P. MANZANO (coord.): Volver a pensar la educación, vol. I, La Coruña/Madrid, Fundación Paideia/ Ediciones Morata, 1999, 2a edición.

LÜBBE, Hermann: "Philosophiegeschichte als Philosophie. $\mathrm{Zu}$ Kants Philosophiegeschichtsphilosophie", en K. OEHLER / R. SCHAEFFLER (eds.): Einsichten (Festschrift für Gerhard Krüger), Frankfurt/M., 1962. 
MAKKREEL, Rudolf A.: "Immanuel Kant", en: N. KEANE / Chr. LAWN: The Blackwell Companion to Hermeneutics, Malden/ Oxford/ West Sussex, Wiley-Blackwell, 2016.

MAKKREEL, Rudolf A.: Imagination and Interpretation in Kant. The Hermeneutical Import of the Critique of Judgment, Chicago, The University of Chicago Press, 1990.

MEIER, Georg F.: Versuch einer allgemeinen Auslegungskunst (1757), herausgegeben von A. Bühler u. L. Cataldi (= Philosophische Bibliothek, Bd. 482), Hamburg, Felix Meiner, 1996.

MEIER, Georg F.: Auszug aus der Vernunftlehre, Halle, Johann Justinus Gebauer, 1752.

ORTEGA Y GASSET, José: "Guillermo Dilthey y la idea de la vida" (1933/34), en id.: Obras completas, vol. 6, Madrid 1964, $6^{\mathrm{a}}$ ed.

SHAKESPEARE, William: The Complete Sonnets and Poems, edited by C. Burrow, The Oxford Shakespeare, Oxford University Press, 2002.

SCHOLZ, Oliver R.: "Die allgemeine Hermeneutik bei Georg Friedrich Meier", en A. BÜHLER (ed.): Unzeitgemäße Hermeneutik. Verstehen und Interpretation im Denken der Aufklärung, Frankfurt/M., 1994

SCHOPENHAUER, Arthur: "Fragmente zur Geschichte der Philosophie", en id.: Parerga und Paralipomena I, Sämtliche Werke, Bd. IV. Textkritisch bearbeitet und herausgegeben von W. Frhr. v. Löhneysen, Frankfurt/M., Suhkamp, 1986.

SZONDI, Peter: Einführung in die literarische Hermeneutik (= Studienausgabe der Vorlesungen, Bd. 5), hg. v. J. Bollack/ H. Stierlin, Frankfturt/M., Suhrkamp, 1975.

TERRASSON, Jean L.: Des Abtes Terrassons Philosophie nach ihrem allgemeinen Einflusse, auf alle Gegenstände des Geistes und der Sitten - aus dem Französischen verdeutschet. Mit einer Vorrede von Joh. Chr. Gottscheden, Leipzig, 1756.

TOMMASI, Francesco V.: "Zwischen Aufklärung und Vernunftkritik. Der Schematism der Analogie und die biblische Hermeneutik Kants", en: G. FRANK/ S. MEIER-OESER (eds.): Hermeneutik, Methodenlehre, Exegese. Zur Theorie der Interpretation in der frühen Neuzeit, Stuttgart - Bad Cannstatt, frommann-holzboog Verlag, 2011.

WOLFF, Christian: Discursus praeliminaris de philosophia in genere. Einleitende Abhandlung über Philosophie im allgemeinen (1728). Historisch-kritische Ausgabe. Übersetzt, eingeleitet und herausgegeben von G. Gawlick und L. Kreimendahl (= Forschungen und Materialien zur deutschen Aufklärung, Bd. I/1), Stuttgart-Bad Cannstatt, frommann-holzboog, 1996. 



\title{
Continuidad y novedad en la concepción histórica de Kant en El conflicto de las facultades
}

NATALIA LERUSSI ${ }^{1}$

\begin{abstract}
Resumen
En el trabajo analizamos algunas continuidades y novedades fundamentales en la concepción kantiana de la historia en el texto El conflicto de las facultades (1798) en comparación con su perspectiva histórica previa, fundamentalmente, de Idea para una historia universal en clave cosmopolita. Mostramos que, en líneas generales, Kant conserva el marco teórico a partir del cual explica el desarrollo histórico en sus textos anteriores, es decir, los conceptos de disposiciones humanas y de circunstancias externas de desenvolvimiento de dichas disposiciones. Sin embargo, en 1798 modifica el tipo de disposiciones que cumplen el rol explicativo en el desarrollo histórico pues ahora es la disposición moral y no, como antes, las disposiciones no morales aquello que motorizan el progreso histórico.
\end{abstract}

Palabras clave: Historia, Progreso, Disposiciones, Kant

\section{Continuity and Novelty in Kant's Historical Conception in The Conflict of the Faculties}

\begin{abstract}
In the paper I analize some fundamental lines of continuity and novelties in Kant's conception of history in the text The Conflict of the Faculties (1798) in comparison with hisprevioushistoricalperspective, specially in Idea for a Universal Historywith Cosmopolitan Purpose. I show that Kant keeps the theoretical framework through which he explains historical development in his earlier works, that is to say, the concepts of human dispositions and external circumstances. However in 1798 he modifies the kind of dispositions that have the explanatory role in history since now the moral disposition and not like before, the no moral onesis that which motorizes human progress.
\end{abstract}

Key Words: History, Progress, Dispositions, Kant

Introducción

En la segunda parte de El conflicto de las facultades (El conflicto) "Reiteración de la pregunta: Si el género humano se halla en continuo progreso hacia lo mejor" ("Reiteración de la pregunta"), Kant plantea nuevamente la cuestión de la posibilidad del discurso histórico, bajo la pregunta “¿Cómo es posible una historia a priori?". 2

Algunos investigadores han afirmado que en El conflicto Kant desarrolla una concepción nueva de la historia y/o del progreso histórico. Así, hace algunas décadas Jean-François Lyotard (1994 [1986]: 59) y Hannah Arendt (2003 [1982]: 37) subrayaban, cada uno a su manera, una

\footnotetext{
${ }^{1}$ CONICET-UBA

${ }^{2}$ Reinhard Brandt (2003: 121) se pregunta en relación a qué otra pregunta de cuál otro texto debemos remitir el texto "Reiteración de la pregunta". Según su conjetura, la misma se refiere "claramente" a la pregunta que Kant se hace en la sección tercera de Teoría y práctica: En torno al tópico: esto vale para la teoría, pero no sirve para la práctica (Teoría y práctica): “¿Hay que amar al género humano en su totalidad o es éste un objeto que se ha de contemplar con enojo?” (TP AA, VIII, 307). La respuesta a esta pregunta, según señalaría Kant, depende de la respuesta a otra: “¿Hay en la naturaleza humana disposiciones de las que se pueda desprender que la especie progresará siempre a mejor...?" Ibidem. De la opinión de que "Reiteración de la pregunta" debe remitirse al texto de 1793 también es Kleingeld (1995: 68); (2009: 171-186).
} 
diferencia sustantiva entre la concepción histórica de Kant de la década de los 80's expuesta ejemplarmente en Idea de una historia universal en sentido cosmopolita (Idea) y aquélla de los 90's, especialmente, de El conflicto. Según ellos, la primera concepción histórica de Kant estaría articulada a través de una teleología fuerte y los conceptos de "intención de la naturaleza", "providencia" e "hilo conductor". En los desarrollos posteriores, sin embargo, estos conceptos habrían sido desplazados por una matriz más cercana a la estética, esto es, por la perspectiva del "espectador" y los conceptos de "signo histórico", "entusiasmo", "enjuiciamiento", etc. ${ }^{3}$ En una líneainterpretativa cercana, aunque centrada en la figura del "actor" (político) que se revela en la segunda parte de El conflicto,se ubican algunos intérpretes más recientes. Así, por ejemplo, Brandt (2003: 119) afirma que "hasta 1795 [inclusive], aquello que conduce a la humanidad hacia el progreso, es llamado Naturaleza o Providencia, cuyas intenciones sólo el filósofo escolar puede descifrar, ahora [es decir, en $E l$ conflicto] es la acción colectiva misma del hombre aquello que es descubierto como lo que nos orienta hacia el progreso". Asimismo, Perez (2014: 158) afirma que "en 1784 la historia de la humanidad es la historia de un propósito de la naturaleza. En 1798 la historia del género humano es la historia de un sujeto colectivo que actúa con entusiasmo en la realización de las ideas de la razón práctica". ${ }^{4}$ Tanto para Brandt como para Perez en la concepción histórica de Kant de finales de los 90's el pueblo (o la acción colectiva del hombre) se define como el actor del progreso histórico en desmedro de la agencia que la naturaleza o providencia parecía tener en las reflexiones kantianas sobre la historia del período 1784-1795. Constatamos, así, un acuerdo creciente entre los especialistassobre el cambio de posición de Kant en los (tardíos) 90's y sobre la novedad de la reflexión histórica de El conflicto. ${ }^{5}$ En el presente trabajo nos interesa participar en esta discusión a partir de un análisis de lascontinuidades y novedades quenos ofrece el marco teórico general mediante el cual Kant piensa la historia. Así, aportaremos nuevos elementos que iluminan el cambio de posición en la concepción histórica de Kant en el texto de 1798, aunque, veremos, el mismo se produce dentro de una misma familia conceptual. ${ }^{6}$

\footnotetext{
${ }^{3}$ Una visión diferente, contemporánea a la de estos autores, es defendida, en 1983, por Michel Foucault (1996: 71-82) quien encuentra una superposición, más que una evolución o cambio, entre diferentes concepciones de la historia de Kant entre 1784 y 1798. Así, vincula fuertemente el texto “¿Qué es la ilustración?” de 1784 -el mismo año en el que Kant publica Idea y en el que se encontraría una visión de la historia "teleológica" - con la segunda parte del texto El conflicto. En ambos textos Kant plantearía el problema del "signo histórico" o signo de la época, las preguntas fundamentales por la actualidad y la revolución que, según e autor (Foucault 1996: 82), definen la tarea de la filosofía (en tanto moderna) bajo la nómina de "ontología del presente" u "ontología de nosotros mismos" y en la cual incluye a su propia filosofía

${ }^{4}$ Véase, además: Perez (2006: 76-77; 101-102).

${ }_{5}^{5}$ Aunque Ana Marta Gonzalez sostiene que "a través de los años la perspectiva de Kant sobre la historia no cambió de forma significativa" (Gonzalez, 2014: 266), matiza su posición, en concordancia con esta línea de interpretación, cuando señala que en $E$ conflicto - en contraste con Idea- Kant "parece ser más consciente de las dificultades involucradas en la adopción de la perspectiva de la providencia...", "mientras que en Idea para una historia universal en clave cosmopolita Kant basa su concepción general de la historia, exclusivamente, en un concepto teleológico de naturaleza [...] en Reiteración de la pregunta explícitamente trata con la historia de la libertad" (Gonzalez, 2014: 281). Asimismo, tanto para Flikschuh (2007: 239) como para Rodriguez Aramayo (2016: 404) la concepción histórica tardía de Kant (de 1798) se desenmarca de la concepción teleológica de la naturaleza o basada en la providencia presente en su concepción histórica previa, llegan, incluso, a afirmar, en los términos de la primera intérprete, que en El conflicto "no hay referencia ni a la providencia ni a propósito alguno de la naturaleza" (parece suavizar esta posición en Filkschuh, 2009: 108-109). Ambos comportan la visión, en las palabras del segundo según la cual "todo indica que el vocabulario de la providencia, abundante en los opúsculos de Kant sobre filosofía política o filosofía de la historia, es reemplazada, progresivamente, por un recurso a las leyes de la naturaleza como un tipo de esquema sensible o, incluso un tipo [el autor nos remite aquí a CPrR 5:43] de ley del derecho". Por otro lado, Kleingeld (1995: 82-83; cf. además: 31, 49, 50, 64) también reconoce un cambio de posición en los 90's, aunque a partir del texto Teoría y práctica de 1793. Según esta intérprete tanto en Idea para una historia universal como en la Crítica de la facultad de juzgar (1790) Kant habría defendido una "filosofía de la historia" "desde un punto de vista teórico" pero desde 1793 y hasta 1795, esto es, en Teoría y prácticay en Hacia la paz perpetua habría abogado por una concepción dela historia "desde el punto de vista práctico". Sin embargo, defiende que, en El conflicto,la concepción histórica de Kant sufre una especie de retroceso inexplicable, pues allí la historia sería comprendida "no sólo desde una intención práctica sino también [...] en consideración a lo teórico". De esta manera, Kleingeld (1995: 180), se ve obligada a deci que en el texto de 1798 se encuentran "considerables inconsistencias y dificultades" y, por lo tanto, que "sería metodológicamente insostenible suponer simplemente que Kant aquí no ha sido dogmático". Esta consecuencia de la lectura de Kleingeld nos parece muy insatisfactoria.

${ }^{6}$ En el presente trabajo presentamos una línea argumental principal que da cuenta de algunas de las continuidades y novedades de texto de 1798 sin pretender ser exhaustivos. Hay un cambio importante en la argumentación, mencionado por Brandt (2003: 121),que vale la pena indicar: la condición de la pre-existencia de un orden internacional justo (en la forma de un Estado mundial (1784) o de federación de Estados (1795)) para la institución de órdenes civiles internos justos o repúblicas no tiene rol alguno en
} 
¿Cuáles son los conceptos centrales que Kant utiliza en 1798 para explicar el decurso histórico? ¿Es nuevo el uso que hace Kant de esos conceptos? ¿Cuáles son los conceptos fundamentales mediante los cuales Kant desarrolla su concepción de la historia antes de 1798? El hecho de que Kant no use aquí, recurrentemente, el concepto de una "providencia", que supone fines e intenciones en la naturaleza por fuera de los seres y procesos que actúan y se desarrollan -a la que llamaremos "concepción trascendente" del progreso histórico- no implica que Kant haya abandonado el marco teórico general mediante el cual comprende la historia en los textos previos a 1798. Como hemos mostrado en otro trabajo (Lerussi, 2015) y veremos sumariamente abajo Kant utiliza en su comprensión de la historia humana, paradigmáticamente, en Idea para una historia universal en clave cosmopolita (Idea) un modelo de desarrollo histórico que inscribe los fines o tendencias (de mejoramiento) en una fuerza interna y formadora de la naturaleza humana, visión que podemos llamar, por oposición, "concepción inmanente" del progreso histórico. ${ }^{7}$ Esto significa, específicamente,que el desarrollo histórico o cultural se explica a partir de los conceptos de "disposiciones" inscriptas en la naturaleza humana y de las "circunstancias externas" que favorecen u obstaculizan el despliegue de dichas disposiciones. ${ }^{8}$

Como veremos en este trabajo, en El Conflicto Kant continúa defendiendo, en líneas generales, un marco teórico semejante al previo, una concepción inmanente de la historia según la cual son, principalmente, los conceptos de "disposiciones" inscriptas en la naturaleza humana y las "circunstancias" externas (u "oportunidad") aquellos quedan cuenta del desarrollo histórico. Ahora, aunque Kant mantenga una misma concepción, realiza modificaciones importantes en la argumentación. Antes de 1798, paradigmáticamente en Idea, aquello que permite comprender el desarrollo histórico son las disposiciones no morales de los hombres: son estas disposiciones las que explicarían el despertar final de la disposición moral. Por el contrario, en 1798 las disposiciones no morales no juegan papel alguno en la argumentación. El progreso del género humano hacia lo mejor se asegura a través de la prueba de que hay una disposición moral en el género humano. Una consecuencia de este giro en la argumentación que comentaremos, muy brevemente y como corolario, al final del trabajo atañe a la estructura de la historia o del progreso. Hasta 1798, paradigmáticamente en Idea, el progreso es el resultado de una acumulación continua de experiencias culturales y civilizatorias pasadas, en El conflicto, el "progreso" es la interrupción del curso del tiempo a partir de la irrupción (por revolución o reforma) de la forma política que esjusta y buena por sí misma, la república.

\section{Disposiciones del género humano y circunstancias externas en El conflicto de las Facultades}

Kant señala en El conflicto que el progreso hacia lo mejor no debe ser esperado del "curso de las cosas de abajo hacia arriba" (SF AA, VII, 092), esto es, del mejoramiento de los hombres tomados individualmente a través de la educación, ${ }^{9}$ sino "de arriba hacia abajo". Esto es:

el texto de 1798 lo que hace pensar que Kant modificó el sentido de la dependencia entre los dos órdenes: ahora (en 1798) dependería de la institución de repúblicas (y, por lo tanto, del pueblo) la conformación de un orden de derecho internacional justo y, no al revés.

${ }_{7}^{7}$ En el artículo, que abajoretomaremos, hemos mostrado no sólo que en Idea Kant defiende una concepción de la historia que denominamos "inmanente", sino además que esta concepción de la historia es utilizada por Kant también en el marco de su historia natural, en su concepción de la filogénesis de las especies y que coincide con su concepción de la "epigénesis". Véase nuestro artículo: Lerussi, 2015.

${ }^{8}$ Otros intérpretes también defienden que uno de los conceptos claves para comprender la concepción histórica de Kant, en líneas generales, es el de "disposición” (natural u originaria). Véase: Lebrun (2009); Wood (1999: 208; 2009: 113); Kleingeld (1995: 126, 194, 214).

${ }^{9}$ Kant no rechaza de plano que el progreso dependa de una buena educación. No obstante, enfatiza que el plan que parte del curso de las cosas "de abajo hacia arriba" hace "más difícil" esperar (hoffen) el progreso. Así: "Esperar (erwarten) que por medio de la formación (Bildung) de la juventud, bajo la dirección familiar y luego de las escuelas [...] con una cultura intelectual y moral 
Pero, como siempre son hombres los que deben realizar esta educación, hombres que han debido ser educados para esa finalidad, es necesario, teniendo en cuanta la flaqueza de la naturaleza humana y la contingencia de los acontecimientos que favorecen tal resultado, poner la esperanza de su progreso sólo en una sabiduría que viene de arriba (in einer Weisheit von oben herab) (que se llama Providencia cuando es invisible para nosotros), como condición positiva. SF AA, VII, 093.

Esta cita indica que, en El conflicto, Kant no abandona, como afirman algunos intérpretes, lo que en la Introducción denominamos "concepción trascendente" de la historia. Una concepción semejante de la historia se encuentra aquí sugerida, aunque debamos reconocer que no tiene el peso que tenía en los textos previos ni tampoco que sea posible extraer del contexto qué quiere decir Kant cuando señala que la esperanza en el progreso hacia lo mejor debe ponerse en una "sabiduría que viene de arriba", como de una "condición positiva". ${ }^{10}$ Dejamos deliberadamente en suspenso una explicación de la concepción trascedente de la historia presente en El conflicto, puesno es un objetivo del presente trabajo probar que Kant defiende -y en qué medida lo hace- una concepción semejante de la historia aquí o en otro contexto. Lo que buscamos mostrar es que Kant defendió en 1798, como también lo había hecho, según veremos, en 1784, una concepción inmanente de la historia.

Ahora bien, como el filósofo indica en el párrafo que copiamos arriba, dado que el educador de los hombres ha debido ser educado por otro hombre bajo circunstancias contingentes no puede, por sí solo, garantizar aquella educación que conduce a la humanidad hacia el desarrollo de su disposición moral dormida. De allí que señale que la esperanza en el progreso hacia lo mejor debe ponerse en una "sabiduría que viene de arriba". Esta expresión se aclara si la tomamos en su acepción "negativa", según continua el argumento, por la cual aquello que "puede ser esperado (erwartet werden kann) de arriba" es también lo que "puede esperarse y exigirse (erwartet und gefordert werden kann) [de los hombres] para el avance de este fin" (SF AA, VII, 093). Si la cuestión del progreso se decide a partir de aquello que los hombres no sólo deben, sino también pueden hacer como especie tomada colectivamente (y no, distributivamente, como es el caso de la educación), cabe suponer que aquélla atañe a lo que puede la naturaleza humana, esto es, según veremos, a la naturaleza "disposicional" de nuestra especie.

El problema fundamental de "Reiteración de la pregunta", aquello que se intenta saber, es si el devenir futuro ${ }^{11}$ de la especie humana como género moral constituye un progreso hacia lo mejor o no. Puesto que la experiencia no nos permitiría inferir cómo se comportará nuestra especie en el futuro (dado que los hombres son seres libres) y que la vía adivinatoria ("una comunicación y ampliación sobrenaturales de la perspectiva del futuro". SF AA, VII, 079) no es posible, parece clausurado un saber sobre el futuro tanto por la vía natural como por la sobrenatural. Kant, sin

reforzada por la doctrina religiosa, se llegará finalmente no sólo a educar buenos ciudadanos, sino a educar para el bien [...] es un plan del que difícilmente se puede esperar (schwerlich hoffen läßt) el éxito deseado" (SF AA, VII, 092). Kant menciona dos razones por las cuales la educación de los hombres sería insuficiente, dada las circunstancias, para despertar la disposición moral de los hombres. Esto es, según la primera dificultad, el pueblo considera que los costos de la educación de los jóvenes no deben recaer sobre él sino sobre el Estado, pero los Estados no republicanos no tienen dinero para la educación pues requieren todo para la guerra. De esta primera dificultad se sigue una segunda pues si la educación no es diseñada según un plan meditado desde e poder superior del Estado que responda a sus propósitos, la misma carece de coherencia alguna (véase: SF AA, VII, 093). Los ciudadanos que costean su propia educación, son formados de acuerdo a planes y criterios educativos y políticos que pueden ir en desmedro del progreso. En consecuencia, en la medida en que la cuestión de la educación se enfrenta a serios obstáculos, no podemos confiarnos que será precisamente ella el medio de mejoramiento de la especie.

${ }^{10}$ Pauline Kleingeld (1995: 84) señala que el filósofo se refiere aquí "a un orden de una sabiduría suprema (divina) [...] que gobierna el mundo" "que implica una modificación fundamental del punto de vista histórico" de Kant, al menos, como "sabiduría positiva". En este contexto, la intérprete señala que Kant también puede estar refiriéndose al Estado (véase: ibídem). P. Kleingeld, sin embargo, no fundamenta ninguna de las dos tesis. Con la expresión "de arriba hacia abajo" como sabiduría en sentido "positivo" es probable que Kant no esté mentando, como supone P. Kleingeld, a un ser divino que gobierna el mundo, sino a la razón en sentido práctico como fuerza capaz de actuar según un principio propio y de producir positivamente las condiciones para el desarrollo moral pleno de la humanidad. Agradezco al Prof. Volker Gerhardt haberme sugerido esta interpretación de la enigmática expresión "sabiduría que viene de arriba" como "condición positiva" anotada aquí por Kant. Con todo, el texto no permite más que conjeturas. Añadimos que, si Gerhardt tuviera razón, entonces, lo que hemos llamado "concepción trascendente" de la historia no implica necesariamente premisas teológicas, pues podría estar sostenida sobre una concepción "sustantiva" de la razón práctica.

${ }^{11}$ Aunque también el pasado es objeto de discusión en El conflicto en los pasajes: SF AA, VII, 084; 088. 
embargo, abre una tercera alternativa. Hacia el final del apartado cuarto, Kant concluye que podríamos prever el futuro del acontecer humano -en el sentido de un progreso hacia lo mejor- si pudiéramos otorgarle al hombre una "invariable buena voluntad, aunque limitada". Así:

Si se pudiera atribuir al hombre una voluntad innata e invariablemente buena, aunque limitada, podría predecir con certeza este progreso de su especie hacia lo mejor; pues este progreso se referiría a una circunstancia que él mismo puede producir. SF AA, VII, 084.

Nótese que aquello que se debe probar no es que hay en el hombre una voluntad sujeta a la ley moral -problema que Kant ha discutido y resuelto en la Crítica de la razón práctica- o incluso que habría un aumento "creciente de la moralidad de la intención" (SF AA, VII, 091). La prueba que se busca no puede coincidir con aquella que determina el carácter moral del género humano y esto no sólo porque dicho carácter se prueba suficientemente a partir de la conciencia de la ley moral, sino además porque el mismo no permite predecir el modo como los hombres actuarán, de hecho, en el futuro. ${ }^{12}$ La conciencia de la ley en el hombre determina cómo debe actuar él en cualquier circunstancia pero nunca cómo lo hará efectivamente. ${ }^{13}$ Por eso, aquello que el argumento quiere probar es si los hombres tienen una tendenciadispuesta a trabajar a favor de crear las circunstancias del progreso y, por lo tanto, que se inscribe en la naturaleza humana una disposición hacia la moralidad. ${ }^{14}$ En El conflicto, Kant es muy explícito sobre el alcance de dicha disposición pues se trata de una tendencia al mejoramiento de las condiciones morales jurídico-políticas (ámbito del derecho) y no a una tendencia hacia el aumento de la moralidad en el sentido de la buena intención de los hombres (ámbito de la ética). ${ }^{15}$ Esto significa que si hay progreso "[habría] un aumento de los efectos de la legalidad de sus actos [del hombre] conforme al deber cualquiera que sea la razón que los determine" (SF AA, VII, 091, las itálicas son nuestras).

Así, en la sección quinta, Kant defiende que, aunque no puedan darse pruebas empíricas del progreso, como ya hemos señalado, debe haber algún hecho en la experiencia que nos permita inferir indirectamente, como "signo histórico", al menos, la "posibilidad del progreso" mediante la apelación a un cierto "talante" o "facultad" del género humano (en beneficio del derecho). De este modo:

Debe haber en la especie humanaalguna experiencia que, como hecho (Begebenheit), indique una cualidad (Beschaffenheit) y una facultad de esta especieque sería la causa del progreso hacia lo mejor (puesto que debe ser el acto de un ser dotado de libertad),el autor del mismo; pero se puede predecir que un hecho es efecto de una causa dada cuando se producen las circunstancia que concurren a ello. SF AA, VII, 084 .

En el pasaje precedente se evidencia que la prueba de la posibilidad del progreso contiene, precisamente, dos elementos centrales: lo que a través de una cierta experiencia se debe probar es 1) una cualidad o un talante (Beschaffenheit) o una facultad del género humano hacia lo mejor que actúa cuando 2) concurren las circunstancias para ello. Esto significa que el desarrollo histórico depende de una concepción de la naturaleza humana en la cual actúan oportunamente ciertos dispositivos

\footnotetext{
${ }^{12}$ Esto lo señalaría expresamente Kant en la sección cuarta del texto titulada "Con la experiencia no se puede resolver directamente el problema del progreso", véase: SF AA, VII, 083.

${ }^{13}$ En Teoría y prácticaencontramos, no obstante, un único pasaje en los textos dedicados a la historia universal en el cual Kant pretende demostrar el progreso futuro de la humanidad a partir de "un deber innato" del hombre a contribuir en el mismo. Véase: TP AA, VIII, 309. Pero que dicho argumento no es suficiente se evidencia en el mismo texto cuando Kant señala que, en relación al progreso moral de la especie confía, además de en el deber, en la naturaleza de las cosas "que lleva por la fuerza a donde no se quiere de buen grado (fata volentem ducunt, nolentem trahunt)". TP AA, VIII, 313. También: TP AA, VIII, 310. Esta última tesis se halla nuevamente en Hacia la paz perpetua: ZeF AA, VIII, 365. Katrin Flikschuh (2007) se ha dedicado a estudiar específicamente la tensión entre aquellas dos afirmaciones y defiende que Kant no logra resolverla en el marco de este texto (según la intérprete, recién en la Doctrina del derecho, primera parte de la Metafísica de las costumbres (1797), a través del principio de derecho y en desmedro de una concepción teleológica de la naturaleza, Kant ofrece una perspectiva consistente del progreso histórico).

${ }^{14}$ La disposición moral o "disposición para la personalidad" es definida en La religión dentro de los límites de la mera razón como una "receptividad al respeto por la ley moral". Así, la disposición moral no coincide con el respeto a la ley moral pues se trata de un impulso natural previo a ese sentimiento y "facilitador" del mismo. Véase: RGV AA, VI, 028.

${ }^{15}$ Cf. Brandt (2003: 122). Sobre la distinción entre moral-jurídica (derecho) y ética, véase: Terra (2005).
} 
tendientes a fin, en este caso, una facultad o talente que posteriormente, como veremos, será designada directamente como "disposición moral". Como indicamos en la Introducción y veremos más abajo, estos dos elementos: 1) ciertas "disposiciones" humanas que se desarrollan en 2) determinados contextos o circunstancias externas definen la concepción de la historia -que llamamos "inmanente"- que Kant defiende también, paradigmáticamente en Idea (y en todos sus textos previos,con excepción de Hacia la paz perpetua, tesis que aquí no podremos probar en toda su extensión). ${ }^{16}$

Kant expone en unas páginas que se volverán célebres el hecho que hará las veces de "signo histórico" buscado. Reproducimos aquí parcialmente este pasaje:

Este hecho no consiste en acciones u omisiones buenas o malas, importantes, realizadas por los hombres [...] No: nada de esto. Se trata sólo de la manera de pensar (Denkungsart) de los espectadores, que se trasluce públicamente en ese juego degrandes revoluciones [...] y que manifiesta, sin embargo, una participación (Teilnehmung) tan general y a la vez tan desinteresada por los actores de un partidorespecto de los del otro, demostrando así (a causa de launiversalidad) una carácter de la humanidad en general y, también (a causa del desinterés) un carácter moral dela misma, al menos en su disposición, que no sólo permite esperar un progreso hacia lo mejor, sino que constituye él mismo un progreso, en la medida en que la facultad para el progreso es alcanzada ahora. SF AA, VII, 085. Las itálicas son añadidos nuestros.

El signo o la experiencia que se busca no es una acción o la omisión de una acción, ni tampoco, por lo tanto, la puesta en escena de la intención de un actor o un conjunto de actores. Consecuentemente, el hecho en cuestión no es el acto revolucionario mismo. ${ }^{17}$ Kant señala rápidamente que dicho acontecimiento es la expresión pública de un hecho del pensamiento, eso es, dela "manera de pensar" de los espectadores de la revolución francesa. La expresión pública y generalizada a favor del bando republicano señala que los hombres tienen un interés en la defensa de constituciones populares, las cuales, además de ser aquellas en donde el pueblo es libre políticamente, son aquellas en las cuales, "por principio", se evita la guerra agresiva, se trata de aquella constitución que "es justa y moralmente buena en sí misma" (SF AA, VII, 085). Los espectadores externos de la revolución no son imparciales en la contemplación del acontecimiento, por el contrario, toman parte,

\footnotetext{
${ }^{16}$ En Hacia la pazperpetua Kant defiende un modelo exclusivamente trascendente del progreso histórico, perspectiva que está presente en todos los otros textos, aunque de manera simultánea e intercalada (de una manera que exige una clarificación que no podemos dar aquí) con una concepción "inmanente". Esto no significa que defendamos que Kant haya propuesto en 1795 una concepción "novedosa" de la historia, como decíamos, esta visión está también presente en el resto de sus textos, incluso, como vimos arriba, en El conflicto, aunque los acentos sean diferentes.

${ }^{17}$ De este modo, no consideramos acertadas las interpretaciones que sostienen que la revolución francesa es el signo histórico buscado. Esta interpretación se encuentra, sin embargo, defendida por varios intérpretes (Axinn 1971: 426; Brandt 2003: 123/6, 129; Cohen 2009: 133; Kuehn 2009: 70; Flickschuh 2009: 109). De nuestra opinión es: Beck (1791: 419) Kleingeld (1995: 77); Recki (2005: 240), Gonzalez (2014: 282), Rodriguez Aramayo (2016: 404). Nótese que Kant no se pronuncia en "Reiteración de la pregunta" a favor de la revolución, por el contrario, expresamente señala que la misma "siempre es injusta (ungerecht)". AA, VII, 088. La primera condena (moral), por parte de Kant, al acto revolucionario se encuentra en Teoría y práctica(en el pasaje: TP AA, VIII, 299-300). Con todo, a comienzos de la década de los 90's corría el rumor en Europa de que Kant defendía la revolución. E mismo se deja constatar, por ejemplo, en la carta de Biester a Kant, editor de la Berlinische Monatsschrift, a donde se publica, precisamente, Teoría y práctica, quien, luego de recibir el opúsculo, le declara a Kant que le "complació máximamente [Teoría y práctica] puesto que refutaba el rumor [...] según el cual [el filósofo] se había resuelto a favor de la cada vez más repulsiva revolución francesa". Br AA, XI, 456. Los corchetes son añadidos nuestros. Ahora, la condena (moral) por parte de Kant de la revolución y su simultáneo entusiasmo por la misma -que se infiere del párrafo transcripto aquí arriba- ha conducido a algunos intérpretes a distinguir la posición pública de la verdadera posición de Kant respecto a la revolución, la última de las cuales habría sido cautelosamente ocultada por el filósofo a fin de evitar problemas con la censura. Esta interpretación es defendida paradigmáticamente en: Strauss (1988 [1952]: 33); Vaughan (1939: 83). Sin embargo, puesto que esta interpretación implica a Kant en una suerte de "mentira noble" no puede ser aceptada. Véase, por ejemplo, el artículo Anuncio de un cercano término de un tratado hacia la paz perpetua en filosofía (VNAEF AA, VIII, 411-422) en donde Kant niega enfáticamente la legitimidad de mentir en filosofía. Lewis B. Beck (1971: 411) refuta también esta lectura a través de la regla de prudencia filosófica que Kant le habría expresado a Mendelssohn en carta del 8 de abril de 1766 según la cual, aunque "habría muchas cosas que jamás tendr[á] el valor de decir, jamás diría algo en la que no cre[a]" (Br AA, X, 069. Los corchetes son añadidos nuestros) que el filósofo repite nuevamente, en 1798 (en El conflicto, véase: SF AA, VII, 032). Beck (1971: 413) resuelve la aparente paradoja de la posición de Kant respecto a la revolución mediante la distinción entre un rechazo "jurisprudencial" al derecho a la revuelta (o revolución) y una simpatía "no jurisprudencial" hacia la misma. Puesto que la posición negativa se localiza en un nivel lógico diferente a la posición positiva, las mismas no se contradicen.
} 
aunque desinteresadamente, por el lado que alberga la causa moral, es decir, por el bando republicano. Esto significa que ellos expresan una disposición moral de todo el género humano. En los términos de Kant:

La revolución de un pueblo lleno de espíritu, que hemos visto realizarse en nuestros días [...] encuentra en los espíritus de todos los espectadores (que no están comprometidos ellos mismos en este juego) una participación según el deseo (Wunsche), rayana al entusiasmo (Enthusiasm), y cuya manifestación, que lleva aparejado un riesgo, no podía obedecer a otra causa que una disposición moral del género humano. SF AA, VII, 085.

De este modo, se prueba a través de un indicio, esto es, la manifestación de un afecto cercano a una pasión, el entusiasmo, ${ }^{18}$ que el género humano tiene una disposición moral. El verdadero entusiasmo es "una participación con afecto en el bien" y "se refiere siempre a lo ideal y lo puramente moral, esto es, al concepto de derecho" (SF AA, VII, 086). Puesto que es un afecto que nace de la idea pura de derecho parece ser un candidato adecuado para expresar que el género humano tiene una tendencia a desarrollar en la historia aquello que es deber moral para la especie. Esto significa que el progreso histórico se comprende en El Conflicto a partir de un dispositivo inmanente de la naturaleza humana, orientado a fin -la disposición moral- que opera, como veremos inmediatamente, según la ocasión.

Pues bien, si hay una disposición moral en el género humano, ¿por qué es, entonces, la historia el escenario de la opresión interna y la guerra externa? Si bien es cierto que Kant afirma que puede haber progreso en la medida en que es "una circunstancia que él [el hombre] mismo -mediante su buena voluntad- puede realizar" (SF AA, VII, 084) eso no significa que aquella "disposición moral" pueda realizarse en cualquier momento o circunstancia. Las circunstancias del progreso dependen de una disposición moral... pero la actualización de dicha disposición depende, a la vez, de que ocurran ciertas circunstancias. ¿Cuáles son esas circunstancias? En la sección quinta Kant señalaque las mismas "tienen que ocurrir" alguna vez. Como en el "cálculo de probabilidades en el juego de azar" (SF AA, VII, 084) se puede afirmar que dichas circunstancias ocurrirán probablemente alguna vez, aunque no se pueda determinar con precisión cuándo esto vaya a suceder. En la sección séptima Kant nos asegura que por los signos de la época la especie humana logrará algún día el fin esperado y que "desde ese momento su progreso hacia lo mejor nunca reconocerá una regresión total" (SF AA, VII, 088). Nuevamente aquí indica que "en lo que se refiere al momento, (podemos predecir dicho acontecimiento) solo de una manera indeterminada" (SF AA, VII, 088). Sin embargo,aunque asegura una y otra vez el requerimiento de que ciertas circunstancias co-actúen junto a la disposición moral en el desarrollo histórico, nunca define ni deja en claro de cuáles se trata. Lo importante para nosotros es notar que este factor apunta a mostrar que la disposición implicada no se desarrolla por sí misma y en aislamiento, sino que depende siempre de un contexto propicio para su desenvolvimiento.

\section{Sobre la novedad de la concepción kantiana de historia en 1798}

Según veremos en el presente apartado, antes de 1798, paradigmáticamente en Idea, Kant defiendeuna concepción inmanente del desarrollo histórico. Esto es, una visión que da cuenta del progresoa partir de la idea de que ciertas "disposiciones" internas de la especie humana se despliegan segúnciertas "circunstancias externas". Así se debe admitir una continuidad en el marco teórico general con el que Kant concibe el desarrollo histórico en los años 1784 y 1798, inclusive.Ahora, esto no significa que la concepción kantiana de la historia no sufra cambios significativos. De hecho,

${ }^{18}$ Para el concepto de "entusiasmo" (Enthusiasm, Enthusiasmus o Begeisterung), véase, fundamentalmente: KU AA, V, 271/2, además: NTH AA, I, 329; GSE AA, II, 221, 251, 253, 267; KU AA, V, 157, 272, 274, 275, 363; RGV AA, VI, 050, 195; MS TL AA, VI, 409; SF AA, VII, 085, 086; Anth AA, VII, 202, 254, 259, 269, 314; TP AA, VIII, 287. Se ha ocupado especialmente de la cuestión del "entusiasmo revolucionario" en tanto forma de lo sublime en Kant Jean-François Lyotard (1986). 
como analizaremos abajo, en Idea, el peso del argumento del progreso está en mostrar que las disposiciones no morales del hombre dirigen a la especie hacia un ámbito moral y no, como en $E l$ conflicto, en probar, directamente,la existencia de una disposición moral.Según Idea se inscriben en la naturaleza humana disposiciones no morales de las que surgen pasiones cuya tensión produce mecanismos de transformación cultural que, a la larga, conducen a toda la especie humana, incluso sin quererlo,a la institución de un orden legal interior y exterior, perfectamente justo, en donde se puede desarrollar la disposición moral de los hombres. Así, el desarrollo de la disposición moral depende en el texto de 1784, como mostraremos a continuación,del desarrollo de dispositivos no morales.

De esta manera, en Idea Kant inaugura la problemática de la historia universal mediante los conceptos de "disposiciones originales" o "disposiciones naturales", que son centrales entre las tesis primera y cuarta. ${ }^{19}$ En la primer tesis el filósofo afirma que todas las disposiciones de un ser orgánico han de desarrollarse en algún momento de manera completa y conveniente. ${ }^{20}$ En la segunda tesis añade, sin embargo, que puesto que las disposiciones destinadas al uso de la razón en el hombre se desarrollan de forma ilimitada y que los seres humanos son mortales, las primeras no se desarrollan de forma completa en cada individuo, sino sólo en la especie. Estas dos tesis son las premisas de la afirmación hacia el final de la tesis tercera cuando asegura que es necesaria la idea de que las generaciones pasadas de la humanidad deban laborar para la fortuna de las generaciones futuras.

Pues bien, en la tesis cuarta de Idea Kant se ocupa de comprender el tránsito desde el estado de barbarie de la especie hacia la cultura ${ }^{21}$ a partir del concepto de "disposición" inscripta en la "naturaleza humana". Las disposiciones juegan aquí un doble papel pues no sólo son aquello que se debe desarrollar en el tiempo, sino también el medio o la circunstancia mediante el cual las mismas se desarrollan. Así, el paso de la animalidad hacia la humanidad del hombre es comprendido mediante el "antagonismo de las [disposiciones] dentro dela sociedad" del que finalmente resulta un ordenamiento legal que es condición, a la vez, para el desarrollo de "todas las disposiciones" de la especie. ${ }^{22}$ Veamos:

El medio del que se sirve la Naturaleza para llevar a cabo el desarrollo de todas sus disposiciones es el antagonismo de las mismas dentro de la sociedad, en la medida que ese antagonismo acaba por convertirse en la causa de un orden legal de la misma. IaG AA, VIII, 020.

Kant señala inmediatamente a continuación que el "antagonismo de las disposiciones dentro de la sociedad" es equivalente al concepto de "insociable sociabilidad" (ungesellige Geselligkeit) que, según defiende aquí Kant, es un conjunto de disposiciones que se reducen a la "propensióna vivir en sociedad, vinculada con una resistencia continua" ${ }^{23}$ a entrar en la misma. ${ }^{24} \mathrm{La}$ "insociable sociabilidad" está compuesta, así, por un lado, por una disposición social del hombre a reunirse en sociedad, esto es, una inclinación a estar en compañía de los otros y, por otro lado, por la disposición insociable que consiste en una inclinación a aislarse y a vivir según el propio sentido. ${ }^{25}$ Así, ni a la disposición sociable ni a la insociable se le adscribe una connotación moral. Por el contrario, refieren, respectivamente, a una inclinación o a un rechazo hacia la compañía de los otros y no a un deseo de hacerles el bien o hacerles daño, de competir o cooperar con ellos. Ahora bien, la disposición a aislarse degenera tan pronto se pone en tensión con la disposición sociable, pues seres que tienen la inclinación a vivir según el propio modo de pensar querrán continuar haciéndolo cuando se encuentren, por el principio de la sociabilidad, en comunidad con los otros. Por eso, se dice en Idea

\footnotetext{
${ }^{19}$ Reponemos aquí parte de lo que hemos desarrollado en nuestro artículo: Lerussi, 2015.

${ }^{20}$ IaG AA, VIII, 018

${ }^{21}$ Una definición amplia de "cultura" se encuentran en: KU AA, V, 430, 431

${ }^{22}$ Véase: IaG AA, VIII, 022

${ }^{23}$ Véase: IaG AA, VIII, 020.

${ }^{24}$ Hemos desarrollado nuestra interpretación del concepto de "insociable sociabilidad" en: Lerussi (inédito).

${ }^{25}$ Véase: IaG AA, VIII, 020/1.
} 
que el hombre en sociedad se encuentra en un permanente estado de alerta, ya que "como se sabe inclinado a oponerse a los demás, espera hallar esa misma resistencia por doquier". ${ }^{26} \mathrm{El}$ hombre en sociedad se resiste frente a los demás porque sabe que los demás querrán, como él, vivir según su propio criterio en sociedad. Más aún, es la presunción de que los otros pretendan imponerle su propio sentido o modo de pensar lo que inclina al hombre a entrar, en una carrera por el rango entre sus congéneres, a un estado de competencia por obtener los medios que otorgan superioridad al hombre y que facilitan la imposición del propio sentido. Es a partir de esta competencia por el rango de donde surge una tríada de pasiones que implican las tres formas centrales de competencia entre los hombres, esto es, la competencia por la riqueza, por el dominio y por el honor. Así, mediante la "ambición, el afán de dominio o la codicia" se produce, finalmente, "los primeros pasos desde la barbarie hacia la cultura". ${ }^{27 "}$ Aunque por el principio a la sociabilidad, el hombre quiere vivir "cómoda y placenteramente", en "laxitud y ocioso conformismo", por su disposición a la insociabilidad en el contexto de la sociedad debe salir de la indolencia y del inactivo contento, "entregándose al trabajo y padeciendo las fatigas que sean precisas para encontrar prudentemente los medios de sustraerse de tales penalidades." 28 De este modo, mediante los frutos del trabajo fatigoso, riquezas, dominio y honores, el hombre puede encontrar una ventaja en relación a sus congéneres y, por consiguiente, facilitar la imposición del propio sentido o modo de pensar.

Pues bien, en este esquema de desarrollo de la cultura a través del antagonismo de las disposiciones no morales las circunstancias externas también juegan un papel. Como señala el filósofo,el desarrollo de ciertas disposiciones produce un estado de cosas (A) -que Kant denomina "tensión de fuerzas" (Anspannung der Kräfte) ${ }^{-29}$ que despierta disposiciones aún dormidas cuyo desenvolvimiento dará en un nuevo estado de cosas (B) -"nueva tensión de fuerza"- que será punto de partida para el desarrollo de nuevas tendencias.Entre la tesis cuarta y octava de Idea se destacan una serie de factores externos, "relaciones de fuerza" o circunstancias culturales mediante las cuales son promovidas diferencialmente las disposiciones naturales de los hombres. Significativamente, en la sección cuarta, quinta y octava de Idea, Kant presenta una concepción del progreso histórico según la cual el paso de cada circunstancia cultural a la siguiente, esto es, de la barbarie a un orden legal, de éste, a una sociedad civil plenamente justa y, finalmente, de ésta, a una sociedad moral en donde pueden desarrollarse todas las disposiciones humanas, se produce a partir de las condiciones generadas por las circunstancias culturales previas.

En la tesis cuarta de Idea, Kant indica abruptamente que el efecto que tendrían ciertos productos de la cultura, es decir, del arte y la ciencia, es producir un cierto sentimiento (la formación de gusto) y un nuevo modo de pensar, en general. ${ }^{30}$ Una sociedad patológicamente formada en la que los hombres compiten por producir cultura, a la larga, a través de la apreciación y discusión pública de sus productos, hace nacer una nueva afectividad y modo de pensar que "andando el tiempo,puede transformar las toscas disposiciones naturales hacia la disquisición moral en principios prácticos determinados", que es base de una "sociedad moral". ${ }^{31}$ De este modo, una sociedad del gusto y de la ilustración, resultante del estado de competencia, tendría por consecuencia, la moralidad y el consecuente desarrollo de todas las disposiciones humanas, esto es, incluso la disposición moral. ${ }^{32}$

Así, en 1784 Kant defiende -como en El conflicto- una concepción inmanente de la historia, aunque aquíla función explicativa del desarrollo histórico está del lado de las disposiciones no morales (disposiciones sociable e insociable); el desarrollo de la disposición moral es, por el

\footnotetext{
${ }^{26}$ Véase: IaG AA, VIII, 021.

${ }^{27}$ Véase: IaG AA, VIII, 021.

${ }^{28}$ Véase: IaG AA, VIII, 021.

${ }^{29}$ Véase: IaG AA, VIII, 019.

${ }^{30}$ Véase: IaG AA, VIII, 021.

${ }^{31}$ Véase: IaG AA, VIII, 021.

${ }^{32}$ Esta tesis se repite en: KU AA, V, 433ss.
} 
contrario, aquello que tiene que ser explicado y es resultado del progreso histórico. Hacemos notar brevemente que el devenir histórico se entiende, así, en este contexto, como un procesosucesivo y continuo de formas culturales o civilizatorias (sociales, político-jurídicas y afectivas) cuyas tensiones internas producen nuevas formas culturales que, a la larga y por acumulación, produciría un estado en donde los hombres pueden desarrollarse moralmente. El esquema de progreso histórico implicado en El conflicto parece ser muy diferente.

Según vimos, en 1798 Kant propone una línea argumental en la que las disposiciones no morales no tienen ninguna función explicativa en la comprensión del progreso humano. Por el contrario, el progreso se comprende a partir de la puesta al descubierto de que hay en el género humano una disposición moral que se despliega cuando concurren las circunstancias para ello. ${ }^{33}$ Este giro en la argumentación tiene, a la vez, consecuencias en la concepción de la estructura de la historia pues Kant parece abandonaren 1798 la concepción del progreso como proceso acumulativo de formas culturales o civilizatorias. Esta vez, "progreso" significa la institución de una constitución en la cual el pueblo se da su propia ley y evita la guerra (agresiva) contra otros Estados. Kant señala en $E l$ conflicto que la prueba del progreso del género humano hacia lo mejor no sólo está orientada al futuro, sino que también "podría ser extendida a la historia de los tiempos pasados", esto es, "que siempre ha habido progreso" (SF AA, VII, 084), sin embargo, esto no implica que él entienda también aquí por "progreso" un continuum lineal e incesante del mejoramiento moral de la especie humana desde los primeros tiempos hasta el presente. "Siempre ha habido progreso" significa, por el contrario, que en todos los tiempos ha sido posible para los pueblos, dadas las circunstancias, republicanizarse. El "progreso" no implica como antes la acumulación de experiencias pasadas, sino la irrupción impredecible de la causa moral en la historia.

\section{Bibliografía}

Primaria

KANT, Immanuel: Kantsgesammelte Schriften, Berlin, KöniglichPreussischen Akademie der Wissenschaften, 1900ss.

Ediciones en español

KANT, Immanuel: "Idea para una historia universal en clave cosmopolita”, ¿Qué es la Ilustración?, traducción de R. Rodriguez Aramayo y Concha Roldán Panadero, Madrid, Alianza, 2011. [Hemos introducido variaciones en esta traducción cuando lo hemos considerado pertinente].

KANT, Immanuel: "Teoría y práctica: En torno al tópico: esto vale para la teoría, pero no sirve para la práctica", traducción de Roberto Rodríguez Aramayo y Francisco Pérez Lopez, Madrid, Alianza, 2011.

KANT, Immanuel: La religión dentro de los límites de la mera razón, traducción de Felipe Martínez Marzoa, Madrid, Alianza, 1969.

\footnotetext{
${ }^{33} \mathrm{La}$ circunstancia de que el rol del explanans del progreso histórico recaiga en El conflicto sobre la disposición moral y no, como antes, en las disposiciones no morales permite quizás iluminar, al menos en parte, por qué -como han señalado tanto Brandt (2003) como Perez $(2006,2014)$ - Kant hace (mayor) uso de la figura de la "intención de la naturaleza" o "providencia" en los textos que van desde 1784 (Idea) a 1795 (Hacia la paz perpetua). Esto es así, sugerimos, porque las disposiciones no morales son características de la naturaleza humana que actúan tengan o no los hombres conciencia de ellas, el agente es aquí la naturaleza (humana) "no-consciente". En 1798, en cambio, puesto que la agencia histórica corre del lado de la disposición moral, el acento es puesto en los efectos conscientes de la naturaleza humana, esto es, en la acción colectiva y organizada de los hombres.
} 
KANT, Immanuel: El Conflicto de las facultades, traducción de Elsa Tabering, Bs. As., Losada, 1963. [Hemos introducido variaciones en esta traducción cuando lo hemos considerado pertinente.]

Literatura crítica

ARENDT, Hannah:Lectures on Kant's Political Philosophy, edited and with an interpretative Essay by Ronald Beiner, Chicago, The University of Chicago Press, 1982. Los textos citados provienen de la traducción de Carmen Corral: Lecciones sobre la filosofía política de Kant, Madrid, Paidos, 2003.

AXINN, Sidney: “Authority, and the French Revolution”, Journal of the History of Ideas Vol. 32 Nro. 3 (1971) 423-432.

BECK, Lewis. W.: "Kant and the Right of Revolution”, Journal of the History of Ideas Vol. 32 Nro. 3 (1971) 411-422.

BRANDT, Reinhard: Universität zwischen Selbst- und Fremdbestimmung. Kants >Streit der Fakultäten<, Berlin, Akademie Verlag, 2003.

COHEN, Alix: Kant and the Human Sciences. Biology, Anthropology and History, Hampshire, Macmillan, 2009.

FLIKSCHUH, Katrin: "Duty, nature, right: Kant's response to Mendelssohn in Theory and Practice III”, Journal of Moral Philosophy, 4 (2), 2007, pp. 223-241.

FLIKSCHUH, Katrin: "Hope or prudence? Practical faith in Kant's political thinking”, en Stolzenberg, Jurgen y Rush, Fred (eds.), Faith and Reason. International yearbook of German idealism 7, De Gruyter, Berlin/New York, 2009.

FOUCAULT, Michel, Qu'est-ce que les lumières?, Paris, Breal, 2004 [1983]. Se usa la traducción al español de Silvio Mattoni: “¿Qué es la ilustración?”, Córdoba, Alción, 1996.

GERHARDT, Volker: "Kulturelle Evolution. Philosophische Anmerkungen zu einem nicht erst seit Darwin aktuellen Programm", en GERHARDT, Volkery NIDA-RÜMELIN, Julian (ed.): Evolution in Natur und Kultur, Berlin, De Gruyter, 2010.

GERHARDT, Volker: Immanuel Kant. Vernunft und Leben, Stuttgart, Reclam, 2002.

GONZALEZ, Ana Marta, "Kant on History”, Estudos Kantianos, V. 2, N. 2, p. Jul./Dez. 2014, pp. 265-290.

KLEINGELD, Pauline: Fortschritt und Vernunft: Zur Geschichtsphilosophie Kants, Würzburg, Königshausen \& Neumann, 1995.

KUEHN, Manfred:"Reason as a species characteristic", en RORTY, Amélie Oksenberg y SCHMIDT, James (eds.), Kant's Idea for a Universal History with a Cosmopolitan Aim, Cambridge, Cambridge University Press, 2009, 68-93.

LEBRUN, Gérard: Kant et la fin de la métaphysique. Essai sur la Critique de la faculté de juger, Paris, Armand Colin, 1970.

LEBRUN, Gérard: "Une teléologie pour l'histoire? La première proposition de l'Idée d'une histoire universelle", en CLAVIER, Paul y WOLFF, Francis (eds.), Kant sans kantisme, Paris, Fayard, 2009.

LERUSSI, Natalia: “Acerca de una consideración naturalizada de la filosofía de la historia de Immanuel Kant. Epigénesis e historia universal", Cadernos de Filosofia Alemã, Vol. 20, Nro. 1, 2015, pp. 93-105.

LERUSSI, Natalia: "Unsocial Sociability, Human Nature and Evil”, presentado en el marco del VI KANT MULTILATERAL COLLOQUIUM: Kant on Violence, Revolution, and Progress: Historical, Political, and Metaphysical Themes, organizado por la Hofstra University, New York, 7-9 de agosto de 2016, inédito.

LYOTARD, Jean-François: L' enthousiasme, Paris, Galilée, 1986. Hay edición en español: El entusiasmo. Crítica kantiana de la historia, Barcelona, Gedisa, 1994. 
PEREZ, Daniel Omar: “Os significados da história em Kant”Philosophica 28 (2006) 67-107.

PEREZ, Daniel Omar: "Discussão. História e teleologia na filosofia kantiana. Resposta às críticas de Ricardo Terra contra a «Escola semántica de Campinas»”, Studia kantiana 16 (2006) 144159.

RECKI, Birgit: "Fortschritte als Postulat und die Lehre von Geschichtszeichnen", en GERHARDT, Volker (ed.): Kant im Streit der Fakultäten, Berlin/New York, De Gruyter, 2005.

RODRIGUEZ ARAMAYO, Roberto, "Right as a Sign of a Philosophical Chiliasm: Freedom and its Evolution in Kant's Opuscules", en VV.AA., Critical Paths outside the Critiques. Kant's Shorter Writings, Cambridge Scholar Publishing, New Castle, 2016.

STRAUSS, Leo: Persecution and the Art of Writing, Chicago/London, The University of Chicago Press, 1988, [1952]. Hay edición en español: La persecución y el arte de escribir, Madrid, Amorrortu, 2009.

TERRA, Ricardo: "A distinção entredireito e ética na filosofía kantiana”, en PEREZ, Daniel Omar (ed.), Kant no Brasil, San Pablo, Editora Escuta, 2005.

TERRA, Ricardo: "História e Direito em 1784. Comentários sobre a interpretação da «Escola Semântica de Campinas»", Studia kantiana 12 (2002) 175-194.

VAUGHAN, C. E.: Studies in the History of Political Philosophy before and after Rousseau, Manchester, A.G. Little, 1939.

WOOD, Allen: "Unsociable Sociability: The Anthropological Basis of Kantian Ethics", Philosophical Topics 19:1 (1999) 325-351.

WOOD, Allen: "Kant's Fourth Proposition: the unsociable sociability of human nature", en RORTY, Amélie Oksenberg y SCHMIDT, James (ed.), Kant's Idea for the Universal History with a Cosmopolitan Aim. A Critical Guide, New York, Cambridge University Press, New York, 2009 


\title{
Is it "impossible to will to be punished"? Exploring a consensual way out of the kantian dilema
}

\author{
MATÍAS PARMIGIANI
}

\begin{abstract}
In the Metaphysics of Morals Kant wrote that "it is impossible to will to be punished". The main goal of the present paper is to challenge this idea. In contemporary literature, a similar challenge was attempted by assigning a pivotal role to the notion of 'consent'. Therefore, focused on these antecedents, what I will try to do in this paper is to determine whether the notion of consent is capable of playing any role whatsoever in a justificatory theory of punishment.
\end{abstract}

Key words: Kant, punishment, consent, Nino, Finkelstein

\section{¿Es "imposible querer ser castigado"? Explorando una salida consensual del dilema kantiano}

\section{Resumen}

En la Metafísica de las Costumbres, Kant escribió que "es imposible querer ser castigado". El objetivo principal del presente trabajo consiste precisamente en desafiar esta idea. En la literatura contemporánea, un desafío similar fue asumido de la mano de la noción de 'consentimiento'. Pues bien, tomando como base estos antecedentes, lo que intentaré hacer aquí es determinar si la noción de consentimiento está capacitada para desempeñar algún rol en una teoría justificatoria del castigo.

Palabras clave: Kant, castigo, consentimiento, Nino, Finkelstein

I. Introduction: Facing Kant's Challenge

The idea that someone might will to be punished probably strikes us today as strange, nonsensical and counterintuitive as it must have struck people over 5000 years ago. With few exceptions, crimes tend to be anything but public, precisely because it is in the interest of the criminal not to be discovered. Crimes and secrecy go hand in hand. Concealment is what you reasonably need if you want to preserve untouched the benefits of your own offense. And since punishment seems to cancel these benefits, anonymity is what you will be looking for to avoid being caught and punished, as the Book of Job wisely put it in those early times:

There are those who rebel against the light, who do not know its ways or stay in its paths. When daylight is gone, the murder rises up, kills the poor and needy, and in the night steals forth like a thief. The eye of the adulterer watches for dusk; he thinks, 'No one will see me', and he keeps his face concealed. In the dark, thieves break into houses, but by day they shut themselves in; they want nothing

${ }^{1}$ Centro de Investigaciones Jurídicas y Sociales (Universidad Nacional de Córdoba) - CONICET. 
to do with the light. For all of them, midnight is their morning; they make friends with the terror of darkness (24).

Such a generalized idea happens to have kept its philosophical intuitive appeal as it travelled across time. In a famous passage from The Metaphysics of Morals, trying to take some distance from MarcheseBeccaria's position that those punishments (e.g. death penalty) that cannot be consented to in an original civil contract are wrongful, Kant vigorously endorsed it. He wrote: "No one suffers punishment because he has willed it but because he has willed a punishable action; for it is not punishment if what is done to someone is what he wills, and it is impossible to will to be punished" (MS 6:335).

Back to our time, the idea seems indisputable in the philosophical literature on the justification of punishment, with two apparent exceptions. As we will see in more detail in Part\$3, there are at least two philosophical approaches that decide to rest on the notion of consent to justify punishment. Nevertheless, given that none of them really have the intention of equating 'consent' with 'the expression of an individual's real will', or anything like it, in the end they both would prove to gowith the flow. In spite of its compelling character, the main goal of the present paper is to challenge the idea captured in Kant's claim. Now, what does it precisely mean to assume this challenge? What are its implications? To give a straight approximate answer that may be used as a guide from now on, it just means to try to determine whether the notion of consent is capable of playing any role whatsoever in a justificatory theory of punishment.

As abstract as it is, the question doesn't seem to contain anything of value. Different concepts of consent will be able to play different roles in different contexts, depending on what we purport to justify and how we pretend to do it. By the same token, there are certain contexts in which the concept of consent, no matter how it is defined, will not be able to play any justifying role. Thus, for example, if the normative order against whose background consent was given is morally bankrupt, "the moral magic of consent - as Kleinig adverts - will not work" (2010: 21). ${ }^{2}$ Therefore, in order to reduce the scope of the question, a safer and more appealing place needs to be sighted. Personally, I think this place is provided by the next opposition: on the one hand, what we may call a weak notion of consent, such as the one that sometimes happens to be at work in contract law as well as in tort law; and, on the other, a stronger notion of consent, understood as the expression of an individual's real will.

The paper is divided into three parts and a conclusion. In the next two parts ( $\$ 2$ and $\S 3$ ) I will explore the main attempts that can be and have been made to allow the concept of consent play a role in a justificatory strategy of punishment. Though we might be able to obtain from their analysis important conceptual tools to move forward, for different reasons none of them will prove to be successful. In part $\$ 4$ I present the stronger notion of consent and argue as if it were the only one in shape of providing the kind of unique and stringent justification that the infliction of punishment usually demands. After looking for some evidence in fiction stories as well as in real-life cases, I hope to show that an agent that wills to be punished is perfectly conceivable. Nonetheless, this circumstantial evidence under no concept shall lead us to believe that unless someone consents to her punishment, punishment would not be justifiable in her eyes, for this would make us face an unsolvable dilemma. Therefore, in order to bite the bullet without putting us in an untenable position, I would have to come up with anew conceptual strategy. Parts $§ 4$ and $§ 5$ (Conclusion) are meant to shed some light on it.

\footnotetext{
${ }^{2}$ In a Kantian vein, see Korsgaard 1986.
} 


\section{Why not the Esay Way Out?}

\section{II.1. Rawls's "Two Concepts of Rules": Delineating the Esay Way Out}

At least in one sense, to develop an explanatory strategy that successfully defies Kant's challenge is not a difficult task at all. It suffices if we manage to define 'punishment' in such a way that it leaves it virtually devoid of its most typicallystringent features. For the sake of clarity, I propose to consider such a moveas the easy way out of the dilemma. Unsound as it may look, the strategy has nevertheless left its mark in the philosophical tradition. Fortunately, there is no need to look far back into history, for something very much like it was outlined by John Rawls in "Two Concepts of Rules". Following Hobbes' definitionof punishment given in Leviathan, Rawls explains that a person is said to properly suffer punishment whenever the next provisions are satisfied:

(1) He is legally deprived of some of the normal rights of a citizen on the ground that he has violated a rule of law;

(2) The violation [has] been established by trial according to the due process of law;

(3) The deprivation is carried out by the recognized legal authorities of the state;

(4) The rule of law clearly specifies both the offense and the attached penalty;

(5) The courts construe statutes strictly;

(6) And the statute was on the books prior to the time of the offense (1955: 10).

For anyone familiar with the philosophical literature on punishment, the list ofprovisions accounted by Rawls in this passage can hardly be taken as conceptually sufficient. In particular, there are two missing conditions that cry out for admission: on one part, as Kant already knew, it must be granted that punishment be proportional to the offense (Kant convincingly argues in favor of this condition when discussing the iustalionis law) ( $c f$. MS 6:332); on the other part, punishment must express some sort of moral condemnation on the person of the wrongdoer ( $c f$. Feinberg 1971: 95118).

For the moment, I will set aside this second condition ( $c f$. infra). As regarding the first one, it is interesting to note that Rawls himself would have recognized its importance. In footnote $\mathrm{n}^{\circ} 14$ (1955: 12) of that very essay, he refers to the principle of proportionality as a requirement of justice that any system of punishment should abide with, trying to offer a response to David Ross's objection that such a principle would be conceptually incompatible with a purely utilitarian justification. Rawls argues that even if this principle did not havea place within utilitarianism as a requirement of justice, utilitarianism would be able to account for it in plainly prudential terms: apparently, imposing on someone a penalty much severer than his/her offense would be just as irrational as to use a cannon to kill a mosquito, and utilitarianism does always recommend to accommodate our preferences so they can be directed to the less serious possible evil (cf. Rawls 1955:12-13).

In Rawls'ss view, then, plainly prudential considerations seem to be in perfect shape to account for the requirement of justice. Anyway, assuming that such a move were accepted, the problem would still be how to pair off an offense and a penalty in such a way that a rational agent, situated under conditions of perfect enforcement, would not still be encouraged to break the law.As might be seen, the prudential coin chosen by Rawls exhibits a second prudential side. How severe do penalties have to be to deter possible offenders under conditions of perfect enforcement? As we know, Kant had a very reasonable answer to this question, which rested on the law of retribution (iustalionis). Nonetheless, it is not that answer that should distract us right now. Then, let us keep focusing on Rawls'ss explanatory scheme, for it is from it that there can be derived what I meant to call the easy way out of the Kantian dilemma. 


\section{II.2. On Willing and Prices}

In Rawls'ss scheme, punishment works just like any other behavior control system that may employ "threats to deter with various pragmatic or moral side-constraints on the execution of threats" (Hill 2000: 193). Rawls is explicit on this point when he says, precisely, that "punishment works like a kind of price system: by altering the prices one has to pay for the performance of actions it supplies a motive for avoiding some actions and doing others" (Rawls 1955: 12).At first glance, the actions that the system of punishment supplies a motive for doing are supposed to be precisely those that imply no penalty whatsoever, which is what a commonsensical reading of this passage would intuitively suggest. However, this is not the whole story. If punishment behaves like any price system and a criminal penalty is nothing but one kind of price among others, then there is nothing in Rawls'ss account to skip the inference that an individual may be willing to pay exactly the very same price fixed for a criminal offense.

Moreover, given the fact that punishment behaves like any price system, it is reasonable to assume that the same analytical tools that we employ to understand the willing behavior of any rational agent will be equally available when it comes to dealing with the willing behavior of a wouldbe punishable agent. To see that there is no contradiction in this approach, I propose to consider a seven-step practical syllogism (PRS), purported to shed some light on what it generally means for an agent to want (or will) something that can imply to pay a price which one may not be willing (or consenting) to pay for its own sake. Thus:

(PRS) S1: If agent $\boldsymbol{X}$ wants (wills) $\boldsymbol{P}$;

S2: It is highly unlikely that $\boldsymbol{P}$ be accomplished without implying $\boldsymbol{Q}$;

S3: In those rare circumstances in which $\boldsymbol{P}$ implies $\neg \boldsymbol{Q}, \neg \boldsymbol{Q}$ implies for $\boldsymbol{X}$ to bare such costs (measured in terms of actions,deprivations, responsibilities, sufferings, etc.), that $\boldsymbol{P}$ turns out to be much less rewarding for her;

\section{S4: It is highly unlikely that $\neg \boldsymbol{P}$ implies $\boldsymbol{Q}$;}

S5: There are compelling reasons to believe that $\boldsymbol{Q}$ can be afforded by $\boldsymbol{X}$; rather than $\boldsymbol{b}$;

S6: And, of the two next available scenarios $\boldsymbol{a}[\boldsymbol{P}$ and $\boldsymbol{Q}]$ and $\boldsymbol{b}[\neg \boldsymbol{P}$ and $\neg Q], X$ prefers $\boldsymbol{a}$

\section{C: Therefore, $\boldsymbol{X}$ wants (wills/consents) $\boldsymbol{Q}$.}

A few remarks are in order regarding how to read (PRS). Conceived in a purely utilitarian vein, $\boldsymbol{P}$ will be generally represented as a certain state of affairs ( $c f$. Williams 1997: 105). Of course, there might be other interpretations available over the table (cf. Foot 2002: 95-96; Sen 1979: 464465). But, even when therewere not, I think that the formula will receive a much more fruitful interpretation if the state of affairs it refers to is understood as the result of my involvement in certain kinds of activities. So, let $\boldsymbol{P}$ be, for example, the feeling of well-being that subjectively accompanies me as the result of practicing yoga. What I want, then, is not only a certain state of the soul; rather,it is the state of the soul that comes about as a result of doing a certain type of activity, that of practicing yoga. In relation to $\boldsymbol{Q}$, let it be the price that I have to pay to hire a certain instructor, whom I know from personal experience can provide me like no other with the kind of reward I expect. Being these the main ingredients of the story, we can arrive at the conclusion that it is impossible for me to obtain the rewarding state of the soul I expect from practicing yoga $(\boldsymbol{P})$ without paying what the instructor 
charges me as an exchange for his services $(\boldsymbol{Q}){ }^{3}$ If I want (will) $\boldsymbol{P}$ (S1) and $\boldsymbol{P}$ implies $\boldsymbol{Q}$ (S2), therefore, assuming that conditions S3 ...S6 are met, I want (will/consent) $\boldsymbol{Q}(\mathrm{C})$.

Probably the most important principle that inspiresa practical syllogism like (PRS) was raised, again, by Kant. ${ }^{4}$ In the Groundwork for the Metaphysics of Morals he wrote: "Whoever wills the end also wills (insofar as reason has decisive influence on his actions) the indispensably necessary means to it that are within his power" (GMS 4: 417). Based on this principle, Kant did also emphasize the fruitfulness of the strategy that compels us to interpret our ends as states of affairs that involve us in their production. Thus, he said that "it is one and the same thing to represent something as an effect possible by me in a certain way and to represent myself as acting in this way with respect to it" (GMS 4: 417). What he would have had to say, however, regarding each of the conditions (S2 ..S6) that must be met for conclusion (C) to be drawn is quite a different matter.

Details shall not distract us here. Once we set them apart, the key element is brought about by premise S5. In order to be willed, a state of affairs and each and every single one of the costs that it involves (deprivations, actions, responsibilities, sufferings, etc.) must be affordable by the agent. In the example given above, what this just means is that I must be absolutely capable of paying the instructor's fare; that is, despite how painful and troublesome the costs of affording it might be, they cannot be as high as to force me to reconsiderthe end's worthiness. To put it in Kantian terms, paying the fare (if that were the only cost implicated here, of course) should be within my power.

Now, turning back to the Rawlsian conception of punishment, some important clarifications need to be introduced. On this approach, punishment behaves like any other penalty, except for the six provisions that define its nature ( $f f$. supra). At the same time, a penalty would tend to behave like any other price system, were it not for the fact that the application of penalties (especially law-like ones) is generally ruled by a centralized structure very much like the one governing the application of punishment, whereas prices (especially in a free-market economy) respond to different standards. In order to be justifiable applied, however, a penalty does not always have to meet the Rawlsian provisions. Due in part to this sort of deeper liberalized nature that penalties and prices would approximately share, the Argentine Criminal Law Professor, Eugenio R. Zaffaroni, believes it necessary to keepthese concepts cautiously apart from the concept of punishment (cf. 2005: 71-72). For my part, and as long as the Rawlsian provisions are clearly set forth in advance, I have no quarrels with such an analogical way of understanding punishment. In fact, the notion of 'price' possesses such an open texture and malleability that it can come as no surprise to realize how it managed to function perfectly well in the widest possible range of contexts. However, once we get seduced by its fertility and assume the challenge to play with it in the criminal law context in particular, some precautions will have to be taken.

For instance, it would look mandatory to say at least a couple of words on the specific pricy nature of penalties. In modern economy, as has been extensively explained ( $c f$. Barnett 1992: 845; Kotler 1973: 408-409), money is what tend to govern most of our transactions, mainly because its quantitative character, its lack of ambiguity and its one-dimensional nature make it really easy for us to know for sure what to expect from each other. In addition, when a price is fixed for a product (or a service) and the product is in perfect shape, the transaction will be completed as soon as the price is paid. In the case of punishment, however, things are far from being that simple. When someone is sanctioned not merely with an economical fine (or with the loss of a license to run a business, for

${ }^{3}$ Many other examples can similarly do the job. For instance, let it $\boldsymbol{P}$ be to acquire a certain house in Park Migdia. Given that in this park I spent most of the happiest years of my childhood, living in that house would fulfill like no other alternative the dream of my life. Let it $\boldsymbol{Q}$ be interpreted, on the other hand, as paying its market price, which is 500.000 euros. Conclusion: it is impossible to fulfill the dream of my life without paying the house's market price.

${ }^{4}$ Originally I have chosen the verb 'to govern' instead of 'to inspire' to express the idea. Nonetheless, it is important to emphasize that Kant's principle is, so to speak, of a different scope than $(\boldsymbol{P R S})$. For further details on this point, see footnote 12 below. 
example), but with a curtailment of his freedom, what this would really imply can sometimes be very hard to tell. But even if that were not the case, what are we supposed to do with the expressive nature of punishment? Are we supposed to interpret it just as another typical transactional device? Regrettably, the expressive feature that is present in most of our forms of punishments does not seem to have a parallel in any other transaction. Moreover, it would be very odd if the blaming function of a specific kind of penalty such as is executed on a particular convicted felon would necessarily have to be interpreted as something that s/he must have accepted beforehand.

\section{II.3. An Analogy between Penalties and Prices}

Be it as it may, I truly believe that these important differences are no impediment to keep on strengthening the nuances of the analogy. It must be kept in mind that what we are trying to find out is a clear case of an individual that might be reasonably said to will (or consent) to be punished. Subsequently, once it is admitted that punishment behaves like a price system and prices are fixed on utilitarian grounds, a wide range of credible scenarios is open, in which there is always a chance of finding someone exhibiting a will to be punished. In $M S$, Kant gives many illustrative examples. In one of them, he urges us to consider the case of two men that may have taken part in the $18^{\text {th }}$ Century Scottish rebellion. One of them is a man of honor, whereas the other is a scoundrel. Kant says that if the penalty fixed for taking part in the rebellion had been convict labor, the scoundrel would have had more than one reason to peacefully embrace it (cf. 6:334). In a previous paragraph, he criticizes fines as the penalties to be imposed for verbal offenses with the argument that someone wealthy enough "might indeed allow himself to indulge in a verbal insult on some occasion" (MS 6:332). In this example, as will be easily seen, the rich man might indeed will (consent) to be punished, for here punishment seems to performthe same function that $\boldsymbol{Q}$ performs in our practical syllogism (PRS), namely -to say the least: punishment looks as unproblematically affordable by him (S5 clause). Unlike Kant, in Rawls'ss scheme cases like these are not at all hard to conceive.

At this stage of the exposition, what we need to do is to explain why such an easy way out of the Kantian dilemma does not look very promising. To do that, I propose to introduce an additional distinction that seems to be concealed in Rawls'ss scheme. Not surprisingly, it is a kind of distinction that Rawls himself succeeded in making during the years of philosophical labor that followed his 1955's essay and crystallized in A Theory of Justice (1971). In the shape I would like to introduce it, however, part of the credit goes to H.L.A. Hart. In "Bentham on Legal Rights" (1973), Hart makes a distinction between a concept of a legal right limited to "those cases where the law [...] respects the choice of individuals" and a more demanding concept of a legal right, designed to operate as the platform from where to monitor and morally criticize the law. Such a concept of right, Hart says, "is inspired by regard for the needs of individuals for certain fundamental freedoms and protections or benefits," which would not have been paid due care and attention by Bentham's utilitarian approach, exclusively concerned with the problem of how the law was supposed to "maximize aggregate utility" (1973: 200).

Following Hart, Rawls'ss himself and some others ( $c f$. Nino 1991), I would like to distinguish between what we may call non-negotiable fundamental rights, on the one hand, and negotiable non-fundamental rights, on the other. As clear examples of the first kind of rights, there can be mentioned, for instance, all the basic liberties that Rawls derived from his First Principle of Justice, such as the political liberty to vote and run for office, freedom of speech and assembly, liberty of conscience, freedom of personal property and freedom from arbitrary arrest ( $c f$. ibid: 53), among others. As clear examples of the second kind of rights, on the other hand, there can be mentionedmany of the most common or even trivial rights that I may have, such as the right to buy a ticket to fly to Hong Kong in business class or the right to have a date this very evening with the person I love. Some of these rightscan surely be derived from the liberties consecrated by the First Principle of Justice. Nonetheless, there are some other rights, like the liberty to "own certain kinds of property (e.g. means 
of production)" and the "freedom of contract as understood by the doctrine of laissez-faire" (ibid: 54), which are not derivable in this sense and are not, for the same reason, protected by the First Principle.

Without pretending this classification to be exhaustive, there seems to be a great difference not only in the way these kinds of rights are philosophically grounded, but also in the way they must be balanced to protect individuals against illegitimate hindrances of their freedom. In Rawls's Theory of Justice impressive account, whereas the list of primary goods is obtained as the result of a mental experiment that leaves mere considerations of preference satisfaction out of the picture, there is nothing there to prevent that at least an important part of the non-fundamental rights that a person must be recognized as having can be defended on a simple preference-based account of human welfare. After all, as Richard Arneson put it, once a fair background of fundamental human rights is granted, "each individual is responsible for developing a set of final ends and a plan of life to achieve them and for organizing her own life to satisfy this plan" (2000: 236). At this point, utility-based considerations are widely accepted.

Hence, when it comes to realize how to conceive a penalty, the deprivation of rights that it implies by definition (see supra, Rawls'ss provision 1) can be accounted for in two ways, as the aforementioned considerations seem to suggest: a) it can be accounted on a model of negotiable nonfundamental rights; or b) it can be accounted on a model of non-negotiable fundamental rights. If we choose the first model, a typical penalty will take the form, for example, of a deprivation of individual bodily movement's freedom, which is one of the most universal forms of punishment. On the contrary, if we decide to take side with the second model, typical penalties may be conceived in the form of fines, restitution, seizure of assets, and the like.

Assuming that a deterrent justification of punishment has some appeal, each alternative modeltaken in isolation will give rise to the next possible conceptions of penalties:

A) Penalties that trivially deter, because the price they fix for an action is established with the help of a negotiable non-fundamental rights model (grounded on a preference-based criterion of human welfare), and this price is highly enough as to discourage a reasonable agent provided with certain rights, preferences and resources.

B) Penalties that do not trivially deter, because the price they fix for an action is established with the help of a non-negotiable fundamental rights model (grounded on a nonpreference based criterion of human welfare), and this price is highly enough as to discourage a reasonable agent provided with certain rights, independently of her preferences and resources.

Related to A), it must be said that the deterrent function of a penalty grounded on a mere preference-based criterion of human welfare can be thought to be accomplishedmainly with regard to agents whose preferences and resources do not allow them to afford certain prices. Thus, be it a $\$$ 10.000 fine the penalty at stake for insulting someone. In conditions of perfect enforcement, the threat that it involves will mainly work for agents who, in spite of willing to break the law, lack the economic resources that would allow them to afford its cost.For these agents, such a penalty can hardly ever be a welcome consequence. That is why, in a scenario like this, it would be almost impossible to observe non-wealthy law-breaking people. Of course, if an agent possesses not many economic resources but sufficient enough to face the $\$ 10.000$ fine, once she decides to break the law it would be reasonable to conceive her willingness to be punished as a function directly derived from her own preferential background. Notwithstanding her relatively low level of resources, it is likely that she prefers a state of affairs in which she insults someone and pays the fine $[\mathbf{P}$ and $\mathbf{Q}]$ rather than one in which she does not commit the offense but keeps the money $[\neg \mathbf{P}$ and $\neg \mathbf{Q}]$. Meanwhile, for a wealthy law-breaking agent in conditions of perfect enforcement, the willingness to be punished seems indisputable. 
Conversely, in conditions of less than perfect enforcement, things are not that clear. In those conditions, the meaning of human acts tends to be highly and, sometimes, unyieldingly ambiguous (cf. Barnett 1992: 902). There, what both wealthy and non-wealthy agents may be said to be willing or preferring when they decide to break the law will usually be a purely speculative matter. Regarding non-wealthy agents, considerations of rationality will generally suggest that they are acting with the hope of circumventing the penalty. But what are we supposed to infer from the non-law-abiding conduct of wealthy agents? In conditions of uncertain enforcement, their actions may or may not signify a willingness to be punished. Likewise, what both wealthy and non-wealthy agents may be said to be willing or preferring when they decide to abide by the law will also tend to be a mere speculative matter. Just as there are prudential reasons, there are non-prudential or moral reasons as well. Ergo, it is possible that both wealthy and non-wealthy agentscould be moved from time to time to abide by the law when their preferences and resources push them in the opposite direction.

In contrast to $\mathbf{A}$ ), the $\mathbf{B})$ conception sees universal deterrence as a perfectly accomplishable enterprise, at least in theory. Be it, for instance, a one-year prison term the penalty to be imposed on whoever insults someone. In conditions of perfect enforcement, who could really dare to insult someone and be punished? The immediatereply would read: anyone who prefers a state of affairs in which she insults someone and receives a one-year prison sentence $[\mathbf{P}$ and $\mathbf{Q}]$ rather than one in which she abides by the law and keeps her freedom $[\neg \mathbf{P}$ and $\neg \mathbf{Q}]$. Yet, multiply that amount by two, by three, or by any number you want, and sooner or later you will find a penalty that no reasonable agent can be taken to assume, at least not on the basis of her trivial preferential background. Further in this paper, we will see the importance of this last clarification ( $c f$. infra). For the moment, it suffices to note why, according tothis conception of penalties, real personal preferences and resourcescan be accounted as almost practically irrelevant to determine how punishment must accomplish its proper deterrent function.

With regard todetermining the precise amount of a penalty for a given offense, the nontrivially deterrent conception recognizes a distinctively human characteristic that is totally absent in the other conception. In A Theory of Justice, Rawls built a philosophical device (e.g. the Original Position) to try to expose how it might be the case that the reasons to recognize a basic set of rights cannot rest upon mere preferential evaluations. Even if that account was far from raising total agreement among philosophers, other compelling arguments have been given to acknowledge such a basic set. ${ }^{5}$ On these accounts, the set of rights that we cannot do withoutis precisely the one that defines the autonomy of a person, being its presence the minimum standard requirement that must be granted for a human life to be worth living. Without autonomy, no one would be in the condition neither of pursuing the most ordinary life-plan, nor even to form a preference set order and live in accordance with it. ${ }^{6}$

Hereof, as soon as we are persuaded by the force of any of these arguments (and I truly believe that there are compelling reasons to be thus persuaded, though I cannot go here into further details), there seems to be similar powerful reasons to recognize that, in conditions of total enforcement, a system of punishment organized on a conception of penalties molded by a nonnegotiable fundamental rights' model is perfectly capable of accomplishing its deterrent function beyond human beings' contingent preferences. After all, how strong would have to be a preference to

${ }^{5}$ The list of arguments that have been given in the philosophical literature is immensely huge. Some of the most deeply discussed, for instance, appeared in: Raz 1979; Sen 1982; Höffe 1989; Nino 1991; Barry 1995; Wall 1998; Scanlon 1998. But there have been others indeed. Here it suffices to note that the need to recognize a basic set of rights as defining the contours of an autonomous agency has been widely acknowledged, although there reigns no unanimous agreement over which specific rights must be part of this set. For my argument, that contention has no further implications.

${ }^{6}$ In Not Just Deserts (1990), this basic set of inalienable rights is conceptualized as constituting not the freedom (or autonomy) bu the dominion of a person, which is a notion deeply embedded in the republican tradition of political philosophy. I will have the chance to rescue additional elements form Braithwaite and Pettit's republican theory of criminal justice along subsequent sections of this paper. 
motivate someone to withdraw nothing less than what enables her not only to form most of her preferences but to live by them?

In conditions of partial enforcement, it is out of discussion how non-trivial penalties accomplish their deterrent function. There too will one observe the presence of wealthy and nonwealthy agents trying to break or abide by the law. And there too will often be their preferences and motives (prudential as well as non-prudential ones) the ones that decide the bestcourse of action. When moral reasons are absent and a preference set order motivates a law-breaking conduct, what happens next is always a complex matter. If the threat of punishment istoo weak, there will be probably too many agents disposed to break the law. If the threat is stronger, there will be fewer. How many law-breakers there could be, however, will always be a varying issue, depending on many intervening factors. Amongst them, there can be mentionedfrom personal conditions determining the agents' resources ortheir level of risk aversion, for instance, to institutional conditions, such as the effectiveness of the police authorities to catch criminals or the way the procedural criminal system works. All of these factors operating together will contribute to determine the price that a would-be offender is able to pay within a system of punishment in conditions of partial enforcement. That price, indeed, will be unknown most of the time. But the most important corollary of this section has to do with what can be said of an offender's presumed willingness when she commits an offense. And I am sure that the intuition many of us deeply share is that, in a system like this, it is highly unlikely that an offender might be taken to express a will (or consent) to be punished.

\section{II.4. After All, Why not the Easy Way Out?}

In Rawls'ss scheme, where punishments are equated with penalties and penalties are equated with prices, there is not the slightest chance of telling what exactly is that distinguishes a criminal system of penalties enforcement from other penalties enforcement systems, such as those that are so common in contract law and tort law. The reason for this silence has to do in part with something already seen at the beginning of this section (cf. supra, 2.1), when it was suggested that Rawls'ss definition of punishment omits two important features that cry out for recognition: an adequate principle of proportionality and the assignation of an expressive function to penalties.

In relation to the principle of proportionality, what I tried to show is that Rawls'ss utilitarian scheme indirectly accounts for it (cf. supra, 2.1). An adequate account, however, would require not only to establish how much is too much but also how much is too low regarding the nature and amount of a penalty, and here is where Rawls'ss account fails. Again, when punishments and penalties are equated in conformity with the price analogy, some precautions will have to be taken. To begin with, one would need to account for the difference between trivial and non-trivial prices (or penalties). A trivial price (or penalty), as I said above, is a price that any agent holding certain preferences and resources might be willing to pay, even in conditions of less than perfect enforcement. But if a non-trivial price is, on the other hand, a price whose value no reasonable agent would be willing to afford, despite her preferences and resources (and in conditions of perfect enforcement), then there is probably something there that can give us the key to try to finally understand the distinctive nature of a properly criminal penalty.

In relation to the other crucial feature, Rawls'ss silence is even more revealing, for it shows in what sense an adequate account of criminal penalties cannot do without a certain conception of criminal offenses.According to the Kantian scheme, for instance - which we do not have to accept, of course -a crime is any transgression of public law that "makes someone who commits it unfit to be a citizen." (MS 6:331) In his own terms, what separates a criminal transgression of law from a noncriminal one (e.g. a civil transgression) isthat, whereas a criminal transgression endangers the commonwealth, a non-criminal one just endangers an individual person ( $c f$. ibid.) As I said, we are 
not compelled to accept such a scheme. Nevertheless, something like an explanation must be given of what it makes of a simple offense a properly criminal offense.

In my view, which is derived from what have been said in a previous section of this paper (cf. supra), the distinctive nature of criminal offenses has mainly to do with the kinds of personal rights and goods that are affected by them. Here I cannot enter into details, but in general I tend to think that the non-negotiable fundamental rights that constitute the heart of a person's autonomy are precisely those that a criminal justice system will want overwhelmingly to protect. ${ }^{7}$ In this context, the expressive function of penalties becomes salient, for they will not merely purport to prevent future offenses or to restore a lost equilibrium, as would be the case, for example, if we were working within a corrective justice theory of tort law -according to which the plaintiff is supposed to be returned to her status quo ante ( $c f$. Goldberg and Zipursky 2012: 25). Instead, penalties will mainly purport to communicate a message that something significantly wrong has been done. Morality, in any case, will have to enter the picture. ${ }^{8}$

To sum up, attending to these differences, it can be helpful to trace another distinction, namely that between what may be called Trivial Systems of Punishment (TSP) and Non-trivial Systems of Punishment (NSP). A TSP will be, in general, any system of punishment that satisfies the Rawlsian definition. In order to be a TSP, it suffices if a system reunites all the features captured in Rawls'ss definition of punishment, including a proportionality test based on a utilitarian preferencecentered account of penalties. And, as can be inferred, it is not necessary for it to embrace a Feinberginspired condition, which demands the presence of an expressive element in every kind of penalty. Furthermore, a TSP is, in principle, easily compatible with any penalties enforcement lawlike systemthat may have as its central function to rectify or correct harms. In this sense, a contract law enforcement system as well as a tort law enforcement system can both be considered to fit in perfectly well with the characteristic normative structure of TSP. ${ }^{9}$

On the other hand, a NSP will be, by all means, any system of punishment satisfying the Rawlsian definition, but with a double surplus-condition: a) it must include a proportionality test that pairs off penalties and offenses on a non-merely preferential account of penalties, be it utilitarian or

\footnotetext{
${ }^{7}$ Here I am in broad agreement with Braithwaite and Pettit's position, though the concept they use is not 'autonomy' but 'dominion'. As they say, the evil associated with central cases of crime implies the invasion of dominion, which is constituted by an agent's person, province and property. Crimes such as murder or rape trespass against the victim's person; crimes such as kidnap or harassment trespass against the victim's province; and crimes such as burglary or theft trespass against the victim's property ( $c f$. 1990: 69). What specific kinds of trespasses should be criminalized and how they should be so, however, raise quite different and intriguing questions indeed. Braithwaite and Pettit reasonably believe that in order to promote dominion - or to minimize its invasion - "criminalization is not the only way of inhibiting behavior; indeed it is probably the most clumsy and intrusive means available to the state" (1990: 71).

${ }^{8}$ On Goldberg and Zipursky's philosophical account of tort law, it is wrongs and not simple harms or losses what tort law is mainly about, where a wrong implies a "breach of a duty not to harm [..] through careless conduct." (2012: 35) At face value, it seems as if there was nothing really significant in this theory to account for the distinctive wrongness of criminal offenses. Indeed, as the authors explicitly recognized at the end of their paper, one of the main functions of a system of tort law is to further those values that morality tends to regard as important, "such as liberty of action, security against injury, attention to the interests of fellow-citizens, and the like." (ibid: 37) The furtherance and protection of these values, as they call them, seem to coincide, precisely, with the aim I have assigned to a criminal justice system. Is this not an unwelcome consequence for a view like my own? The key element to understand why it is not, I think, is provided by the same authors, who say that the distinctive characteristic of a tort law system is to further these ends by empowering individuals (not government officials) to hold wrongful injurer responsible to them ( $c f$. ibid: 27 ; 37). In contrast, a criminal justice system will try to accomplish this task even when the victims were not able to see that they were injured. It is the state, and not individuals, that must decide when a wrong was committed and when a value needs to be reassured. The difference between the two kinds of wrongs, then, is quite obvious. Behind the tort law conception of wrongs, there lays a defeasible conception of values, which means that unless individuals decide to seek redress they will not be fulfilled ( $c f$. ibid: 37). On the contrary, behind the criminal law conception of wrongs, there lays a non-defeasible conception of values, which means that there are some values that cannot be violated, no matter what.

${ }^{9}$ Imagine that a criminal justice system is built in such a way that the penalties it distributes among citizens can be afforded with the help of insurances. In principle, a system like this seems perfectly capable of meeting each and every single one of the conditions enumerated by Rawls in his definition of punishment. However, even in a system like this, not every claim would be of a kind that could be met by insurance ( $c f$. Williams 1993: 70). What are we supposed to say, for example, about those claims looking for an apology? What about repentance? Can we try to live within a system that ignores these social functions?
} 
not $^{10}$; and b) it must also embrace a Feinberg-inspired condition, which here means that the expressive element of condemnation be not simply directed to the contingent unreasonableness of the agent but to her moral status. By the way, in order to avoid confusion it must be noticedthat it is not only our current systems of punishment - as we actually know them - those that will fit in with a NSP structure. Assuming that we adopt a philosophical approach to tort law à la Goldberg-Zipursky (e.g. a civil recourse theory) ( $c f .2012)$, then many of our civil law enforcement systems will also fit in with thetypical NSP's normative structure. For our present purposes, such a disappointing implication can be regarded as totally innocuous. ${ }^{11}$

Now, if we come back to our original question and ask again how the Kantian dilemma can be solved, the answer seems quite obvious. Within a TSP, it can perfectly be the case that an offender may want (will/consent) to be punished, depending on factors such as her preferences, her resources and the enforcement characteristics of the particular criminal justice system to which she might belong. This is what I meant to call the easy way out of the dilemma. ${ }^{12}$ By contrast, within a NSP, as I tried to argue, things look radically different. Indeed, within a system like this, a promising way out of the dilemma seems at least rather problematic to foresee. Notwithstanding these impediments, there are at least two theories that tried to defendthe view that the best way to justify the infliction of punishment, where punishment must be interpreted as operating within a NSP's sort of system -even in conditions of partial enforcement, is by appealing to the offender's consent. In the next part I will try to assess these approaches in a critical way, showing that the notion of consent that they work with is conceptually spurious and justificatory inert, for it has nothing to do with the notion of consent that typically plays a justifying role, for instance, in a contract-law context.

\section{The Consensual Way Out}

Deterrent justifications of punishment have exerted a wide and deep influence among philosophers. In Rawls'ss case, as we saw above, that influence was incontestable, especially in his younger years. In more recent days, and in spite of the several objections that were raised against it, deterrence could manage to keep its philosophical appeal. Probably the most serious of these objections has an undeniable Kantian flavor, and it was raised even by those who defended a consequentialist justification of punishment but at the same time feared that it could infringe the moral imperative prescribing that we should never treat people merely as a means.Especially for some of those deterrent theorists who share this fear but do not dare to fall in the hands of retributivism, which was Kant's choice, a consensual justification of punishment was the right way to go.

In the present part, I will briefly analyze two of these justificatory strategies: Claire Finkelstein's and Carlos Nino's. What would lie behind them both is a fairness owed to consent's approach to social morality ( $c f$. Honderich 2006), according to which once an individual has given

${ }^{10} \mathrm{Cf}$. Williams 1973, where the author denies the possibility of a non-preferential account of practical justification conceived in a utilitarian vein. According to me, utilitarianism can do much more than that but it is not my intention in this paper to further argue in this direction.

${ }^{11}$ For further details on this discussion, seefootnote 7 above. On the other hand, Braithwaite and Pettit seem to have in mind a similar NSP model of a criminal justice system when they analyze the different sorts of sentences that should be permitted or enjoined (see 1990, Chapter 6, Section 2). In accordance with their previous distinction relative to what counts as an agent's dominion (cf. supra, footnote 4), Braithwaite and Pettit write that "the punishments imposed by courts can be neatly divided into three kinds, turning on our earlier distinction between an agent's person, his province, and his property" (1990: 102). Of the three kinds of penalties, however, the last one (in the form of fines, restitution, or seizure of assets) is also compatible with a TSP model. ${ }^{12}$ In a comment made on a previous version of this paper, José Juan Moreso suggested that from the novels of the $18^{\text {th }}$ century we know the behavior of people disposed to commit minor crimes with a view to go to jail and spend the winter period there. In 2010, The Guardian newspaper said that a "fifth of homeless people have committed imprisonable offences to spend a night in cells" and "crime plays a big part in rough sleepers lives". Nearly $30 \%$ of them admitted that they had committed a "minor crime such as shoplifting or anti-social behavior in the hope of being taken into custody for the night". Therefore, it is undeniable that there are cases in which people commit crimes with the only intention to be punished. However, my contention here is that although this kind of information can perfectly accommodate a TSP, it cannot accommodate a NSP so easily, which is what I try to argue in the paper. I would like to thank José Juan Moreso for raising this as well as other important issues. 
his/her consent to be deprived of some good, any objection to such a burdensome state of affairs will remain, prima facie, out of place. Whether punishment can be one of these burdensome states of affairs, however, is what I would like to challenge from now on. Of course, neither Nino nor Finkelstein seem to be suggesting that in order to offer a prominent account of justification, the concept of consent must be the expression of an individual's real will or anything like it. Quite the contrary, they both conceive its justificatory function as operating at a different level. Here, my main purpose will consist in showing that, even if we take these attenuating moves into consideration, consent to punishment will remain looking in our eyes as strange, nonsensical and counterintuitive as it must have looked to people over 5000 years ago.

\section{III.1. Finkelstein’s Consensual Proposal. Why not?}

As the partial deterrent theorist she recognizesherself to be, Claire Finkelstein sees a crucial defect in any purely deterrent account of punishment. Resting on Rawls'ss terminology, she attacks any account like this by saying that it violates the "no traveling across personsrestriction", which establishes the impermissibility of making someone suffer in order to prevent some other agents from suffering (2005: 212). Such an objection has been so extensive and persuasively defended in the literature that it is not my intention here to sound reiterative (see, for instance, Rawls 1971: 27; Nino 1983: 183-84; Finkelstein 2005). It is much more important for our present purposes to assess Finkelstein's own proposal to overcome it. Labeled by her as a contractarian approach or, alternatively, as a consent-based approachto punishment, what it maintains is that "the way in which the aim of deterrence is incorporated into punishment theory is not premised on total, or even average, social utility, but on the assent of each individual to the scheme by which such deterrent ends are pursued" (2010: 320)

In order to find out what this precisely means, we need to take a look into her main philosophical assumptions. Finkelstein begins again with the Rawlsian idea that society is itself "a cooperative venture for mutual advantage" (Rawls 1971: 4) and reasonably interprets it as implying that "society is the product of agreement among rational agents who see themselves as advantaged under the terms of social interaction, using as a baseline how they would fare in its absence" (Finkelstein 2005: 214). Immediately after that, she adds that one might even depart from Rawls and treat his idea "as something in the nature of a requirement for the basic institutions and practices that make up the fabric of social interaction" (ibid.). And then she asks: what basic institutions are supposed to be agreed upon by rational agents that are meant to decide when they will be better off? Amongst the basic institutions that agents will probably select,there is, of course, the institution of punishment, for it is reasonable to assume that each and every single one of them will be left better off than they would be in its absence ( $c f$. ibid.: 215).

So far, everything seems to be in perfect order. Given that without an institution like punishment members of a social order would have no way of ensuring compliance to the terms of the agreement, punishment passes the benefit test and thus becomes justified ( $c f$. ibid.). This compliance, it must be noticed, would not be possible if punishment did not make its job through the deterrent function that its threat supposes. However, what about the "traveling across persons" objection? In Finkelstein's view, the consensual nature of punishment defeats the concern because "each party to the social contract agrees that he will submit himself to punishment in the event that he would violate the conditions of the social contract". Indeed, she emphasizes, "it is this self-imposed threat that he offers to his fellows as his assurance that he will not defect", to conclude that "punishment itself is legitimate to inflict, not because it deters others, but because it has already been consented by the offender himself' (ibid: 217).

As I said in the introduction to this part, my reply to Finkelstein's proposal will be very brief. In particular, the only thing that really worries me is related to the kind of consent chosen to do 
the justificatory work. There is one line of criticism that is not going to be here of my direct concern but that is nonetheless worth mentioning. Finkelstein's notion of consent is, in a way, exactly like the notion Rawls employs in the Original Position's argument, namely a hypothetical notion of consent. It has been convincingly argued that such a notion, taken in certain contexts, becomes absolutely unfair when is used to justify the imposition of significant losses on real people, disregarding their tastes, preferences, social positions, and the like ( $c f$. Scanlon 1982: 122-33; Wannberg 2003: 32). This line of criticism, however, would apply to Finkelstein's approach if and only if it pretended to conflate into one single notion the will of the offender as a social contractor and the will of the offender qua offender. I think that a charitable reading of her position can avoid this undesirable consequence, making it plain that when she refers to the consent of the offender, the reference is given by his will as a social contractor -full stop.

The problem is that once we accept this charitable reading, we are unable to provide an answer to the "travelling across persons" objection, which is, as a matter of fact, the very motive that triggered her own ameliorating proposal. Indeed, the notion of consent that Finkelstein develops to justify punishment is in principle replaceable by any act of the will of a hypothetical contractor trying to make up his mind in an original social contract. That very act, nevertheless, exhibits no differences whatsoever if we compare it to the act of will that can lead a rational agent to choose and be guided by institutions such as tort law or contract law. For the sake of the argument, let us just focus on this second kind of institution. When someone signs a particular contract and accepts a given authority to enforce it, what is he supposed to be doing? What is his will's content? Are we supposed to believe that he is expressing consent to be guided by a social institution such as the one that made it possible to sign not only this but any other possible contract? Maybe that is true, but in no sense does it offer the slightest clueto help us start justifying the enforcement of that specific contract on that particular occasion.

With the notion of consent that happens to be at stake in Finkelstein's justificatory approach the problem is almost the same. In order to determine how and why that particular criminal offense has to be punished, the consenting will of the offender as a social contractor is not relevant at all.To put it in Kantian terms, it is his phenomenological will that we are interested in, not his noumenal one. In fact, that is precisely the argument that Kant offers in $M S$, when he says that one thing is to will to be punished and quite another is to will a punishable action. Thus:

As a colegislator in dictating the penal law, I cannot possibly be the same person who, as a subject, is punished in accordance with the law; for as one who is punished, namely as a criminal, I cannot possibly have a voice in legislation (the legislator is holy). Consequently, when I draw up a penal law against myself as a criminal, it is pure reason in me (homo noumenon), legislating with regard to rights, which subjects me, as someone capable of crime and so as another person (homo phaenomenon), to the penal law, together with all others in a civil union. [...] For, if the authorization to punish had to be based on the offender's promise, on his willing to let himself be punished, it would also have to be left to him to find himself punishable and the criminal would be his own judge (MS 6:335).

Finkelstein's approach, unfortunately, has proven to be too ideal to provide an answer to the Kantian dilemma. Naturally, since Finkelstein's intention has never been to accomplish such a task, there is no reason to blame her for not doing so. The possible success of her approach can only be measured against the benchmark of herown attempt to meet the objection against the purely deterrent account. It was in relation to that attempt that her notion of consent was introduced. However, even if we are guided by that criterion, her proposal does not improve, for it is her notion of consentthe one that is conceptually spurious and justificatory inert. In what comes next we will try to see whether Nino's approach is better suited to deal with the 'travelling across persons' objection' problem, providing a more robust notion of consent. 


\section{III.2. Nino's Consensual Proposal. Why not?}

In Towards a General Strategy for Criminal Law Adjudication (TGS) (1977) as well as in a plurality of essays coping with different criminal topics (the death penalty, drug abuse, proportionality between harm threatened and harm averted, self-defense, etc.), but mainly in "A Consensual Theory of Punishment" (1983), Nino has tried to offer a twofold justificatory approach to the practice of punishment. On the one hand, as I said above, Nino openly confesses his keenness on the typical deterrent justification addressing consequential considerations of social protection. Yet, aware at the same time that a purely utilitarian justification of punishment could be objected on behalf of the Kantian worry that we should never treat people merely as a means, Nino offers, on the other hand, a consensual type of justification whose main desideratum goes exactly as follows: "The fact that the individual has freely consented to make himself liable of punishment (by performing a voluntary act with the knowledge that the relinquishment of his immunity is a necessary consequence of it) provides a prima facie moral justification for exercising the correlative legal power of punishing him" (Nino 1983: 299)

As might be seen, two are the conditions Nino seems to have signaled as shaping the definiens of consent: (1) a voluntary act (which here means, essentially, a free and not coerced act) plus (2) a certain knowledge or foresight of the normative consequences that it leads up to (which in the case of punishment means, as seen earlier, a relinquishment of immunity to punishment, 'which is to say to the gaining of a power by officers of the society') (Honderich 2006: 50). Moreover, were these not the defining conditions of consent, it wouldn't have made sense that Nino had chosen to appeal in TGS to an analogy: "It is a matter of positive law -he wrote as a way of illustration -that (...) taking something off the shelf of a supermarket involves the obligation to pay the price, that accepting to travel with a drunk driver means (according to some opinions) to waive the right to compensation in case of accident, etc." (Nino 1980: 231)

Based on this analogy, some interpreters noticed that the concept of consent that Nino imagined to play a role in justifying punishment was the notion of 'tacit', 'alleged' or 'ex actionem' consent ( $c f$.Boonin 2008: 164; Malamud Goti 2008: 227-255; for a contrary view, see Imbrisevic 2010), a notion that, as we all know from Locke, raises a number of semantic problems whose severity is not to be taken lightly (Second Treatise on Government, §119; see also Simmons 1993: 8387; Lloyd Thomas 1995: 39; Boonin 2008; Imbrisevic 2010: 213-214). These specific semantic problems, however, will not be here of my concern, for I am manly interested in the analogy that Nino draws between contract law (and tort law), on the one side, and criminal law, on the other. Based on it, consent to punishment is paralleled, for example, to the assumption of risk that takes place whenever one gets involved into dangerous activities which may require our waiving the right of compensation in case of an accident. Thus, assuming that the criminal act was voluntary and made after having the chance to foresee the normative consequences it may lead up to, punishment for that act is supposed to be objectively consented.

At first glance, it gives the impression as if Nino's notion of consent were conceptually stronger than Finkelstein's one. Hence, whereas Finkelstein's approach failed because it merely seemed to rest on the noumenal will of the offender, in that sense Nino's approach seems to be better suited to do the justificatory work. To say it again using Kant's terminology, his approach seems to have been conceived not for the noumenal but for the phenomenological world instead. And taking into consideration that it seems to have been conceived to operate withina NSP in conditions of less than perfect enforcement, Nino's justificatory strategy appears to be even more ambitious from a practical point of view. Unlike Rawls, Nino is perfectly aware that punishment cannot be equated with a simple monetary fine. Punishment implies the infliction of great suffering on the person of the wrongdoer, which is why it demands a special kind of justification. In any case, the problem with it would lie, as I will try to show as briefly as I can, in the analogy on which it rests. My humble 
purpose until the end of the section will be to debunk Nino's account by challenging the nuances of his analogy.

Recall again what it was said in a previous section regarding the analogy between penalties and prices (cf. supra). Mutatis mutandis, something similar is valid in the present context. Before consent can find its place in a general justificatory strategy of punishment, a lot of extra work needs to be done to allow the types of actions typically involved in each area of law run in parallel. Nonetheless, for reasons that have mainly to do with the characteristic elements that define the nature of each activity, such a work will prove in the end to be hopeless. Just to take a simple case by way of illustration, think of those dangerous activities, such as undertaking a life-saving surgery or the practice of extreme sports. While the risk involved in those activities is a non-dissociable part of their nature, the greatest risk associated to criminal activities - e.g. punishment - usually depends on what the state does as the agency that claims the monopoly of violence. Indeed, while it wouldn't make any sense at all to get involved in a naturally risky activity without somehow accepting to pay its costs, it makes perfect sense to commit a crime - or an action deemed criminal - without accepting to bear its merely contingent consequences.

Our (PRS) practical syllogism can be of help here too. If we say that agent $\boldsymbol{X}$ wants (wills) to practice parachuting $(\boldsymbol{P})(\mathrm{S} 1)$ and that it is highly unlikely that practicing parachuting $(\boldsymbol{P})$ can be accomplished without implying a certain risk to be seriously injured as a consequence of a failure in the parachute mechanism $(\boldsymbol{Q})(\mathrm{S} 2)$, therefore, if conditions (S3 ...S6) are met, we can arrive at the conclusion that agent $\boldsymbol{X}$ will consent to assume that very risk $(\boldsymbol{Q})(\mathrm{C})$. In such a case, of course, consentinghas a lesser practical status than wanting or willing, which is the proper status that comes withsome of our subjective attitudes in regard to certain affordable prices (see again our practicing yoga example, cf. supra). However, a conceptual difference like this, rather than invalidating the analogy, makes it even more interesting, for it paves the way towards achieving a more compelling case for consent to punishment. It must be noticed by the way that, according to Nino, it is not necessary that a positive subjective attitude be found in the offender for consent to punishment to be possible. Quite the contrary, as Imbrisevic remarks, "I can consent reluctantly - and even without hiding my reluctance" (2013:115); moreover, I can consent less than wholeheartedly, for example with grudging acquiescence or even out of indifference (Barnett 1992: 866). In none of these cases, however, the phenomenological character of the subjective attitude would turn it into less consensual.

With these clarifications in view, let us try to apply our syllogism to Nino's account. What would the first premise (S1) be? What isthe $\boldsymbol{P}$ that $\boldsymbol{X}$, the offender, may be said to will? Assuming that it is the state of affairs that is brought about as a consequence of his implication in a criminal activity, like the money he could get from assaulting a bank, the conclusiveness of the syllogism will depend on what we say next to interpret $\boldsymbol{Q}$. For the sake of the argument, let it be the risk of being caught by the police authorities and then prosecuted by the public officials of the state. If it is highly unlikely that $\boldsymbol{P}$ be accomplished without implying $\boldsymbol{Q}$ (S2), then, as in the case of practicing parachuting, it is reasonable to presume that the willingness of $\boldsymbol{P}$ will be tied to the risk's materialization degree. When the risk is too high and can be known in advance (for example, when the parachutist knows that the parachute mechanism is not well-designed or whatever / when the offender knows that the enforcement conditions are almost perfect), the willingness of $\boldsymbol{P}$ (let us say, the enjoyment of free falling / the enjoyment of money) might be seriously distorted. ${ }^{13}$

\footnotetext{
${ }^{13}$ As one of my anonymous referees wisely noticed, there seems to be an important difference between saying of an agent who decides to practice an extreme sport that she assumes the consequences that may be generated as a product of it, and saying that what she is actually doing is to want certain necessary means to her end, which is actually the Kantian claimbehind the practical syllogism. Recall, however, that whenI refer to the parachute case, for instance, I do not take for granted that what the agent want are the consequences of her actions, which might be sometimes almost impossible to predict. Here we should be very careful to draw a line of separation between the predictable risks associated with an action and the real consequences that are materialized afterwards. My argument rests on the former, not on the latter. Of course, the risks assumed when doing $\mathrm{X}$ with a given end in
} 
In contrast, let us suppose now that the risk $(r)$ is too low and can be known in advance with an important degree of certainty. Reasonably, agent $\boldsymbol{X}$ may still want $\boldsymbol{P}$ and can bet for her action vigorously, with the hope that $(r)$ never materializes. If, for whatever reason, $(r)$ finally materializes and the state of affairs $\boldsymbol{P}$ is not realized, there are some cases in which we would still be willing to say of agent $\boldsymbol{X}$ that she wanted to doexactly what she did, even when that produced a different outcome. Regarding the parachute case this is perfectly clear. Once we are certain that the parachute failed because it was in the nature of its mechanism to fail and there was nothing within $\boldsymbol{X}$ 's power to prevent that failure, it is perfectly legitimate to affirm that $\boldsymbol{X}$ has no motives to blame herself for having acted as she did. Indeed, that is the reason why we might even dare to say that $\boldsymbol{M}$ [namely the materialization of risk $(r)$ ], was consented by $\boldsymbol{X}$, although $\boldsymbol{M}$ implies $\neg \boldsymbol{P}$.

Regarding the criminal case, however, things are not that simple. In order to be able to say of an offender $\boldsymbol{X}$ that he has no motives to blame himself for ending up in prison, which is what $\boldsymbol{M}$ generally implies here, there must be granted that $\boldsymbol{X}$ didn't do anything wrong to give rise to the unwelcome outcome. ${ }^{14}$ However, when it comes to determine the risks that are materialized when a criminal act is committed, in a vast amount of occasions it would look as if the offender could always have done something different to avoid being caught. This impression is confirmedevery time we get to the conclusion that the offender behaved in a careless way, or even out of ignorance of the possible consequences of his acts. But not everything has to be the offender's fault after all. In contrast to the parachute example, in criminal contexts it is sometimes very hard to tell what the risks of being caught are for breaking the law. Our criminal systems tend to be inherently stochastic in their functioning, which means that no one (perhaps with the exception of a few authorities) is ever capable of determining with precision what will happen.In those contexts, it would seem rather unnatural to say of an offender that he has consented to go to prison, even if going to prison was one of the possible implications of his actions.

Compared to the notion of consent that was operating in the original practical syllogism $(\boldsymbol{P R S})$, the notion of consent we have arrived at in the end looks indeed very peculiar, to say the least. Consent is here equated with the absence of reproach for how things unfortunately turned out to be in spite of my preferences and actions. Such a notion, of course, should not be mistaken for conformity with respect to a certain state of affairs, for there is nothing in the resulting state of affairs that actually conforms to my desires. But given that, as Williams would say it, "I acted and deliberated as well as I could, and it is sad that it turned out that way" (1993: 69), there certainly is a kind of conformity with myself, a kind of irremediable and peaceful acceptance of the circumstances, that will not always be present in the post-factum evaluative stance of the punished offender. Quite the contrary, even after doing his wrong, the offender will probably struggle to evade punishment by defending himself in a fair trial according to the due process of law. And even after being declared guilty, if he were given the chance to escape, he would probably take it ( $c f$.Honderich 2006: 51).

Nino's consensual theory of punishment is more than aware of that peculiarity. For this reason Nino has repeated many times how his notion of consent was supposed to be interpreted. When someone commits a criminal act, what he shall be taken to be consenting to through the act per seis a relinquishment of immunity to punishment, which only means that he is renouncing to the righthe would otherwise have to demand from the officers of the society a kind of redress for inflicting him that sort of wrong. If we assume the validity of this explanation, it would give us a way of justifying the loss of that particular right. The offender justifiably loses a right because he has

view do not coincide with the means to further that very end, which is Kant's point. But that is precisely the reason why, when presenting $(\boldsymbol{P R S})$ in the original version of this article, I should have writtenthat it wasinspired by the Kantian principle, instead of governed by it -as I actually did (cf. supra, 2.2, especially footnote 3above). I would like to thank my reviewer for noticing these differences, which allowed me to improve this presentation.

${ }^{14}$ Blame, as might have been guessed, is not being used here as a moral notion. For a more comprehensive notion of blame, see for example Williams 1995 and Sher 2001. 
consented to lose it. However, as Honderich notices, what seems to be at work here is "the offender consenting in a secondary sense to a necessary condition of punishment, and not consenting, in any sense, to his punishment" (2006: 52).

Consent to punishment implies, to be sure, quite a different loss, a kind of loss more stringent from the moral point of view, and it is this loss the one that still begs for justification. In a consequentialist approach like Nino's, it is out of question how the act of inflicting it becomes justified. Were it not for the fact that a loss like the curtailment of the offender's bodily movement's freedom, for example, succeeded in promoting a goal of social protection, under no concept would that be permitted. But, again, this implies treating the offender as a mere means, which is what Nino's justificatory strategy sought to avoid from the beginning. Therefore, the challenge remains: until the offender's consent can prove to be directed towards punishment itself and not towards a different substitute (e.g. a relinquishment of immunity), consent to punishment will look as counterintuitive and strange as it certainly looked to Kant and many others before and after him.

\section{Is it Possible a Way Out of the Dilemma?}

From the beginning, the main goal that the present paper embraced was to challenge the idea captured in Kant's claim that it is impossible to will to be punished. Discarded what I called the easy way out of the dilemma, as well as the consensual way out that derives from Finkelstein's and Nino's justificatory approaches to punishment, it is now time to give a straight and final answer. Without further ado, I would like to say that it is perfectly possible to will to be punished, even if that willingness is not able to play any justifying role in a justificatory theory of punishment. Two, then, are the main commitments of this final part: on the one hand, to assess how it is possible to will to be punished (4.1); and, on the other, to briefly describe what is the exact place that such a willingness can occupy within a more general approach on the justification of punishment (4.2).

\section{IV.1. What does 'Consent to Punishment' Really Mean?}

In my view, the main problem that all the attempts analyzed in this paper face to find out a convincing way out of the dilemma is that they are lookingin the wrong place. They all seem somehow to suppose that the only way to credit for the willingness of the wrongdoer to his punishment is by trying to determine whetherthe very criminal act expresses a subjective attitude that may transpire such a flavor. These attempts, however, often ignore that when people commit crimes, they tend to behave more or less in the way described by the Book of Job. For offenders, "midnight is their morning"; to get away with it, "they make friends with the terror of darkness". In order to reverse the tendency, what we need to keep in mind is that whatever one may feel towards punishment, one may get to feel that at a later stage, for example during the judicial procedure that is judging a suspect or even after a conviction sentence is passed against him.

In Punishment, Communication and Community (2003), Anthony Duff did a great work to clarify this idea, which owes much of its force to what I referred above as the second defining feature of punishment, neither acknowledged in a scheme like the Rawlsian one (cf. supra), nor in a scheme like Nino's. ${ }^{15}$ According to Duff, there is no way of conceiving punishment independently of its communicative and expressive functions. Punishment purports a message to the individual whom it is applied to, as well as to the liberal and democratic community which witnesses it. Hence, as a

\footnotetext{
${ }^{15}$ Here I cannot argue as I should to support this claim. Instead, let me just offer a general remark. Even if Nino accepts the expressive element as one of the defining features of punishment (cf. 1980: 205), it was never clear whether that element finally managed to find a place in his theory. For instance, Nino rejected the blaming function of punishment, for considering that the notion of blame necessarily commits us to a perfectionist conception of the person. In ["Datoseliminadosparafavorecer la anonimidad del envío"], I extensively dealt with this issue, trying to demonstrate that it is perfectly possible to conceive a notion of blame fully consistent with liberalism.
} 
communicative entity, punishment must attempt to persuade a criminal to repent her/his crime and "to accept the values that condemn it", even if this persuasion can only take place in a forcefully institutionalized context. Yet, this forceful element is justified when punishment addresses "the offender as a member of the liberal polity whose autonomy must, like that of any citizen, be respected". And punishment manages perfectly well to do this for it is, "like any exercise in rational communication, necessarily fallible: not because it might in fact fail to persuade him, but because it must itself leave that possibility open" (2003: 122). In the end, that is why justified punishment may be conceived as an authentic consensual enterprise, i. e., because by appealing to the conscience and understanding of the offender, embracing her/him as an autonomous and rational agent, it seeks for her/his consent as a necessary and final source of legitimization. ${ }^{16}$

But even if this alternative were foreclosed, I think that there is another plausible way to conceive an offender's consenting to his punishment. Conceptually, this way shares the focus of the approaches previously objected, for it takes as central the manifestation of consent that is produced $e x$ ante the judicial procedure, when punishment is still a remote possibility. Nonetheless, in contrast to these approaches, I think that it can be preserved from some of their most dubious assumptions. Imagine, for instance, a case like this. Harry Fertig in Sol Yurick's novel (1966) killed seven workers of the Mercy Memorial Hospital, including well-known doctors and its administrator. The motive, as Fertig confessed for the first time to one of his captors, was that they were responsible for the death of his son, Stevie, who had been negligently treated a few months ago. "You see - Fertig says -, killing balanced it out, and my being caught closes the account. That's why I had to be caught" (1966: 38). Or recall, on the other hand, the case of Anders Behring Breivik, the right-wing extremist who was found guilty of murdering 77 people by the Oslo District Court. When confronted to the judging audience, Breivik did not only assume the authorship of the horrible murderers, demanding to be punished; neither was he even interested to show a minimum gesture of remorse.

Evidently, cases like these are extremely rare. However, once we are invited to trust in their realism, a mere preferential account of human rationality will soon reveal its insufficiency, inadequacy and incompleteness to understand their nature. For what these cases expose like no other is that, even under Non-trivial Systems of Punishment (NSP) in conditions of perfect enforcement ( $c f$. supra), there could be human beings who might not be deterred to break the law. Under Trivial Systems of Punishment (TSP) in conditions of almost perfect enforcement, the natural account of the typical case will go approximately as follows: it is reasonable for agent $\boldsymbol{X}$ to break the law when the subjective costs that she will have to face for refraining to commit an offense are not only higher than the costs entailed by the corresponding penalties (after all, high-certainty regimes usually require lowseverity penalties) ( $c f$. Kahan 1997: 379) but even higher than the costs of trying to avoid being caught. But, of course, in cases such as Fertig's or Breivik's, the costs implied in avoiding being caught were by all means set apart from the pack.

Following again our practical syllogism, we can think of these individuals as people who want to kill other people $(\boldsymbol{P})$ even taking for granted that $\boldsymbol{P}$ certainly implies 'being punished' $(\boldsymbol{Q})$, but who, having figured out scenarios $\boldsymbol{a}[\boldsymbol{P}$ and $\boldsymbol{Q}]$ and $\boldsymbol{b}[\neg \boldsymbol{P}$ and $\neg Q]$ as the two exclusive alternatives, are more than eager to choose, out of non-preferential reasons, scenario ' $\boldsymbol{a}$ ' over scenario ' $\boldsymbol{b}$ '. Here it is really important to emphasize the non-merely preferential character of those reasons, for it is much more than simple preferences what push them to make up their minds. Typically, most of these cases involve individuals who do not care for their fortune (a life in prison, let us say) as much as they care for their moral selves or personal identities. They may feel that unless their personal values - honor,

${ }^{16}$ Alfredo Traps in Dürrenmatt's tale (e. g. Die Panne) is the perfect example to illustrate the whole point, although not Duff's particular position. At the first stage of the imaginative judicial procedure that is going to determine his presumed guilt, Traps is totally convinced of his innocence. However, as the procedure goes on, he begins to discover not only that he has brought off a murder but that the same murder merits admiration, astonishment and respect. In the end, he "makes claim to the murder as his and demands the prescribed punishment - death" (Morris 2001: 257). 
reputation, self-esteem, honesty, heroism, civility, social commitment and the like - are somehow vindicated or preserved, their integrity as agents will be in serious danger. ${ }^{17}$

Fertig, for example, is a clear sample in this sense. According to Yurick's description, he is neither a madman nor a murderer. He is "a victim who has risen up against corruption and man's humanity to man [...] by offering his life up so that it may no longer be" (1966: 251). By doing what he did and accepting to be punished, but only by accepting to be punished, he experiences a second birth, a birth that, "unlike the first one which merely brings us into the world of man, [...] cuts off from all mankind" (1966: 281). As I said, this is a perfect sample. But there may be others. A lover who kills his/her partner because s/he resents his/her infidelity can be a paradigmatic example (Kahan 2001: 177). Rawls'ss civil disobedient can be another example too, since he publicly breaks the law but expresses at the same time his fidelity to it "by the willingness to accept the legal consequences" of his conduct. As Rawls put it, this is the price to be paid to convince our fellow citizens that "our actions have, in our careful considered view, a sufficient moral basis in the political convictions of the community" (Rawls 1969: 182). Assuming that they are credible cases, do not they represent authentic ways of tacitly or even explicitly consenting to punishment? I truly think that they do.

One additional feature is worth mentioning before turning the page. In section 3.2 above, we have seen that an agent who embarks in a course of action whose consequences happen to contravene her desires has no motives to blame herself for her misfortune as long as there was nothing within her power to prevent it. Of course, she might regret for how things turned out to be in the end; but this is quite a different subjective attitude ( $c f$. Williams 1993: 69). Regarding non-law abiding conduct, we have also seen that for a non-law abiding agent it might be much harder to escape personal reproach, especially when the criminal justice system is organized in such a way that there is no chance to predict with precision what to do to avoid being punished. Finally, I tried to show that when an agent blames herself in such a way for the resulting outcome, any attempt to read in it a consensual elementwould be pointless. This sort of personal reproach, however, shall not be confused with the moral reproach that the agent might want to direct against herself for breaking the law, assuming that she is not the kind of amoral agent that used to be the topic of many philosophical discussions in the past. Nor shall it be confused, for the same reason, with the moral reproach usually purported by punishment itself.

Now, the additional characteristic feature of consent to punishment that I would like to mention can be interpreted as a corollary derived from these considerations. When consent is absent, as is generally the case, for instance, in those systems of punishment operating in conditions of less than perfect enforcement, in principle it would be much easier for the blaming function of punishment to get a grip. This is not difficult to see. Compare two non-law abiding agents: Fertig and Vertig. Whereas Fertigcommits a crime and confesses his guilt, Vertig commits the same kind of crime but tries to conceal it. Whose conscience looks more opprobrious? Anyone can see that it is the second agent's conscience the onethat punishment, accomplishing its moral expressive function,will be mainly interested to be directed to. By contrast, when consent is present, as Fertig's case clearly exemplifies, punishment might experience some expressive limitations. Obviously, that's not impediment to try to condemn every act that turns away from the law, especially when they seem to be the manifestation of an individual's non-sharable idiosyncratic values. However, given that in consensual kinds of crimes it is the very wrongdoer the one who has accepted to be punished, it is likely that the expressive function of punishment be directed mostly to those members of society that

${ }^{17}$ For more extensive remarks on this point (especially regarding moral and immoral actions) see Cohen 1996, Geuss 1996 and Frankfurt 1998 . 
contemplate the crime and its punishment from the outside, perhaps as mere impartial spectators, perhaps as their direct or indirect victims. ${ }^{18}$

\section{IV.2. Molding an Alternative Consensual Approach}

If the reasons presented so far are credited with some plausibility, then consent to punishment would turn out to be possible even under Non-trivial Systems that distribute penalties in accordance with a non-merely preferential account of human rationality. Nonetheless, in order to infer from this premise the desired conclusion, namely that consent is what justifies the imposition of punishment on an individual, absolutely nothing of what have been said so far will do.

Furthermore, assuming that agents such as Fertig and Breivik did both express authentically consensual attitudes to be punished and although consent may find in their cases a justifying function - which, of course, need not be the case at all -, there is almost nothing there that can be useful to cope with the vast universe of offenders, unwilling to pay for what they have done. In contexts where it really makes sense to talk about consent and consent plays a justificatory role, we tend to believe that it does, to quote David Boonin, if and only if it "can be overridden by an explicit declaration of the contrary" (2008: 164). But once we reach this definition, we easily get to appreciate its fatal implications for the criminal context. For, as Boonin remarks again, if the application of punishment must be mediated by an individuals' consent, "any offender could free himself from liability to punishment merely by announcing that in doing a certain act he did not intend to consent to liability to punishment" (ibid: 145).

Therefore, what we need to do to know what amount of special attention must be given to the concept of 'consent to punishment' is to start acknowledging thatthe specific role that certain attempts to justify punishment have unsuccessfully conceded to it in the past shall not lead us to believe that there is no other alternative. In my view, the notion of consent is perfectly capable of playing a role in a general approach to evaluate the practice of punishment, even if that role is not itself a justifying one. At the beginning of the last section (4.1) I mentioned Antony Duff's appeal to this concept in an attempt to show how it is supposed to intervene in a post factum stage of a criminal law adjudication strategy, being useful to morally guide officers who run the execution of punishment. Instead, the problem thatconcerns me here is closer to the other notion of consent, the one that is at stake in criminal actions such as those that I tried to cope with above (cf. supra 4.1). The following lines are meant to shed some light on this problem.

One of the most difficult tasks that any comprehensive approach to justify punishment must face even today is how to match crimes with punishments. According to retributivism, lextalionis was the simplest way to accomplish this task, by insisting on the idea that offenders deserve to experience the suffering they inflicted on their victims. However, such an answer leaves us with empty hands when taken too literally, for "no one would advocate raping rapists, assaulting assailants, or burgling the homes of burglars" (Finkelstein 2010: 212). Probably, an assaulting penalty for an assailant will manage to deter many would-be assailants. Nonetheless, as the liberal and democratic citizens that we proudly claim to be, no one would even dare to come up with a proposition like that. But which are the penalties that must be morally admitted?

\footnotetext{
${ }^{18}$ In "Communication, Expression, and the Justification of Punishment", Andy Engen distinguishes between the communicative and the expressive functions of punishment. To fulfill its communicative function, the moral message of punishment must always be accepted in the end by the wrongdoer, who must show repentance and a disposition to reform her future behavior ( $c f$. Duff 2003: 91-113). However, what if we have enough compelling reasons to believe that, in spite of what we do, the wrongdoer will not be willing to accept the moral condemnation that punishment purports? The objection of The Unreceptive Wrongdoer, which is the placeholder Engen uses to refer to "possible cases in which the punished does not respond in the desired way to the message punishment sends" (2014: 301), overrides communicative theories of punishment, especially those proposed by Hampton and Duff (cf. 2014: 300). For its part, punishment fulfills its expressive function even when it is not accepted by the punished. Engen writes in line with Feinberg and Scanlon: "Punishment that expresses condemnation, then, plays the important social role of affirming the rights of crime's victims and this could be among those things that crime victims are owed by the state" (2014: 305). In Fertig's case and cases alike, therefore, it seems to be precisely this expressive function the one that punishment is still supposed to fulfill.
} 
In the last years, a bunch of compelling theories have been displayed on the screen. Restorative approaches to criminal justice, for instance, have made notable efforts to conceive alternative ways to deal with criminality, proposing to replace the more traditional penalties-based accounts of our criminal justice systems for other novel accounts, more focused on the needs of victims and offenders ( $c f$. Braithwaite 2002; Urban Walker 2006). Deterrent punishment as such, defined as the necessary infliction of suffering fostered by a goal of social protection, does not seem to have a comfortable place in these accounts, for they are interested in promoting repair and reconciliation between victims and offenders rather than in simply preventing the occurrence of future crimes. In more than one sense, those attempts are highly valuable and it is not my intention to criticize them here. However, as Allison Morris acknowledges (2002), how they are supposed to effect real change and toprevent recidivism are among the main questionsthey haven't yet provided a straight answer for.

The alternative approach to punishment that I would like to propose here does not pretend to have a voice to deal with these legitimate concerns. For a similar reason, neither does it seek to position itself as a competitor within the well-known universe of justificatory approaches to punishment already existent, such as retributivism, preventionism, utilitarianism or even consensualism. As became clear from the discussion above - especially regarding consensualism - it surely shares some of their commitments as well as it rejects some of their implications. A general justificatory approach to the institution of punishment, however, is what my approach cannot pretend to be. With greater humility, it just seeks to offer in its place a theoretical framework that allows us to understand exactly what can be expected from a system of punishmentconceived in wide preventionist terms.And what it has to say in this respect is that, even if we were capable enough to conceive a system of punishment operating in conditions of perfect enforcement, still there would be citizens who might want to break the law. Who would they be? Well, precisely those who happen to consent to their punishment.

If we had to put a label on it I would be found myself forced to say that my approach is alternatively consensual. In choosing to call it that way, however, we should be preserved from the wrong impression that it might give, as if it were somehow trying to compete with the traditional consensual approaches previously criticized. As a matter of fact, the tentative label alternatively consensualdoes only make sense if it happens to suggest where its main interest is being directed to.Here we should proceed with caution. When consent plays a normative role, oddly does it so by offering a final source of legitimation or the like. In "Government by Consent", Joseph Razwas really emphatics on this point. There he claimed in relation to our consensual attitudes towards our own governments: "Consenting to be ruled by someone expresses confidence in that person's ability to rule well. [...] consent has an expressive value only where the conditions of legitimacy are satisfied or are nearly satisfied. [...] Hence consent has an independent, but auxiliary and derivative, place as a source of legitimacy" (1994: 351-53).

In a similar vein, Ernesto Garzón Valdés once said that although the factual consent of autonomous citizens is neither a necessary nor a sufficient condition for the genesis of a political system's legitimacy, this does not make it irrelevant to determine the actual effectiveness of the system, for such a factual consent is a crucial element of stability ( $c f$.Garzón Valdés 1990: 22-23). Because I tend to agree with these authors that consent is called upon to play mainly a derivative and expressive role, no general approach to punishment can make use of it as a fundamental or sufficient notion. That is why, in my scheme, consent exclusively behaves as signaling how well a given system of punishment - whose general justification is to be sighted somewhere else - might be performing in the application stage of its organizational structure.

With that end in view, our previous battery of distinctions can be very helpful again. Recall that we have distinguished between Trivial and Non-trivial Systems of Punishments (TSP and NSP 
respectively). Now, in order to evaluate how well a TSP can perform in its application stage, the evaluative criterion can be provided by what we may call a Consensual Ideal of a Trivial System of Punishment in conditions of perfect enforcement (be it CI-TSP). Whether such a System is empirically conceivable is not relevant here, for we are only interested in the evaluative criterion it offers. Hence, a CI-TSP in conditions of perfect enforcement can be characterized as seeking the following main goals:

a) To deter those crimes that would be committed out of mere preferential motives if the trivial preferential motives brought in by punishment were not as unaffordable as they are for some people.

b) To expectonly those crimes committed out of mere preferential motives that can be affordable by some people in spite of the imaginable contravening effects thatthe actual application of punishmenthas over those motives.

Alternatively, in order to evaluate how well a NSP can perform in its application stage, the evaluative criterion can be provided by what we may call a Consensual Ideal of a Non-trivial System of Punishment in conditions of perfect enforcement (be it CI-NSP). Assuming that a CI-NSP can be comprehensively conceived as to include a typical CI-TSP, a sort of mixed CI-NSP in conditions of perfect enforcement willthen becharacterized as seeking the following main goals:

a) To deter those crimes that would be committed out of mere preferential motives if the trivial preferential motives brought in by punishment were not as unaffordable as they are for some people.

b) To deter those crimes that would be committed out of mere preferential motives if the non-preferential motives brought in by punishment were not as unaffordable as they are for some people.

c) To deter those crimes that would be committed out of non-preferential motives if the nonpreferential motives brought in by punishment were not as unaffordable as they are for some people.

d) To only expect:

i) those crimes committed out of mere preferential motives that can be affordable by some people in spite of the imaginable contravening effects that the actual application of punishment has over those motives; and

ii) those crimes committed out of non-preferential motives that can be affordable by some people in spite of the imaginable contravening effects that the actual application of punishment has over those motives.

It is in contrast to these ideal models that our actual systems of punishment have to be consensually evaluated. This task can be done in more than one way. In a general way, it would be almost impossible to determine with precision the consensual status of a system, forsystems tend to be highly selective in enforcing most of the norms that are codified. Nonetheless, in a more particular way, that can be done more easily, for it is just a question of trying to assess from the whole universe of possible offenses codified in a given criminal legislation, which specific kinds will be less or more likely to flourish. So, for example, if it happens that a vast amount of type-A offenses are being punished but this does not bring about as a result a type- $A$ offenses' reduction, it would be legitimate to assume that the particular system of punishment under analysisis being consensually applied, sincetheir addressees seem to be willing to pay for what they have done. Being that the case, it is also legitimate to infer that such a consensual system - at least in relation to those offenses - is not accomplishing at all a proper deterrent function. 
If it happens, on the contrary, that the system proves to be quite effective in sanctioning type- $B$ offenses, an accomplishment that is followed by a type- $B$ offenses' reduction scenario in a later phase of the criminal-law application stage, it will be legitimate to assume that most of the type- $B$ offenses to be committed from then onwards are going to be the unmistakable expression of the offenders' consent to be punished. How vast can be the universe of possible consensual offenders for a system - thus organized - not to collapse is quite a different matter, which must be determined within the boundaries of each concrete system of punishment. As is reasonable to suppose, that will vary depending on different factors, such as the gravity and intensity of the rights' deprivation that punishment purports; the individuals' average tolerance threshold; the beliefs, values and desires that are predominant in a social community; the way punishment is seen by those who suffer it as well as by victims and citizens in general; and so on and so forth.

$\mathrm{Be}$ it as it may, it must never be forgottenwhat the notion of consent is capable of doing.In company with the aforementioned ideal scenarios that are theoretically conceivable with its help, what the notion gives us is just one criterion among others to determine how well a given system of punishment performs in order to protect the social values and individual freedoms that might be endangered by criminality. That is precisely why, in conditions in which the rates of law enforcement are very low and most offenders succeed to go unpunished, it will be less likely forcriminal conductsto exhibit subjective attitudes such as the willingness of their authors to be punished. According to preventionism, a system of punishment with these characteristics is, typically, a system of punishment failing to accomplish its proper deterrent function. Meanwhile, according to the alternative consensual approach that I tried to present in this paper, it shall be seen as more than this. In fact, it can also be seenas a system that failed to give individual consent the expressive derivative function that is supposed to be inseparable of any legitimating account of human institutions.

Last but not least, the notion of consent represents just one criterion among others to evaluate a system of punishment's performance because it is not much what it can really do by itself. For instance, it is not allowed to determine the fairness of a system. Imagine a 1984 's social scenario in which surveillance is really intense: there is a police officer on every corner, there are hidden cameras transmitting alive what happens in every building of every neighborhood, electronic bracelets for tracking persons under house arrest, satellite surveillance, and the like ( $c f$. Braithwaite and Pettit 1990: 109-110). Moreover, imagine also that prosecution policies are organized "on the basis of possible rather than probable guilt" (ibid: 44). Under these brave-new worldly conditions, it may be very unlikely for a rational individual to will to commit an offense without expecting to be punished. We may even dare to say that, under these conditions, offenders will tend to express their consent to be punished. Is such a system fair or remotely desirable? Doubtfully could it be so, unless penalties were really affordable by anyone. But if they were not and the only offenses taking place were those perpetrated by individuals on the basis of their non-preferential motives, such a system would probably satisfy the consensual ideal being at the same time totally unfair in regards to many of the values and liberties that are sacred to the immense majority of the population.

A Consensual Ideal of a Non-trivial System of Punishment (CI-NSP), therefore, need not be after all an ideal system of punishment. Nonetheless, it would be more accurate to say that a system of punishment cannot embrace any ideal target worth going for, whichever that is (namely restitution, furtherance of dominion, incapacitation of offenders, crime prevention, minimization of harm, etc.),ignoring the personal motives that people might have to break the law. The alternative consensual approach that I brought into consideration simply encourages measuring a criminal justice system's performance without taking our eyes off the complex world of human motivations.

To see the point more clearly, recall Sol Yurick's novel once again. The American justice system did not fail to prevent Fertig's actions because the law enforcement's rates were low. In fact, even though Fertig's intention was to be caught, he did not surrender voluntarily to the police. Quite 
the contrary, Fertig was arrested because the criminal justice system's authorities were efficient in collecting the evidence that drove them to him. What should have happened, then, for Fertig's actions not to have taken place as they did? To put it bluntly, the complex social tissue in which Fertig's motivations were nurtured and engendered must have been radically different. For instance, the inexistent human commitment showed by the Mercy Memorial Hospital's workers to treat Fertig's son disease must have had to be present at least at a minimum rate. In case none of these social phenomena had actually bred Fertig's motivations, it is reasonable to presume that his owncriminal actions would not have been what they were.

As we know, this is a fictitious story in which the main character's motivations may seem at least understandable, even if not morally (or legally) justifiable. But consider, in contrast, the hundreds of gender-based violent crimes that sadly take place every day in our societies. What we tend to see as morally objectionable in those cases is not just the violence that ends up in taking an innocent human life or putting it at serious risk. It is also the outrageous motivations that underlie them, closely related to a millenarian culture that unfairly put women in an inferior scale of human evolution. If we believe that a criminal justice system can prevent by itself these kinds of crimes, for example by reinforcing the mechanisms of control or by intensifying the severity of the penalties, but acting as if the discriminatory elements incorporated in our culture over the course of the centuries were irrelevant, I seriously fear that our prospects are hopeless.

Changing the social tissue, as I said, can hardly ever be the saliently definitive function of any criminal justice system, which is just one system operating within a much bigger network integrated by other complex systems, legal and extra-legal as well ( $c f$.Luhmann 1995, Chap. 10; Braithwaite and Pettit 1990: 82). At most, it can represent one of its possible functions, andespecially if it is defined in such a modest way as not to arouse false expectations. The alternative consensual model of a criminal justice system here proposed has the merit of allowing us to understand why to be modest and to what extent, for it signals that crimes that are the expression of an individual's willingness to be punished will usually have to be interpreted as the representation of human characteristics whose presence or absence could always lie far beyond the scope of the preventionist target. Against this background, our accountreminds us that the complex world of human motivations and the preventionist target of a criminal justice system do not necessarily go hand in hand. Precisely, the consensual ideal of a system of punishment operating as a whole sets the maximum scope of the preventionist target. ${ }^{19}$ And, as such, it gives a first clue to begin to imagine how to act from within other social systems to prevent what the criminal justice system cannot prevent by itself.

\section{Conclusions}

In human affairs, as I said in the introductory part of this paper, different concepts of consent will be able to play different roles in different contexts, depending on what we purport to justify and how we pretend to do it. In political theory, for instance, a hypothetical notion of consent actually managed to do a magnificent job that probably would not have done in other areas. In legal theory, for its part, the notion that is typically at stake at the moment of justifying a given arrangement in tort law or in contract law - let us suppose - is doubtlessly more real and robust than the hypothetical notion, even if the required features it must reunite to acquire normative power will have to be evaluated on the

\footnotetext{
${ }^{19}$ I borrowed the expressions in italics from Braithwaite and Pettit 1990. For the preventionist target, the authors basically understand 'crime-prevention', which is "usually broken down into one or more sub-goals: the incapacitation or rehabilitation of actual offenders, for example, or the deterrence of potential offenders" (1990: 45). On the other hand, a criminal justice system operating as a whole must be read as including the operations that take place within each of the sub-systems that are part of it, such as the surveillance sub-system, the prosecutorial sub-system, or the sentencing sub-system, to mention some of the most important ones (cf. 1990: 7-8).
} 
merits of each case. A tacit notion of consent will suffice in some contexts, whereas an explicit notion will be required in other, more demanding ones.

As regarding the criminal area of law, in this paper I tried to make it plain that, in principle, any notion will do, depending again on what we purport to justify. An intense willingness to be punished does not look odd at all when interpreted following Rawls'ss scheme, valid for what I called a TSP. Finkelstein's hypothetical notion of consent, for example, is very usefulat the normative design's political stage of a criminal justice system, but practically inert at its application stage. In contrast to these approaches, the notion of consent to punishment that I tried to rescue in the end of this paper is able to represent the individual's real will even in the context of a NSP. The role that it is supposed to play, however, is far from being a justificatory one, as the traditional consensual theories would have thought. In my view, it is better to conceive it as a purely expressive one. Generally speaking, when consent to punishment is predicated from the actions of an agent, what such a subjective attitude will express is that, in relation to certain types of offenses and in relation to certain ways of matching crimes with penalties, the preventionist target of a criminal justice system operating as a whole will see insurmountable limitations. Nonetheless, how that message can be unambiguously read in an individual's criminal actions will depend, among other things, on the level of law enforcement of that system. In conditions of less than perfect enforcement, as Randy Barnett once put it, the meaning of human actions will tend to be irreducibly ambiguous (cf. 1992: 902).

(A Kantian) Post-Script. The solution attempted in this paper as a way out of the Kantian dilemma has proved toexhibit no real influence from what might be deemed asa Kantian spirit. In a sense, that is a predictable outcome, since it was no other but Kant the one who addressed from the beginning the impossibility of there being someone willing to be punished. Despite this explicit refusal, I am confident that an authentic Kantian solution is still waiting to be brought to light from his writings. In the next conclusive remarks I would like to suggest, paraphrasing Habermas, how ' $m i t$ Kant gegen Kant denken' canbe, after all, a promising enterprise.

In the Groundwork, Kant traced a distinction among three kinds of imperatives, namely: rules of skill, counsels of prudence, and commands (laws) of morality, which are also called 'technical (belonging to art)', 'pragmatic (belonging to welfare)' and 'moral (belonging to free conduct as such, that is, to morals)' (GMS 4: 416), respectively. With respect to the moral imperative, what Kant says is almost common knowledge among practical philosophers: it is categorical, for according to it "action is represented as objectively necessary of itself, without reference to another end" (GMS 4: 414). Regarding the other two, Kant says that they are hypothetical, for they "represent the practical necessity of a possible action as a means to achieving something else that one wills" (ibid.). In a previous section of this paper we had the opportunity to bring aboutthe principle that governs human conduct when rules of skill are at stake (see supra, 5). Now special attention must be givento the way Kant conceives the second kind of imperative. To his purpose, it is the contrast between it and the moral imperative that becomes salient. Hence, whereas "the categorical imperative (...) is limited by no condition and, as absolutely although practically necessary, can be called quite strictly a command"; on the contrary, "the necessity involved by counsels of prudence can hold only under a subjective and contingent condition, whether this or that man count this or that in his happiness" (GMS 4: 416). In the end, it is precisely the empirical and conditional character of this condition the responsible of ensuring the practical possibility of any pragmatic imperative.

If we are guided by this insightful reconstruction of our polyvalent normative agency - let us say, we easily get to the conclusion that agents such as the onesembodied in the characters of Fertig, Breivik, the Rawlsian civil disobedient, and others, are not inconceivable at all. Because according to Kant "happiness cannot be an ideal of reason but of imagination, resting merely upon empirical grounds" (GMS 4: 418), or subjective, or contingent ones (cf.GMS 4: 416), there seems to be no real impediment for him to envisage an agent who, in the name of her idiosyncratic well-being, 
decides to rest on her own punishment as a means to further her end, even under a NSP. Of course, Kant proceeds with caution when it comes to recognize a given ideal of happiness (cf. GMS 4: 419). Such a thing is futile, Kant writes, once we realize that even the mostinsightful and powerful human being will face serious limitations to figure out a comprehensive and detailed picture of "what he really wills here" (GMS 4: 418), which would include, in his own terms, "the totality of a series of results in fact infinite" (GMS 4: 419). For the moment, however, this is irrelevant. What rather matters most is that "if it is supposed that the means to happiness can be assigned with certainty", therefore "the imperative of prudence would [...] be an analytic practical proposition" (ibid.), recommending a course of action over whose desirability no one can pretend to have the final word. It has been my contention all along this paper that such a course of action, when it represents an offense or a crime within a given legal system and under certain conditions of enforcement, can express an authentic consent to punishment on the part of its perpetrator. Over and above Kant's explicit position thereon, I suspect that he would agree with it.

\section{Bibliography}

BEISER, Frederick: "Wolff, Chladenius, Meier: Enlightenment and hermeneutics", en J. MALPAS/ H.-H. GANDER (eds.), The Routledge Companion to Hermeneutics, New York, Routledge, 2015.

AMERSON, Richard: "Rawls versus Utilitarianism in the Light of Political Liberalism", in Victoria Davion and Clark Wolf (eds.), The Idea of a Political Liberalism: Essays on Rawls, Lanham, Rowman and Littlefield, 2000.

BARNETT, Randy E.: "The Sound of Silence: Default Rules and Contractual Consent", Virginia Law Review78 (1992) 821-911.

BARRY, Brian: Justice as Impartiality, Oxford, Clarendon Press, 1995.

BOONIN, David: The Problem of Punishment, Cambridge, Cambridge University Press, 2008.

BRAITHWAITE, John and Pettit, Philip: Not Just Deserts: A Republican Theory of Criminal Justice, Oxford, Clarendon Press, 1990.

BRAITHWAITE, John: Restorative Justice and Responsive Regulation, Oxford, Oxford University Press, 2002.

COHEN, G. A.: "Reason, Humanity, and the Moral Law", in Christine Korsgaard et al. (authors) The Sources of Normativity, Cambridge, Cambridge University Press, 1996.

DUFF, Anthony: Punishment, Communication and Community, New York, Oxford University Press, 2003.

ENGEN, Andy: "Communication, Expression and the Justification of Punishment", Athens Journal of Humanities and Arts (Oct., 2014) 299-307.

FEINBERG, Joel: "The Expressive Function of Punishment", in Joel Feinberg, Doing and Deserving: Essays in the Theory of Responsibility, New Jersey, Princeton University Press, 1971.

FINKELSTEIN, Claire: "A Contractarian Approach to Punishment", in Martin P. Golding and William A. Edmunson, The Blackwell Guide to Philosophy of Law and Legal Theory, Oxford, Blackwell Publishing, 2005.

"Punishment as Contract", Ohio State Journal of Criminal Law, Vol. 8 (2010) 319-340. 
FOOT, Philippa: Natural Goodness, Oxford, Oxford University Press, 2001. Spanish translation by Ramón VilàVernis: La bondad natural. Una visión naturalista de la ética, Barcelona, Paidós Contextos, 2002

FRANKFURT, Harry: "Identification and Wholeheartedness", in H. Frankfurt (author) The Importance of What We Care About, Cambridge, Cambridge University Press, 1998.

GARZÓN VALDÉS, Ernesto: “Consenso, racionalidad y legitimidad”, Isegoría 2 (1990) 13-28.

GEUSS, Raymond: "Morality and Identity", in Christine Korsgaardet al. (authors) The Sources of Normativity, Cambridge, Cambridge University Press, 1996.

GOLDBERG, John C. P. and Zipursky, Benjamin C.: "Tort Law and Responsibility", in Goldberg et al. (editors), Tort Law: Responsibilities and Redress, New York, Wolters Kluwer Law \& Business, 2012

HART, H. L. A.: "Bentham on Legal Rights", in Oxford Essays in Jurisprudence, Alfred W. B. Simpson (editor), Oxford, Clarendon Press, 1973.

HILL, Thomas E., Jr.: "Kant on Punishment: A Coherence Mix of Deterrence and Retribution", in Respect, Pluralism, and Justice: Kantian Perspectives, Oxford, Oxford University Press, 2000.

HÖFFE, Otfried: Politische Gerechtigkeit: Grundproblem der praktischen Philosophie, Fernuniversität, Gesamthochschule, FachbereichErziehungs-, Sozial- u. Geisteswiss, 1989.

HONDERICH, Ted: Punishment: The Supposed Justifications Revisited (Revised edition), London, Pluto Press, 2006.

IMBRISEVIC, Miroslav: "The Consent Solution to Punishment and the Explicit Denial Objection", Theoria, 68 (2010) 211-224.

—_:"Carlos Nino's Conception of Consent in Crime”, Diacrítica vol.27 no.2 (2013)103-123.

KAHAN, Dan M.: "Social Influence, Social Meaning, and Deterrence", Virgina Law Review Vol. 83, $\mathrm{N}^{\circ} 2$ (Mar. 1997) 249-395.

__: "Two Liberal Fallacies in the Hate Crimes Debate", Law and Philosophy 20 (2001) 175-193.

KANT, Immanuel: Die Metaphysik der Sitten (MS). English translation and edition by Mary Gregor: The Metaphysics of Morals, Cambridge, Cambridge University Press, 1996.

: GrundlegungzurMetaphysik der Sitten (GMS). English translation and edition by Mary Gregor: Groundwork of the Metaphysics of Morals, Cambridge, Cambridge University Press, 1998.

KLEINIG, John: "The Nature of Consent", in Miller, F. \& Wertheimer, A. (Eds.), The Ethics of Consent, Oxford, Oxford University Press, 2010

KORSGAARD, Christine M.: “The Right to Lie: Kant on Dealing with Evil”, Philosophy and Public Affairs, Vol. 15, No 4 (1986) 325-349.

KOTLER, Philip: Marketing Management, New Jersey, Prentice Hall, 1967. Spanish translation by Ramón Palazón Bertrán: Dirección de mercadotecnia: análisis, planeación y control, México D. F., Editorial Diana, 1973.

LLYOD THOMAS, D. A.: Locke on Government, London, Routledge, 1995. 
LUHMANN, Niklas: Das Recht der Gesellschaft, Berlin, Suhrkamp Verlag, 1995.

MALAMUD GOTI, Jaime: Suerte, moralidad y responsabilidad penal, Buenos Aires, Hammurabi, 2008.

MORRIS, Herbert: "Persons and Punishment", in Readings in the Philosophy of Law, New Jersey: Prentice Hall, 2001.

MORRIS, Allison: "Critiquing the Critics: A Brief Response to Critics of Restorative Justice", The British Journal of Criminology: An International Review of Crime and Society 42 (2002) 596-615.

NINO, Carlos S: Towards a General Strategy for Criminal Law Adjudication, Oxford, unpublished $\mathrm{PhD}$ thesis, 1977 (for the revised Spanish translation, see Nino 1980).

— Los límites de la responsabilidad penal, Buenos Aires, Astrea, 1980.

“The Consensual Theory of Punishment", Philosophy and Public Affairs, 12 (4) (1983) 289306.

: The Ethics of Human Rights, Oxford, Clarendon Press, 1991

PEREDA, Carlos: "Lógica del consentimiento", in León Olivé (comp.), Ética y diversidad cultural, México, Fondo de Cultura Económica, 2004.

RAWLS, John: “Two Concepts of Rules”, The Philosophical Review Vol. 64, No 1 (1955) 3-32.

"The Justification of Civil Disobedience", in Hugo Adam Bedau (ed.), Civil Disobedience: Theory and Practice, New York, Pegasus Books, 1969.

— : A Theory of Justice, Cambridge, Massachusetts, Harvard University Press, 1971.

RAZ, Joseph: The Morality of Freedom, Oxford, Clarendon Press, 1979.

"Government by Consent", in Joseph Raz, Ethics in the Public Domain: Essays in the Morality of Law and Politics, Oxford, Clarendon Press, 1987.

SCANLON, Thomas: "Contractualism and Utilitarianism", in AmartyaSen and Bernard Williams (editors), Utilitarianism and Beyond, New York, Cambridge University Press, 1982.

: What We Owe to Each Other, Cambridge, Massachusetts: Harvard University Press, 1998.

SEN, Amartya: “Utilitarianism and Welfarism”, Journal of Philosophy Vol. 76, nº 9 (1979) 463-489.

: Choice, Welfare and Measurement, Cambridge, Basil Blackwell, 1982.

SHER, George: "Blame for Traits”, Noûs 35:1 (2001) 146-161.

SIMMONS, John: On the Age of Anarchy: Locke, Consent and the Limits of Society, New Jersey, Princeton University Press, 1993.

URBAN WALKER, Margaret: Moral Repair: Reconstructing Moral Relations after Wrongdoing, Cambridge, Cambridge University Press, 2006.

WALL, Steven: Liberalism, Perfectionism and Restraint, Cambridge, Cambridge University Press, 1998. 
WENNBERG, Mikko: "Modeling Hypothetical Consent", Journal of Libertarian Studies Vol. 17, No 3 (2003) 17-34

WILLIAMS, Bernard: "A Critique of Utilitarianism", in J. J. C. Smart and B. Williams, Utilitarianism: For and Against, New York, Cambridge University Press, 1973.

_

"Internal Reasons and the Obscurity of Blame", in Making Sense of Humanity and Other Philosophical Papers, Cambridge, Cambridge University Press, 1995.

YURICK, Sol: Fertig, New York, Trident Press, 1966.

ZAFFARONI, Eugenio Raúl: “VVale la pena?”, in Controversias de derecho penal, Bahía Blanca:Programma No 1 (2005) 41-59. 



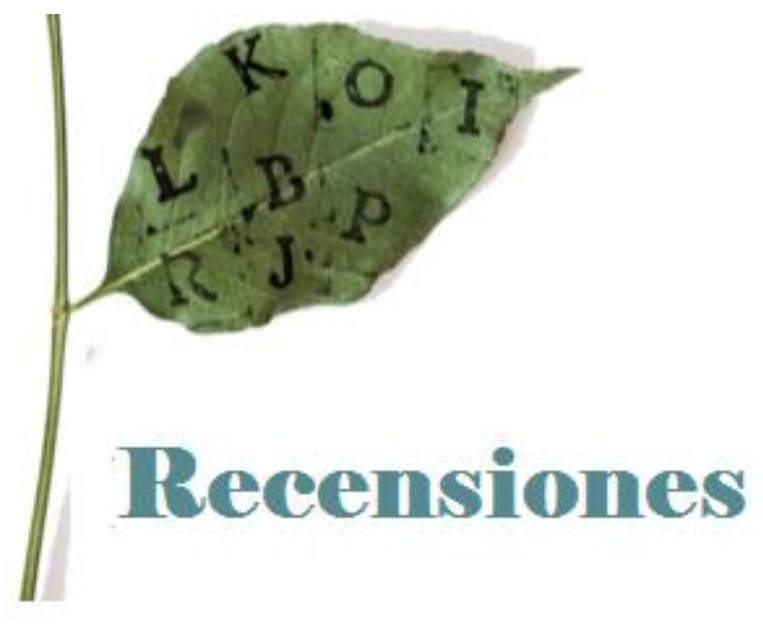





\title{
Immanuel Kant (trad. Alba Jiménez): Lecciones de filosofía moral. Mrongovius II. Salamanca, Sígueme, 2016, 160 pp. ISBN: 978-84-301- 1954-7.
}

\author{
PABLO VERAZA TONDA ${ }^{1}$
}

\begin{abstract}
A fines de 2016 se publicó la oportuna edición bilingüe del manuscrito Mrongovius II que recoge las lecciones de filosofía moral de Kant del semestre de invierno de 1784/85, originalmente publicado en el tomo XXIX 1,1 de la Akademie-Ausgabe editado por Gerhard Lehmann. La publicación se inserta en el contexto de una Kant-Forschung internacional que ha otorgado cada vez más relevancia a las Vorlesungen, como señala la editora. Se trata de la primera traducción completa del texto a cualquier idioma, pues hasta ahora sólo había aparecido una selección de fragmentos en la criticada versión inglesa de Peter Heath. ${ }^{2}$ La edición y rigurosa traducción a cargo de Alba Jiménez proporciona por primera vez a los lectores de Kant en castellano una edición bilingüe cabal del texto de la AkademieAusgabe, que se enriquece con una presentación, un estudio especializado y notas aclaratorias que ayudan a ubicar estas lecciones en el conjunto de la teoría y el corpus kantianos. También suministra una orientación sobre las principales discusiones y apropiaciones de la tradición que se encuentran en el origen de la filosofía moral de Kant, realizando especial énfasis al año de gestación de la Fundamentación de la metafísica de las costumbres (1785).
\end{abstract}

El Mrongovius II es un manuscrito de carácter excepcional, como dice la editora, pues recoge no sólo una elaboración oral complementaria de la doctrina de la Fundamentación, publicada ese mismo año, sino que también deja ver a un Kant que lee con atención a la tradición griega, a las teorías inglesas del sentimiento moral (Hume, Shaftesbury, Hutcheson) o a Rousseau para elaborar sus propias concepciones, además de llevar a cabo un constante diálogo crítico con Wolff, Leibniz y Baumgarten. Este último pensador está particularmente presente en el curso, pues su manual de filosofía práctica era de uso obligatorio en la asignatura y Kant aprovechará la ocasión para retomarlo, corregirlo y replantearlo constantemente.

En medio del amplio contexto hermenéutico que el manuscrito deja ver, el pensador de Königsberg apuntala su propia filosofía moral tras dividir la filosofía material en una metafísica de la naturaleza, una metafísica de las costumbres y una antropología como aplicación de la filosofía moral. Cabe destacar la distinción entre la voluntad santa y la humana como un fundamento importante de la concepción de la moral expuesta en las lecciones, que separan una y otra vez la orientación de la voluntad de acuerdo a fines pragmáticos de la orientación de la voluntad de acuerdo a leyes morales. Correspondientemente, Kant distinguirá entre Triebfedern y Bewegungsgründe, heteronomía y autonomía, consilia y motiva, bien físico y bien moral. En el plano de la teoría del derecho y del estado vemos asimismo una continuación de la confrontación kantiana con el eudemonismo, cuando en el apartado "Von der Jurisprudence" se rechaza la doctrina de la salus rei publica de Achenwall. Al respecto, la editora nos recuerda que se trata de un punto de intersección con el fragmento del curso contemporáneo Naturrecht Feyerabend.

En el estudio especializado, Jiménez aborda el distanciamiento crítico frente a Baumgarten, Achenwall y Wolff y traza los puentes que vinculan las lecciones con la Fundamentación de la metafísica de las costumbres, la propia Metafísica de las costumbres y el Naturrecht Feyerabend. Asimismo, el estudio expone el marco común de la distinción entre lo nouménico y lo fenoménico

${ }^{1}$ Albert-Ludwigs Universität Freiburg.

${ }^{2}$ Cf. Immanuel Kant, Lectures on ethics, edición de Peter Heath y Jerome Schneewind, Cambridge University Press, Cambridge, 1997, 223-248, y el comentario y análisis crítico de Jens Timmermann, "Mrongovius II: a supplement to the Groundwork of the Metaphysics of Morals", en Denis Lara y Oliver Sensen (eds.), Kant's Lectures on Ethics. A Critical Guide, Cambridge University Press, Cambridge, 2015, 68-83. 
como base tanto de la filosofía moral como de las concepciones jurídicas kantianas. Partiendo de ello, Jiménez enfatiza la función clave de la teoría de la imputación y delimita la postura del filósofo de Königsberg respecto a los fundamentos del contrato social y del derecho penal, la propiedad privada o la pena de muerte, en contra de diversas malinterpretaciones. El estudio se cierra con la explicación del esquematismo kantiano que ordena los procedimientos prácticos, en el cual se expone la triple articulación de la práctica humana en una esfera religiosa, una natural y una moral que media entre estas dos.

Cabe resaltar, de entre los múltiples hilos conductores de las lecciones, la atención especial que se concede a los griegos . Desde la parte introductoria, Kant señala que "de la filosofía de los antiguos nada es tan instructivo como su moral" y reconoce la insuperable riqueza de la pregunta griega por el bien supremo y de su exploración de las maneras de alcanzarlo. Incluso exalta que los antiguos filósofos no sólo llevaron a cabo un camino teórico sino que en Grecia y Roma varios hombres vivieron efectivamente de acuerdo a sus ideas, con respecto a lo cual señala, por ejemplo, que la "idea estoica es sublime y no un mero ideal". ${ }^{3}$ En este y otros lugares del manuscrito -sobre todo en la "Einleitung", pero también en la parte con el título genérico "Erster Theil" y los subapartados "Vom Gesetz überhaupt" y "Von der Jurisprudence"- se muestra que Kant se sirve del diálogo con lo que llama "la moral de los antiguos" para construir su propio intento de fundamentación de la metafísica de las costumbres. Un ejercicio histórico paradójicamente relevante para la construcción de un sistema trascendental, como señala Jiménez en el estudio especializado.

La cuidadosa interpretación kantiana de los griegos toma como hilo conductor el dualismo entre lo natural y lo ideal. Como para Kant sólo la religión sería capaz de unificar ambas cosas, en las lecciones se critica que la moral griega careciera de la misma, aunque se reconoce que agotó casi todas las posibilidades en la búsqueda del bien. Vemos, por ejemplo, una atenta interpretación de la escuela cínica, de la cual Kant incluso recupera la exaltación de la ingenuidad, si bien señala que el sólo hecho de tener que enseñar principios, como hacía Diógenes, demuestra la debilidad del hombre cuando este se atiene meramente a su condición natural. En otro extremo ubica el ideal de Platón, que tendría el mérito de orientarse a lo sobrenatural, elevándose a la "intuición directa" de lo divino en las ideas. Ahora bien, las lecciones centrarán su atención sobre todo en la comparación y contraposición entre estoicos y epicúreos, pues se interpretan como dos formas paradigmáticas de relación con la virtud y la felicidad: unos exaltan el valor de la persona (del sabio virtuoso) y los otros el valor de la condición o estado (Zustand) de felicidad. Para Kant se trata de dos elementos irreductibles dada la finitud y fragilidad del ser humano. Según nuestro pensador no se puede "derivar la felicidad de la virtud ni la virtud de la felicidad", de tal manera que la moral ha de cumplir una tarea mediadora. A través de la coacción del imperativo moral se abre para Kant "un nuevo camino", no sin recuperar el "ejemplo" del cristianismo, que enseñaría una virtud capaz de reprimir las inclinaciones del deseo que llevan al mal. Kant construirá su moral de imperativos sintéticos a priori para mediar lo que ve como conflicto irreductible entre el bien físico y el bien moral, insistiendo en la posibilidad de insertar a los seres finitos e imperfectos que somos en un ámbito universal de libertad y racionalidad.

Salta a la vista la ausencia de Aristóteles en Mrongovius II, pero el rico trasfondo de interlocución de estas lecciones vuelve a poner de relieve la actualidad del diálogo entre la ética aristotélica y la kantiana. Sobre todo, dada la importancia de la teleología para el "reino de los fines" que aquí se exalta citando a Leibniz y Agustín. En nuestra época, el mencionado diálogo sigue siendo la base de sistemas éticos contemporáneos como por ejemplo el de Soi-même comme un autre de Ricoeur que nos recuerda la vigencia del intento de poner en diálogo a Kant y a los griegos.

Es de celebrarse la aparición de la edición bilingüe del Mrongovius II, que viene a enriquecer la bibliografía kantiana en castellano. Se trata no sólo de un valioso complemento de la Grundlegung, sino también de una destacada vía de acceso al espacio hermenéutico de mediaciones y discusiones que atraviesan toda la filosofía práctica de Kant.

\footnotetext{
${ }^{3}$ Immanuel Kant, Lecciones de filosofía moral. Mrongovius II, Sígueme, Salamanca, 2016, 34-37.
} 


\title{
Faviola Rivera Castro: Virtud, Felicidad y Religión en la Filosofía Moral de Kant. México, Instituto de Investigaciones Filosóficas-UNAM, 2014, 328 pp. ISBN: 978-607-02-4788-0.
}

\author{
Gustavo LEYVA ${ }^{1}$
}

\begin{abstract}
Existen por desgracia pocos libros publicados originalmente en español que hayan sido dedicados íntegramente a la ética de Kant. Es por ello que debe ser altamente valorada la reciente aparición del libro de Faviola RiveraVirtud, Felicidad y Religión en la Filosofía Moral de Kant (México: Instituto de Investigaciones Filosóficas-UNAM, 2014). Se trata de una exposición muy completa de la ética kantiana, escrita, además, y ello es digno de encomio, en un lenguaje claro, comprensible tanto para el lector especializado en Kant como para los interesados por la filosofía en general. El libro se estructura conforme a un doble propósito, a saber: en primer lugar, el de ofrecer un cuidadoso análisis sobre la tensa relación entre las exigencias del deber y de una moral basada en la autonomía, por un lado, y la búsqueda de la felicidad, por el otro.En segundo lugar, Rivera desea ofrecer una exposición ordenada y, al mismo tiempo, un comentariomuy bien argumentado sobre la filosofía moral kantiana en su conjunto.
\end{abstract}

Con relación al primer propósito del libro, esto es, al análisis de la relación entre el deber moral fundado sobre la noción de autonomía de la razón y dotado de una pretensión de validez universal, por un lado, y la aspiración a la felicidad (entendida ésta como el bienestar ligado a la satisfacción de deseos e inclinaciones particulares), por el otro, Rivera expone con detalle el modo en que la justificación del principio supremo de la moralidad es desarrolladapor Kant inicialmente bajo la forma de una deducción orientada a probar su pretensión de universalidad y necesidad (vuelvo a este punto más abajo). No obstante, agrega Rivera con razón, esa justificación no puede considerarse como concluida sino solamente hasta después de haber respondido adecuadamente al problema de la motivación moral, esto es, hasta no haber probado que el principio de la moralidad incide efectivamente enla estructura motivacional de los sujetos y ofrece así a ellos el motivo para actuar conforme a él. Es aquí donde se localiza justamente la vinculación del principio de la moral con la aspiración a la felicidad mediante la doctrina del bien supremo que Kant comprende justamente como la unión entre la virtud y la felicidad. Es en este punto, sin embargo, donde, según Rivera, se plantean algunos nudos de difícil resolución: en primer lugar, la felicidad es considerada por Kant en términos solamente formales y se presenta por ello desvinculada de una dimensión que es constitutiva de cualquier noción de felicidad, a saber: su enlace con la satisfacción de deseos e inclinaciones personales; la felicidad se enlaza así más bien, en segundo lugar, con la noción de merecimiento y, de ese modo, con una fe religiosa de carácter racional lo cual plantea, en tercer lugar, la disyuntiva de cómo poder conciliar una moral basada en la idea de la autonomía con una fe religiosa que parece contradecir dicha autonomía.

El análisis de la relación entre la moralidad fundada sobre la autonomía y vinculada a la noción de deber, de un lado, y la felicidad, del otro, conduce al segundo objetivo del libro - esto es, el de una exposición y comentario de la filosofía moral de Kant. En efecto, siguiendo ante todo el hilo argumentativo presentado por Kant en la GrundlegungzurMetaphysik der Sitten (1785), Rivera ofrece en el primer capítulo de su obra la concepción de la filosofía moral en la que se basa la Grundlegung: la manera en que se relacionan el valor incondicionado de la voluntad con el principio supremo de la moralidad, la comprensión de la buena voluntad como voluntad autónoma, la relación entre el saber moral ordinario que no requiere ser enseñado sino más bien esclarecido, la dialéctica entre la razón práctica pura y la razón práctica empíricamente condicionada vinculada a la felicidad. Posteriormente, en lo que podría ser considerado el eje fundamental del libro, Rivera ofrece en los capítulos III a V

${ }^{1}$ Universidad Autónoma Metropolitana-Iztapalapa 
una cuidadosa y bien argumentada exposición de las tres fórmulas del imperativo categórico, a saber: la fórmula de la ley universal de la naturaleza (capítulo III), la fórmula de la humanidad como fin en sí mismo (capítulo IV) y la fórmula del reino de los fines (capítulo V), señalando en forma clara como las dos últimas fórmulas presuponen en último análisis a la primera. La exposición y análisis de la primera fórmula permite establecer una distinción entre dos tipos de contradicciones que podrían surgir en el proceso de universalización de las máximas: por un lado, una contradicción en el pensamiento que da lugar a los deberes perfectos y, por el otro, una contradicción en la voluntad que permitiría comprender los deberes imperfectos. El tratamiento de la segunda fórmula permite considerar a la humanidad como objeto de respeto, y el de la tercera, finalmente, posibilita la incorporación de una expectativa de felicidad al vincular en forma expresa al reino de los fines con la consecución de la felicidad. Ello conduce, como Rivera lo ve correctamente, a la presuposición de un legislador divino y, de ese modo, a la noción de una fe racional lo que conduce a plantear la relación no exenta de tensiones- y posibilidad de vinculación entre el principio de la moralidad autónoma y la fe religiosa de carácter racional.

El análisis de Rivera la lleva en el capítulo VI a analizar con más detenimiento la fundamentación del principio de la moral que Kant ofrece en la Grundlegung en la forma de una deducción análoga a la deducción trascendental de los conceptos puros del entendimiento presentada en la primera Crítica,distinguiendo este proceder del seguido en la Kritik der praktischenVernunft (1788) en la que Kant señala que una deducción semejante es no solamente imposible, sino también innecesaria en razón de las diferencias entre el uso teórico y el uso práctico de la razón. Kant introduce en este sentido la tesis de los dos puntos de vista, a saber: por un lado, el inteligible que nos presenta a seres racionales libres y, por el otro, el sensible en el que los seres se nos presentan sometidos -como ya su nombre lo indica- a la sensibilidad. La doctrina kantiana del idealismo trascendental que se erige sobre la base de esta distinción puede ofrecer así la salida al círculo de la deducción al mostrar que somos seres inteligibles libres desde un punto de vista y, al mismo tiempo, sometidos a la sensibilidad, desde otro. El principio moral debe tener en cuenta por ello a la receptividad y a las condiciones de espacio y tiempo a las que ésta se encuentra sometida. Es aquí donde se abre la vía para desarrollar una teoría de la virtud que Rivera expone con claridad en el capítulo VII de su libro. En efecto, se trata de ofrecer no una ética sino una teoría de la virtud que atienda a los problemas relacionados con el carácter moral, esto es con la sensibilidad para percibir rasgos moralmente relevantes del horizonte en el que los sujetos actúan, y con su cultivo, es decir con el cultivo de las disposiciones y sentimientos morales. Con ello vuelve a aparecer uno de los problemas que guían al libro entero y que ya habían sido mencionados al inicio de esta reseña: el de la relación entre la moral autónoma del deber y la felicidad y el modo en que la tentativa de resolución de su tensión conduce hacia la esfera de la religión (capítulo VIII).

El libro muestra en su conjunto un sólido conocimiento de la obra kantiana -especialmente de su vertiente ética- al que se aúnan una claridad expositiva, un lenguaje claro y un gran rigor argumentativo. Como en toda obra quedan, por supuesto, algunos puntos que el lector desearía que se hubieran tratado quizá con un poco de mayor detalle. Entre ellos, por ejemplo, el de la relación de la propuesta kantiana con otras tradiciones no solamente en relación con el problema de la felicidad (Aristóteles, Hume y el Utilitarismo), sino también respecto al modo en que Kant comprende la acción (Aristóteles), los principios (morales) como reglas (Wittgenstein), la psicología moral (Rawls, Kohlberg), etc. Igualmentedeseable habría sido la consideración de literatura secundaria sobre las diversas reconstrucciones e interpretaciones de la ética kantiana realizadas fuera del ámbito anglosajón (por ejemplo, en el alemán). Ello no obsta, sin embargo, para reconocer a este libro como una gran contribución al estudio, reconstrucción e interpretación de la ética kantiana en el mundo hispanohablante 


\title{
Vicente de Haro Romo: Duty, Virtue and Practical Reason in Kant's Metaphysics of Morals. Hildesheim, Zürich, New York, Georg Olms Verlag, 2015, 342 pp. ISBN: 978-3-48742-2152-0.
}

\author{
EDUARDO E. CHARPENEL ${ }^{1}$
}

\begin{abstract}
La filosofía moral kantiana es, como es bien sabido, una de las propuestas más decisivas e influyentes dentro de la tradición y un tópico fecundo de debate académico. Autores de muy distintos perfiles se han ocupado de la misma ya sea para rehabilitarla o para criticarla, y es de esperar que la discusión sobre esta faceta del pensamiento de Kant siga ocupando un lugar central y decisivo. El panorama para ello en nuestros días es, sin embargo, muy distinto que en antaño, toda vez que, si bien entre ciertos interlocutores existen todavía prejuicios muy arraigados en contra de la propuesta kantiana que se remontan a críticas tan diversas como las de Schiller, Hegel, Scheler y Bernard Williams, la visión sobre la misma, sobre todo entre los círculos especializados, es cada vez más informada y se apoya, entre otras cosas, en una lectura más detallada y atenta de las diversas obras que conforman el corpus kantiano. En este sentido, se ha vuelto una tarea fundamental en las últimas décadas traer al centro del debatela Metafísica de las costumbres, y en concreto, la Doctrina de la virtud (Tugendlehre) -un texto éste que, dicho sea de paso, fue siempre tenido por Kant como aquella obra a la que, de alguna u otra manera, su filosofía crítica debía de conducir, como de ello dan testimonio varias afirmaciones en las dos primeras Críticas así como en la Fundamentación, las cuales la anuncian y vislumbran en ella la culminación de una vasta empresa intelectual. En efecto, muchas de las objeciones en torno a la ética kantiana asumen una lectura sumamente procedimental que descansa en una interpretación sesgada y descontextualizada de la primera formulación del imperativo categórico, y dejan de lado otros desarrollos como los contenidos en la Tugendlehre que no sólo complementan sino que dimensionan ciertas tesis de Kant que sólo encuentran una fundamentación o una aproximación inicial en otras obras.
\end{abstract}

Frente a este contexto, puede afirmarse que el libro de Haro es una contribución decisiva para poder superar objeciones poco informadas dirigidas en contra de la ética kantiana. La Tugendlehre es, en muchos aspectos centrales, como lo muestra con acierto de Haro, una ética material; de lo que en dicha obra se habla son de fines concretos de la acción que es obligación de todos tener, con lo cual se establece, entre otras cosas, que hay una importante dimensión teleológica en la filosofía práctica kantiana y que la objeción planteada por Scheler, entre otros, en contra del supuesto carácter recalcitrantemente formalista de la misma ignora por completo este importante punto. La ética kantiana se nos revela en la Tugendlehre como una ética que hace importantes consideraciones sobre el cultivo de nuestros talentos y nuestros afectos, que invita a un genuino compromiso por el bienestar y la búsqueda de felicidad de nuestro prójimo, y que reconoce la complejidad intrínseca de la acción y los asuntos humanos, ante los cuales sólo se puede dar una respuesta de forma reflexiva, meditada y deliberada, y no mediante una solución mecánica y prefabricada, es decir, cuasi-instrumental técnica, como muchas veces se le atribuye, equivocadamente, a Kant. De una forma que combina tanto el mayor rigor filológico como sistemático, de Haro acomete, en los dos primeros capítulosde su obra, tareas tan distintas como complejas como lo son explicar la relación y el hilo conductor común que hay entre la Fundamentación, la Crítica de la razón prácticay laTugendlehre, elucidar la compatibilidad y unidad esencial de las distintas formulaciones del imperativo categórico, reconstruir la teoría de la motivación moral kantiana mediante el esclarecimiento de nociones como las de voluntad (Wille), arbitrio (Willkür), y fundamento de determinación (Bestimmungsgrund), y corregir ciertas interpretaciones dentro de la propia Kantforschung que a su juicio son desacertadas. La objeción a la

${ }^{1}$ Universidad Panamericana. Campus México, Facultad de Filosofía. 
que le da un mayor peso en su discusión -y que se remonta al propio Hegel- es la que le imputa a Kant el que las máximas en el test de evaluación moral son siempre manipulables, de modo que éstas son siempre susceptibles de acomodarse a los intereses y fines personales del agente práctico. Con respecto a este punto particular, me permito observar que el tratamiento de esta objeción y una consecuente defensa de la posición kantiana son de los mejores desarrollos que ofrece de Haro con su obra.

Con su texto de Haro logra desmentir varias objeciones que se le hacen a Kant; algunas de ellas, cabe decirlo, son refutadas más bien de modo indirecto, y uno desearía quizás oír con mayor detalle la voz de Haro en relación con las mismas, pero es entendible en buena medida que su desarrollo no sea éste, pues su objetivo en el libro no es únicamente reivindicativo o polemista. Duty, Virtue and Practical Reason in Kant's Metaphysics of Morals es un genuino intento por hacer filosofía con Kant -adviértase aquí el uso enfático de la preposición-, pues el autor ve en el pensamiento crítico kantiano, y, en concreto, en la vertiente práctica del mismo, una guía que puede ser iluminadora ante el desconcierto moral de nuestros tiempos. El libro podría haberse limitado a ser una brillante obra sobre Kant -nótese aquí también el uso de la preposición- si sólo mostrara un sólido trabajo de las fuentes originales en alemán, si aclarara el empleo de ciertas nociones reconstruyendo fielmente su contexto histórico de aparición, o si sus interlocutores fuesen todos ellos comentaristas kantianos discutiendo problemas inmanentes a la literatura secundaria, pero en realidad un examen muestra que el libro va más allá de esto. En efecto: además de satisfacer estos estándares, de Haro muestra, con auténtico compromiso intelectual, que, en su lectura, la filosofía práctica de Kant no es una pieza decorativa de museo. Antes bien, de Haro pondera a la filosofía práctica kantiana como una propuesta robusta, atinada y congruente que, contrariamente a lo que muchos han pensado, tiene un rostro humano y un apelo a las inquietudes existenciales de más hondo calado. En otras palabras, se trata de una filosofía moral que, a pesar de lo que muchos han llegado a creer, no se queda corta ante las exigencias de nuestros tiempos.

Retomando, sin embargo, el tema de las objeciones comunes en contra de Kant, me parece también conveniente resaltar la pertinente respuesta dede Haro, en el capítulo cuarto de su libro, a la crítica según la cual la noción o idea de tener "deberes para con uno mismo" es una especie de contrasentido o confusión categorial, pues, según reza dicha crítica, quien obliga siempre está en condiciones de suspender o levantar la obligación, por lo cual siempre tendríamos la licencia de dispensar o desatender dichos deberes para con uno mismo. Si bien defender la pertinencia de esta noción implica, desde una perspectiva exegética, retomar la siempre polémica distinción trascendental y distinguir entre un homo noumenon y un homo phenomenon, también es cierto que de Haro da elementos para hacer asequible esta noción a través una perspectiva fenomenológica bastante cercana a la experiencia cotidiana, desde la cual muchas veces tenemos plena conciencia de que "nos debemos algo a nosotros mismos" y de que estamos siempre lejos de satisfacer los criterios con los cuales, idealmente, desearíamos regir nuestras propias vidas. Como un breve apunte: vale decir sobre esto que la exigencia tematizada por Kant de autoconocimiento a la que nos someten los deberes con nuestra propia persona hermana de modo directo a su filosofía con las exigencias que ya Sócrates plantease en la Antigüedad para el hombre virtuoso. Pero volviendo al punto principal de la discusión: de Haro tiene la virtud, siempre que la ocasión lo amerita, de presentarnos, por un lado, la línea de interpretación que es más fiel al autor desde las categorías y presupuestos característicos del mismo, y por otro lado, perfilar una línea de pensamiento que hace más plausible y próxima la línea argumentativa kantiana en términos sistemáticos, de modo independiente a la arquitectónica global del proyecto crítico.

Otro punto que me gustaría subrayar de la argumentación de de Haro es el acierto que tiene de escapar a los rótulos con los que comúnmente se pretende caracterizar a las posiciones filosóficas. El que, por ejemplo, gran parte de los debates en ética normativa se dan desde bandos antagónicos como los denominados de "ética de la virtud" o "deontológicos", suele simplificar, sin duda alguna, las tareas propias de la manualística, pero esto se convierte en un obstáculo real cuando uno lo que busca es asir en toda su complejidadel pensamiento de figuras importantes de la tradición como lo es sin duda Kant. De Haro evita estas salidas fáciles, cuestiona a intérpretes que incluso han querido ver cierto consecuencialismo en Kant como David Cummisky, y, para nuestro asombro, el propio Allen W. Wood, y muestra que en Kant hay en realidad varios puntos de afinidad con las éticas de la virtud de la Antigüedad, lo cual, en cierta medida, no podía ser de otra manera si se toma en cuenta el hecho 
de que Kant conocía sumamente bien a los autores latinos. Lo que resulta sorprendente, sin embargo, es que Kant también -aunque esto no lo reconozca él mismo- coincide en puntos fundamentales con la propuesta de Aristóteles. Y en este punto en concreto, se aprecia nítidamente que el compromiso de de Haro con Kant no es ciego y acrítico y que él mismo sabe tomar distancia respecto del autor cuando esto es necesario. De Haro no muestra reparo en reconocer, en el capítulo tercero de su libro con ocasión de una discusión sobre la teoría aristotélica del justo medio, que la visión de Kant sobre Aristóteles es bastante parcial y deficiente, lo cual precisamente se debe a que Kant conoció a Aristóteles a través de manuales y no a partir de un estudio directo de las fuentes originales. Esto no impide, sin embargo, que desde un terreno más bien sistemático de evaluación, de Haro afirme con acierto que las propuestas de estos autores coinciden en varios puntos esenciales, y que, en cierto sentido, nuestra tarea consistiría en pensar la relación de estas dos teorías éticas noen términos de antagonismo, sino en términos de propuestas que pueden una a otra esclarecerse y arrojarnos sinérgicamente una luz importante sobre aspectos esenciales de la praxis humana.

Como mencionaba en un principio, la literatura sobre la Tugendlehre va cada vez más en aumento. En lo que corre de esta y la década pasada, es posible mencionar trabajos muy destacados como los editados por Timmons, Kant's Metaphysics of Morals. Interpretative Essays (2002), por Denis, Kant's Metaphysics of Morals (2010), y por Trampota, Sensen y Timmermann, Kant's "Tugendlehre". A Comprehensive Commentary (2013), así como la monografía elaborada por Forkl, Kants System der Tugendpflichten. Eine Begleitschrift zu den "Metaphysischen Anfangsgründen der Tugendlehre" (2001). Sin desestimar en lo absoluto estos trabajos -todos ellos clave hoy en día para una interpretación informada de Kant-, me atrevería a decir, no obstante, que la monografía de Haro es en buena medida el más ambicioso entre ellos, toda vez que, si bien sus capítulos tercero, cuarto y quinto siguen con cierta meticulosidad el orden de discusión de la propia Tugendlehre, el libro de de Haro es el que más aspira a trascender el género del comentario y a combinar momentos exegéticos con reflexiones y argumentos de corte más sistemático de cara a discusiones actuales. Por supuesto, dicha empresa no está libre de riesgos y exenta de ciertos puntos debatibles, pero considero que la misma, aunada a la de los otros esfuerzos ya referidos, no hará sino avivar el debate académico sobre una de las propuestas en filosofía moral más atractivas de la tradición filosófica. 



\title{
Paolo Grillenzoni: Kant e la scienza (1755-1760). Roma, Aracne, 2016, 575 pp. ISBN: 9788854895232.
}

\author{
DANIELE SAVINO ${ }^{1}$
}

La obra de Paolo Grillenzoni Kant e la scienza, 1755-1760 dedicada al análisis del componente científico del pensamiento kantiano y de su aportación a su desarrollo, toma en consideración los escritos del período pre-crítico sucesivo al abordado en Kant e la scienza. 1747-1755 (Milán, Vita e Pensiero, 1998). En este último, fueron analizadoslos Gedanken von der wahren Schätzung der lebendigen Kräfte, los dos artículos aparecidos en 1754 en la revista Wöchentliche Königsbergische Frag- und Anzeigungs-Nachrichten y la Allgemeine Naturgeschichte und Theorie des Himmels.

Atento a la enseñanza de Mariano Campo, quien invitaba a preguntarse cuáles fuesen "los problemas que interesaron primeramente a Kant, cuál fue la mentalidad con la que los percibió y planteó, cuál fuese su primera formación científica y metafísica en el marco de las corrientes científicas y filosóficas de la época" (Kant precritico, 1944), Grillenzoni había puesto de relieve en su primer volumen la influencia incisiva y creciente de Newton sobre las investigaciones de juventud dirigidas en un principio -tras muchas incertidumbres- a las "fuerzas vivas" y seguidamente al cosmos y al planeta Tierra; en todo ello y entre otros asuntos mostró cómo tales investigaciones se dirigían a un examen cada vez más pormenorizado de los fenómenos naturales y de los elementos constitutivos de la materia. A dicho examen, orientado cada vez más "desde el movimiento de los cuerpos astrales [...] al movimiento en los cuerpos" (Introducción, 13) se consagra el presente volumen.

El procedimiento de la investigación kantiana de lo general a lo particular, del sistema solar al átomo -a saber, desde una visión comprehensiva de la realidad, que contemplase también la extensión infinita del Universo, a una teoría general de la materia, la divisibilidad de las partículas constitutivas últimas, la naturaleza de las fuerzas activas en los cuerpos y su interacción en el espacio- tenía en la ciencia newtoniana, tanto por su método como por sus tesis, un precedente insoslayable. La influencia de Newton, ya claramente subrayada por el subtítulo de la obra cosmológica de 1755 (Versuch von der Verfassung und dem mechanischen Ursprunge des ganzen Weltgebäudes nach Newtonischen Grundsätzen abgehandelt), se remitía a Martin Knutzen, joven docente de la Albertina, quien introdujo a Kant no sólo a las doctrinas de los Philosophiae Naturalis Principia Mathematica y de Opticks, sino también, con toda probabilidad, a los desarrollos del newtonianismo ligados a la obra de sus principales divulgadores e intérpretes holandeses -de P. van Musschenbroek a H. Boerhaave y W. 's Gravesande.

En este segundo volumen, que dedica amplio espacio a las investigaciones sobre el éter, sobre la estructura de los cuerpos y sobre los elementos constitutivos de la materia, Grillenzoni muestra cómo la influencia del componente newtoniano -tan estimulante como problemática, si se considera que por "mucho tiempo, durante el siglo XVIII, ser newtonianos pudo significar tantas cosas distintas" (Introducción, 15-16)- se viene enriqueciendo progresivamente gracias a las principales doctrinas químicas de la edad pre-lavoisieriana. La primera de las tres secciones que componen el volumen -que, por este motivo, hubiera podido ser subtitulado Doctrina de la materiase propone justamente reconstruir el marco histórico de la química en la primera mitad del siglo XVIII y constituye un esencial pórtico propedéutico para comprender cómo Kant se injertase en un debate científico dotado de un estatuto epistemológico todavía muy incierto, cuyos lábiles confines -concernientes tanto al contenido como al método- oscilaban aún entre experimentación científica e hipótesis casi alquímicas.

${ }^{1}$ Universidad "Sacro Cuore” de Milán. 
El autor lleva a cabo un esmerado análisis, consciente de que:

la investigación química regresará al meollo del pensamiento kantiano en su última fase con la plena aceptación de la teoría antiflogística de Lavoisier [...] y retomando justamente la noción de éter que, así pues, reclama ya desde ahora ser enfocada de modo específico. En efecto, no sólo servirá para aclarar los desarrollos pre-críticos -que desembocaron en la elaboración de una teoría química del éter, basada fundamentalmente en las principales doctrinas de la época- sino que, observados en perspectiva, podrán contribuir también a la comprensión de la teoría filosófica del éter adelantada en el Opus postumum con vistas alÜbergang von den methaphysischen Anfangsgründe der Naturwissenschaft zur Physik. (22)

La presente investigación, pues,

pretende contribuir a sentar las bases para la comprensión de dicha evolución y prestará atención, por tanto, no sólo a aquellos aspectos que a la larga fueron fatigosamente superados tras los desarrollos de la madurez tardía, sino sobre todo a aquéllos que pudieron vehicular -al menos, en parte- tales desarrollos y 'soluciones' con connotaciones no sufragadas por la experiencia ('a priori') e instancias, ya más bien explícitas, de una uni-totalidad de la experiencia. (23)

Las dos secciones sucesivas se dedican respectivamente al De igne (1755), traducido en su integridad en el Apéndice -al autor se debe su primera versión italiana (Milán, ISU, 1987) - y a las disertaciones Nova dilucidatio (aún de 1755) y Monadologia physica (del año siguiente). Junto con la más célebre disertación para el cargo de profesor ordinario (De mundi sensibilis atque intelligibilis forma et principiis), las tres obras latinas marcan las etapas señeras de la carrera académica de Kant. En efecto, con el De igne Kant obtuvo el título de Magister legens en la Universidad local; al mismo tiempo secundaba intereses y orientaciones de las Academias de la época, dado que el problema de la naturaleza y propagación del fuego había sido objeto de un concurso convocado en 1738 por la Academia Real de Ciencias de París y habría podido suscitar la atención de algún miembro de la Academia de Ciencias de Berlín (dirigida entonces por el filósofo y matemático francés Maupertuis y animada por personalidades fuertes como Euler). La Nova dilucidatio garantizó a Kant la habilitación docente, mientras que con la Monadologia physica esperó obtener la cátedra de Lógica y Metafísica dejada vacante en 1751 por Knutzen; sin embargo, como es sabido, el estallido de la Guerra de los Siete años hizo vana esa esperanza.

Analizando las tres disertaciones latinas e insertándolas en el contexto científico de la época, Grillenzoni ilustra el paso progresivo desde las posiciones científicas-mecanicistas del De igne (y de la Allgemeine Naturgeschichte) a las filosófico-dinamicistas de la Monadologia physica. Evidenciaasí un aspecto crucial del Kant pre-crítico, útil para entender su interés por los aspectos dinámicos y vitales de la Naturaleza -éstos, por ahora, sólo en el trasfondo: piénsese en la "oruga" y la "brizna de hierba" evocadas ya en la Allgemeine Naturgeschichte- y, sobre todo, para aclarar en el plano teorético la relación intrínseca entre física y metafísica, una relación -orientada, durante los primeros quince años, al connubio- también determinante para los despliegues sucesivos.

La indagación kantiana sobre el fuego es sólo en apariencia un escrito coyuntural:

Si bien fue una cuestión específica la que dio lugar al De igne, sería un error pretender reducir la disertación magisterial de Kant a la merarespuesta a la pregunta sobre la "llama". Sería reductivo tanto como creer que los Träume eines Geistersehers fueran sólo la resolución de las cuestiones planteadas a Kant por sus conciudadanos en torno a Swedenborg, o que el Was heißt: sich im Denken orientieren? fuese sólo la toma de postura en la polémica entre Mendelssohn y Jacobi. Al De igne subyace una concepción general de la materia y del entero mundo físico, que Kant entendió deberabordar en todo su vasto alcance y con el máximo esmero. (14)

Grillenzoni ilustra esta concepción con minuciosidad filológica -a la luz también del Vorarbeit recuperado y comentado por H.-J. Waschkies (Ein Entwurf zu Kants Dissertation De Igne Loses Blatt Dorpat / Tartu, 1994)- subrayando tanto el ambicioso intento del futuro licenciado como su espíritu de iniciativa y crítica. Kant no se dejó inhibir por las muchas dificultades que albergaba el tema ni por la problematicidad del marco histórico; antes bien fue "estimulado" por ellas,

o, mejor dicho, quizá, fue reforzado en su espíritu de búsqueda de una solución unitaria que resolviese los contrastes y, quizá, enmendase ciertas incongruencias puestas de relieve por autores dignos de todo crédito o al menos integrase sus doctrinas: una empresa, en definitiva, incluso más ambiciosa ciertamente, con menos garantías de éxito- que aquélla cosmológica que había llevado felizmente a puerto. (20) 
La actitud de Kant respecto de dichas doctrinas es de tipo sincrético: individualiza analogías y diferencias entre ellas y, valiéndose de observaciones empíricas y argumentaciones remitidas a "demostraciones" geométricas, arriba a una síntesis personal que le permite definir un elemento natural fuertemente metamórfico, el éter, capaz de explicar la mayor parte de los fenómenos naturales. «Imperceptible y físico a un tiempo, dada su indeterminación y su carácter poliédrico el éter pareció consentir a Kant una audaz unificación y la posibilidad de mantener ligados -por el momento- planos diversos: al menos, los dela realidad inorgánica y la orgánica, los de la física y la química, así como perspectivas filosóficas (naturales) distantes entre sí» (343).

Particular interés reviste la tentativa de cotejar Newton y Stahl, orgullo del mundo germánico, por otra parte, ensayada por J.-B. Sénac en los años veinte del siglo XVIII (Nouveau cours de chymie, suivant les principes de Newton et de Stahl, 1723) y más adelante también por Buffon, Macquer y Guyton de Morveau (I, 142-144). Dicha empresa venía vehiculada por una noción de éter definida sólo aproximadamente y hasta enigmática en ciertos aspectos:

A menudo hemos sorprendido a Newton», escribe Grillenzoni, «en el acto de animar a discípulos y colegas a buscar las muchas fuerzas activas en la naturaleza y aún "ignotas" o "sustraídas" a la observación [como, por ejemplo, el éter]. Kant [...] no titubeó en recoger el testigo. Más aún, cuando otros ámbitos de investigación ofrecían situaciones análogas, con prometedoras oportunidades de amplios espacios de maniobra. La hipótesis flogística, por ejemplo, no le iba a la zaga al éter en la estela de un "postulado omniexplicativo" y en un contexto que distinguía entre elementos primeros sensibles y elementos o principios primeros inaccesibles. (344)

Dado que todos los fenómenos naturales acontecen en un orden espacio-temporal que determina las relaciones constantes que constituyen las leyes físicas, en la Nova dilucidatio Kant se esfuerza en definir el espacio como principio metafísico del conocimiento mismo.

Espacio y tiempo son los nuevos "fecundos principios" que dan razón del saber cultivado por la ciencia» y que vienen a ser elevados al estatuto de elementos metafísicos. Aun ateniéndose a los principios fundamentales de la lógica clásica, analizados por Kant en las secciones I y II de la disertación, en la sección III «parecería abrirse camino [...] la exigencia de una nueva lógica, capaz de gobernar a los juicios en el plano de los contenidos y de la experiencia, casi un tímido pre-anuncio de la 'lógica trascendental. (379)

Sin espacio ni tiempo, toda experiencia se halla prejuzgada; bastecon ello para aclarar los motivos que indujeron a Kant a considerar los dos "nuevos" principios, motivos que "pueden ser individualizados", leemos en la página 393:

en la voluntad de integrar y formalizar los resultados de la paralela indagación científica en la búsqueda de una fundamentación metafísica de la doctrina newtoniana de la fuerza de atracción y en el reconocimiento (y justificación) de las condiciones relacionales de la ciencia, que de ello salía como ennoblecida - por la remisión al Intelecto divino- y, sobre todo, habilitada para acceder a los lugares institucionales asignados a la tradición de la cultura y de la instrucción -a saber, las Universidades. de Grillenzoni:

Llegando ya a la Monadologia physica, tres son los motivos de interés que guían el estudio

(1) como prueba de la convicción kantiana de que la ciencia precisa de la iluminación de la metafísica [...]; (2) en cuanto allí se expone una teoría dinamicista de la realidad a la que Kant, aun entre correcciones y rectificaciones, se mantendrá fiel en adelante; (3) por [...]el dilema de si todo cuerpo o substancia compuesta conste de partes simples o si, en cambio, no exista en lugar alguno nada simple (401-402).

En la disertación de 1756, Kant -haciendo memoria de las ganancias precedentes-vuelve a abordar el problema de la materia y más específicamente el relativo a la divisibilidad de sus partículas mínimas, llevando a cabo el examen y anticipando los extremos de la segunda antinomia matemática (a la primera antinomia, en cambio, le había abierto las puertas la Allgemeine Naturgeschichte).

Desde el plano empírico-experimental de la disertación de licenciatura, la Monadologia physica pasa, pues, al plano metafísico de los principios y de las fuerzas, a menudo activas en la oscuridad y en el misterio, presentándose como unauténtico espécimen del nexo intrínseco entre física y metafísica. Recurriendo todavía a la mónada leibniziana, Kant integra la visión materialista de los fenómenos naturales con un más maduro dinamismo. Ahora bien, en este caso la mónada queda "fisicalizada" - esto es, depurada de todo carácter psíquico y sometida a los rigores de la ciencia 
newtoniana- con el propósito de ganar un saber más sólido y mejor fundado. A diferencia de cualquier ente definido que la experiencia nos pone a la vista, la mónada -principio último indestructible, indivisible, irreducible - es una fuerza que, irradiando su propia y misteriosa energía, determina con su radio de influencia incluso esa extensión espacial en virtud de la cual es legítimo conjeturar una infinita divisibilidad, divisibilidad aplicable sólo parcialmente a los cuerpos (entendidos como agregados) y en absoluto a las mónadas mismas.

Con la Nova dilucidatio y la Monadologia physica, Kant pensó haber hecho su pequeño aporte a la revisión de la metafísica, advertida como necesaria desde los preámbulos del período precrítico: «Nuestra metafísica», escribía en 1747, «se halla en realidad, como muchas otras ciencias, sólo en el umbral de un conocimiento en verdad sólido; sabe Dios cuándo veremos cruzarlo» (Gedanken § 19). En 1956, la esperanza de verlo cruzadoparecía, quizá, más concreta. La confianza en una colaboración más estrecha entre metafísica y ciencia salió fortalecida, como demuestra la explícita invitación a la búsqueda de las "causas primeras" contenida en la Premisa a la Monadologia physica:

A quienes se limitan a los fenómenos de la Naturaleza les queda siempre vedada la recóndita inteligencia de las causas primeras; no arriban a alcanzar la ciencia de la naturaleza de los cuerpos en sí misma, de modo parejo aquien,ascendiendo cada vez más alto por un monte, creyera por ello poder tocar alguna vez el cielo con sus manos. De ahí que, aun cuando la mayoría piense poder prescindir de la metafísica en la investigación de la Naturaleza, ella sigue siendo aquí, sin embargo, la única que puede echar una mano y encender una luz. (482ss.)

Bien pronto, también esta solución mostraría grietas y contradicciones; empujaría así a Kant a nuevas contrastaciones y a un planteamiento más radical.

Traducción al castellano: Pedro Jesús Teruel 


\title{
Nuria Sánchez Madrid: A civilização como destino. Kant e as formas da reflexão. Florianópolis, Nefiponline, 2016, 288 pp. ISBN: 978-85-99608- 16-6
}

\author{
JOSEFA Ros VELASCO ${ }^{1}$
}

La obra de Kant es una de aquellas que nunca dejan de arrojar sorpresas y que jamás termina de ser leída e interpretada; y precisamente por ello su recepción tampoco deja de crecer frente al paso del tiempo y a pesar de que los intereses filosóficos circulen en la actualidad por caminos que podrían parecer contrarios o lejanos al pensamiento kantiano. El monográfico en portugués A civilização como destino. Kant e as formas da reflexão [La civilización como destino. Kant y las formas de la reflexión], publicado en 2016 de la mano de la editorial brasileña Nefiponline, de la Profesora Dr. Nuria Sánchez Madrid (Universidad Complutense de Madrid) es un ejemplo de relectura y redefinición del corpus kantiano frente a las interpretaciones tradicionales que circunscriben la filosofía kantiana a la metafísica en su sentido más canónico. Esta obra recoge algunos de los textos de la autora publicados entre los años 2012-2017 y otros tantos inéditos en los que analiza la unión entre los presupuestos trascendentales kantianos y las emociones y los sentimientos con relación al proceso de desarrollo de la civilización humana desde un punto de vista antropológico.

La civilización como destino es una obra que nace en el seno del proyecto de investigación Poetics of Selfhood: memory, imagination and narrativity (CFUL, Fundação para a Ciência e a Tecnologia del Gobierno de Portugal), y de los grupos Naturaleza humana y comunidad (III). ¿Actualidad del humanismo e intelectualidad del hombre? y Retóricas del Clasicismo. Los puntos de vista (contextos, premisas, mentalidades) (MINECO). Su contenido empezó a gestarse durante una estancia que Sánchez Madrid realizó en la Faculdade de Filosofia e Ciências da UNESP (2012), y quizá tuvo ocasión de perfilarse durante 2014-2015, durante una estancia en el Instituto de Filosofía del CSIC. Pertenecen a aquellos años gran parte de los textos que compendia ahora en este volumen y que habían sido publicados previamente como artículos o capítulos de libro: «Filosofía, tom e ilusão musical em Kant. Da vivificação sonora do ânimo à recepção do tom da razão» (Trans/Form/Ação, 2012); «Maneira e método. Notas para uma genealogia da Crítica a partir da "Metodologia do gosto" da Crítica do Juízo» (Studia Kantiana, 2012); «Dos obstáculos da natureza aos obstáculos da razão. Uma leitura das «Preleções de pedagogia» de Kant em seis passos» (Kant e-prints, 2010); «Razão, consciência e ficção: J.-J. Rousseau nas Vorlesungen über Anthropologie de I. Kant», (Dissertatio,2014); «Corpo, desejo e razão: a sedução como arte de dominação na Antropologia de Kant» (Comentário da Antropologia em sentido pragmático de I. Kant, 2014); «Decorum e sociedade civil: Kant em diálogo com B. Gracián e Chr. Thomasius» (Investigações kantianas I: um debate plural, 2014); y, finalmente, «Kant e Freud sobre os fundamentos da obediência» (Ethic@, 2012).

Dos contribuciones, sin embargo, son completamente inéditas y sólo pueden encontrarse en el monográfico La civilización como destino. Nos referimos al capítulo 1, «A "Técnica da natureza": A co-originariedade crítica de arte, natureza e razão», y al capítulo 7, «A normatividade pragmática na Antropologia de Kant», además de la «Introducción» que brinda la propia autora. A estos inéditos se suman un «Prefacio» del Prof. Dr. Leonel Ribeiro dos Santos, del Centro de Filosofía de la Universidad de Lisboa, y un «Posfacio», del Prof. Dr. Márcio Suzuki, de la Facultad de Filosofía, Letras y Ciencias Humanas de la Universidad de São Paulo de Brasil, que revisan los puntos cardinales del volumen de la Dr. Sánchez Madrid. Este cómputo de textos que damos paso a revisar en mayor profundidad hace de La civilización como destino un lugar de máximo interés para todo aquél interesado por la filosofía contemporánea y la interpretación más reciente de la filosofía kantiana.

${ }^{1}$ Universidad Complutense de Madrid. Departamento de Historia de la Filosofía, Estética y Teoría del conocimiento. 
«As formas da reflexão e a genealogia da ordem» es el primer capítulode la obra de la Dr. Sánchez Madrid y está compuesto por los subapartados"Técnica da natureza": A co-originariedade crítica de arte, natureza e razão;Filosofia, tom e música em Kant: Vivificação sonora do ânimo e recepção do tom da razão; y, por último, Maneira e método: Notas para uma genealogia da Crítica a partir da "Metodologia do gosto" da Crítica do Juízo. En el primer subapartado, la autora propone un paralelismo entre la percepción musical y la búsqueda conceptual del que se desprende la idea de que la filosofía es capaz de arrojar luz cuando se adentra en la investigación de conceptos indeterminados, así como la música sugiere al oyente un determinado orden composicional a partir de la tonalidad. Este ejercicio no trata sino de establecer una heurística que posibilita el paso de las ideas reguladoras de la Crítica de la razón pura a los juicios reflexionantes estéticos y teleológicos de la Crítica del Juicio. Serán nombres de referencia, en este primer capítulo, los de Gilles Deleuze y Gérard Lebrun. El segundo subapartado es, de alguna manera, una continuación del primero. Filosofía, tom e ilusão musical em Kant, propone que la música es el arte más apto para captar los sentimientos que confieren sentido y proporción al mundo de la vida. Se trata de un arte de carácter físiológico, explica Sánchez Madrid, que a un mismo tiempo se entrelaza con la razón. En este punto, la autora aunará los presupuestos kantianos con los schopenhauerianos. Este capítulo termina de clarificar lo expuesto en el primero y advierte de la línea que seguirán los demás, mediante la exposición de que el sentimiento no se separa de la razón. Será ya en el tercer apartado en el que se manifieste de manera innegable que el método filosófico está ligado al modus aestheticus, así como la comunicabilidad del juicio del gusto sirve al proyecto de ilustración del público general.

El segundo capítulo de la obra se titula «Paradoxos da cultura: educação, consciência e diferença sexual» y se encuentra, como el anterior, dividido en tres subapartados: Dos obstáculos da natureza aos obstáculos da razão: Uma leitura das «Preleções de pedagogia» de Kant em seis passos; Razão, consciência e ficção: J.-J. Rousseau nas Vorlesungen über Anthropologie de I. Kant; y Corpo, desejo e razão: a sedução como arte de dominação na Antropologia de Kant. Como apreciamos en un primer acercamiento, esta segunda parte del libro enfrenta tres temas que conjugan no sin dificultades: la pedagogía, la relación entre la conciencia, la razón y la ficción, y la cuestión de la diferencia sexual. Dos obstáculos da natureza aos obstáculos da razão y Razão, consciência e ficção, se adentran en la comunión posible entre la pedagogía y la antropología pragmática, partiendo de la analogía entre el concepto de educación en Kant y el pensamiento nietzscheano. Así las cosas, Sánchez Madrid pone de manifiesto que la educación no puede ser el resultado de modelos, toda vez que el individuo alcanza la autonomía a través del error y la transgresión. Corpo, desejo e razão, por su parte, aborda las diferencias entre los sexos desde el punto de vista de dos polos inseparables: el jurídico y el antropológico. Aunque la combinación de ambos resulta aparentemente conflictiva, desembocará de nuevo a la unión entre los afectos y la razón.

El tercer y último capítulo, «Os alicerces da civilização: a sociabilidade como aprendizagem da coação», discute el problema de la idea de normatividad en la antropología -y aquí enlaza con el capítulo anterior-. A lo largo de los apartados A normatividade pragmática na Antropologia de Kant; Decorum e sociedade civil: Kant em diálogo com B. Gracián e Chr. Thomasius; y Kant e Freud sobre os fundamentos da obediência, se presentan diferentes modalidades de articulación entre la antropología pragmática y moral en el sistema kantiano, a partir de la explicación de lo que conforma la prudencia mundana. La Dr. Sánchez Madrid tomará como punto de partida a Baltasar Gracián y a Christian Thomasius para reconstruir los temas del decoro y de la diferencia entre los deberes perfectos e imperfectos. Todo ello nos conduce a la clarificación de la idea de sociabilidad y del refinamiento cortesano propio de la Ilustración alemana. El cierre del libro, de la mano del subapartado que pone en relación a Kant y a Freud, hace las veces de una conclusión al volumen en su totalidad. En este último punto, la autora reconoce que Kant había hecho alusión a lo que Freud consideraba las pulsiones egoístas que afectaban negativamente a la vida colectiva. Así las cosas, observamos una anticipación de El malestar en la cultura en la filosofía kantiana que sólo Sánchez Madrid ha sabido abordar desde una posición distanciada de las interpretaciones tradicionales del pensamiento de Kant.

Es precisamente este ejercicio el que confiere a la obra de Nuria Sánchez Madrid un hilo conductor capaz de mostrar la vigencia de los planteamientos del ilustrado, aunando temas propios de la filosofía política y moral, de la estética y de la antropología, y poniendo sobre la mesa algunos de los tópicos que han sido desatendidos por los investigadores y desde los que se justifica una nueva 
lectura del corpus filosófico del pensador de Königsberg. A nadie extrañará, tras la lectura de esta obra, que una especialista como la Prof. Dr. Nuria Sánchez Madrid, que no sólo ha enriquecido el paradigma de recepción de la obra kantiana con sus aportaciones, sino que, además, colabora activamente para que otros tengan la oportunidad de hacerlo, haya sido capaz de ver lo que para otros ha quedado en la sombra: la vigencia del pensamiento kantiano y la importancia de su relectura y reinterpretación a la luz de las cuestiones que más preocupan a la sociedad contemporánea. 



\title{
Laura Anna Macor: Die Bestimmung des Menschen (1748-1800). Eine Begriffsgeschichte. Forschungen und Materialien zur deutschen Aufklärung. Abteilung II: Monographien. - FMDA II, 25. Stuttgart, Frommann-Holzboog, 2013, 432 pp. ISBN: 978-3-7728-2615-3.
}

\author{
DANIEL SCHWAB ${ }^{1}$
}

Laura Anna Macor unternimmt mit ihrer 2013 erschienenen Monographie „Die Bestimmung des Menschen (1748 - 1800)“ einen aus sprach- und philosophiegeschichtlicher Perspektive überaus interessanten und bereichernden Streifzug durch die philosophische Diskussions- und Publikationslandschaft des deutschen Sprachraums zur Blütezeit der Aufklärung. Leitfaden ihres Streifzuges bildet, wie schon der Titel verrät, der Begriff der Bestimmung des Menschen. Dieser Begriff kann Macor zufolge, neben dem der „allgemeinen Menschenvernunft“ (S. 21), als die das Denken der Aufklärung wesentlich prägende und dessen „anthropologische[s] Fundament“ (ebd.) bildende Basisidee angesehen werden, an deren Behandlung durch die unterschiedlichen zeitgenössischen (Vor-)Denker sich der damalige intellektuelle wie politische und gesellschaftliche Strukturwandel auf paradigmatische Weise ablesen und darstellen lässt. Es geht, um die Autorin selbst sprechen zu lassen, näher um die Frage

„der Bestimmung des Menschen als ,philosophischer Grundfrage der Theologie in der Aufklärungszeit ${ }^{\circ 2}$, also [...] der sprachlichen Verankerung des Begriffs, [...] dessen Quellen und Bedeutung sowie [...] dessen kulturellem, sprich religiösem und philosophischem Hintergrund [...].“ (S. 32)

Bevor ich näher auf den eigentlichen Inhalt des Buches eingehe, will ich an dieser Stelle auf eine (mögliche) Unstimmigkeit sprachlicher Natur hinweisen, die mir seine Lektüre ein wenig erschwert hat. Spricht Macor in der eben zitierten Passage noch differenziert von „der sprachlichen Verankerung des Begriffs [der Bestimmung des Menschen]“" im Unterschied zum Begriff der Bestimmung des Menschen, des Begreifens seines ,Wozu? selbst, lässt sie diese Differenz in der Folge allem Anschein nach immer wieder außer Acht. So schreibt Macor, um nur ein paar Beispiele zu nennen, S. 36: „Der Begriff ,Bestimmung des Menschen“ wird 1748 offiziell in das theologische und philosophische Sprachgut der Aufklärung eingeführt“ [Herv.: D.S.]; S. 151: „Wielands Aneigung des Begriffs ,Bestimmung des Menschen' beruht [...] auf der völligen Übereinstimmung mit Spaldings theologisch äußerst innovativem Entwurf“; S. 168 von der „offiziellen Einführung des Begriffs ,Bestimmung des Menschen““ und S. 355 von der ,unvermeidliche[n] Ausbeutung eines zu verwendeten Begriffs“. Dass in dem von ihr behandelten Fall „Wort- und Begriffsgeschichte [...] Hand in Hand [gehen]", wie Macor S. 33 vorab bemerkt, mag zwar richtig sein, gereicht jedoch nicht zur Rechtfertigung dafür, den Ausdruck „Bestimmung des Menschen“ und den Begriff der Bestimmung des Menschen auf diese Weise zusammenzuwerfen. Dass sie dies tut, verwundert umso mehr, als Macor S. 36 bemängelt, dass in den bis dato existierenden Forschungen „Wort“, ,Wendung', ,Begriff" u.a. [...] immer wieder als Synonyme fungiert" hätten und S. 37 für eine nur durch „methodische Genauigkeit“ zu erreichende Unterscheidung zwischen „Wort- und Begriffsgeschichte“ plädiert. Mag es auch keine Konsequenzen für den wissenschaftlichen Gehalt der Untersuchung haben (was einer eingehenden Prüfung unterzogen werden müsste), so verwirrt es doch und es stellt sich zumindest die Frage, welchen Begriff von „Begriff“ Macor eigentlich hat, wenn ein Begriff „offiziell“ (s.o.) eingeführt und ausgebeutet werden kann, andererseits aber doch vom Wort

${ }^{1}$ Universität Heidelberg.

${ }^{2}$ Macor zitiert an dieser Stelle den Titel eines ihrer Aufsätze. Näheres zu den bibliographischen Daten findet sich im Literaturverzeichnis. 
verschieden sein soll. ${ }^{3}$ Sollte dieses Problem nicht zufriedenstellend anhand des bloßen Wortlauts des Textes zu Macors Gunsten gelöst werden können, so womöglich doch dem Sinn nach. Daher belasse ich es an dieser Stelle bei einem bloßen Verweis auf eine mögliche Unstimmigkeit - oder auch auf die Möglichkeit, dass ich meinesteils zu starr auf einer bestimmten Sprachkonvention beharre. In jedem Fall handelt es sich bei Macors Arbeit um eine fraglos hervorragende und lehrreiche Untersuchung, bestechend nicht zuletzt durch detaillierte Quellenarbeit und einen treffsicheren Spürsinn für historische und sprachhistorische Zusammenhänge. S. 52, 53 etwa macht Macor für das Substantiv „Bestimmung“ „bis zur ersten Hälfte des 18. Jahrhunderts drei Bedeutungen“ aus, [1.] eine voluntative, auf den Willen und die Wirkmächtigkeit des Subjekts bezogene, [2.] eine prädikative, eigenschaftsdeterminierende und [3.] eine finale, (end)zweckgebundene. Dabei weist sie die erste Bedeutung als die sprachhistorisch ursprüngliche aus, zu der im Laufe der Zeit die zweite und schließlich auch die dritte Bedeutung hinzugekommen sind. ${ }^{4}$ So seiner Bedeutung nach erweitert, konnte sich das Wort „Bestimmung“ in eine Reihe mit Worten wie „Zweck“, „Schicksal“ oder „Berufung“ setzen und so auch für die theologische wie philosophische Bearbeitung der Frage verwenden lassen, wozu der Mensch ist, was er sein und tun soll - und wer ihm hierüber einzig gebieten darf. Ich werde die von Macor in der Hauptsache hervorgehobenen und untersuchten historischen Zusammenhänge am Leitfaden dieser Bedeutungsdreifaltigkeit in der in gegenwärtigem Rahmen gebotenen Kürze darzustellen versuchen. ${ }^{5}$

Doch zunächst noch ein paar Worte zu Gliederung und Aufbau des Buches. Nach einer methodisch vorausblickenden Einleitung konzentriert Teil I sich auf die sprachliche und begriffliche Vorgeschichte (Kapitel I) der nachzuzeichnenden Entwicklung und auf deren historischtheologischen Anfangspunkt, den Macor an der 1748 von Johann Joachim Spalding verfassten Schrift „Die Bestimmung des Menschen“ festmacht, durch welche die voluntative Komponente des menschlichen ,Wozu?' erstmals prominent und richtungsweise ins Spiel gebracht und ausgearbeitet wurde (Kapitel II). ${ }^{6}$ Teil II widmet sich den in den darauffolgenden Jahren erfolgten inner- wie überkonfessionellen Reaktionen auf besagte Schrift und die ihr inhärente Provokation für orthodoxe Lutheraner (Kapitel III) bzw. Gelegenheit für aufgeschlossenere Theologen (Kapitel IV). In Teil III zeichnet Macor nach, wie der zunächst vor allem innertheologisch geführte Streit um besagten Begriff und dessen Ausdruck Einzug in philosophische Erörterungen gehalten hat; angefangen bei der Debatte zwischen Abbt und Mendelssohn (Kapitel V) über die anschließenden Gedanken des jungen Schiller (Kapitel VI) bis hin zu Kants Versuch einer kritischen Vereinigung des voluntativen Aspekts der menschlichen Bestimmung mit ihrem finalen Aspekt (Kapitel VII). Teil IV behandelt die Ausweitung des Begriffs auf geschichtsphilosophische Erwägungen durch Herder (Kapitel VIII) und Kant (IX), die für letzteren allem Anschein nach zu einer ,gattungsgeschichtliche[n] Uminterpretation der menschlichen Bestimmung“ (S. 268) geführt haben, die u.a. von Herder, Schiller und Mendelssohn kritisch kommentiert wurde. Schließlich erörtert Macor in Teil V die Gründe für die zum Ende des 18. Jahrhunderts hin sich abzeichnende Abkehr wo nicht von der inhaltlichbegrifflichen Thematik, so doch von dem lange vorherrschenden sprachlichen Ausdruck ihrer. Dabei thematisiert sie zunächst Spaldings Versuch, die letzte Auflage seiner Schrift sowohl dem Inhalt wie dem Duktus nach der kantischen Philosophie anzupassen (Kapitel X). Anschließend stellt sie anhand der Schriften Fichtes einen sprachlichen Wandel von „Bestimmung“ zu „Beruf“ des Menschen fest (Kapitel XI) und kommt schlussendlich zu der Diagnose, dass der Ausdruck „Bestimmung des Menschen“, obwohl auch noch im 19. und 20. Jahrhundert vielfach, jedoch eher lose verwendet, in Folge der ihm über die Jahrzehnte aufgeladenen und schwer miteinander in Einklang zu bringenden

\footnotetext{
${ }^{3}$ Wobei anzumerken ist, dass Macor auffällig oft (vgl. etwa S. 33 ff.) den Ausdruck „Wort“ in Verbindung mit dem Ausdruck „Bestimmung“ und den Ausdruck „Begriff“ in Verbindung mit dem - zusammengesetzten - Ausdruck „Bestimmung des Menschen“ verwendet und nur selten umgekehrt. Dies könnte vermuten lassen, dass für Macor ein Begriff einfach eine komplexe Wortzusammenstellung ist. Dass sie andererseits, wie zitiert, doch die „sprachliche Verankerung“ eines Begriffs kennt, spricht allerdings gegen diese Vermutung.

${ }^{4} \mathrm{Vgl}$. hierzu S. 55. In diesem Zusammenhang interessant ist übrigens auch der S. 56, 57 erbrachte Beleg, dass die heutzutage in den römischen Sprachen geläufige finale Bedeutung von „destination“ im Französischen und Englischen bzw. „destino“ im Spanischen und „destinazione“ im Italienischen nicht ohne Weiteres auf das lateinische Wort „destinatio“ zurückgeführt werden kann, das ursprünglich eher voluntativ gebraucht wurde.

${ }^{5}$ Dabei werde ich der Einfachheit halber auf die mir geläufige sprachliche Konvention zurückgreifen, zwischen „Wort“ bzw. „Ausdruck“ einerseits und „Begriff“ andererseits so zu unterscheiden, dass letzterer einen diskursiven Bewusstseinsgehalt bedeutet, der durch ersteres bzw. ersteren sprachlich-körperlich ausgedrückt wird.

6 Aus sprachhistorischer Sicht, auf das Wort „Bestimmung,, ist der voluntative Aspekt zwar der ursprüngliche, aus begriffsgeschichtlicher Sicht, auf den Sinn und Zweck des menschlichen Daseins, hingegen der nachträgliche.
} 
Bedeutungen als Ausdruck einer präzisen philosophischen, theologischen oder historischen Diskussion ausgedient hat (Kapitel XII).

Durch die voluntative Komponente der Bedeutung des Wortes „Bestimmung“, von Spalding 1748 erstmals in Bezug auf den Menschen und sein Verhältnis zu Gott verwendet, ${ }^{7}$ geriet der Ausdruck „Bestimmung des Menschen“ zum Katalysator einer sich in Spannung zwischen Sakralem und Säkularem befindlichen Gesellschaft. Denn jene auf die eigene Wirkmächtigkeit bezogene Komponente fügte dem Begriff dessen, was der Mensch ist und zu welchem Zweck er da ist, etwas hinzu, das dem Geist der Aufklärung sehr wohl, der Ansicht der eher traditionellen Geister jedoch ganz und gar nicht entsprach: Johann Melchior Goeze etwa, ein „lutherische[r] Theologe“ (S. 111), setzte Spaldings Versuch, die eigene Wirkmächtigkeit des Menschen zum Guten und Gottgewollten gegen seine ihn zum Bösen treibenden Neigungen herauszustellen, die alte Lehre eines „[total[en]] Sieg[es] der verkehrten Neigungen“ über des Menschen selbsteigenen „Widerstand“ entgegen. Nach dieser Lehre war es dem Menschen nicht vergönnt, bei dem Versuch, sich als gottgefällig zu erweisen, „ohne die Gnade“ Gottes „zurecht[zu]kommen“ (S. 116) - eine Gnade, die, wie wir wissen, de facto in einer Stellvertretung zweifelhafter Legitimation von gänzlich irdischen Wesen und nicht selten auch nach deren irdischen Interessen erteilt oder verweigert wurde. Johann Martin Chladenius, ebenfalls ,lutherischer Theologie“ (S. 125), schlug in eine ganz ähnliche Kerbe und vertrat - aus seiner Sicht folgerichtig - die Ansicht, dass, wie Macor paraphrasiert,

,[d]er Terminus ,Bestimmung“ [...] für eine zutreffende Definition des Endzwecks des Menschen nach Gottes Plan ungeeignet [sei], denn er rücke die Rolle Gottes in den Hintergrund und schreibe dem Menschen Eigenschaften zu, über die er nicht verfüge." (S. 128)

Der offenbar nicht nur sehr verständige, sondern auch gewitzte Spalding führte, wie Macor S. 136 ausführt, die (durch die Lutheraner propagierte) „Hervorhebung des Glaubens und die konsequente Herabsetzung der Werke, die die protestantische Kirche kennzeichnen, [...] auf eine bestimmte historische Lage zurück[...]“, in der „die Kur“ der Protestanten wider die geheuchelte Werktätigkeit der prunkvoll sich gebenden alten, katholischen Kirche „zum Anfang einer neuen Krankheit" wurde, unter deren Einfluss die menschliche Werktätigkeit im Ganzen unter den Generalverdacht der Heuchelei gestellt wurde. ${ }^{8}$ (Eine Diagnose, die ihrer Struktur nach wohl auf die meisten der vergangenen und gegenwärtigen gesellschaftspolitischen Bewegungen zutreffen dürfte.) Spalding selbst dagegen versuchte, die Überreaktion in beide denkbare Richtungen zu vermeiden und die (moralisch gute) Tat mit dem Glauben zusammenzuführen. Damit ging er allerdings das Risiko einer mutmaßlich unguten, da nicht leicht aufzulösenden „Spannung zwischen Vernunft und Offenbarung, Natur und Gnade“ (S. 161) ein, über deren (Un-)Lösbarkeit prominent zunächst Thomas Abbt und Moses Mendelssohn Mitte der 60er Jahre des 18. Jahrhunderts erst durch Aufsätze bzw. Bücher, dann brieflich diskutierten. ${ }^{9}$

Schiller indessen ging, folgen wir den Nachzeichnungen Macors, gleich alle der im Großen feststellbaren Wallungen der Debatte um die menschliche Bestimmung für sich im Kleinen mit. Von seinem Lehrer Abel in der Stuttgarter Karlsschule beeinflusst, erklärte er sich mit der Vereinbarkeit von göttlicher Fremd- und menschlicher Selbstbestimmung zunächst einverstanden. Um die ausgehenden 70er und angehenden 80er Jahre entwickelte er sich jedoch zunehmend zum Zweifler jener Spaldingschen Lehre, deren inhärente Spannung er anders als zuvor Goeze und Chladenius nicht zu Gunsten des finalen, sondern mit Abbt zu Gunsten des voluntativen Aspektes des Begriffs der Bestimmung aufzulösen versuchte. ${ }^{10}$ Dass bei dieser Wandlung offenbar auch eben jener Hume Pate gestanden hatte, dem gegenüber Kant 1783 zugestehen sollte, seinen „dogmatischen Schlummer“ (Prol., A 13) unterbrochen zu haben, ${ }^{11}$ zeigt, wie tief Schiller in seinem persönlichen Denken mit der allgemeinen denkgeschichtlichen Bewegung, samt ihren Spannungen und Auflösungsbestrebungen zu jener Zeit verwachsen war. So war es denn auch mehr als ein bloß persönlicher Zufall, dass Schiller,

\footnotetext{
${ }^{7}$ Vgl. S. 74.

${ }^{8}$ Spalding, selbst ein protestantischer Theologe und Prediger, wendet sich damit offenbar vor allem gegen den - ebenfalls protestantischen - Calvinismus und den diesem verwandten Zwinglianismus.

${ }^{9}$ Vgl. S. 168 ff. bzw. 177 ff. - besonderes Thema dabei war die Frage nach der Unsterblichkeit der Seele, wobei Abbt Macor zufolge den „Angreifer[...]“" (S. 178) und Mendelssohn den „Verteidiger“ (ebd.) derselben gab.

${ }^{10}$ Vgl. S. 188 ff. bzw. 193 ff.

${ }^{11}$ Vgl. S. 190
} 
wie Macor S. 267 ff. schildert, sobald er mit Kants Schriften bekannt geworden war, sowohl deren Versuch der kritischen Vereinigung zwischen dem voluntativen und dem finalen Aspekt des Begriffs der menschlichen Bestimmung, den Menschen zur "Selbstbestimmung bestimmt“ (S. 34) zu konzipieren, wie auch die durch Kant - scheinbar (s.u.) - vorgenommene „gattungsgeschichtliche Uminterpretation der menschlichen Bestimmung“ (S. 268) in seiner „Idee zu einer allgemeinen Geschichte in weltbürgerlicher Absicht" ${ }^{\text {12 }}$ zunächst mit Begeisterung aufnahm. Dass er sich später doch wiederum von Kants kritischem Ansatz distanzierte, ist, wie Macor S. 272 ff. darlegt, auf ein Problem zurückzuführen, das sich aus eben jener „Uminterpretation“ Kants, der Schiller sich anfangs so begeistert angeschlossen hatte, zu ergeben scheint und das er zuvor zwar keineswegs übersehen, aber für lösbar gehalten hatte. Diese Haltung gab er unter dem Einfluss des abtrünnigen Kantschülers Herder Mitte der 90er Jahre jedoch wieder auf. Denn wenn, wie es scheint, Kant zufolge allein die Gattung die menschliche Bestimmung vollständig erreichen kann, dann geraten wir zu bloßen Mitteln von Zwecken der Nachgeborenen, die es schon besser machen, dabei aber immer noch bloß zum Mittel ihrer Nachgeborenen dienen können, die wiederum etc. Zudem mutet es prima facie alles andere als glaubwürdig an, die Menschheit als beständig im moralischen Fortschritt befindlich zu begreifen. Ohne in der Frage über die Stimmigkeit von Kants Konzeption entscheiden zu wollen, scheint mir an dieser Stelle dennoch angebracht, auf einen Umstand hinzuweisen, der dieselbe zumindest in einem etwas differenzierteren Licht erscheinen lässt, als der späte Schiller, Herder ${ }^{13}$, Mendelssohn ${ }^{14}$ und auch Macor ${ }^{15}$ selbst offenbar vermutet haben.

Kant entwickelte in seiner 1788, also vier Jahre nach seiner „Idee“ erschienenen „Kritik der praktischen Vernunft“ die sogenannte „Postulatenlehre“16. Ihr zufolge kann in der Tat auch von einer ins Transfinite gehenden Vervollkommnung nicht bloß der Gattung, sondern auch des Individuums (einer unsterblichen Seele) gesprochen werden. Und muss es auch, wenn „[d]ie Bewirkung des höchsten Guts in der Welt" (KpV, A 219), die Vereinigung von moralischer Vollkommenheit und Glückseligkeit, wenigstens der Idee nach als möglich vorgestellt werden können soll. Dass Kant wiederum zehn Jahre später, in seinem 1798 erschienenem „Streit der Fakultäten“, seine gattungsgeschichtliche Lehre gegen Mendelssohn verteidigt, würde dann nicht etwa bedeuten, dass er, wie Macor S. 290 behauptet, ,an seiner Geschichtsauffassung fest“" gehalten, sondern vielmehr, dass er seine Meinung innerhalb von 14 Jahren mindestens zweimal geändert hat. Eine solche Meinungspirouette, einem Wahrheits- und Systemskeptiker wie Nietzsche ohne Weiteres zuzutrauen, steht bei Kant ganz und gar nicht zu vermuten. Vielmehr scheint es wahrscheinlich, dass Kant beide Aspekte der menschlichen Bestimmung gesehen und dabei, wie so oft, Differenzierungen vorgenommen hat, durch die der Schein ihrer Unvereinbarkeit gehoben werden könnte. In der Tat bemerkt Kant zu Beginn seiner „Idee“, dass es ihm um die Untersuchung der „Erscheinungen [der Freiheit des Willens]“ (IaG, A 385) zu tun ist, um in dieser Hinsicht auf eine „Naturabsicht“" (IaG, A 386) schließen zu können. Von einer unsterblichen Seele kann dort für Kant schon qua Zielsetzung überhaupt keine Rede sein. In seiner „Kritik der praktischen Vernunft“ hingegen beschäftigt Kant sich mit den intelligiblen Bestimmungsgründen des freien Willens. Im Hinblick auf die Frage der Vervollkommnung in Hinsicht auf die menschliche Bestimmung ließe sich dann wie folgt ansetzen: Wenn die Frage die nach einer Naturabsicht ist, die durch und durch an die ihr eigene Bedingung, sinnlich erscheinen zu müssen, gebunden ist (und von einer unsterblichen Seele also keine Rede sein kann), muss man auf der Suche nach fortführenden Trägern des menschlichen Endzwecks nach anderen Erscheinungen in der Natur - anderen Menschen - Ausschau halten, deren Komplexus eben die Gattung ist. Wenn aber überhaupt nicht von einer Naturabsicht die Rede ist, wenn also von den natürlichen Erscheinungsbedingungen im Zweifel auch abgesehen werden kann, ist eine derartige Verlagerung nicht nötig - dann kann ich der Vollendung meiner (gott- oder vernunft-, jedenfalls nicht naturgegebenen) Bestimmung auch selbst nachgehen. Im gegenwärtigen Format kann hierüber nicht weiter Auskunft oder die kantische Lehre gar verteidigt werden. Dass Kant selbst die Disjunktion „Was vom einzelnen Individuum auf der Erde nicht vollendet werden kann, wird entweder vom selben Individuum im Jenseits [...] oder von anderen, später lebenden Individuen im Diesseits [...]

${ }^{12}$ In der Folge nur noch „Idee“

${ }^{13} \mathrm{Vgl}$. S. $257 \mathrm{ff}$

${ }^{14} \mathrm{Vgl}$. S. $252 \mathrm{ff}$

${ }^{15} \mathrm{Vgl}$. S. 251

${ }^{16} \mathrm{Vgl} . \mathrm{KpV}$, A $219 \mathrm{ff}$. 
vollzogen“, wie Macor S. 249 schreibt, offenbar nicht unterschrieben hätte, ist aber schon aus rein philosophiegeschichtlicher Perspektive sicher einen Hinweis wert. ${ }^{17}$

Ferner ist Macors auf S. 315 in Bezug auf Fichtes Philosophie vorgetragener Schluss von der Notwendigkeit, seiner „Aufgabe nur innerhalb eines besonderen Standes entsprechen“ zu können, darauf, dass man „sich bloß seines weltlichen Berufs annehmen“ dürfte „und dabei sicher sein“ könne - dass es also dazu hinreichen würde - dass man „,seine Bestimmung als Mensch nicht verfehlt", in dieser (logischen) Form offenbar nicht korrekt. Ein solcher Schluss ist den Fichteschen Überlegungen, sofern zumindest von Macor angeführt, auch nicht zu entnehmen.

$\mathrm{Ob}$ darüber hinaus Spaldings mit der 1794 erschienenen „elfte[n] und letzte[n] autorisierte[n] Auflage“ seiner „Bestimmung des Menschen“ (S. 304) erfolgte „Versuch einer [...] Aneignung der Kantischen Philosophie“ (S. 309) wirklich als „nur partiell“ (ebd.) zu verstehen ist und es ihm „nicht im mindesten gelungen war, sein System mit dem Kantischen zu versöhnen“, wie Macor S. 310 als ,auf der Hand“ liegend bezeichnet, oder ob Spalding nicht vielleicht doch auch dem Geist der kantischen Überlegungen entsprochen hat, geht aus den zitierten Passagen meines Erachtens ebenfalls nicht hervor. ${ }^{18}$ Wobei Macor sicher Recht hat, wenn sie die Klärung dieses Sachverhalts als „nicht in das Feld“ der von ihr ,nachgezeichneten Begriffsgeschichte“ (S. 310) gehörig verortet. Was in dieses Feld gehört, ist der historische Wandel von der Betonung des finalen hin zu derselbigen desvoluntativen Aspekts der menschlichen Bestimmung, der sich unter ein und demselben Ausdruck vollzogen hat. Ein Wandel, durch den eben jenem Ausdruck - „Bestimmung des Menschen, - eine Spannung aufgeladen wurde, zwischen theologisch und moralphilosophisch ausgerichteter Bedeutung einerseits, und individuen- und gattungsspezifisch gedeuteten Implikationen andererseits, die zu tragen er aus historischer Sicht nicht imstande war. Dass bei der philosophischen bzw. theologischen Erörterung der allgemeinen Sinnfrage später (wieder) vermehrt auf andere Termini wie „Beruf,,, „Zweck,, - oder eben „Sinn,, - zurückgegriffen wurde, dies zudem unter zunehmender Konzentration auf individuen-, standes- oder nationenspezifische Aspekte, war in der Folge kaum zu vermeiden. Dies legt Macor in den letzten Kapiteln ihres Buches überzeugend und treffend dar. Fest steht daher bei aller angebrachten Kritik, dass Macors Darlegungen eine reichhaltige und vor allem historisch zuverlässige Quelle darstellen, die schon der bloßen Anzahl ihrer Bezugstexte wegen, mehr noch aber durch deren gelungene historische und begriffliche Einordnung besticht. Ungeachtet der (von Macor auch nicht intendierten) Antwort auf die Frage, welche - falls überhaupt eine - der wirklich vertretenen Positionen die philosophisch korrekte ist, wird der historische Wandel im Verständnis des ,Wozu?' des Menschen im Verlauf der zweiten Hälfte des 18. Jahrhunderts von Macor sinnig und umfassend dargestellt, werden seine Nuancen treffend hervorgehoben und die verschiedenen Positionen hinsichtlich jener Frage in ihrer systematischen Bezogenheit aufeinander ausführlich erläutert. Daher lässt sich ohne jeden Vorbehalt schließen, dass es sich bei ihrer Untersuchung um ein äußerst wichtiges und anschlussfähiges Stück Philosophiegeschichte handelt, das in keiner philosophischen Bibliothek fehlen sollte.

Verwendete Literatur:

DREESMAN, Ulrich. Aufklärung der Religion. Die Religionstheologie Johann Joachim Spaldings, Stuttgart 2008.

MACOR, Laura Anna. Die Bestimmung des Menschen (1748 - 1800), Stuttgart-Bad Cannstatt 2013.

MACOR, Laura Anna. Die Bestimmung des Menschen als philosophische Grundfrage der Theologie in der Aufklärungszeit. Johann Joachim Spalding als Beispielsfall, in: Theologie und Glaube 103 (2013), H. 3, S. 342 - 362.

KANT, Immanuel. Kritik der praktischen Vernunft (1788), Frankfurt am Main 1974.

KANT, Immanuel. Idee zu einer allgemeinen Geschichte in weltbürgerlicher Absicht (1784), in: Schriften zur Antropologie, Geschichtsphilosophie, Politik und Pädagogik, Frankfurt am Main 1977.

${ }^{17}$ Macor erwägt S. 252 selbst eine solche Möglichkeit, legt sie jedoch als offene Frage bei Seite.

${ }^{18}$ Die von Macor S. 305 ff. zitierten Passagen legen m.E. insgesamt eher letzteres nahe. 
KANT, Immanuel. Prolegomena zu einer jeden künftigen Metaphysik, die als Wissenschaft wird auftreten können (1783), in: Schriften zur Metaphysik und Logik I, Frankfurt am Main 1977. 


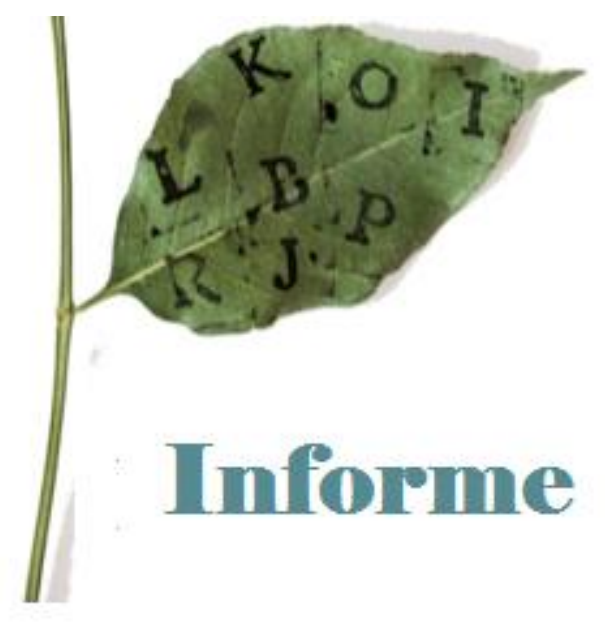





\title{
Rezension zur Internationalen Tagung „Teleologische Reflexion in Kants Philosophie"
}

\author{
ANNA PiCKHAN (GEB. BRECHTEL) $)^{1}$
}

Am 10. und 11. Februar 2017 fand am Philosophischen Institut der Universität Heidelberg die von Paula Órdenes und Daniel Schwab organisierte Internationale Tagung „Teleologische Reflexion in Kants Philosophie" statt. Ziel war eine Auseinandersetzung mit den unterschiedlichsten Ansätzen, die Immanuel Kants Konzeptionen von Teleologie betreffen. So waren die Beiträge inhaltlich sehr weit gefächert.

Peter McLaughlin und Peter König vom Philosophischen Seminar in Heidelberg eröffneten mit ihren Vorträgen am Freitagnachmittag die Veranstaltung.

Das Anliegen McLaughlins war es in seinem Vortrag „Freiheit und technisch-praktische Vernunft bei Kant" Probleme bei der kantischen Freiheitskonzeption aufzuwerfen. In seiner sehr umfassenden Betrachtung (Ausführungen zur Handlungstheorie und Philosophie der Biologie, der poiesis und praxis, dem Begriff der Verantwortung, der Empirischen Freiheit u.v.m.) machte er u.a. darauf aufmerksam, dass Kant mit seinem Ansatz von ausschließlich kausalen Handlungserklärungen gegenüber Locke und Leibniz sogar rückständig sei, weil ihm die Sphäre rationaler Handlungsbegründungen fehle. Daraus erwüchsen viele Probleme im Bereich der Freiheitskonzeption, die McLaughlin als abschließende Fragen an Kant formulierte.

Das Anliegen von Peter König mit seinem Vortrag „Teleologische Kriterien materialer Wahrheit. Zur Theorie des Gemeinsinns bei Kant" war systematischer Art. Die Stelle der Kritik der Urteilskraft im System der kantischen Kritiken sowie der systematische Zusammenhang von ästhetischer und teleologischer Urteilskraft sollten aufgezeigt werden. Mit Hilfe einer neuen Deutung des „unum verum bonum” aus $\$ 12$ der Kritik der reinen Vernunft konnte er deutlich machen, dass es in der Kritik der Urteilskraft, entgegen der einfachen Schulmeinung, auch um Wahrheitserkenntnis, i.S. der Bedingungen wahrer Erkenntnis des empirisch Gegebenen, gehe. Für die Systematik innerhalb der Kritik der Urteilskraft sei der Gemeinsinn entscheidend, weil er im Gegensatz zum System der Natur (der objektiven Seite der Bedingungen der Möglichkeit empirischer Urteile) die subjektive Seite liefere.

Anna Brechtel (Jena) vertrat mit ihrem Beitrag zur Körperkonzeption „Der Körper in Kants Opus postumum. Einige teleologische Implikationen” die These, dass durch den Körper, so wie ihn Kant in seinem Nachwerk fasst, eine neue Dimension des Übergangs zwischen Metaphysik und Physik in teleologischer Absicht geschaffen werde. Der Körper forme dort ein teleologisches Prinzip, welches der Urteilskraft einen Leitfaden zur Erschließung der Natur an die Hand gebe. Neben dieser konkreten Anweisung für die Methode des Naturforschers wird qua unserer eigenen Körperlichkeit auch der Wahrheitswert der Naturerkenntnis auf eine neue Weise gefasst: Wir Menschen bekommen nur das aus der Natur heraus, was wir zuvor in sie hineingelegt haben.

Mit dem Vortrag „Die Antinomie der teleologischen Urteilskraft und Kants Auflösung im Licht der Einleitung in der Kritik der Urteilskraft" unternahm Daniel Schwab (Heidelberg) einen eigenen Versuch der Interpretation der Antinomienproblematik in der Kritik der Urteilskraft. Mit einem Durchgang durch die einschlägigen Paragraphen (\$§70-78 der Dialektik) erklärte er, dass kein Widerspruch zwischen den Maximen zu finden sei. Der bei vielen Interpreten noch immer umstrittene Schein bestehe allerdings gerade im antinomischen Anschein eines Widerspruchs zwischen den

\footnotetext{
${ }^{1}$ Friedrich-Schiller-Universität Jena. Anna.brechtel@uni-jena.de
} 
Maximen der reflektierenden Urteilskraft. Dem könne man sich jedoch nicht entziehen, da er qua unserer eigenen teleologischen Beurteilungsweise immer bestünde.

Am Samstag Vormittag kam Georg Toepfer (Berlin) in seinem Vortrag „Kants Teleologie heute" auf vier verschiedene Themenbereiche zu sprechen, die bei Kant mit Teleologie in Verbindung gebracht werden: Biologie, Ökologie, Anthropologie und Geschichtsphilosophie. Interessante Perspektiven eröffneten sich, als Toepfer zeigte, welche Aktualität die kantischen Ansätze in diesen Bereichen heutiger wissenschaflicher Debatten haben. Zum Schluss seiner Erarbeitungen konstatierte er Kant eine Einheit in der Teleologie-Konzeption selbst. So seien vor allem zwei Bereiche auszumachen, die, obwohl sehr unterschiedlich, doch voneinander abhängen: der natural-zyklische (mit der Biologie und Ökologie) sowie der kulturell-lineare (mit der Anthropologie und der Geschichtsphilosophie).

Manuel Sánchez Rodríguez (Granada) trug über das Thema „Kants Theorie der reflektierenden Urteilskraft als eigentliche Apologie (und Kritik) der leibnizschen Prästabilierten Harmonie" vor. Sein Anliegen war es mit dem Leibnizianer Johann Augustus Eberhard zu zeigen, dass die Kantrezeption nie nur werkimmanent stattfinden sollte, sondern vielmehr Kants Auseinandersetzung mit seinen Vorläufern sowie Zeitgenossen für sein Schaffen berücksichtigt werden muss. Historisch sehr genau machte er deutlich, dass die Theorie der reflektierenden Urteilskraft am besten durch Kants kritische Revision von Leibniz prästabilierter Harmonie zwischen Substanzen zu erklären sei, die dieser durch die Idee eines freien Spiels zwischen den Erkenntniskräften ersetzt.

Ina Goy (Tübingen) unternahm in ihrem Vortrag „Why animals let man belive in God” den Versuch Teleologie mit Kants generellen Äußerungen über Tiere in Verbindung zu bringen. Sie zeigte, dass Tiere Menschen dazu bringen an Gott zu glauben, damit die Einheit zwischen der natürlichen und moralischen Ordnung innerhalb und zwischen Tieren gewährleistet werden kann. Die Idee von Gott sei dabei einheitsstiftend für mechanische und physiko-teleologische Kräfte und Gesetze genauso wie für physiko-teleologische und moralische Kräfte und Gesetze. Insofern sei der Mensch selbstverständlich als Teil des tierischen Kosmos zu sehen.

Eine weitere Hauptfrage der Teleologie ist zweifelsohne die Frage nach dem Zweck der Schöpfung. Fernando Moledo (Buenos Aires) ging in seinem Beitrag „Der kantische Begriff des Menschen als Zweck der Schöpfung: verschiedene Argumente um eine grundlegende Idee” vor allem auf die Frage ein, warum gerade das Moralisch-Sein den Menschen zum Zweck der Schöpfung macht. Mit Hilfe von Kants Anthropologie sowie dessen Moralphilosophie führte Moledo aus, dass es die vernünftige Natur des Menschen sei, die denselben zum Zweck der Schöpfung macht. Nur dadurch könne ein freier Wille garantiert werden und durch die Gleichsetzung von frei sein und unter sittlichen Gesetzen stehen sei schließlich der moralische Mensch als Zweck der Schöpfung bei Kant gezeigt.

Dann beschäftigte sich Paula Órdenes (Heidelberg) in ihrem Vortrag „Teleologische Einheit der Vernunft?" mit der einheitsstiftenden Funktion der Vernunft. Mittels eines Durchgangs durch die Kritik der reinen Vernunft, die Kritik der praktischen Vernunft und die Kritik der Urteilskraft konnte sie plausibel darstellen, dass das Bedürfnis einer Einheit aus unserer Vernunft selbst kommt. Die Einheit werde dabei weder gegeben noch deduziert sondern bestehe als notwendige Annahme für die Erforschung der Natur, die als Objekt des theoretischen sowie praktischen Bereichs zu verstehen sei.

Der letzte Vortrag am Samstag Abend stammte von Jacinto Rivera de Rosales (Madrid) mit dem Titel „Versuch einer Auslegung der teleologischen Dialektik von Kant”. Vor einer Analyse der Dialektik eröffnete er den Zuhörern eine ganz bestimmte Perspektiv auf den kantischen Text. Als Vereinigungspunkt von Natur und Freiheit seien Lebewesen, genauer ihr Leib und seine vor-reflexive Subjektivität, zu sehen. Damit ist nach einer Auslegung der Antinomie für Rivera de Rosales klar, dass so gezeigt werden kann, dass bei Lebewesen immer beide Erklärungen gefordert werden müssen: die mechanische (als objektive) und die teleologische (als Indikator dafür, was als objektiv zu erklären sei).

Insgesamt war dieses Zusammentreffen der Kantexperten ein sehr gelungener Kongress: Die Atmosphäre war jederzeit angenehm und so konnten die an die Vorträge anschließenden 
Diskussionen auch oft wertvolle, neue Perspektiven für alle Seiten eröffnen und Beiträge zur aktuellen Forschungsdebatte entstehen. 



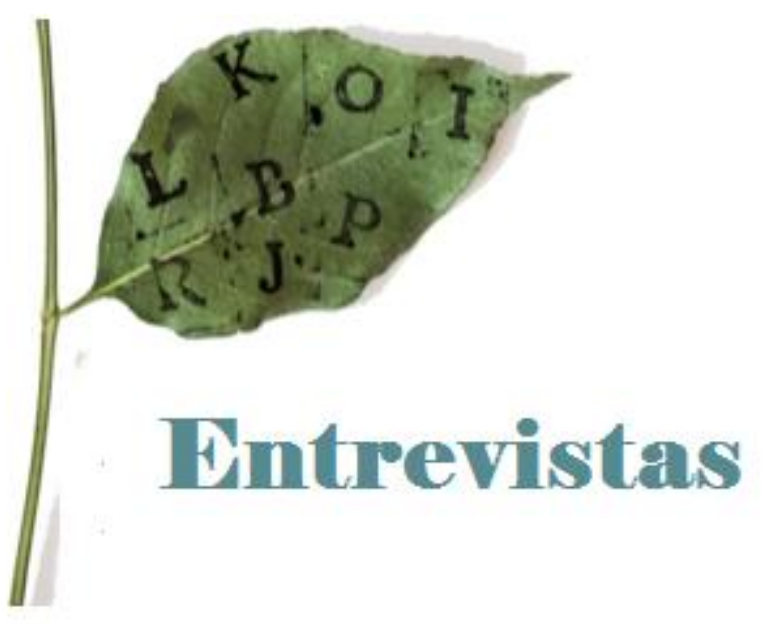





\title{
Entrevista a Pablo Muchnik (Emerson College)
}

\author{
FERNANDO MOLEDO ${ }^{1}$
}

Tenemos el agrado de acercar a nuestros lectores el diálogo mantenido con Pablo Muchnik, ${ }^{2}$ en el que hemos conversado sobre cuestiones relativas a la filosofía kantiana, pero también al desarrollo de la investigación kantiana en general y en español en particular.

Muchnik es profesor asociado en Emerson College y ha publicado numerosas investigaciones sobre la filosofía de Kant, con especial acento en la filosofía moral, política, y de la religión. Es autor de Kant's Theory of Evil: An Essay on The Dangers of Self-Love and the Aprioricity of History (Lexington Books, 2009), editor de los dos primeros volúmenes de Rethinking Kant (Cambridge Scholar Publishing, vol. I, 2008; vol. II, 2010) y coeditor de los volúmenes IV (2014) y V (de próxima aparición), así como también coeditor de Kant's Anatomy of Evil (Cambridge University Press, 2010). A su vez dirige dos colecciones: Kantian Questions (Cambridge Scholar Publishing) y Kant's Sources in Translation (Bloomsbury). Además, ha sido presidente de la North American Kant Society (2014-2017), después de haber servido como vice-presidente entre 2009-2014.

Fernando Moledo: Comencemos con las preguntas dirigidas a su interpretación de la filosofía de Kant. Usted se ha dedicado intensamente al estudio de la posición de Kant, sobre uno de los problemas más fascinantes de la historia de la filosofía: el problema del mal. ¿Cómo resumiría las tesis de Kant? O, dicho de otro modo: ¿en qué consiste, para usted, la esencia del concepto kantiano del mal?

Pablo Muchnik: En contra de las interpretaciones consecuencialistas que conciben el mal en términos del impacto que tienen los actos perniciosos, para Kant el mal designa el tipo de voluntad que subyace y hace posible la inmoralidad en todas sus formas. Tal estructura volicional está presente tanto en los actos observables de transgresión moral (en la agresión, la violencia, la opresión, la humillación, etc.), como en los subterfugios del auto-engaño, que corrompen el juicio moral, pero son invisibles a los ojos. En todos los casos, "malo" es el hombre que erige al amor propio como criterio fundamental para determinar su conducta, y por lo tanto cumple con su deber siempre y cuando éste no se interponga a su felicidad. Para Kant, esta actitud de obediencia condicional expresa una disposición moral en la que el agente ha invertido el orden ético de prioridades, de acuerdo al cual el deber es un incentivo autosuficiente, capaz de ponerun límite a las inclinaciones y subordinarlas a los dictados de la ley.

La maldad designa, así, una forma auto-impuesta de incorregibilidad moral: el hombre malo se rehúsa a someter su concepción subjetiva del bien (su felicidad) al examen objetivo de la moralidad. Sus deseos e inclinaciones son la medida de todas las cosas, soslayando no sólo cómo afectana la capacidad de otros agentes paradeterminar sus propios fines, sino también, y de modo más esencial todavía, ignorando cómo tal actitud corrompe su propia capacidad de agencia. Pues, al otorgar prioridad volicional al deseo irrestricto, el sujeto somete su racionalidad a su sensibilidad y transforma su autonomía en heteronomía -en suma, la primacía al amor propio socava el fundamento mismo de ladignidad humana. Para Kant, la instrumentalización y reificación de otros agentes son siempre precedidas por un acto de auto-destrucción moral.

${ }^{1}$ Universidad de Buenos Aires - CONICET

${ }^{2}$ Web oficial: https://www.emerson.edu/academics/faculty-guide/profile/pablo-muchnik/2954 
Lo más interesante de la concepción kantiana es, en mi opinión, que la maldad así entendida puede ser perfectamente asintomática, compatible con la legalidad de las acciones. Tal como sugiere el ejemplo del comerciante en la Fundamentación, esimposible distinguir al hombre bueno del hombre de buena conducta, pues los dictados del amor propio y las prescripciones del deber tienden a coincidir en la sociedad contemporánea. Inspirado por Rousseau, Kant sostiene que el progreso de la civilización y la consolidación del poder coercitivo del Estado han hecho del hombre una criatura calculadora, eficiente en ocultar su inmoralidad más profunda. Por eso concluye en la Paz Perpetua que demonios inteligentes pueden constituir un pueblo de ciudadanos ejemplares. Para Kant, las leyes sociales no erradican al mal, sino que lo perpetúan bajo la "apariencia de la virtud" (Tugendschein). Esta disimulación en masa hace del mal un "enemigo invisible, que se esconde detrás de la razón, y es por ello aún más peligroso" (RGV AA 6:57).

La persistencia de la guerra, la opresión, la crueldad, y la infinidad de atrocidades que los hombres cometen unos contra otros, nos recuerdan que la batalla moral no concluye con la victoria política -apenas comienza allí. La ética kantiana contiene así la clave para comprender mejor los males que afligen al mundo, y nos prepara para combatirlos, pues denuncia la ceguera de quienes confían que el liberalismo político y el progreso económico pueden, por sí mismos, transformar la moralidad de los hombres.

Fernando Moledo: El punto de vista de Kant acerca del hombre, su visión antropológica en sentido fuerte (moral), parece oscilar entre dos grandes ideas: a) El concepto de la buena voluntad, como un bien absoluto que no sólo tiene valor normativo, sino que incluso da sentido a la creación misma.b) El mal radical, esto es, la concepción acerca de la corrupción fundamental de la voluntad humana. ¿Qué piensa Kant realmente sobre el hombre? ¿Es bueno? ¿Es malo?

Pablo Muchnik: La especie humana para Kant exhibe una disonancia fundamental: aunque el hombre es malo por naturaleza, está teleológicamente orientado hacia el bien. El hombre es malo, pues se le puede atribuir, incluso al más virtuoso, una propensión a dar a su amor propio un valor desmesurado. Esta es una tendencia básica, primordial, presente en nuestra voluntad desde que tenemos memoria, que nos lleva a acomodar las demandas estrictas del deber a los caprichos de las inclinaciones. Para tener valor moral, sin embargo, esta tendencia no puede ser entendida como resultado de una determinación meramente biológica -los genes son "moralmente inertes", ni buenos ni malos. Sólo de aquello de lo que somos autores se nos puede imputar.

Ahora bien, para ser imputable un acto debe ser libre. Pero el concepto de "libertad" es para Kant incomprensible fuera de su relación con la ley moral, pues es la conciencia de la ley la que nos alerta de la presencia de una forma de causalidad independiente de la naturaleza. En la ética kantiana, "libertad" y "moralidad" son conceptos que se implican mutuamente. Esta relación tiene consecuencias fundamentales para la antropología: se sigue de ella que es imposible concebir al ser humano como una criatura diabólica, capaz de hacer el mal por el mal mismo. Pues si la maldad fuera un incentivo autosuficiente, podríamos constituir nuestro carácter morala espaldas de la ley, en un rechazo absoluto de las constricciones de la racionalidad práctica. Pero tal rechazo es incompatible con la libertad y convertiría al agente en un autómata, más allá del bien y del mal, sin responsabilidad alguna por sus acciones. En tanto criatura libre, por lo tanto, el ser humano no puede ignorar por completo el dictado de la ley, y con ello la agonía de elegir la forma que dará a su voluntad. Este es un dilema que el diablo y los ángeles desconocen. Por ello, Kant concluye, aún el peor de los hombres "no repudia la ley moral [...] en actitud de rebeldía (revocando toda obediencia a ella). La ley se impone a sí misma sobre él irresistiblemente, debido a su predisposición moral, y si otro incentivo no la contradijera, la incorporaría en su máxima suprema como determinación suficiente de su arbitrio" (RGV AA 6:36).

El hombre padece, entonces, de una dualidad constitutiva: la propensión al mal, que expresa los intereses de su amor propio, coexiste con una predisposición al bien, que expresa los intereses de la moralidad. Ambas tendencias son igualmente naturales, pero empujan a la voluntad en direcciones opuestas y la fuerzan a elegir darle prioridad a alguna de ellas. Esta elección determina nuestra identidad moral, pero no cancela la fractura interior, la disonancia fundamental con la cual Kant describe la condición humana. Por más arraigada que sea la propensión al mal, la obligación de erradicarla nos confronta con implacable urgencia. Esta confrontación es para Kant la condición de posibilidad de la formación de la conciencia moral, a la vez que cumple un papel esencial en la 
educación ética. Pues, suponer la presencia de una maldad natural de la que nadie está exento, nos lleva a establecer una constante vigilancia contra ella.

Fernando Moledo: ¿La clave para explicar la complejidad que Kant le atribuye a la naturaleza humana estaría entonces en el concepto de propensión al mal, que, a pesar de su radicalidad, sería perfectamente compatible con una disposición moral en el hombre?

Pablo Muchnik: Para entender la lógica interna de la posición kantiana es necesario distinguir dos nociones que los intérpretes normalmente confunden: "propensión al mal" (Hang zum Bösen), un concepto que Kant aplica para describir el carácter moral de la especie humana en su conjunto, y "disposición" (Gesinnung), un concepto que Kant utiliza para describir la orientación moral de un individuo en particular. A diferencia de la "propensión al mal" en la especie, la "disposición" individual puede ser buena o mala, según la forma que le hayamos dado a nuestra voluntad. Bueno es el agente que da primacía al deber sobre el amor propio, malo quien lo subordina. "Propensión" y "disposición" son, entonces, nociones que se refieren a unidades de análisis distintas: la primera tiene aplicación antropológica global; la segunda se restringe al ámbito de la moralidad individual.

Para ser imputables, tanto la propensión (en la especie) como la disposición (en el individuo) deben ser concebidas como actos de libertad relativamente independientes. De no ser así, la mera afiliación biológica de un agente, y no su libertad, determinaría su carácter. Es por ello que, aunque podamos caracterizar a la especie humana en su conjunto como "mala por naturaleza", los individuos que la componen pueden, sin embargo, ser buenos, i.e., tener una buena "disposición."

A diferencia de la visión agustiniana del pecado original, que corrompe no sólo nuestra voluntad, sino también nuestra capacidad de conocer el bien, el pesimismo antropológico kantiano es compatible con el optimismo moral. No hay contradicción entre ellos, pues cada unidad de análisis posee un tipo característico de obligación y de teleología, cuya fuerza normativa no desaparece, incluso en el caso de la desobediencia más extrema. La propensión al mal, interpretada de este modo, es expresión de un fracaso colectivo en obedecer al deber que la especie tiene de realizar el bien supremo; una mala disposición, en cambio, indica el fracaso, a nivel individual, en limitar la felicidad personal a las condiciones impuestas por el imperativo categórico. Mientras que del primer fracaso el individuo es parcialmente responsable, pues la realización del bien supremo depende de la cooperación de todos los hombres, frente al segundo fracaso no hay excusa posible, pues la conciencia de la ley es un Faktumder Vernunft, incorruptible e inextirpable.

En la Religión, Kant llama a este Faktum "personalidad", la tercera de las predisposiciones hacia el bien (Anlage zum Guten) con las que Kant describe la naturaleza humana y su teleología. Junto con las propensiones al mal, las predisposiciones al bien constituyen un esquema conceptual independiente, de validez antropológica, distinto en sus objetivos y métodos al aparato conceptual a priori que fundamenta la moralidad a nivel individual. Gran parte de las confusiones teóricas que se le endilgan a Kant son el resultado del hecho de que sus intérpretes confunden los conceptos de "propensión al mal" y de "mala disposición," y los tratan como si fueran sinónimos. Esta confusión ignora la independencia relativa que Kant atribuye a las distintas unidades de análisis en su concepción del mal radical, y genera falsos problemas de interpretación. La consistencia de la posición kantiana depende, en la lectura que propongo, de trazar una distinción sistemática entre ellos.

Fernando Moledo: ¿Cómo cree usted entonces que debemos entender el "hecho inteligible" (RGV AA 6: 31) al que Kant se refiere para explicar la adopción de la máxima de máximas que consiste en privilegiar el amor propio por sobre la ley moral y corrompe nuestra voluntad? ¿Se trata de otro de los facta cuyo origen no podemos explicar y que debemos, en cambio, aceptar sin más?

Pablo Muchnik: El significado de "inteligible" varía, una vez más, según las distintas unidades de análisis. A nivel individual, Kant cree que podemos determinar a priori (con certeza) la maldad de un agente. Esta determinación resulta de una cadena de inferencias: de acciones cometidas con conciencia de su inmoralidad, debemos inferir la presencia de máximas malas que las hacen posible; y de un conjunto de tales máximas, debemos inferir, en segunda instancia, la presencia de una máxima suprema (un principio último de selección de máximas), como condición de posibilidad de la inmoralidad de las acciones observables. Este tipo de argumento regresivo, transcendental, efectuado desde el punto de vista de la tercera persona (del espectador), es típico en la filosofía kantiana. La 
disposición es "inteligible," en el sentido de que, aunque no exista intuición de ella, debemos aceptarla como condición sine qua nonpara explicar el fenómeno de los actos inmorales.

El sentido de "inteligible" cambia cuando pasamos de la tercera a la primera persona, y adoptamos la perspectiva del agente. Para Kant, todos los hombres están obligados a interrogar su corazón y descubrir su orientación moral fundamental -tienen el deber de conocerse a sí mismos. A través del autoconocimiento, el individuo es llevado a descubrir que su disposición es "innata" -no porque la naturaleza sea su causa, sino porque la disposición que él ahora posee, su identidad moral, ha estado presente en su voluntad desde el principio, desde su "nacimiento," por así decir. En este sentido, la disposición es "inteligible," pero no porque se la infiera con certeza (como en el caso del argumento transcendental por parte del espectador). Al contrario: en el ejercicio de la introspección, descubrimos que nuestra disposición es inescrutable, que la certeza respecto a ella siempre nos elude, pues no se trata de un objeto de conocimiento teórico, sino de un objeto de deseo, un anhelo que moviliza nuestra voluntad. En tanto tal, la disposición debe permanecer inasible para poder motivar la pregunta: “¿Quién soy yo (moralmente hablando)?” Para Kant, la respuesta que cada agente ofrece a esta pregunta insondable no está fundada en una verdad objetiva sobre su carácter -tal verdad transciende los límites del conocimiento, pues depende del misterio que es nuestra libertad. Está basada, en cambio, en una relación subjetiva que el agente establece con su pasado y con su presente, en un vínculo con su identidad moral en función del cual cada hombre decide su futuro -sus próximos pasos como autor de su persona.

Existe, por último, un tercer sentido de "inteligible", asociado con la propensión al mal y su función en la narrativa kantiana de progreso moral de la humanidad en su conjunto. Pasamos aquí a un tipo distinto de discurso: un discurso antropológico basado parcialmente en la observación de la conducta colectiva, pero inspirado en una teleología moral de naturaleza a priori, independiente de la investigación empírica. Podríamos llamar a este discurso "cuasi-transcendental" - un nombre artificial, apto para designar el abordaje sui generis, conceptualmente híbrido, característico de la antropología moral kantiana. Este abordaje combina elementos normativos a priori con generalizaciones empíricas, el lenguaje de la observación con el lenguaje del deber. Los componentes heterogéneos que lo constituyen son parte un esfuerzo por parte de Kant por generar una nueva concepción de la naturaleza humana, de acuerdo a la cual la identidad de la especie no es un datum (como lo es en la antropología física), ni una posibilidad (como lo es en la antropología pragmática), sino un desideratum - una expresión de deseo, una tarea. La propensión al mal, entendida en este contexto, es "inteligible" en el sentido de que funciona como contrapunto al fin último de la historia, al destino moral del hombre. Tanto el telos como el punto de partida funcionan como herramientas heurísticas, como principios regulativos para generar una narrativa coherente de la trayectoria moral humana. En la medida en que Kant considera a la especie no sólo como autor de su carácter, sino también como responsable por realizar su futuro, el tercer sentido de "inteligible" combina elementos de los dos significados anteriores: la perspectiva del espectador se combina aquí con la del agente. Pero se trata ahora de un agente colectivo, cuyo campo de acción es la historia universal, no de un individuo particular, a cargo de su propia vida.

Fernando Moledo: Kant parece resignificar el concepto filosófico del mal, al darle un fundamento que no requiere apelar a concepciones teológicas propias de la metafísica dogmática tradicional, ni tampoco a una teoría naturalista sobre el hombre, de tipo empírico. ¿Lo cree usted de este modo? Si es así, ¿Cuál es, según su parecer, el aporte novedoso que la doctrina kantiana del mal proporciona a la tradición filosófica?

Pablo Muchnik: Efectivamente, uno de los aspectos más innovadores de la antropología moral reside en su concepción de la naturaleza humana: el hombre no es concebido ni como criatura de Dios, ni como producto de las fuerzas ciegas de la naturaleza; el ser humano debe, en cambio, concebirse a sí mismo como responsable absoluto de su carácter moral. Tanto la ciencia como la teología dogmática, Kant sostiene, son incapaces de hacer justicia a la autonomía humana, pues conciben al hombre en función de un modelo externo (el orden natural o el orden divino), que debemos imitar y al que debemos obediencia. Kant rehúsa aceptar esta visón heterónoma de la humanidad e introduce una revolución copernicana en el concepto de "naturaleza humana," de acuerdo a la cual no existe autoridad más sagrada que la ley moral dentro de nosotros mismos, ni objeto de respeto más alto que la dignidad de nuestros semejantes, ni ofensa más grande que la que destruye nuestra agencia. Para poder responder a la pregunta “¿Qué es el hombre?” debemos abandonar la práctica infantil, iniciada 
por Platón y continuada por el cristianismo tradicional, de invocar poderes superiores, ajenos, que nos impiden tomar responsabilidad plena por nuestro destino. Debemos, en cambio, correr el riesgo de pensar por nosotros mismos, sin la guía de otros, y asumir el coraje de vivir de acuerdo a nuestras propias luces, obedeciendo nuestra propia ley.

Fernando Moledo: ¿En qué medida, si es que lo es, la concepción kantiana del mal resulta filosóficamente fructífera hoy en día?

Pablo Muchnik: La promesa de la concepción kantiana, creo, reside en dos ámbitos principales. El primero es de carácter práctico, y concierne, tal como sugerí al principio de nuestra entrevista, la necesidad de combatir la ilusión de quienes identifican el progreso moral con la reducción de la crueldad. Para Kant, tal identificación, típica del utilitarismo y de los liberales del miedo (Shklar, Rorty, Rawls, etc.), sirve simplemente para enmascarar la seriedad del problema, y perpetúa el "letargo moral" al que somos tan proclives. El segundo es de carácter teórico, y concierne el desarrollo de las consecuencias conceptuales de la antropología moral, un campo de estudios que Kant inició en la Religión y esbozó en sus escritos sobre historia, pero que dejó fundamentalmente inacabado, ofreciéndonos piezas sueltas de un esquema conceptual cuya coherencia debemos todavía establecer. La idea de una revolución copernicana inconclusa en el concepto de "hombre" nos ofrece una alternativa teórica, un nuevo paradigma, para cuestionar la hegemonía de las ciencias naturales, y el platonismo que aún domina buena parte de la ética contemporánea.

Fernando Moledo: A lo largo de nuestra entrevista se refirió varias veces a la idea de una antropología moral, que no coincidiría, ciertamente, con la antropología en sentido pragmático. Es ella, a saber, la antropología moral, la que debe responder, pues, la pregunta fundamental "¿qué es el hombre?" ¿Sería parte de esa respuesta la doctrina que usted expuso, acerca de la disonancia fundamental en el hombre, que se encuentra entre la propensión natural al mal y la disposición moral?

Pablo Muchnik: Exactamente: tal como Kant indica en las lecciones de Lógica, de las preguntas esenciales que afligen a la razón humana (“¿Qué puedo conocer?”, “¿Qué debo hacer?”, “¿Que puedo esperar?"), la más decisiva, la que contiene la clave para responder al resto, es la pregunta: "Qué es el hombre?" Sería un error ceder a la epistemología (o las ciencias naturales), a la moral individual, o la a religión racional nuestra responsabilidad de darle una respuesta a esa pregunta. La respuesta debe originarse en esta ciencia híbrida, que yo llamo "antropología moral" para distinguirla de otros tipos de discursos que nos son más familiares. Su promesa consiste en concebir un nuevo tipo de agencia una agencia colectiva, universal, que involucra a todos los hombres. Pues sólo entendiendo la posibilidad y los límites de este tipo de agencia la humanidad podrá confrontar las consecuencias de su indeterminación biológica, del hecho de que la naturaleza del animal "hombre" consiste en no tener "naturaleza" y que por lo tanto su futuro depende exclusivamente de lo que, como ser parcialmente racional, decida hacer de sí mismo. La crisis ecológica que confronta actualmente la humanidad, la creciente desigualdad entre ricos y pobres, el problema endémico de la guerra y la violencia, etc., requieren precisamente del tipo de coordinación y de agencia que Kant esbozó, de manera más sistemática que sus predecesores (particularmente Rousseau) y más sobria que la de muchos de sus contemporáneos (particularmente Herder y Hegel), en las páginas de la Religión y en su filosofía de la historia.

Fernando Moledo: Ahora cambiemos un poco el eje de nuestra charla. Su lengua materna es el español. Sin embargo, ha realizado la mayor parte de su carrera en el ámbito anglo-parlante, concretamente en los Estados Unidos. Incluso ha actuado como presidente, hasta este año, de la North American Kant Society (NAKS). Estoy muy tentado de preguntarle, entre el bien y el mal, dónde situaría usted a las sociedades kantianas... Pero no lo haré. Mejor quisiera preguntarle qué ha significado para usted la experiencia del trabajo en una lengua que originalmente no era la suya.

Pablo Muchnik: El verme obligado a pensar y enseñar en otro idioma me forzó a tomar distancia respecto a los textos que amo, a estudiarlos siempre con un dejo de extrañamiento, como un etnógrafo que ha pasado gran parte de su vida en una tribu, habla con fluidez su idioma, pero no es del todo de la tribu. Esta posición liminal, creo, me ha dado una cierta independencia intelectual, pero su precio ha sido un mayor grado de vulnerabilidad profesional que la de muchos de mis colegas nativos. La academia norteamericana es tremendamente competitiva, y me he tenido que abrir paso a fuerza de perseverancia, buena suerte, y pasión por la filosofía, sin contar con los beneficios de formar parte de algún "clan". El hecho de haber sido elegido Presidente de la NAKS ha sido para mí una especie de 
rito de pasaje, de aceptación en el grupo. Aunque permanezco en lo personal un outsider marcado por mi origen en otra tierra y en otra cultura, me siento profundamente honrado por este gesto de aceptación en la tribu, pues muchos de los kantianos que más admiro en el mundo han ocupado este mismo cargo.

Fernando Moledo: ¿Cuáles son actualmente los proyectos más importantes de la NAKS?

Pablo Muchnik: NAKS ha experimentado un crecimiento enorme en los últimos años: tenemos cientos de miembros, grupos de estudios en todas las regiones de Estados Unidos, premios para graduados y profesores en distinto estadio de desarrollo profesional, una colección de libros propia, presencia activa en las tres divisiones de la Asociación Filosófica Americana (APA), y una relación estrecha con muchas sociedades kantianas alrededor del mundo. En mi gestión, he tratado de crear una cultura institucional más inclusiva e igualitaria, más meritocrática y menos elitista, más cosmopolita y abierta a los debates que ocurren fuera de la tradición alemana y angloparlante. Mi deseo es que los nuevos líderes de la sociedad continúen trabajando en la misma dirección, y profundicen los vínculos internacionales que venimos forjando. 


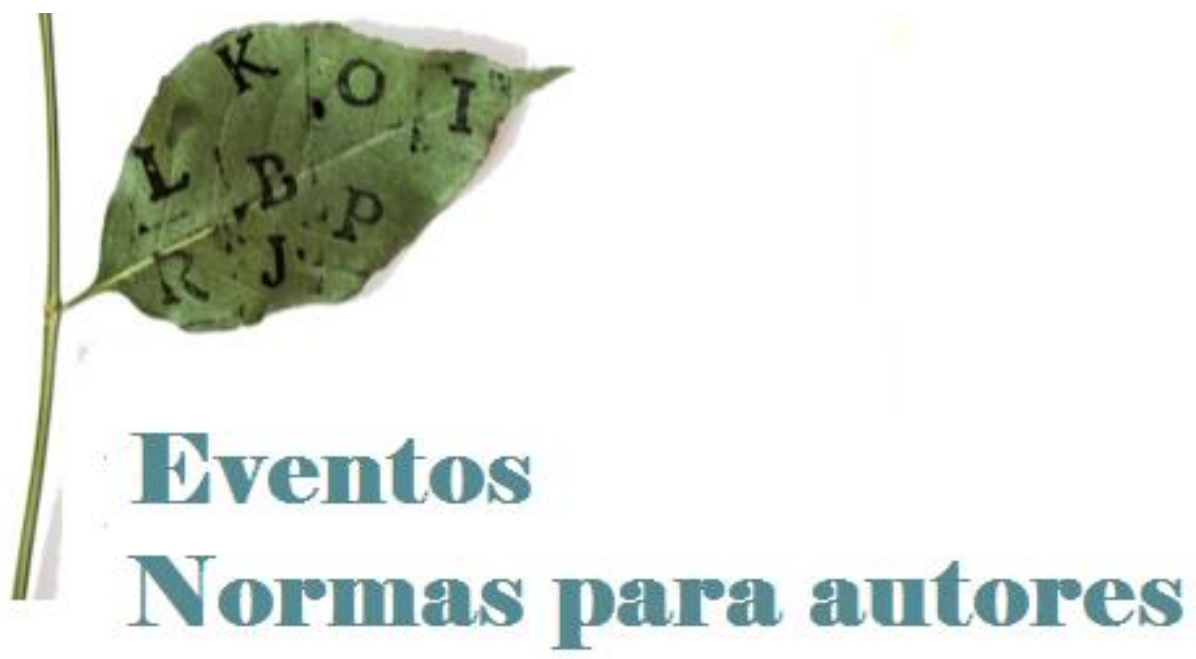





\section{CONVOCATORIA}

Atendiendo a su objetivo de "fomentar el estudio de la filosofía de Kant, de su época, de sus antecedentes y de su influjo posterior, así como de los temas relacionados con su pensamiento, su método filosófico y su posible desarrollo y apropiación actuales" (Estatutos, art. 2), la Revista de Estudios Kantianos (REK) desea impulsar especialmente los estudios sobre la recepción del pensamiento de Kant en el ámbito hispanohablante, enfatizando especialmente autores y obras pioneros que han proyectado líneas de reflexión y comprensión significativas de la filosofía de Kant, sea a partir de su magisterio, o bien sea mediante la publicación de traducciones y obras originales.

Es por ello que la REK desea convocar a todo(a)s los académico(a)s e investigadore(a)s en lengua española interesados a enviar sus trabajos sobre

La recepción de Kant en México

La fecha límite para la entrega de los trabajos es el 30 de junio del 2017. Los trabajos estarán sujetos a las normas de edición de la $R E K$ (http://sekle.org/call-for-papers-revista.html). Los originales aprobados serán publicados en el No. 5 de la $R E K$ que aparecerá en 2018.

Atentamente

Dulce María Granja Castro

Gustavo Leyva Martínez 



\title{
PREMIO KANT \\ PARA JÓVENES INVESTIGADORES E INVESTIGADORAS EN LENGUA ESPAÑOLA
}

\author{
$2^{\text {a }}$ Convocatoria
}

$1^{\circ}$ Se concederá un premio y dos accésits (dos menciones) a artículos de investigación, inéditos y escritos en español sobre cualquier tema acerca del pensamiento y la filosofía de Kant.

$2^{\circ}$ Podrán participar investigadores que tengan menos de 40 años e investigadoras con menos de 43 el día de la convocatoria de este Premio, o sea, el 1 de febrero de 2017, excepto los miembros de la Junta Directiva de la SEKLE y de la Redacción de la REK.

$3^{\circ}$ Los artículos contarán con una extensión máxima de 80.000 caracteres, espacios incluidos.

$4^{\circ}$ Los originales serán enviados hasta el domingo día 11 de febrero de 2018 (inclusive) a la dirección electrónica segundopremiokantsekle@gmail.com,_con un documento oficial (carnet o pasaporte) escaneado que atestigüe la edad del concursante.

$5^{\circ}$ Estos originales serán recogidos por el Secretario de la SEKLE. Sólo él conocerá el nombre de los autores. La evaluación de los originales se efectuará de manera anónima.

$6^{\circ}$ El Jurado estará compuesto por tres miembros nombrados por la Junta Directiva. Su composición se dará a conocer el día 12 de enero de 2018.

$7^{\circ}$ En los artículos presentados se valorarán la solidez y coherencia de la argumentación, la originalidad y el conocimiento de la obra de Kant. Este premio podrá quedar desierto a juicio del Jurado. Su fallo será inapelable.

$8^{\circ}$ El premio consistirá en la entrega de 1.000 euros. Además, el artículo premiado y los dos accésits o menciones serán publicados en la Revista de Estudios Kantianos de la SEKLE, haciéndose allí referencia a dicho galardón.

$9^{\circ}$ Se hará entrega del premio en el marco de un congreso de la SEKLE. En esta segunda edición eso tendrá lugar durante el congreso de octubre de 2018 en Valencia (España).

$10^{\circ}$ Este Premio Kant se convocará cada dos años.

México, 1 de febrero de 2017

Gustavo Leyva

Secretario de la SEKLE

Sociedad de Estudios Kantianos En Lengua Española Sede internacional: Universidad Complutense, Facultad de Filosofía (edificio A), 28040 Madrid Web: sekle.org 



\section{KANT VALÈNCIA}

\section{8}

Por la presente, se abre la convocatoria de presentación de originales para el IV Congreso internacional de la Sociedad de Estudios Kantianos en Lengua Española (SEKLE), que tendrá lugar en la Facultad de Filosofía y Ciencias de la Educación de la Universidad de Valencia del 15 al 19 de octubre de 2018. Entre los ponentes confirmados se ha-llan Adela Cortina (Valencia), Claudio La Rocca (Pisa) y Onora O’Neill (Cambridge).

El lema del congreso será "La actualidad de la Crítica de la razón pura". No obstante, los originales relacionados con cualquier aspecto del pensamiento kantiano, así como con sus fuentes y su recepción, serán bienvenidos.

Los originales —en castellano, alemán o inglés — pueden ser enviados, hasta el 15 de enero de 2018, a la dirección electrónica sekle.kant4@gmail.com. La comunicación de la aceptación tendrá lugar antes del 31 de marzo de 2018.

Aquellos trabajos que vengan evaluados positivamente tras doble revisión anónima serán publicados en un número monográfico de la Revista de Estudios Kantianos.

Valencia, 15 de abril de 2017

Para más información:

http://kant4.blogs.uv.es

\section{VNIVERSITAT (D) VALĖNCIA}

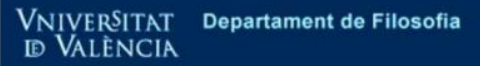

D VALENCIA 



\section{Normas para autores/as}

La revista publica trabajos redactados en lengua castellana, alemana o inglesa y referidos a cualquiera de los ámbitos relativos a la filosofía kantiana o en los que la presencia de ésta tenga una relevancia significativa. Las contribuciones deben ser originales y su extensión no podrá superar los 80000 caracteres con espacios. Las reseñas no excederán los 16000 caracteres con espacios.

\section{Encabezamiento}

El texto será precedido por título, resumen (máx. 100 palabras) y hasta cinco palabras clave, tanto en la lengua propia del artículo como en inglés (si la lengua empleada en el trabajo es el castellano) o en castellano (si el trabajo está redactado en inglés o alemán).

\section{Estilo}

\subsection{Requisitos formales}

Los textos serán redactados en Source Sans Pro (o en su defecto en Times New Roman), 9 puntos (o 12 respectivamente), interlineado múltiple 1,15 .

Las referencias relativas a una cita textual aparecerán preferiblemente en cuerpo de texto, indicando entre paréntesis autor y año seguido de dos puntos y número de página, según el modelo: “...tal y como indica el naturalista inglés (Darwin 1871: 32)...”. Ello no excluye que se abra una reflexión complementaria, si así se estima oportuno, en nota a pie de página, a 7 puntos (10 para Times). Cuando se indique que parte de la cita ha sido omitida se emplearán tres puntos entre corchetes [...]. Si la cita es en lengua distinta a la del artículo, se tratará de buscar su traducción en alguna edición en castellano y se añadirá entre corchetes la cita en la lengua original (en caso de que no se disponga de una traducción, el autor indicará que la misma ha sido elaborada por él mismo mediante la abreviatura a. trad., o bien en una nota a pie de página si todas las traducciones son propias); por ejemplo "...tal y como indica el naturalista inglés...” [“...as the English naturalist states...”]. Cuando las citas textuales superen los 4 renglones se colocarán aparte, a 8 puntos (11 para Times), en un párrafo justificado y sangrado en primera lína a 1,25 puntos.

Los encabezados de los apartados y subapartados se indicarán mediante la siguiente numeración: 1, 1.1, 1.1.1... etc., sin cursiva ni negrita. La enumeración de listados empleará los indicativos i), ii), iii) etc.

La cursiva se reserva para los títulos de obras y palabras extranjeras. Para resaltar el énfasis puesto en una palabra se utilizarán comillas simples '...'.

Los números indicativos de las notas a pie de página (que en ningún caso se colocarán al final del documento, sino al final de cada página) deben encontrarse antes de los signos de puntuación.

El primer párrafo de cada apartado no estará sangrado, mientras que los restantes sí lo estarán en primera línea a 1,25 puntos. Entre párrafos se dejará un renglón en blanco.

Es aconsejable que los autores revisen los artículos publicados previamente para una mejor adaptación a las normas de estilo.

\subsection{Citaciones kantianas}


En el caso de obras de Kant, en cuerpo de texto y nota se aludirá a ellas empleando las abreviaturas establecidas por la Kant-Forschungsstelle de Maguncia. Las abreviaturas se hallan publicadas en su página web (http://www.kant.uni-mainz.de/), pestaña 'Kant-Studien', sección 'Hinweise für Autoren'.

\section{Referencias bibliográficas}

Las referencias bibliográficas completas aparecerán al final de la contribución, en un apartado ad hoc bajo el título "Bibliografía", por orden alfabético aplicado a los apellidos de los autores. En el caso de que varias publicaciones del mismo autor coincidan en el mismo año, se las distinguirá con letras en subíndice (1999a, 1999b).

3.1. Citas de libros

Procederán según el siguiente modelo:

MORENO, Juan: Los retos actuales del darwinismo. ¿Una teoría en crisis?, Madrid, Síntesis, 2008.

En el caso de que en el cuerpo de texto se citen textos procedentes de traducciones, en la bibliografía se especificará como sigue:

DARWIN, Charles R.: The Descent of Man and Selection in Relation to Sex, Londres, John Murray, 1871, 1882 ( $2^{\mathrm{a}}$ ed.). Los textos citados provienen de la traducción castellana realizada por Julián Aguirre: El origen del hombre y la selección en relación al sexo, Madrid, EDAF, 2006 (2ªd.).

3.2. Capítulos de libro

KINSBOURNE, Marcel: "Integrated field theory of consciousness", en MARCEL, A. y BISIACH, E. (eds.): Consciousness in Contemporary Science, Oxford, Oxford University Press, 1988.

3. 3. Artículos

TINBERGEN, Nikolaas: "On aims and methods of Ethology", Zeitschrift für Tierpsychologie 20 (1963) 410-433.

\section{Revisión}

Cada autor/a revisará detenidamente que de su envío haya sido eliminado cualquier indicio que pudiera denotar su identidad. En el caso de que se aluda a publicaciones propias, se sustituirá todos los datos por la indicación "[Datos eliminados para favorecer la anonimidad del envío]". Del mismo modo, se cuidará de que el documento no contenga información sobre la autoría en sus propiedades informáticas.

\section{Envío}

Los trabajos deberán ser enviados a través de la plataforma virtual:

https://ojs.uv.es/index.php/REK/ 


\section{Instructions for contributors}

The journal publishes papers in Spanish, German or English dealing with Kantian philosophy or with issues raised in it. Contributions must be original and should not exceed 25 pages (90000 characters with spaces). Reviews should not exceed 5 pages (18000 characters with spaces).

\section{Heading}

The text will be headed by title, abstract (max. 100 words) and key words (max. 5) in both the language in which the work is written and English (if written in Spanish) or Spanish (if written in English or German).

\section{Style}

\subsection{Formal items}

The text will be written in Source Sans Pro (or Times New Roman), 9 points (or 12 p. respectively), multiple spacing 1,15 . The textual quotes will appear in the text self, by referring to author and year followed by colon and page number. For example: “...so as pointed out by the British naturalist (Darwin 1871: 32)..." If considered suitable, a further discussion in a footnote is not excluded (7 points or 10 for Times). To indicate that a part of the quoted text has been omitted three points will be used in brackets (...). If the quote is in a different language, the author should look for a translation, adding the original quote in brackets as follows: “...tal y como indica el naturalista inglés...” [“...as the English naturalist states..."]. If no translation is available, the author will indicate that it has been drawn up by himself by the abbreviation a. trans. or in a footnote if all translations have been made by the author. When quotations exceed 4 lines will be placed apart, 8 points (11 for Times), in a justified paragraph and bleeding in top line to 1,25 points.

The headings of the sections and subsections shall be indicated by the following numbers: $1,1.1$, 1.1.1., etc., without italics nor bold. To enumerate the elements of a list: i), ii), iii), etc.

Reserves italics for titles of works and foreign words. To highlight the emphasis on a word will be used single quotes '...'

The indicative numbers for footnotes (which in any case will be placed at the end of the document, but at the end of each page) must meet before punctuation.

The first paragraph of each section will not be bleeding, while the remaining will be bleeding in first line to 1,25 points. White line between paragraphs are reserved.

It is advisable that the authors review the previously published articles to better adaptation to the style rules.

\subsection{Kantian quotes}

The citation of Kantian texts will employ the abbreviations established by the Kant-Forschungsstelle Mainz (see website http://www.kant.uni-mainz.de/, 'Kant-Studien', section 'Hinweise für Autoren'). 


\section{Bibliography}

The complete references will be indicated (in alphabetic order of the name of the authors) at the end of the contribution, in a section entitled 'Bibliography'. Should different publications of an author be edited in the same year, they will appear with subscript characters (1999a, 1999b).

\subsection{Books}

The following model will be employed:

Moreno, Juan: Los retos actuales del darwinismo. ¿Una teoría en crisis?, Madrid, Síntesis, 2008.

Translated texts will be indicated as follows:

Darwin, Charles R.: The Descent of Man and Selection in Relation to Sex, London, John Murray, 1871, 1882 (2nd ed.). Spanish translation by Julián Aguirre: El origen del hombre y la selección en relación al sexo, Madrid, EDAF, 2006 (2nd ed.).

\subsection{Book chapters}

Kinsbourne, Marcel: "Integrated field theory of consciousness", en MARCEL, A. y BISIACH, E. (eds.): Consciousness in Contemporary Science, Oxford, Oxford University Press, 1988.

\subsection{Papers}

Tinbergen, Nikolaas: “On aims and methods of Ethology”, Zeitschrift für Tierpsychologie 20 (1963) 410-433.

\section{Revision}

Each author will make sure that all indication of identity has been removed. In case of quotation of the author's own publications, the reference will be replaced by the sentence "[Reference removed to guarantee anonymous review]". The author will take care that the file does not include personal information within its digital properties.

\section{Sending}

Contibutions should be uploaded to:

https://ojs.uv.es/index.php/REK/ 